
prv. Coult. Fist. 






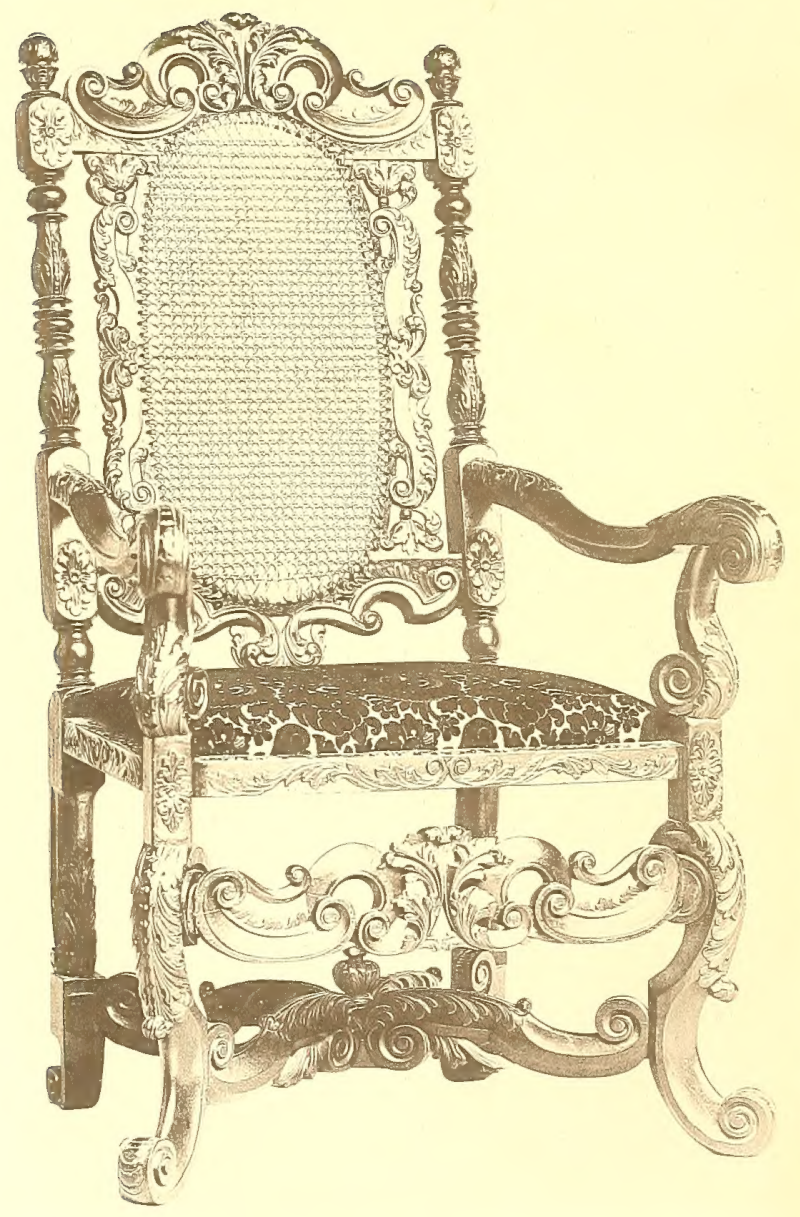

FiG. 66

CANE CHAIR

LATE SEVENTEENTH OR EARLY EIGHTEENTH CENTURY 


\title{
COLONIAL FURNITURE OF NEW ENGLAND
}

\author{
II Stuon \\ OF THE DOMESTIC FURNITURE IN USE IN THE \\ SEVENTEENTH AND EIGHTEENTH \\ CENTURIES
}

BY

IRVING WHITALL LYON, M D.

BUREAU OF C I HWULUGY

2496

1893

LIBRARY.

FULLY ILLUSTRATED

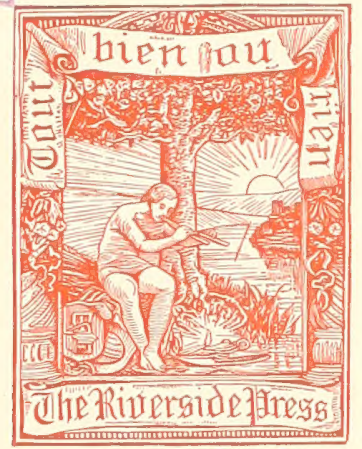

BOSTON AND NEW YORK

HOUGHTON, MIFFLIN AND COMPANY

The Riberside 1Dress, Cambrioge

1892 
Copyright, r8gr,

BY IRVING WHITALL LYON.

All rights reserved.

SECOND EDITION.

The Riverside Press, Cambridge, Mass., U. S.A.

Electrotyped and Printed by H. O. Houghton \& Company.

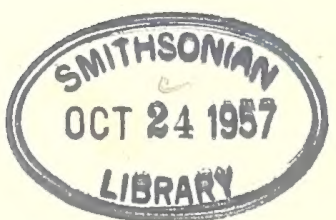




\section{PREFACE}

EARLY in the year 1877 the writer began to collect pieces of old furniture in and about Hartford, Conn., a region rich in the carved oaken woodwork of the seventeenth century. There were at that time a few others quietly engaged in the same pursuit. The number of collectors gradually increased, and the amount of old furniture gathered by them soon became quite considerable. What is here described as taking place in Hartford was also going on in many other places in New England.

With these rich possessions naturally came the desire to know something more about them. When, however, we began to inquire into the origin and history of the various objects and styles represented, it was found either very difficult or impossible to obtain ready and satisfactory answers to many of the questions which arose.

About the year I 880 the writer commenced a somewhat systematic study of this old furniture. This included among other things an examination 
of specimens; an inquiry into what others knew or had written; and an examination of old records, such as inventories of household furniture, old newspapers, account books, and diaries. The furniture of England and Holland for the corresponding period was also studied to some extent.

Among the many interesting results of these researches the following may here be mentioned:-

The proof that much, perhaps the most, of the carved oaken furniture found in New England was made here.

Evidence which renders it very probable that the phrases livery-cupboard and court-cupboard were but different names for the same piece of furniture. The identity of the livery and court-cupboard has before been suggested, but so far as we know no evidence of it has hitherto been adduced. In connection with cupboards we may also call attention to the cupboard cushions found in our inventories, objects which we have not seen mentioned elsewhere.

Proof of the early use of black walnut and mahogany furniture in this country. The former as early as I668, the latter as early as I708. It will probably be found that mahogany was used for cabi- 
net work in the West Indies or in South America considerably before I 708 .

A history of Windsor chairs in this country showing that they were in use in Philadelphia as early as I 736, much earlier than had been supposed.

A somewhat detailed history of the introduction and early use of china and delft ware, table forks, coffee, chocolate, and tea.

The genuineness of the pieces illustrated in this work is here vouched for. With the most of them the writer and his friends have been familiar for several years. Many of them have been repaired to some extent, and in a few instances parts that were missing have been restored. Most of this work for Hartford and its vicinity has been done by $\mathrm{Mr}$. Edwin Simons, a cabinet-maker, who, for fifty years at the head of his craft in this city, has had the rare intelligence to leave pieces that have fallen into his hands for repair just as they were originally made.

In the studies which led to the preparation of these pages the author has received much assistance from many kind friends. His acknowledgments on this score are especially due to Mr. Edwin Simons and to Mr. Walter Hosmer, whose constant aid and friendship have been invaluable on account of their 
superior knowledge of the old furniture of New England.

He wishes also to express here his great obligations to Mr. George T. Robinson, of London, and to Charles J. Hoadly, LL. D., of this city; to the former for much valuable information on many difficult questions relating to the furniture of England and other European countries, and to the latter for many historical facts and references, and for much generous aid in many other ways.

I. W. L.

HARTford, Conn., September I4, I89I. 


\section{CONTENTS}

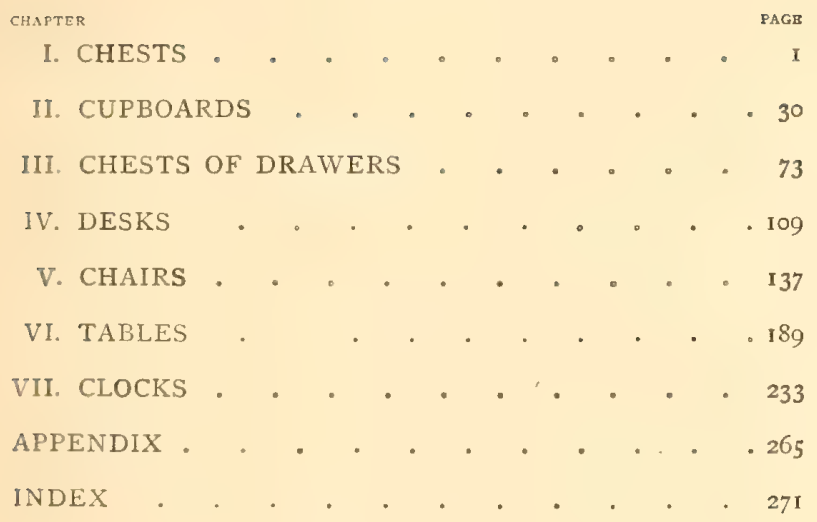




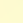




\section{LIST OF ILLUSTRATIONS}

FIGURES PAGE

66. Cane chair, late seventeenth or early eighteenth century . . . . . . . . . . . Frontispiece

I, 2 . Carved oaken chests, first half seventeenth century 2,6

3. Carved oaken chest, about r670 . . . . . . . 8

4. Oaken chest with one drawer, I660-70 . . . . . . I2

5. Carved oaken chest with one drawer, dated r699 . . I4

6. Carved oaken chest with one drawer, 1680-1700 . . . I8

7, 8, 9. Carved oaken chests with two drawers, I680-I 700

$$
20,24,26
$$

10. Carved oaken chest with three drawers, I680-1700. . 28

11. Carved oaken box, about I680 . . . . . . . . . 32

12. Carved oaken box, dated I649 . . . . . . . . 34

3. Cupboard in Stationer's Hall, London, I670-80 . . . $3^{8}$

14. Court-cupboard in hall of Christ Church College, Oxford, I590-I625 . . . . . . . . . . 40

I5, I6. Court-cupboards second half seventeenth century 44,46

I7. Press Cupboard, about I650 . . . . . . . 50

r8. Press Cupboard, I650-75 . . . . . . . . 52

19. Press Cupboard, I680-I700 . . . . . . . $5^{6}$

20. Cupboard with drawers, I680-r700 . . . . . . $5^{8}$

2r. A "Beaufatt," I735 . . . . . . . . . . . 62

22. A "Beaufatt," about $x 750$. . . . . . . . . 64

23. Sideboard, style of Heppelwhite, made in 1804 . . . 68

24. Carved oaken chest of drawers, second half seventeenth century .............. . . . . 
25. Oaken chest of drawers, second half seventeenth century : . . . . . . . . . . . . . 74

26. A chest of drawers, r680-r7oo . . . . . . 76

27, 28. Six-legged chests of drawers . . . . . 80, 82

29. Dressing-table belonging to a six-legged chest of drawers . . . . . . . . . . . . 86

30-35. Old brasses, close of seventeenth and beginning of eighteenth century . . . . . . . . 90, 92

36. A bandy-legged chest of drawers . . . . . . . . 96

37. Dressing-table belonging to a bandy-legged chest of drawers . . . . . . . . . . . 86

38. Japanned chest of drawers about I735 . . . . . 98

39. Chamber table and dressing-box belonging to $3^{8}$. . I02

40. A double chest of drawers . . . . . . . . I04

4I. Steps for top of chest of drawers . . . . . . . I08

42. Chest of drawers showing steps with china . . . . I08

43. Carved desk, dated I654 . . . . . . . . I Io

44. Carved oaken desk, about r650 . . . . . . . I Io

45. Carved oaken box, dated I668. . . . . . . . Ir4

46. Carved box with drawer . . . . . . . . . . II4

47. Scrutoir, close of seventeenth century (after Havard) . I I6

48. Scrutoir, early eighteenth century . . . . . . . I20

49. Scrutoir, $1725-50$. . . . . . . . . . I22

50. Scrutoir, made in the year ז769 . . . . . . . . 126

51. Scrutoir with bookcase . . . . . . . . . I28

52. Secretary and bookcase (after Heppelwhite) . . . . I32

53. The President's chair, Harvard University . . . . I34

54. Turned chair, early sixteenth century . . . . . $13^{8}$

55. Chair from a painting by Jan Steen . . . . . . . I40

56. Turned chair, first half seventeenth century . . . . I42

57. Turned chair, early seventeenth century . . . . . I46

58. Turned chair, about 1650 . . . . . . . . 148

59. Carved oaken "Wainscot" chair, first half seventeenth century .. . . . . . . . . . I50 
6o. Rubens's chair, dated $\mathrm{r}_{33}$. . . . . . . . 154

6r. Leather chair at Trinity College, Hartford, seventeenth century . . . . . . . . . . . 156

62. Leather chair, seventeenth century . . . . . 156

63,64 . Turkey work chairs, second half seventeenth century . . . . . . . . . . . . . . . . . 160

$65,67,68$. Cane chairs, late seventeenth or early eighteenth century . . . . . . . . I62, I64, I68

69,70 . High-backed leather chairs, late seventeenth or early eighteenth century . . . . . . . . I70, I72

71. Dutch bandy-legged chair, early eighteenth century • I74

72. Bandy-legged chair with ball and claw feet, about $175^{\circ}$ I 78

73. Chinese chair with bandy legs, and ball and claw feet, A. D. 254 . . . . . . . . . . . 180

74. A five-backed chair, beginning eighteenth century . . 182

75. Banister backed chair, first half eighteenth century : . I84

76. An easy chair, eighteenth century . . . . . . . I88

77. Roundabout chair, $1750-60$. . . . . . . I90

$78,79,80$. Chippendale chairs, second half eighteenth century . . . . . . . . . . . . $192,196,198$

81. Chippendale double chair, second half eighteenth century . . . . . . . . . . . . . . 200

82. A high-backed Windsor chair . . . . . . 202

83. A Windsor chair . . . . . . . . . . 202

84. A fan backed Windsor chair . . . . . . . 206

85. A fan backed Windsor chair with arms . . . . . 206

86. A Windsor chair with arms . . . . . . . 208

87 . A Windsor chair with supports to back . . . . . 208

88,89 . Heppelwhite chairs, about I796 . . . . . 2 Iо

90. Chair with a Sheraton back. . . . . . . . 212

91. A Sheraton chair . . . . . . . . . 2 212

92. A settle made in 1769 . . . . . . . . . 216

93. Drawing-table, first half seventeenth century . . . 218 
94. A chair table as a table . . . . . . . 220

95. The chair table in Fig. 94 shown as a chair . . . . 222

96. Oaken table, latter part seventeenth century . . . . 226

97. Table, end of seventeenth or beginning eighteenth century . . . . . . . . . . . . . . 228

98. Oval table with leaves, seventeenth and eighteenth centuries . . . . . . . . . . . . 230

99. Folding-table with round top, eighteenth century . . 230 I00, IOI. Tables with leaves, eighteenth century . . . . 232 I02. A table, eighteenth century . . . . . . . . 236 ro3. Table with three leaves, about $1750 . . . . .236$ 104. A Dutch tea table . . . . . . . . . . 238 105. The table shown in Fig. ro4 with top turned up . . . 240 Iо6. A Heppelwhite card table . . . . . . . . . 242 rо7. A brass birdcage clock, seventeenth century . . . . 246 108. A Dutch hanging clock, 1640-1700 . . . . 248 I09. A Dutch clock, seventeenth century . . . . . . $25^{2}$ I I O. A spring clock by Charles Gretton, London, second half seventeenth century . . . . . . . . 254

III. Clock made by Benjamin Bagnall of Boston, first half eighteenth century . . . . . . . . . 256

I 2. Clock made by Enos Doolittle of Hartford, second half eighteenth century . . . . . . . . . 260 I 3. A French clock, time of Louis XVI. . . . . . 262 


\section{COLONIAL FURNITURE OF NEW ENGLAND}

\section{CHAPTER I.}

CHESTS.

IN use from classical times, we find the chest during the Middle Ages the principal piece of household fur. niture, serving not only as a receptacle for clothing, money, plate, and other valuables, but also at times for a seat, or a table, and occasionally as a place upon which to make up a bed. It was also used in churches to inclose the sacred vessels, vestments, records, etc.

Down to about the twelfth century the woodwork of chests in England and France appears to have been either plain or covered with leather or painted cloths. After this time they began to be carved more or less richly, and in the thirteenth century to be paneled. Specimens of the carved and paneled chests which were in use in Europe from the latter part of the thirteenth down to the seventeenth century have been illustrated in many standard works, and may be seen in numerous public and private collections in Europe. 
Many of these examples are of exceeding beauty and richness, being elaborately carved in greater or less relief with architectural details, figures, masks; shells, leaves, flowers, etc.

With the decline of figure cutting, inferior artists took to the flat carving, which was very generally practiced in the seventeenth century in Northwestern Europe, and which found its way to this country upon the chests brought hither by our European ancestors.

Many of the chests in use in New England during the first century of its settlement are to-day carefully preserved in public museums, by private collectors, and by families who cherish them as ancestral relics. From these examples, and from the facts and descriptions to be gleaned from the inventories of estates, we may obtain a tolerably accurate history of this article of furniture during the colonial period.

In looking through the early records preserved in our probate courts we find chests mentioned in almost every inventory from the first. The most frequent entry is the simple word chest without any qualifying adjective; and the price, if given, is the only clue to its character. In many instances, however, the kind of chest is mentioned. The following list embraces most of the varieties met with:-

Joined chests.

Wainscot chests.

Board chests. 


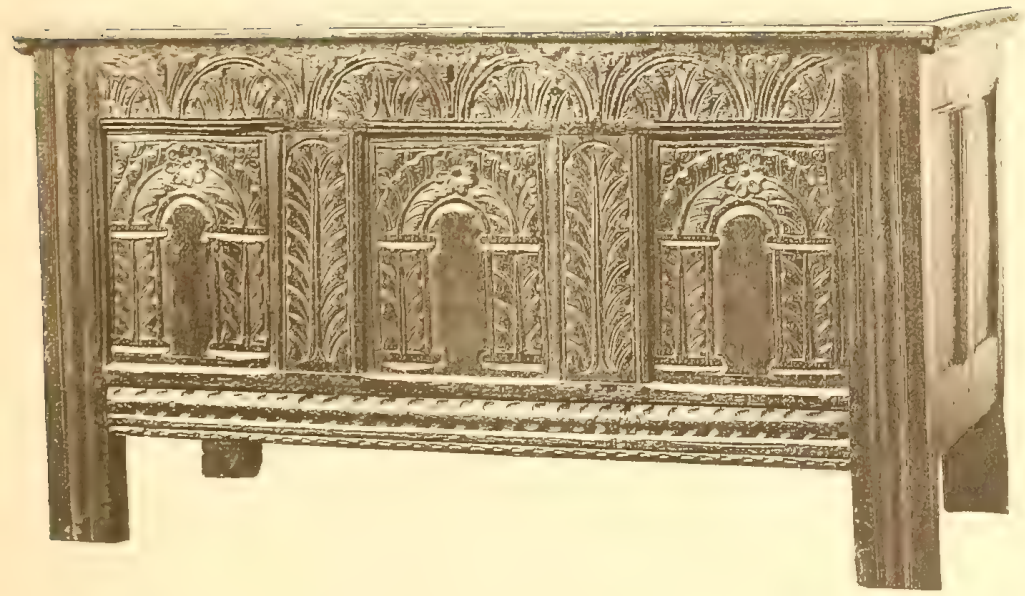

CARVED OAKEN CHEST 

Spruce chests.

Oak chests.

Ship chests.

Carved chests.

Chests with one or two drawers.

Cypress chests.

Furniture made by a joiner and wainscot furniture are varieties which have been mentioned in the English inventories from very early times. Thus, in the inventory of John Cadeby, of Beverley, made before I45I, and published by the Surtees Society, we find a record of " $I$ par tristellorum de waynscote;" and, in the inventory of Thomas Morton, Canon Residentiary of York, made in I449, and published by the same society, the items, "De I cista nova, junyour worke, ii. s.," and, "De I cathedra lignea de junyour worke, xii. d." Again, in the will of Agas Herte, of Bury St. Edmunds, made in 1522 , and published by the Camden Society, we find "A tabyll of waynskott $w^{t}$ to joynyd trestelle, ii. joynyd stolys of the best," and "a gret joynyd cheyre."

Woodwork joined or framed together in any manner, but especially with mortise and tenon, was said to be joined, and the craftsman who did such work was called a joiner. As his chests and chairs and stools were always good, and sometimes handsome, they contrasted strongly with the rude board chests and plank seats in common use; so that by a natural 
process, joined furniture came to mean also wellmade furniture. Most joined chests were, therefore, in all probability framed structures with panels.

The habit of applying the term wainscot to any particular article of furniture doubtless arose from some resemblance in its construction to the wainscoting which lined the walls of medirval palaces and mansions. As this work was usually paneled, it would seem altogether likely that the chests described as wainscot in the old inventories were framed and paneled, the same as the joined chests.

To show that these two words when applied to chests had the same meaning, and were employed to designate framed chests with panels, in contradistinction to those made of plain boards, a few extracts are here introduced, the items in the original record following each other on the same line, or on the line below, in every instance, as here written.

"A winscot chest, I 2 s., a borded chest, 5 s." - Inventory of Sarah Beal, Cambridge, Mass., I678.

"To 2 winscot chests, $£$ I ros. One box, 3 s. One boarded chest, 5 s." - Inventory of John Savage, Middletown, Conn., I684-85.

"By a winscut chest, 20 s. I board chest, 7 s." - Inventory of Stephen Hosmer, Hartford, Conn., I693-94.

"One joined chest and one plain chest, I 2 s." Inventory of Andrew Dewing, Dedham, Mass., I677. 
"A joyned chest, 8 s., a playne chest, 4 s." - Inventory of Henry Wight, Dedham, I68I.

"One pannell chest, one playne chest." - Inventory of John Crafts, Roxbury, Mass., 1685.

Carved chests are seldom mentioned in the New England records of the seventeenth century. We have met with but six. The earliest of these occurs in the inventory of William Bradford made in Plymouth, Mass., in I657. The item is, "A carved chist, £I." The others are found in inventories dated I662, I666, I668, I676, and I690 respectively, and are valued in the order given at $6 \mathrm{~s} .8 \mathrm{~d}$., $£ \mathrm{I}$ Io s., I 5 S., 9 s., and I $2 \mathrm{~s}$. Besides these, we have notes of two "wrought" chests, valued at twenty and twenty-five shillings; one "ingraved chest;" one "sett worke chest," valued at eight shillings; and a "great inlayed worke chest," valued at $£ \mathbf{I} 6 \mathrm{~s}$. No carved chests appear in the Hartford inventories during the seventeenth century, and but one in the inventories of Suffolk County, Mass., including Boston, before the year I 704. Carved boxes are found in the records in about the same numbers as carved chests, the first mention being in an inventory made in 1653 .

It would, however, be an error to conclude from their infrequent mention in the inventories that carved chests were rare in New England in the seventeenth century. It is not at all improbable that they 
were somewhat scarce among the earlier colonists, but that this could not have been the case after 1650 is proved by the numerous specimens which we see to-day. Very many of the wainscot and joined chests that appear in the inventories were undoubtedly carved. Indeed, carved furniture was very common in the seventeenth century, and this may have been one of the reasons why the word carved was so seldom used in the records as a descriptive term.

The silence of our New England records on this point is not exceptional. Carved chests are mentioned in but three of the numerous inventories of the sixteenth century published by the Surtees, Camden, and Chetham Societies. This is the more noticeable, as the carving of the sixteenth century was vastly superior to that of the seventeenth, and because, among the many hundred different chests here recorded, frequent mention is made of other varieties, such as Flanders, cypress, iron-bound, and wainscot chests.

The oldest carved and paneled chests in New England are believed to have been made without drawers underneath, and without the black applied ornaments so often found on later work. Two such examples are here given. The first (Fig. I) was bought a few years since in Windsor, Conn., from a family in which it had descended from colonial 


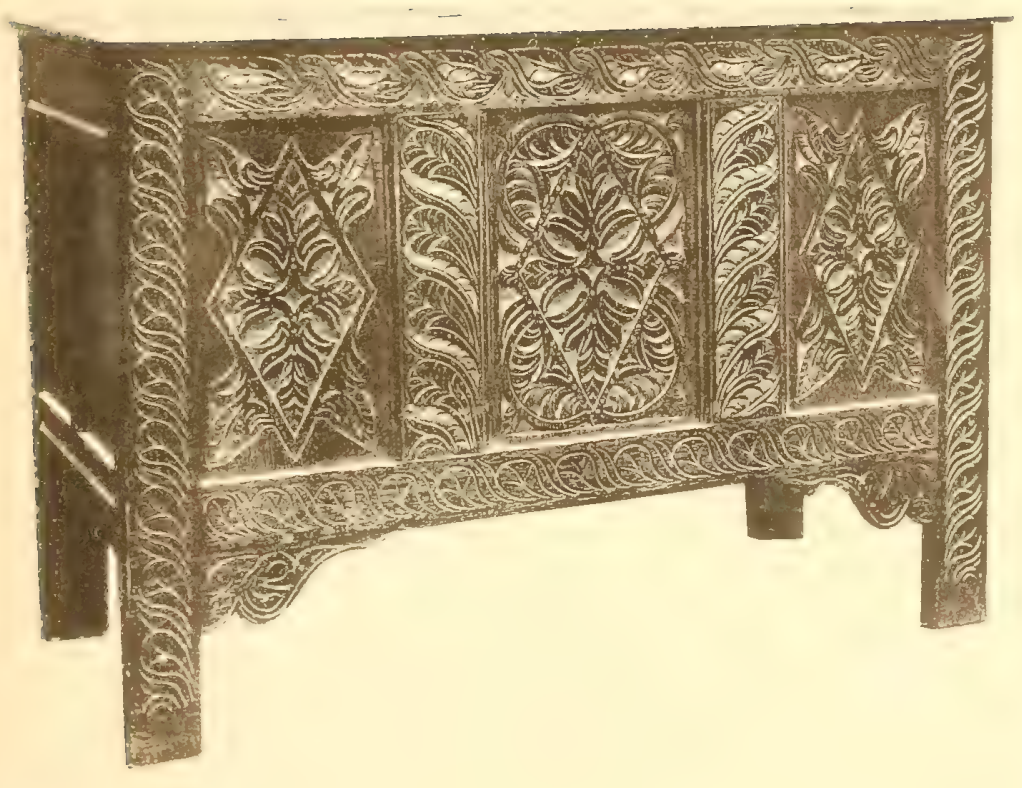

CARVED OAKEN CHEST 

times. The acanthus-like foliage and the arches carved on its front suggest that this chest was made in the reign of James I. of England, or early in that of his successor. The wood is oak except the lid, which is made of yellow pine in one piece. But as pine lids were not put on oaken chests in England at this early period, either the original lid has been lost, or the entire chest was made in New England. The lids of such oaken chests in England in the seventeenth century were not only made of oak, but were also framed and paneled. This chest belongs to the writer, who a few years since saw another of the same pattern in Cheshire, Conn.

The other (Fig. 2) belongs to the collection of Mr. Henry F. Waters, of Salem, Mass. It was bought from a family in Rowley, Mass. It is all original, except the lid, which is new. The carving is excellent. The general effect of this beautiful specimen is improved by the brackets, a feature occasionally found on old chests. It is believed that this chest was made as early as 1650 , and perhaps earlier.

The mere absence of drawers in any particular specimen must not, however, be accepted as proof of its very early date. In Fig. 3 is seen a chest belonging to the writer, which could hardly have been made before the year 1670. This opinion is based upon the presence of soft wood in the construction of the lid, back, and bottom, the design of the carv- ' 
ing, and the use of color on the sunken ground of the panels; features to which reference will again be made.

Chests with one or two drawers underneath are far more numerous in New England than those without drawers. Many of these have also the applied ornaments already alluded to. The fashion of making chests with drawers underneath seems to have sprung up in England at some time in the first half of the seventeenth century. No chests with drawers appear in the English inventories of the sixteenth century published by the three antiquarian societies above named.

The first mention of a chest with one drawer that we have been able to find occurs in the inventory of Rev. Nathaniel Rogers, of Ipswich, Mass., made in August, I655. The item is, "One chest with a drawer, $16 \mathrm{s."}$ The next is, "A cheast with a drawer under, $18 \mathrm{s.,"}$ in the inventory of Robert Risden, of Fairfield, Conn., made in January, I666-67. The third is, "One new Chest with one drawer, I 3 s." in the inventory of John Winsor, of Boston, made in February, 1666-67. After this time they are not infrequently met with in the New England inventories. An early example of a chest with one drawer is shown in Fig. 4. It is the property of the Connecticut Historical Society of Hartford. There is no certain guide to its age; but if we suppose it to 


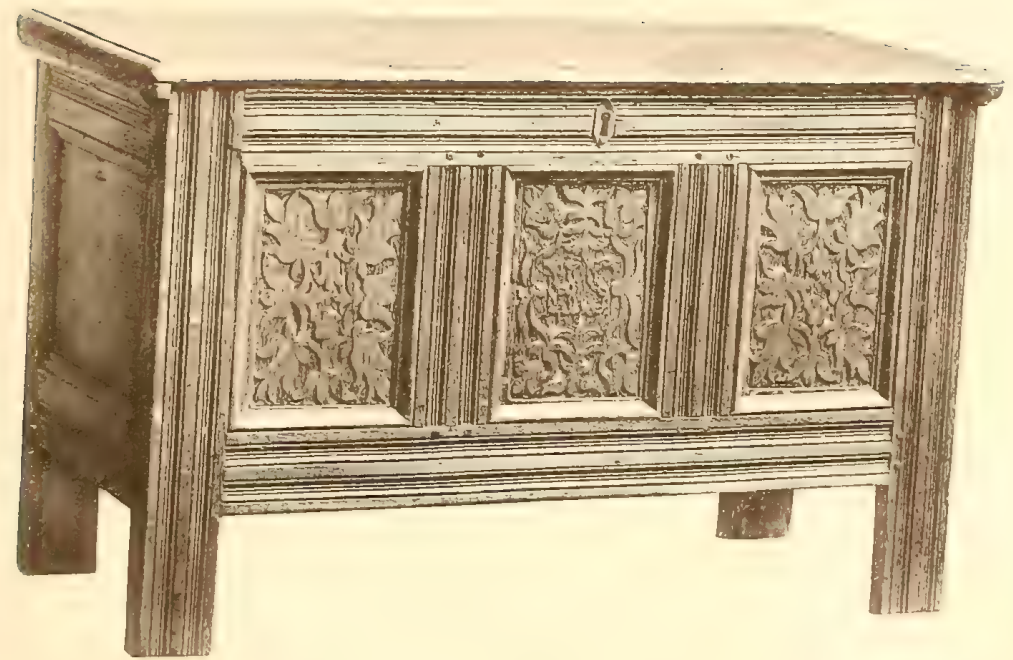

FIG. 3

CARVED OAKEN CHEST

ABNUT I. 

have been made in the decade $1660-70$, no serious error will be committed.

In Fig. 5 we show a dated specimen from the collection of Mr. William E. Hulbert, of Middletown, Conn. The date, $\mathbf{I} 699$, is cut on the drawer, and is undoubtedly genuine. The carving on this chest is worthy of notice from having the edges of the raised work, especially the foliage stems, rounded off more than is usual. The central stiles are enriched with an inlaid strip of yellow and dark colored woods, running up and down their whole length between the turned ornaments. Still another peculiarity is the size and shape of the end stiles, and the manner in which their lower parts, or feet, are finished. The end stiles of chests are usually heavy, rectangular-shaped posts, with their width considerably in excess of their thickness, or antero-posterior measure. In this specimen the end stiles were made very light, their width and thickness being the same; and their lower parts, instead of being left plain, were turned upon the lathe to correspond with the ornament above.

Two other chests with posts, inlay, and carving the same as in this specimen are known. The first is the property of O. O. Roberts, M.D., of Northampton, Mass. It is a very large chest, with two drawers, one above the other.

The second example, which belongs to the writer, 
was originally an exact counterpart of the Roberts chest; but the drawers have been cut away, leaving only the chest, with its top but $2 \mathrm{I} \frac{1}{2}$ inches from the floor. Both of these chests are dated I 700, the figures in each being cut on the top rail at the keyhole.

The third example of a chest with a single drawer (Fig. 6), selected for illustration, is a beautiful specimen with two or three points of interest. The legs, from the fact of their being longer than usual, suggest the possibility of a missing drawer. This chest, nevertheless, was designed and made just as we here see it. Some chests were made to stand, like this, high up from the floor. The Norman design, resembling the tooth ornament carved upon the stiles, is worthy of mention, as being not only more pleasing to the eye, but also in better accord with sound rules of construction than though glued to the surface. These same ornaments in lozenge form are again used with good effect to fill the spaces of the diaper carving on the panels. This chest is not dated, but one very similar to it, in the collection of $\mathrm{Mr}$. Walter Hosmer, of Hartford, Conn., is dated I699. It is made of oak, excepting the bottom of the drawer, which is of chestnut. It was bought in 1884 , in Madison, Conn., where it had probably been for many generations. It now belongs to Mrs. Edmund G. Howe, of Hartford, Conn. 
It is difficult to determine when chests with two drawers - one above the other - first came in use. The general impression among those who have studied the matter carefully is that they appeared considerably later than those with a single drawer.

Chests with drawers are mentioned quite early in the probate records, as the following instances will show :-

"I chest and I little cupboard, both with drawers, $£ 3$ ros." - Inventory of John Cotton, Boston, January, $1652-53$.

"One chest $\mathrm{w}^{\text {th }}$ drawers, $£_{\mathrm{I}}$ I $2 \mathrm{~s}$." - Inventory of Thomas Warner, Boston, I660.

"A great old chest with drawers, $8 \mathrm{s."}$ - Inventory of Thomas Robinson, Boston, I666.

"A great carved chest with drawers, $£$ I IO." Inventory of Daniel Weld, Roxbury, I666.

If we accept these items literally, we shall be obliged to believe that chests with more than one drawer were made from about the middle of the seventeenth century; but, as we shall see in another chapter, there are reasons for supposing that the phrase chest with drawers was occasionally applied to the piece of furniture ordinarily known under the name of chest of drawers.

The wording, however, of another item in the inventory of Daniel Weld seems to sustain the notion that the "great carved chest with drawers" referred 
to might have been a chest above with drawers below. This item is, "A case of drawers, $£ \mathbf{I}$." The inference from this is, of course, that if the great carved chest with drawers had been a chest of drawers, it would have been written either a case of drawers or a chest of drawers, as both these expressions stood for the same thing.

The first mention that we have seen of a chest with two drawers occurs in the inventory of William Wardell, of Boston, made in 1670. The record is, "A chest with two drawers, $£$ I IOs." It is by no means certain that this piece even was anything more than a chest of drawers, made up with a frame and two drawers, as was sometimes the case. But here again the context permits us at least to doubt that this piece was a chest of drawers proper. We quote from the inventory the following: "In the Hall. I greate cheast, I 5 S. I smaller chest with one drawer, $£$ I 5 s." "In the chamber over the Hall. A chest with two drawes, $E^{\prime}$ I Ios." Now we know perfectly well what was meant by a chest with one drawer, and, if we may reason from the sameness of the language used at the same time and in the same place, it would seem that the only difference between this chest and the one in the chamber over the hall was that the former had but one instead of two drawers.

Another possible reference to a chest with two 


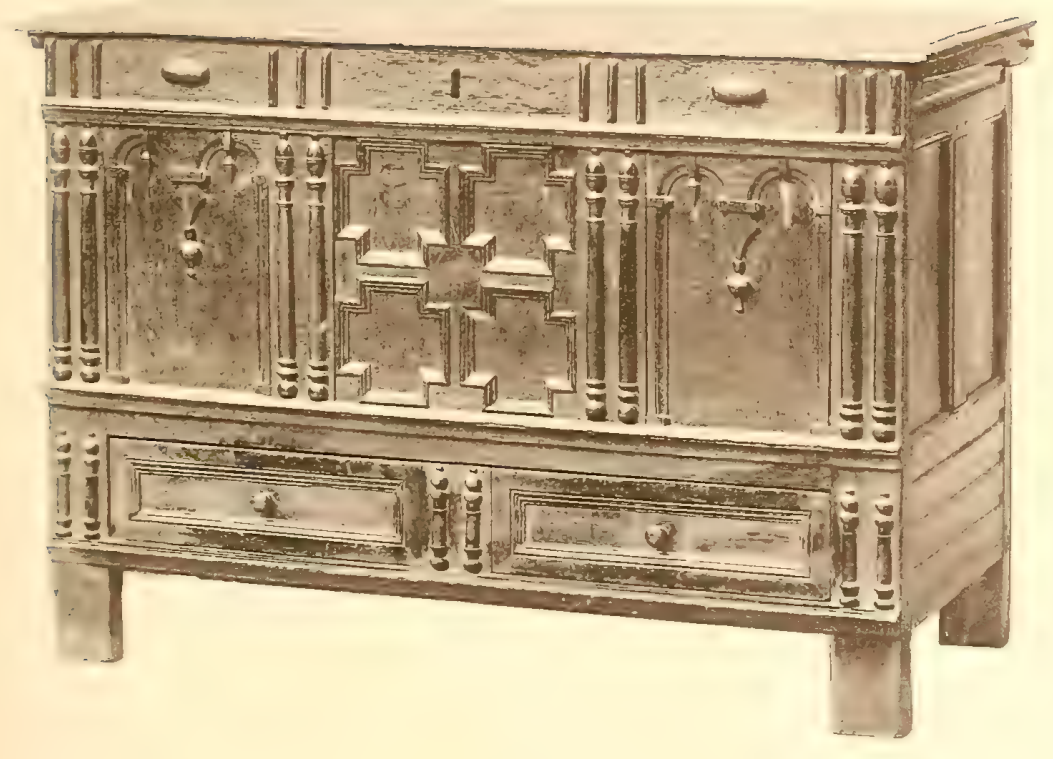

ris 4

OAKEN CHEST WITH ONE DRAWER 
drawers below is the item, "One Chest and drawers $£ \mathrm{I}$," recorded in 1679-80 in the inventory of Mrs. Ann Cole, of Hartford.

We pass now from the stage of possibility and uncertainty to one in which there can no longer be any doubt, as the following quotations show : -

"One wainscot chest and drawers in it, I 2 s." Inventory of Mrs. Anna Haugh, Boston, I69o.

"One chest of drawers, and one wainscot chest and drawers." - Inventory of Peter Welcome, Boston, 1695 .

"A chest $\mathrm{w}^{\text {th }}$ drawes underneath $15 \mathrm{s.}$." - Inventory of Nathaniel Thayer, Boston, I700-I.

To the objection that the chests in some of these instances may have had two short drawers below, on the same level, instead of two long ones, one above the other, as in the next three illustrations, it may be answered that, though such chests occur in Europe, we do not know of any one who has seen a single example in this country.

While, therefore, we cannot at present feel certain of an earlier date for these chests than the last decade of the seventeenth century, we may point out that, from the early date established for chests with a single drawer, from the close resemblance in constructive details and carving between these chests and those with a single drawer, from the early and the frequent mention in the inventories of chests with 
drawers, and from the probability that many of the chests of drawers made during the last decades of the century were of this hybrid character, that is, a chest above with drawers below, - that for these reasons it is not at all improbable that chests with two drawers, such as we here illustrate, may have been in use in New England considerably before the year I 690.

Three good examples of these chests are here shown. The first (Fig. 7) was bought in Mansfield, Conn., in 1883 , with the history of having been brought to this country about the year I72O. It differs in design and in construction from the chests commonly found in New England. It is made entirely of oak. The ends are not framed with stiles and rails in the usual way, but consist instead of plain planks rather more than one inch and a half in thickness. The front edges of these planks above are carved to correspond with the upper rails, which, with them, inclose the single panel at the front of the chest. The carving is better and in more relief than that usually seen in this country. The lid is an oaken plank one inch and five eighths in thickness, with carved and moulded edges. This specimen is larger than the average chest with two drawers. Its hight is a little more than forty-two inches. It belongs to the author.

The chest represented in Fig. 8 is quite unique 


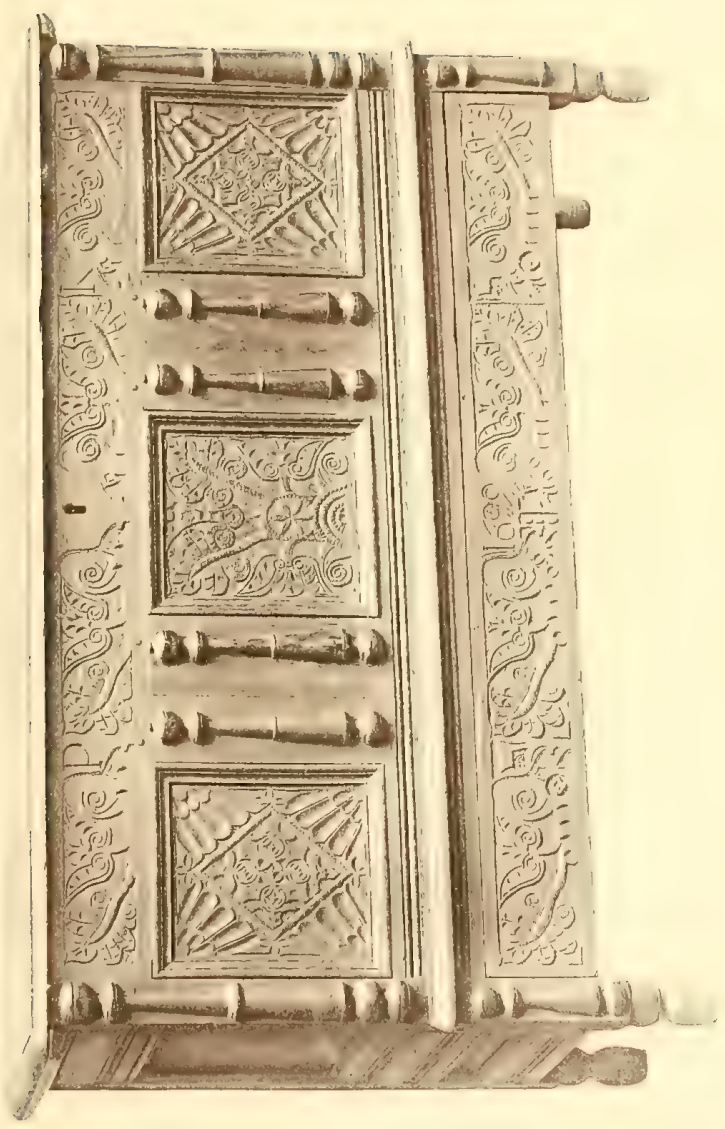



in the arrangement of its ornamental details, though all the enrichments are frequently found on the old chests and cupboards of New England. The inverted and foliated scrolls especially are often seen on drawer fronts and in other situations; but their occurrence on panels around a center, as in this instance, is unusual. This chest was bought in I884, in Madison, Conn., where, according to the history obtained, it had been during the last two centuries. It now belongs to the writer. Its hight is a little over forty inches.

Chests made after the style of the one represented in Fig. 9 are often met with in Connecticut, especially in Hartford County, where about forty examples have been seen. This fact is valuable as evidence that these chests were made in Hartford County. They are made of oak, except the lids and the backs and bottoms of the chest and of the drawers, which are of yellow pine. The carving varies but little in the different specimens. All have the turned ornaments, called drops, on the stiles, and the egg-shaped pieces attached to the drawer fronts. The mouldings around the panels and on the drawers are red, with cross-stripes of black. The other mouldings, whether raised or sunken, are colored black like the applied ornaments; so, also, are the angles of the drawers, and of the central panel of the chest. The hight of these chests is about $40 \frac{1}{2}$ 
inches. The specimen here shown belongs to the writer, who purchased it in 1880 in Farmington, Conn. Chests of this pattern are occasionally seen with but one drawer, and, more rarely still, without any drawer at all.

Oaken chests of the seventeenth century period with three drawers below are very rare. The only specimen to which we can refer is the one in Memorial Hall at Deerfield, Mass., shown in Fig. Io. The lid and back and the backs and bottoms of the drawers are of pine; all other parts are of oak. The carving varies from that of all the preceding varieties. The hight of this chest is forty-six inches. The carving is colored red; the sunken ground is left the natural color of the wood. The four panels at each end are black.

Several other chests with the same style of carving, some with one, others with two drawers, are known. One of these is preserved in the same hall with this chest at Deerfield. Another, in the Hos. mer collection above referred to, has the carving on its stiles and rails colored black, while that on the panels and front of the drawer is colored red. The sunken ground of all these parts is left uncolored. The ends, which are not carved, have their stiles and rails colored red and their panels black.

It is interesting to observe not only the different 
types or patterns of chests, but also the close resemblances which obtain between the individual specimens of any particular type.

The oak in the chests of New England is almost always rived and quartered to show the grain. The only exception to this rule that we have seen is the chest Fig. 7. In this instance the oak is plain, and was evidently got out from the log with the saw.

Some oaken chests were made plain with simple mouldings around the panels, but without any carving or applied ornaments. In others the decoration consisted either of ornamental mouldings alone, or of these with the applied ornaments, as in the chest Fig. 4. It is probable that many of these simpler chests were in use, but that they have not been preserved as carefully as the more valuable carved chests. The simplest and least expensive of all were the board, and pine, and ship chests mentioned in the inventories. The oldest and most interesting example of these is the Elder Brewster chest, which came with him in the Mayflower, and which is now in the hall of the Connecticut Historical Society of Hartford. It is made entirely of pine.

The cypress and cedar chests occasionally mentioned in the inventories were used especially to protect woolens and furs from moths. The former were apprized at from one to five pounds apiece. "I lardge cyprus chest" is valued at $£ 5$ in the inven- 
tory of Richard Bellingham, Governor of Massachusetts, made in 1672 .

Northwestern Europe has already been mentioned as the region where the flat carving seen on our early colonial furniture was largely practiced in the seventeenth century. Two styles of this decoration flourished in these countries. One of these is shown on the box illustrated in Fig. II. This style is very rarely seen in New England. It has been very carefully studied by Herr C. Grunow, First Director of the Royal Museum for Industrial Arts in Berlin, and the results published by E. A. Seemann, Leipzig, I884, in a work entitled "Kerbschnittvorlagen."

This author traces this peculiar carving on stone back to the eighth century. It is found in various localities in Europe, Asia, and the South Sea Islands. It has been practiced for eight centuries in the countries of Northwestern Europe bordering upon the sea from Normandy to Norway.

He says: The English word to carve, which is used alike for cutting, figure carving, and wood sculpture, indicates that the notch work was the beginning of all the carving technics of the North German peoples.

The wood carvings of this sort reach back to the thirteenth century. Examples are to be seen in all collections of art in North Germany, as well as in Holland, Denmark, Norway, and Sweden. They 


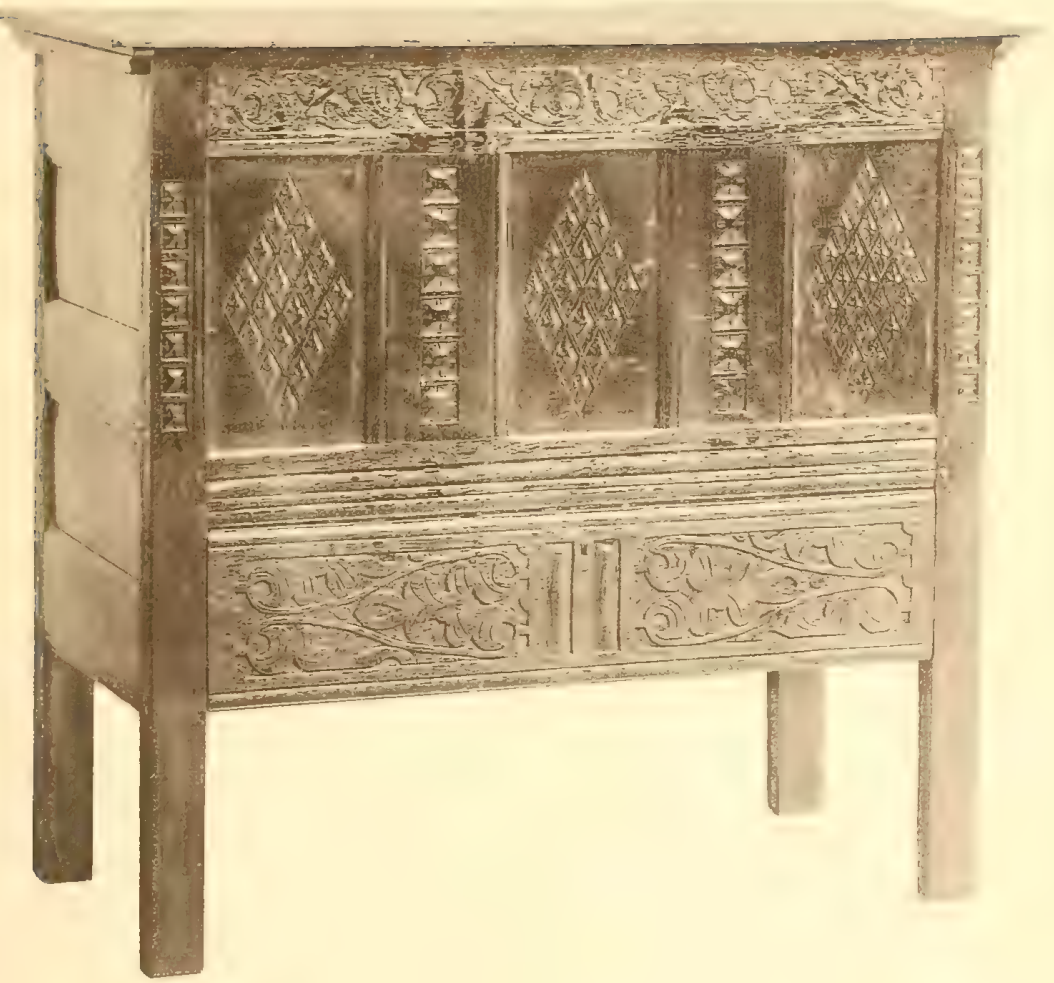

Fio. 6

CARVED OAKEN CHEST WITH ONE DRAWER 

reach the highest degree of perfection in the first half of the eighteenth century.

The peculiarities of this style of carving are its geometric patterns, and the forms of the cuttings, which will be found to consist of two, three, and foursided depressions.

The box here illustrated is the only example of this style that we have seen in New England. It was bought by the writer in Middletown, Conn., in I88 I. Its history made it belong to a family which had lived in New England in the early colonial period. In the opinion of Herr Director Grunow, it was made about the year $\mathrm{i} 680$.

The other and simpler style of carving is that which Herr Director Grunow designates the linear or groove carving. It, like painting, is one of the oldest and most primitive methods of flat decoration, and will arise wherever linear ornaments are to be carved in wood. It was, however, chiefly in the seventeenth century that this linear carving was employed in Northwestern Europe to decorate peasant furniture. It extended thence to England, and was brought to this country by our early ancestors. It is the kind of carving which we see on our old oaken chests and cupboards.

In the opinion of some antiquaries this linear style of carving, which appeared on the peasant furniture of the seventeenth century, was an offshoot or 
development from the other style which we have described, and which is sometimes called Friesland carving, from having been practiced by the peasants of Friesland especially, during the past three or four hundred years. This is the view entertained by Monsieur J. J. Van Ysendyck, the learned architect of Brussels, and by others,

Herr Director Grunow, however, says that this linear carving of the seventeenth century could have arisen either independently of the real notch carving of Friesland, or in connection with it.

The applied ornaments found on our chests are not made of oak, but of finer-grained woods, such as birch, beech, and maple. They were colored black, in imitation of ebony. There are several kinds of these ornaments; but the drops, the egg-shaped pieces, the Norman nail heads, and the triglyphs are the most common.

The drop was invented and first used by Peter Koek, the celebrated Flemish painter and architect, who flourished toward the middle of the sixteenth century. His drops were plain, carrot-shaped pieces, gradually tapering to a point, but without mouldings below the neck. The ornamental drops with mouldings and bulbous points, as seen on our chests, are of later date. The drop continued in use in the architecture and on the furniture of Belgium, Holland, and England fully a century after its introduc- 


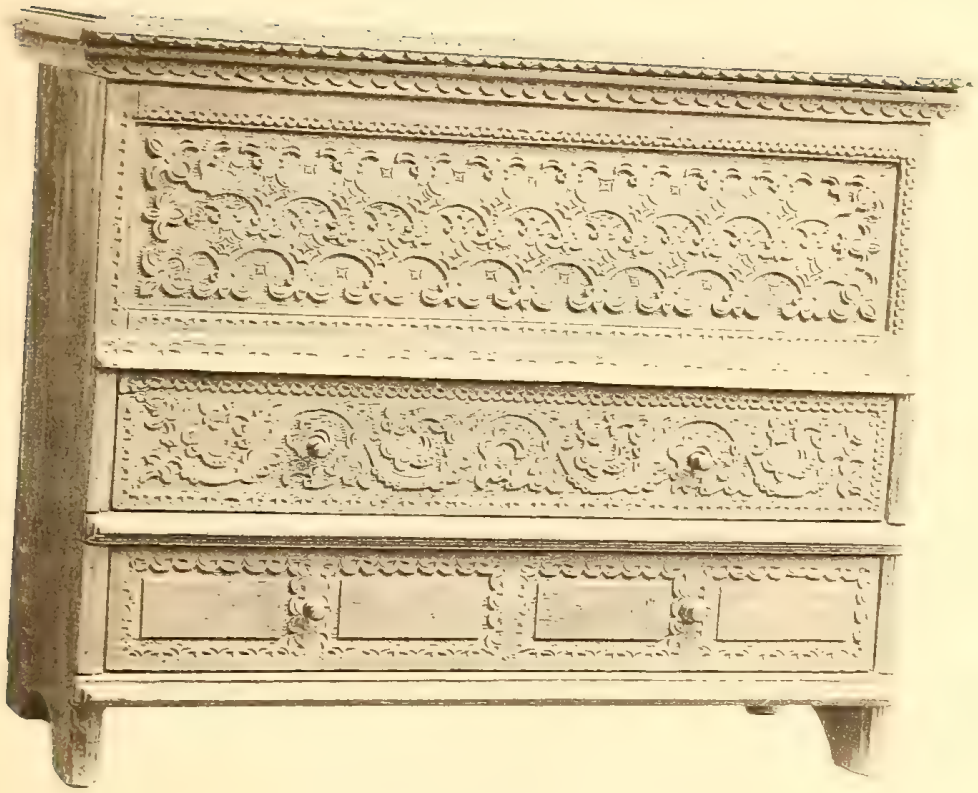

CAPVED OAKEN CHEST W.TH T..O : Z⿱㇒冋厶. E T. 

tion by Koek. It is seen in the designs of Hans and Paul Vredeman de Vries, father and son; and Richardson's "Studies from Old English Mansions" show that it found its way into many of the best houses of England during the reigns of Elizabeth and James I. It lingered upon furniture made in England much later than the latter period, and it is found in New England on chests dated as late as the year 1700 .

The egg ornaments and triglyphs are classical in origin, and appeared on Flemish and Dutch furniture with the Renaissance. The nail head was a diamondshaped ornament much used in Norman architecture.

The colors employed to decorate these old chests were principally black and red. The former appears to have been in use for this purpose somewhat earlier than the red, though in most instances both colors are found on the same piece. This, perhaps, is because most of the earlier chests have been destroyed. The black is oftenest found on the mouldings of the stiles and rails, and on the applied ornaments. It is occasionally seen in other situations, as on the sunken ground of the panels, and on the carving of the stiles and rails. The red was usually restricted to the mouldings around the panels, but is sometimes found applied all over the flat surface of the carving, or, more rarely, to the sunken ground of the carved parts. 
Chests with genuine dates, prior to the last years of the seventeenth century, appear to be very rare in New England. The earliest known to us is dated I698. We have seen a few others, dated either I699 or I 700. One of these (Fig. 5) is illustrated in this chapter, and three others are referred to in the text.

Carved oaken boxes with dates earlier than the above are sometimes seen. One of these is shown in Fig. I 2. It is dated I649. It is the property of the Connecticut Historical Society of Hartford, having been presented by Abel Catlin, late of Litchfield, Conn. It was brought from England to this country by one of his ancestors. The dark color of the wood is proof of its European origin.

Chests were used as receptacles for all manner of things, but especially for the linens and woolens of household use. They held in these early days what was afterwards kept rather in chests of drawers, and in the numerous little closets which were built in the paneled walls of the "Queen Anne" houses. They were no doubt also used secondarily to some extent as seats.

During the seventeenth century the uses of the chest were shared more or less by another article of furniture, namely, the chest of drawers. These latter, from being at first comparatively infrequent, gradually increased in numbers and in favor as the century advanced, so that during its last two decades 
they had become among people of wealth and fashion objects of greater desire and importance than the chests, which they were destined to supersede.

The time-honored chest did not, however, become at once and everywhere unpopular and disused. They continued to be made, as is shown by dated specimens, as late as I 700 certainly, and probably considerably later. They were extensively used in the first half of the eighteenth century, during which period carved chests and chests with drawers are oftener mentioned in the Connecticut inventories than before.

It would be difficult to determine when the chest ceased to be a desirable piece of furniture among plain and unpretentious people. They are found in the Hartford inventories as late as I794, after which the habit of recording separate items of furniture was discontinued. They were little used by wealthy and fashionable people in Boston and elsewhere in New England after I 700, and from this time they may be said to have lost their former preëminence as household receptacles. They slowly declined in popular favor, but existing specimens doubtless continued in some kind of use nearly as long as they remained in good repair.

The belief is common among the people that these old carved and paneled chests were all made in Europe and brought to this country by the early 
settlers as part of their furniture. The grounds for this belief are usually traditional and vague, but occasionally one finds associated with a particular specimen a definite history of Transatlantic origin, with names and dates.

It is true that almost every person who settled in New England during the seventeenth century brought with him a chest of some sort, and it is probable that many persons, particularly the heads of families, had several among their effects. From being in fashion at home, they were reaciy to be used as packing-boxes for the voyage, and in their Western homes, the better pieces especially, were carefully kept, on account of their value as furniture, as well as for their past associations.

There would be no difficulty in accounting in this way for many of the old oaken chests which we find in New England. There are, however, several facts connected with certain other chests which seem inconsistent with the theory of their European manufacture.

One of these facts has already been brought out in connection with the chest illustrated in Fig. 9, namely, that as many as forty chests made after this particular pattern have already been found within a limited territory. If we reflect that this number includes only those known to two or three persons who have studied this point, and that many other 


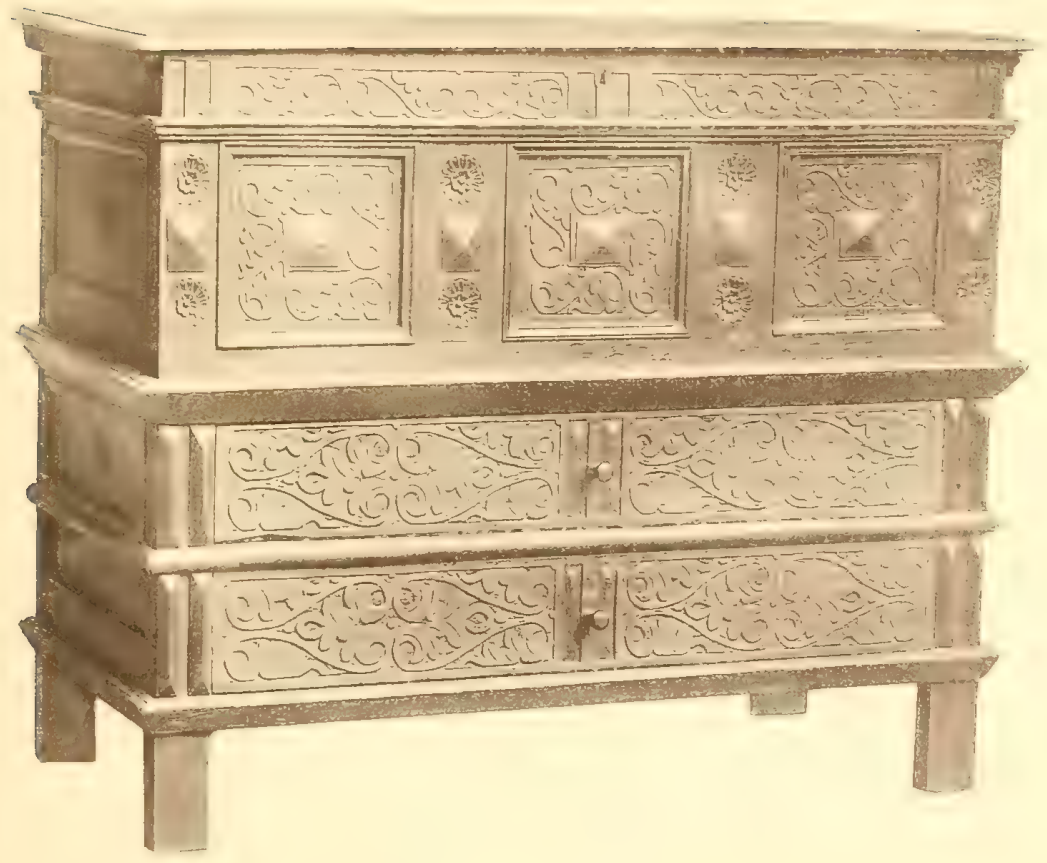

FIG. 8

CARVED OAKEN CHEST WITH TWO DRAWERS

$1890-1700$ 

chests of the same kind doubtless exist within the same area, and that a goodly number must also have disappeared: through removals and decay, we can easily see that the number of these chests, which have been in use in Hartford County, must have considerably exceeded the figures here given.

The most natural and reasonable explanation of this would be that these chests were made in the region where so many have been found.

According to the best collectors and dealers in and about Boston, this particular pattern of chest does not occur in Eastern Massachusetts. There is one in Memorial Hall at Deerfield, Mass., said to have been brought from Scotland about I675.

The design of the carving is pretty certainly European; but none of the connoisseurs in England, Scotland, Holland, and Belgium, who have been consulted, had ever before seen this pattern.

Another fact of much importance in studying the origin of New England chests is that yellow pine was used to a considerable extent in their construction. It is a very common occurrence to find an oaken chest with its lid, back, and bottom all made of pine; and if a drawer or drawers are present, their backs and bottoms are also of pine. All the chests made after the design seen in Fig. 9 have pine in the parts here mentioned.

The best English authorities have assured us that 
they had never seen any pine whatever in the oaken chests and cupboards made in England during the seventeenth century. This would appear to be the rule also for Holland, Belgium, and Northwestern Germany. There is, however, one exception, at least, in the Thaulow Museum at Kiel, No.925 of the catalogue of 1884 . This is a large cupboard in which pine is found in places similar to those mentioned in our chests.

The habit of making chests with one drawer underneath was practiced in Europe in the seventeenth century; but, according to the best information that we can obtain, chests with two tiers of drawers underneath must have been exceedingly rare and exceptional, if, indeed, they were made at all.

The color of the oak in many New England chests corresponds to that found in old timbers of the American white oak taken from houses known to have been built considerably more than a century ago. The color of the American white oak, the Quercus alba, is, as a rule, several shades lighter than the European oak. This color test, however, is not always available, as some specimens of European oak are much lighter than others, and the wood of some chests made of American oak may have acquired, through age and exposure, a much darker hue than the average. When, however, we see in this country a piece of oak with its color nearly or quite as dark 


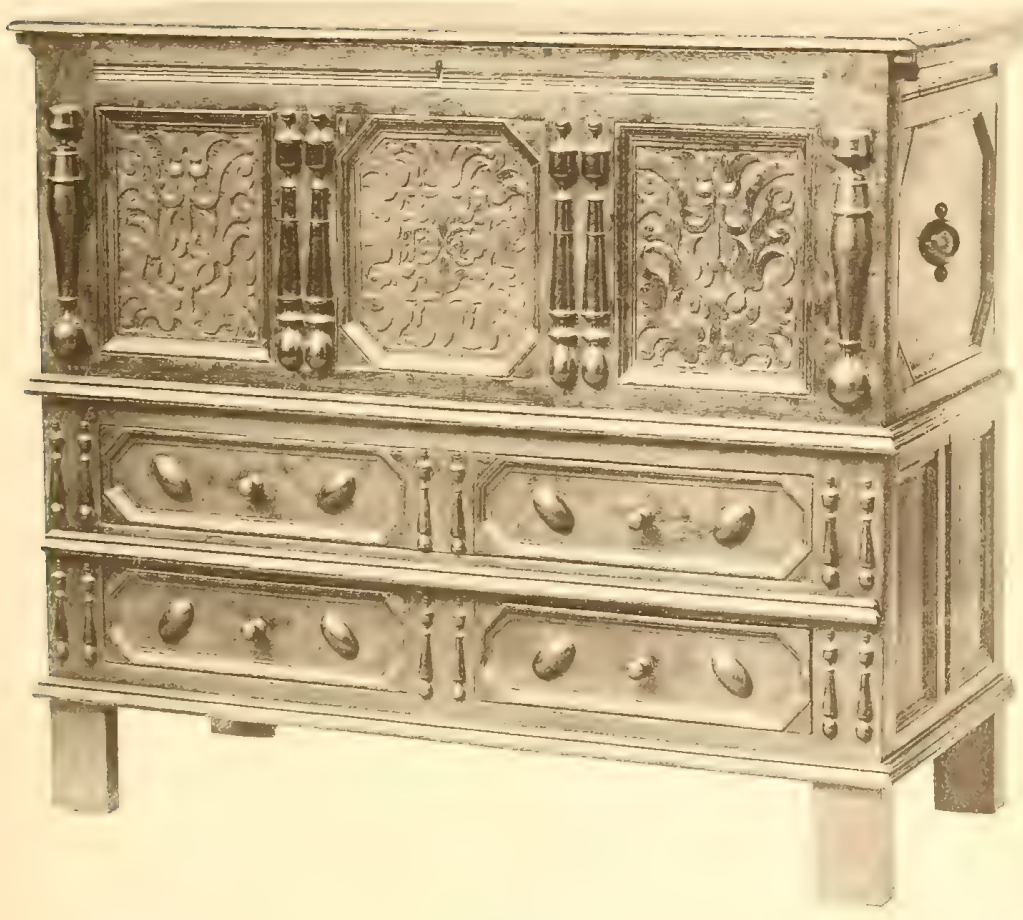





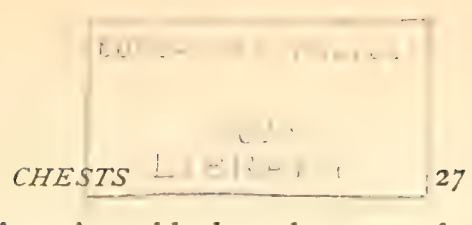

as the wood of the American black walnut, we do not hesitate to pronounce it European. In doubtful cases the presence of pine, or of more than one drawer, would speak in favor of American origin.

The following items show that plates, hinges, and locks for chests and cupboards were kept in stock presumably for new work, as well as for the repair of old pieces :-

"A duzen of playts for chests, I s. 6 d." - Inventory William Ludkin, Boston, 1652.

"I doz cupboard locks at I 2 s." - Inventory Captain Bozone Allen, Boston, I652.

"I doz of Chist Locks at I 2 s." - Inventory Henry Shrimpton, Boston, I 666.

"I4 pr chest hinges, $£$ I I s." " 70 pr chest joynts $£$ I. 3. 4." " 72 pr cross garnetts and chest joynts, $£ 4$ I 2." " 2 doz $\frac{1}{2}$ chest locks, £ I Iо." "Iо doz of trunk handles $£ 3$. " - Inventory Robert Cutler, Charlestown, Mass., I664-65.

In the inventory of David Saywell, a joiner of Boston, made in 1672 , the following articles of furniture are enumerated under the head of "new work," namely:-

" 2 New Bedsteads, 32 s., Io Joint Stoolls, 6 Chaire frames, 40 s." " 2 Chests, 3 tables, I Cubboard, 2 Desks, 2 Boxes, two Cabbinets and sum new work in the shop not finisht, $£$ I 2. I 2. OO."

From the testimony of the witnesses as preserved 
in the records of Essex County Court, Massachusetts, November term, 1674, Simons vs. Ames, it appears that Samuel Simons, a joiner, had made a cupboard for Edmund Bridges for the sum of $£ 3$.

In the inventory of Henry Messinger, a joiner, made in Boston in $\mathrm{I} 68 \mathrm{I}$, "A tabell and chest of drawers not finished " are found "in the shop."

There are no valid reasons why carved and paneled chests should not have been made in New England in the seventeenth century. That the colonists were early supplied with skilled labor is shown by the following list of trades represented in Boston in I647, given by Captain Edward Johnson, in his "Wonder Working Providence," namely, "Carpenters, joiners, glaziers, painters, gunsmiths, locksmiths, blacksmiths, naylers, cutlers, weavers, brewers, bakers, costermongers, feltmakers, braziers, pewterers, tinkers, rope makers, masons, lime, brick, and tile makers, cordmakers, turners, pump makers, wheelers, glovers, fellmungers, and furriers." Shipbuilding was begun as early as I63I, and carried on very extensively.

It is generally conceded that oaken chests were made by joiners in Europe in the seventeenth century. If so, why should not joiners have made them here also? If it should be answered, that joiners might make the chests, but that special skill was needed for the carving, we are ready with the proof that even carvers were not wanting, as in Savage's 


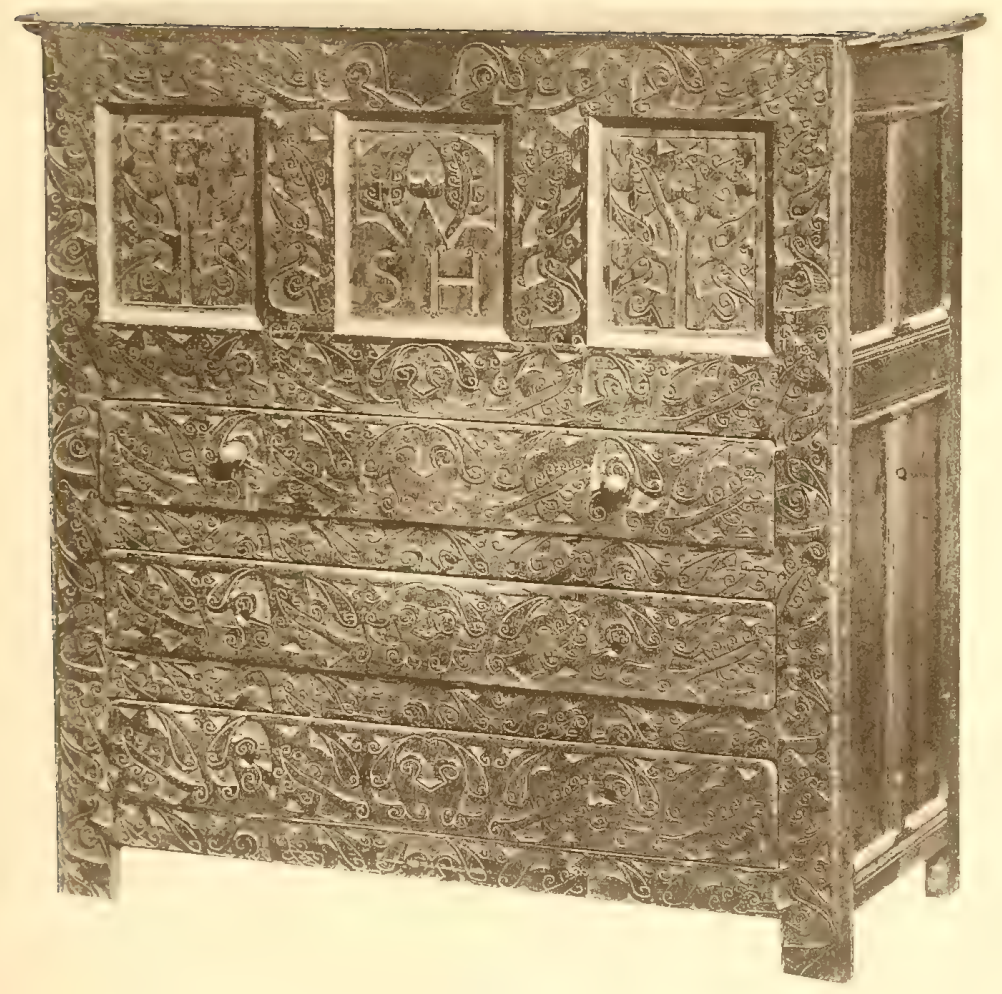

116. 1 .

CARVED OAKEN CHEST WITH THREE DRAWERS

10501706 

"Genealogical Dictionary" we find that Edward Budd, a carver, was living in Boston in " 1668 , and several years before;" and in Wyman's "Genealogies and Estates of Charlestown," Richard Knight is given as "a carver aged 53 years in $1676 . "$ 


\section{CHAPTER II.}

\section{CUPBOARDS.}

IN a list of the accounts of the constables of the Castle of Dover, dated December 20, I344, "j. tabulam vocatam coppebord" is mentioned. In another, dated January 26, I36r, we find the item, "j. table appelle cupbord." How much earlier than the year I 344 the word cupboard appears in our language we do not know. It was used at first, literally, to designate the table or board on which the cups were placed. It is believed by most antiquaries that these early cupboards were in the main open structures, and it is possible that they remained so during the fourteenth century and a portion of the fifteenth.

In the houses of great personages the cupboard was sometimes a very stately piece of furniture, with steps or stages, on which during feasts the household plate was displayed with great ostentation. The high cupboard in the item, "De viijd. rec. pro ij pannis lineis pro alto copard," in the inventory of Thomas De Dalby, Archdeacon of Richmond, made May 2I, 1400, and published by the Surtees Society, may have been one of these grand pieces. 
At what time the word cuyboard began to be applied to inclosed structures is an interesting question. A dressoir, partly inclosed below, is given by Viollet-le-Duc in his view of a chamber in a chateau of the fourteenth century. The buffets and dressoirs of the fifteenth century are often represented with a little closet just beneath the table. A dressoir in the tapestry of Nancy is inclosed from the table to the floor. As the fashions in England followed those of the Continent, it is not at all unlikely that some of the earliest English cupboards were inclosed in the manner and to the extent here described, instead of being altogether plain and open structures.

The "cupbord with two almeries," in Rokewode's "Hundred of Thingoe," from the will of Elizabeth Drury, made in 1475 , shows that inclosed cupboards were made in England at that time. We have found several references to inclosed cupboards in the English wills and inventories of the sixteenth century. The following is an instance from the will of Gilys Levyt, made in $155^{2}$, and published by the Camden Society, namely, "My newe cubbord $\mathrm{w}^{\text {th }}$ ye presse in $\mathrm{y}^{\mathrm{t} . "}$

The mediæval English words for inclosed pieces of furniture with doors and shelves were almery and press. Almery, written also aumbry, ambry, etc., was in use, according to the "New English Diction. ary," as early as I 393 . It is constantly met with in 
some of its forms in the English wills and inventories during the next two hundred years, but gradually gave way towards the close of the sixteenth century to the words cupboard and press. It was used for inclosing various things, such as precious objects, food, and clothing, and corresponded strictly to the armoire of the French.

The first use of the word press that we have noted occurs in the item, "De pretio ij pressurarum lig. nearum pro vestibus conservandis, cum foliis ac clavibus et seris," recorded in $1552-53$ in the inventory of William Duffield, Canon Residentiary of York, etc. Its primary use for storing and preserving clothes seems to have continued to be its principal use, as in the inventories of the fifteenth and sixteenth centuries presses are usually found in the chambers, and are oftenest spoken of in connection with clothing.

We have seen that the word cupboard had begun to extend its original meaning of a board or table for cups as early certainly as the latter part of the fifteenth century, it being at this time occasionally applied to inclosed structures.

The second or new meaning of this word had become so well established by the latter part of the sixteenth century that the words cupboard, almery, and press were then sometimes used as convertible terms, as in the following items, namely, " $\mathrm{ij}$ almeries or 


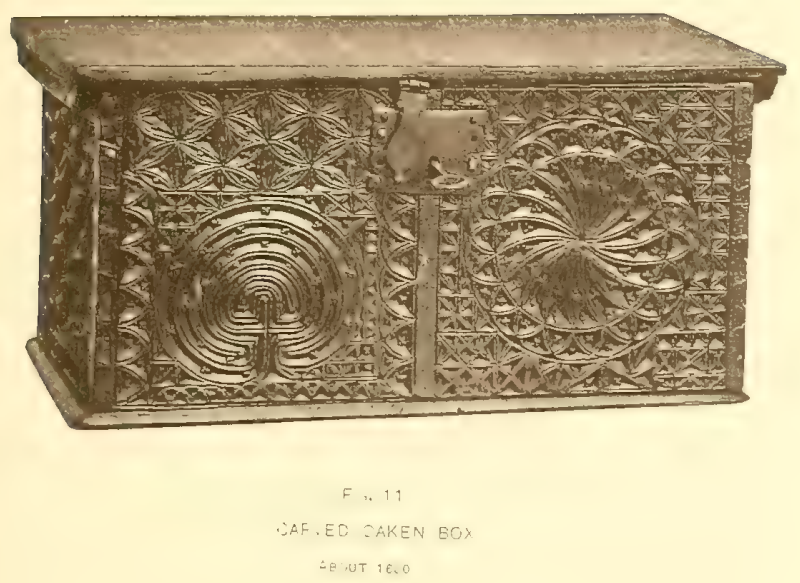



cupbords;" "a presse or cupbord;" the first from the inventory of Julian Mitford, made in 1587 , and published by the Surtees Society, the second from the inventory of Hugh Bellot, Bishop of Chester, dated I 596, and published by the Chetham Society. If further proof be needed of the entirely new signification which this word had acquired, it will be found in the item, "A presse of waynescoote $w^{\text {th }}$ a cubbord in the same," from the inventory of William Glaseor, dated I588-89, and published by the Chetham Society.

The word cupboard, therefore, at this time was applied to two distinct classes of objects, the one open, the other inclosed. Many of the first, with their furniture of plate, were designed for banqueting halls and chambers, and in the sixteenth and seventeenth centuries were sometimes called livery-cupboards and sometimes court-cupboards. The secorrd kind was a cupboard in the new sense of the word, with doors and shelves, into which anything and everything was put, and had no necessary connection with the diningroom. It corresponded to the almeries of the earlier inventories, and in the latter part of the sixteenth century, and through the seventeenth, was called by some a press cupboard and by others a wainscot cupboard.

The early inventories of New England abound with cupboards as with chests. Among the various 
entries we find, "cupboard," "small cupboard," "great cupboard," "court-cupboard," "livery-cupboard," "side cupboard," "press cupboard," " joined cupboard," "wainscot cupboard," "hanging cupboard," "sideboard cupboard," and "cupboard with drawers." We cannot recollect having seen the word almery in the New England records.

The varieties included under the general name of cupboard were doubtless very numerous, ranging from the smallest and plainest to the largest and most pretentious pieces; about the only features that they had in common were their doors and shelves, for, with the exception of some court and livery-cupboards, it is probable that the cupboards of the seventeenth century were inclosed structures.

A court-cupboard is mentioned in the inventory of William Clark, of Salem, Mass., dated I647. After this time they are frequently met with in the New England probate records, the last one noted being in the estate of the Reverend Samuel Stowe, of Middletown, inventoried in the year I 704.

They occur in the English inventories as early as 1586, in which year three "courte cubberds" were apprized in the inventory of Thomas Brickwell, Esquire, published by the Surtees Society.

In addition to the allusions to these pieces found in the writings of the old dramatic authors and lexicographers, we have notes of one hundred and six- 


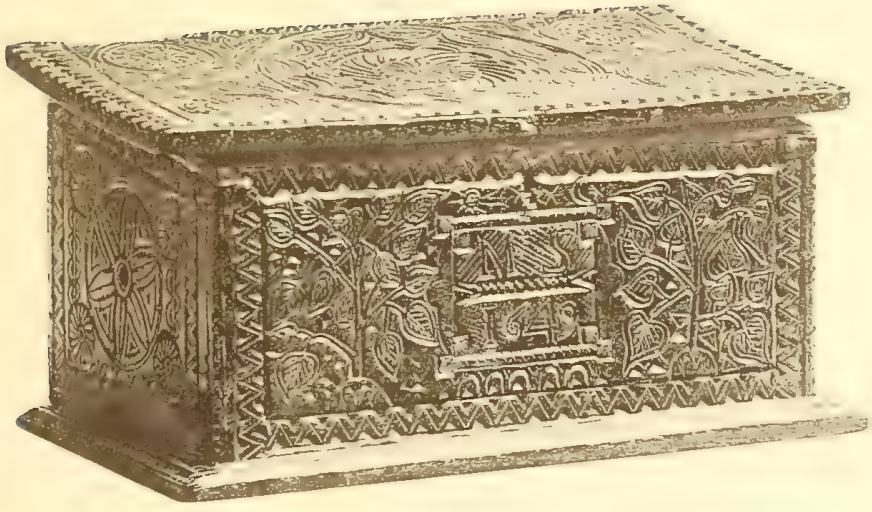

F G. 12

CAR, E', CAKEN EOY

DATED 1EA. 

teen court-cupboards taken from wills and inventories made between the years 1586 and 1704 . In thirty-five instances these were obtained from English sources, and in the remaining eighty-one from the New England records. Let us first study the court-cupboard as it appeared in England.

They are found in the halls, the parlors, and the chambers, and were part of the furniture of the aristocracy and of people of rank and wealth.

The prices before the year 1600 are given in nine instances as follows:-

"In the hall, One greate cobberde and ij courte cubberds, I6s." "In the greate chambre, j cowrte cubberd and j little coffer, 3 s. 4 d." - Inventory of Thomas Brickwell, I 585-86, above mentioned.

"In the chamber called the greate chamber, A court cubbord, with a carpett to the same, 5 s." - Inventory of Henrie Brickwell, I589-90. Publications of Surtees Society.

"In the dyninge chamber, ij courte cupbordes, v s." "In $y^{e}$ great chamber of wallnut, iij courte cupbordes, xij s." - Inventory of Hugh Bellot, before cited.

From these data it is apparent that the court-cupboards of this period were inexpensive structures, the prices of those belonging to the estate of Bishop Bellot ranging from two shillings six pence to four shillings. It is true that in England the purchasing power of money in 1596 was from nine to ten times 
as great as to-day. With the most liberal of these estimates, however, the present valuation of Bishop Bellot's court-cupboards would only be from twentyfive to forty shillings in English money. The prices of other cupboards in the inventories of this period range from one to fifty shillings, those valued at from ten to twenty shillings being of frequent occurrence. Court-cupboards were, therefore, among the cheaper kinds of cupboards.

Very valuable information as to the construction and use of these cupboards is given by Cotgrave, in his "Dictionarie of the French and English Tongues," published in London, in I6I1. A buffet is here defined to be, "A court-cupboord, or highstanding cupboord;" and a dressoir to be, "A cupboord; a court-cupboord (without box, or drawer), onely to set plate on."

There are to-day two interpretations of the definition here given to the word dressoir. By some it is held that Cotgrave meant to express that a courtcupboard should be called a dressoir only when made without a box or drawer, and that the existence of other court-cupboards with the box or drawer was implied. According to this view some court-cupboards, at the beginning of the seventeenth century, were entirely open, while others were inclosed to a limited extent at least.

By others it is believed that the parenthesis "(with- 
out box, or drawer)" was solely intended to explain the word court-cupboard - that Cotgrave's notion was that all court-cupboards were made without boxes or drawers.

The latter view is evidently the one held by the late Halliwell-Phillipps, who, with full knowledge of Cotgrave's definition of dressoir, has defined, in his "Dictionary of Archaic and Provincial Words," tenth edition, London, 1887 , a court-cupboard to be "A movable sideboard, generally covered with plate, and in fact used solely for that purpose, without drawers."

There is proof, however, that the court-cupboards of these early days were sometimes provided with a drawer or other inclosure. In an inventory without name, but dated 16Io, published in the work entitled "Ancient Inventories of Furniture, Pictures, Tapestry, Plate, \&c.," by James Orchard Halliwell, London, I854, we find among the furniture of the Tapestry Chamber the following pieces, namely, "A wainescott table coulered redd and varnished." "A fayer court cubberd soe coulered, with a drawer and cubberd cloth of Indyan stuff."

Again, in Chapman's "Roaring Girl," written in I6I I, occurs the sentence, "Place that in the courtcupboard."

Other cotemporary information as to the use of the court-cupboard is contained in the following passages:- 
"Away with the joint-stools, remove the court-cupboard, look to the plate." - Romeo and Juliet, Act I., Scene 5.

"Here shall stand my court-cupboard, with its furniture of plate." - Chapman's Monsieur D'Olive, Act III., Scene ז, I606.

"And so for the feast, you have your court-cupboards planted with flagons, cans, cups, beakers, bowls, goblets, basins, and ewers." - Chapman's May-Day, i6ri.

That some court-cupboards were more valuable than others, or that they began to be made differently as the seventeenth century advanced, is rendered probable by the price given in the following instance:-

"In Parlor, One court cubbord, Io s." - Inventory of John Chetwode, Esq., July, I6I5. Lichfield (England) District Probate Registry.

That they were sometimes carved is made certain by the following quotation from Corbet, who, like Shakespeare, Chapman, and Cotgrave, saw these pieces in use:-

"With a lean visage, like a carv'd face On a court-cupboard."

Iter Boreale. 1618-21. (Gilchrist.)

So far as we know there are no cupboards in existence that are known to have been called court-cupboards in the sixteenth and seventeenth centuries, nor are there any illustrations of such pieces. There is, however, possibly one exception to the latter statement. In his notes to the court-cupboard, mentioned in " Romeo and Juliet," Singer says:- 


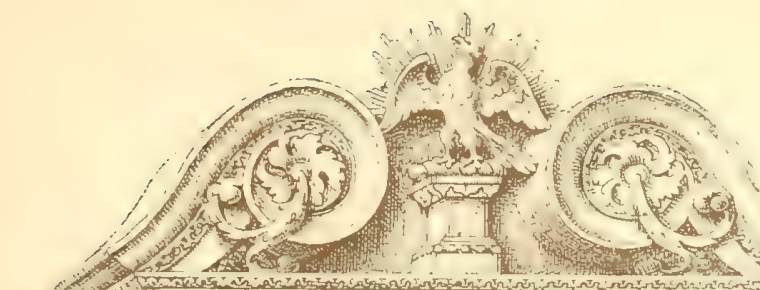

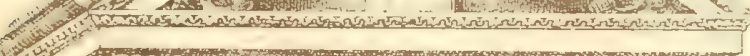

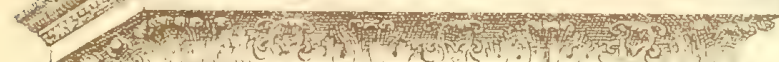

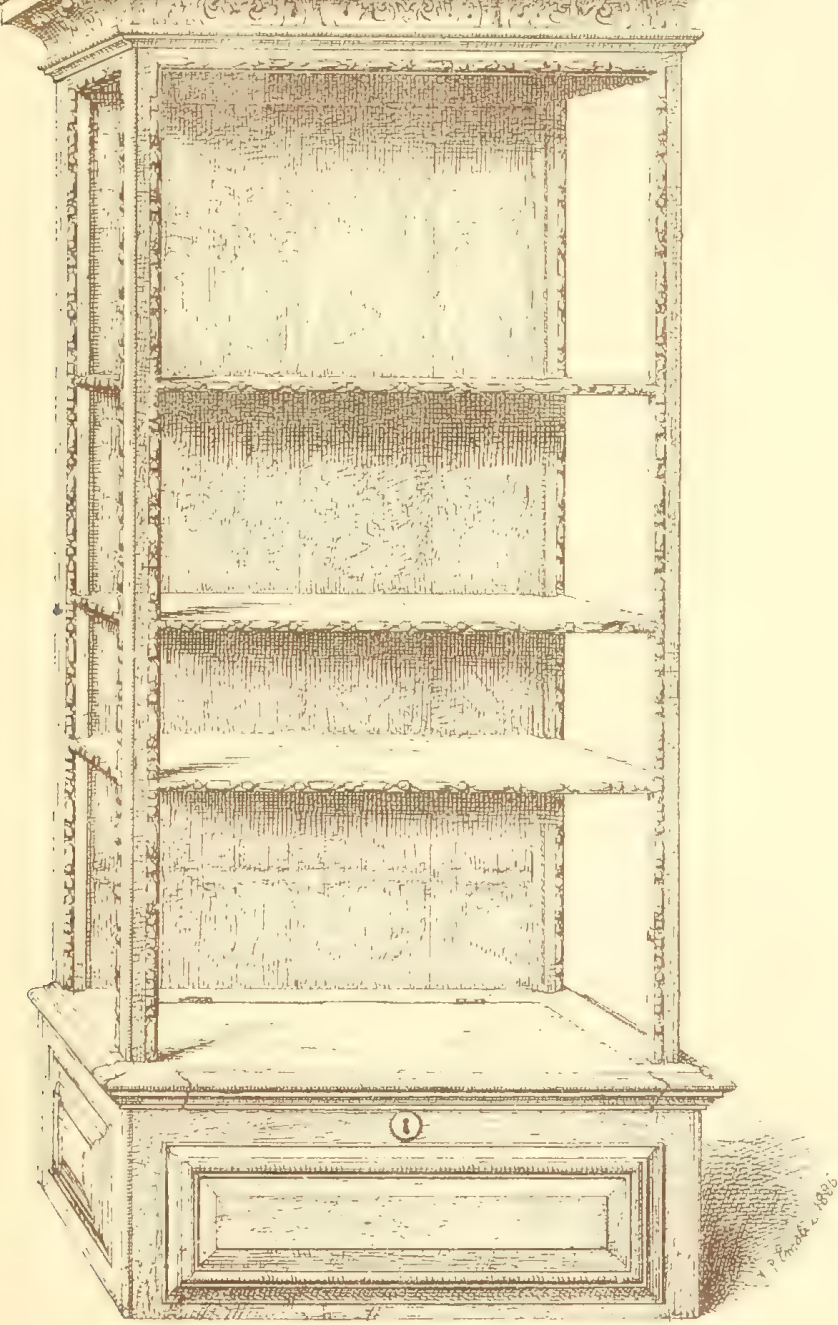



"The court cupboard was the ancient sideboard: it was a cumbrous piece of furniture, with stages or shelves, gradually receding like stairs, to the top, whereon the plate was displayed at festivals. ... There is a print in a curious work entitled 'Laurea Austriaca,' folio, 1627, representing an entertainment given by King James $I$. to the Spanish Ambassadors in $\mathbf{I}_{23}$, from which the reader will get a better notion of the court cupboard than volumes of description would afford him."

"Laurea Austriaca" must be a very rare as well as curious work. The library of the British Museum does not contain a copy, nor has any trace of the book or any other reference whatever to it been found after a somewhat prolonged search.

If the cupboard in this print (which no doubt conforms closely to the above description) is mentioned in the text as a court-cupboard, it would be exceedingly valuable as a cotemporary representation of this piece of furniture. But as Singer is silent on this point, and the work cannot at present be consulted, we cannot feel sure that the piece in question was a veritable court-cupboard, nor can we determine how much value should be attached to the views expressed by this writer as to the form and construction of court-cupboards in general.

The idea of pieces with steps like stairs for the display of plate has descended from the receding stages of the Flemish dressoir of the fifteenth century. It also has for more modern authority such items as the following: "At $\mathrm{y}^{\mathrm{e}}$ greate chamber dore;" 
"A thing made like stayrs to set plate on," from an inventory dated I603, and published in the "History and Antiquities of Hengrave, Suffolk," by J. Gage. London, I822.

There are two pieces in Stationers' Hall in London, which were referred to as court-cupboards as early as I 766 by Steevens, in his edition of Shakespeare of that date. These same pieces were described as court-cupboards by John Gough Nichols as late as January 20,1860 , in a paper read by him in Stationers' Hall. With this history a study of these pieces should not be omitted from any serious inquiry as to the shape and general appearance of the court-cupboard.

Through the courtesy of Charles Robert Rivington, Clerk and Registrar of Stationers' Hall, we were permitted to examine these cupboards in the summer of I 886 , and to have a drawing of one of them made for illustration. They are alike, and it is believed were made by Colledge when he built the hall in I670, after the great fire. Their dimensions are as follows: Hight, to the top of the eagle's head, nine feet; width, thirty-six and one half inches; depth of the shelves, ten and one half inches; depth of the lower shelf or table, sixteen and one half inches.

An examination of these pieces leads one to believe that the lower shelf or table was originally deeper than at present, and that it also stood higher 

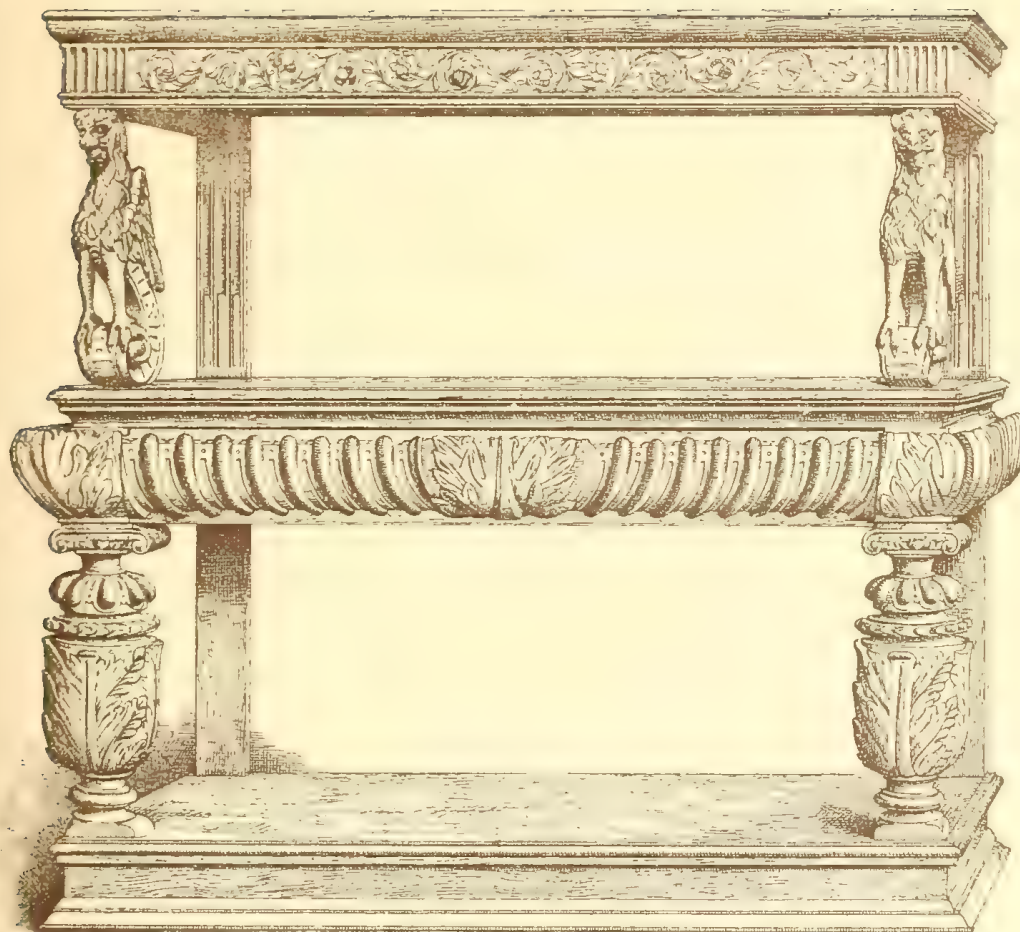

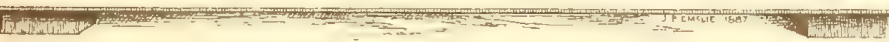

i. $1 .+$ 

up from the floor. It is still the custom to place certain portions of the gold and silver plate on these cupboards when the Company dines in the Hall. One of these cupboards is shown in Fig. 13, from a faithful drawing made by Mr. J. P. Emslie, of London.

Finally, in Shaw's "Specimens of Ancient Furniture," with descriptions by Sir Samuel Rush Meyrick, London, 1836 , are two pieces of the early seventeenth century period (Plates XXVI. and XXVII.), which are put forward as possible specimens of the court-cupboard. A cupboard similar in design to the first of these is illustrated by Halliwell, in his sumptuous edition of Shakespeare, in connection with his notes to the court-cupboard in "Romeo and Juliet." These three pieces resemble the cupboard now in the hall of Christ Church College, Oxford, which is shown in Fig. I4, reproduced from a drawing made for us by Mr. Emslie.

From this history of the court-cupboard in England, we find it in use as early as 1586 in the halls, parlors, and chambers of the nobility and gentry; that at this time it was valued in the inventories at from two shillings six pence to four shillings; that in the first years of the seventeenth century it was described as a high-standing piece, either entirely open or partially inclosed, and used to set plate on; that there are grounds for believing that in some 
cases the ascending shelves were made to recede like stairs; and that, in the opinion of later antiquaries, such cupboards as the one in Christ Church Hall at Oxford and those in Stationers' Hall in London are such as were called court-cupboards in their early days.

It is quite possible that a date considerably earlier than 1586 will be established for these pieces, - that the expression court-cupboard will be found at least coeval with that of livery-cupboard, which, as we shall see, was in use in the early part of the century.

From the facts here adduced as to the variable construction of court-cupboards at the beginning of the seventeenth century, as well as from the well known mutability of all fashions, we may safely conclude that the early court-cupboards not only differed from each other, but also from those that succeeded them. These considerations are quite as important in the study of court-cupboards as in that of any other article of furniture or dress which extended over a period of one to two centuries.

In New England, as well as in the mother country, the court-cupboard was found in the hall, the parlor, or the chambers of the chief magistrates, the clergy, and other persons of wealth and social position.

The prices, given separately in twenty-seven instances, range from eight shillings up to four pounds. It was below one pound apiece for fifteen cupboards; 
from one to two pounds for eight, and above two pounds each for the remaining four. The facts as to the dates, ownership, and prices of the last group are contained in the following items :-

"I court cubberd, $£_{2}^{2} 3$ s." - Inventory of Stephen Goodyear, Deputy Governor of New Haven, I658.

"One court coobard, $£^{2}$ I 5 s." - Inventory of Mrs. Mary Glover, Boston, 1659-60.

"One court cubbert, 50s." - Inventory of Joseph Buckminster, Boston, I668-69.

"I court cupboard, $£ 4$." - Inventory of Edmund Jacklin, Boston, I68 r.

The cheaper pieces of the first group are distributed over the period embraced between the years 1653 and 1690 , eight being before the year 1670 , and seven from 1670 to I690. Court-cupboards, as we shall see, were among the highest priced cupboards in New England.

We have already noticed that in 16 I 5 an English court-cupboard, in the estate of John Chetwode, was apprized at ten shillings - more than double the valuation of those in the inventory of Bishop Bellot, made nineteen years previously. This, together with the fact that some court-cupboards in New England are found not only high in price, but also among the highest priced of all cupboards, tends to show that the style and finish of these pieces was gradually improved, so that in New England, at least, by the mid- 
dle of the seventeenth century they were among the most elaborate and costly of all cupboards, and we have little doubt that future studies will result in finding similar changes in the English court-cupboard of this time.

The wages of carpenters in Massachusetts during the seventeenth century were about two shillings a day. The price of wheat, according to Felt, from I648 to I694 was pretty uniformly five shillings per bushel.

A "court cubbard $\mathrm{w}^{\text {th }}$ one drawer," valued at sixteen shillings, is mentioned in 1658 in the inventory of William Francklin, of Boston. Another, with one drawer, appears in the inventory of William King, of Salem, dated I684; and one with three drawers, in the inventory of Doctor Samuel Alcock, of Boston, made in 1677 . These are the only references to inclosure in the records of the eighty-one New England court-cupboards which we have analyzed.

The only allusions to the uses of the court-cupboard are found in the following extracts : -

"A Court Cubboard $w^{\text {th }}$ Cubbord Cloath, glases

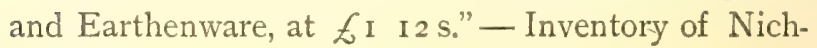
olas Davison, Charlestown, I664-65.

"I courte cubbard cushon; and cloth and earthen and glass furniture, $£$ I IO-s." - Inventory of Jonathan Rainsford, Boston, I67I.

"I court cupboard \& cupbord cloath with earthen- 


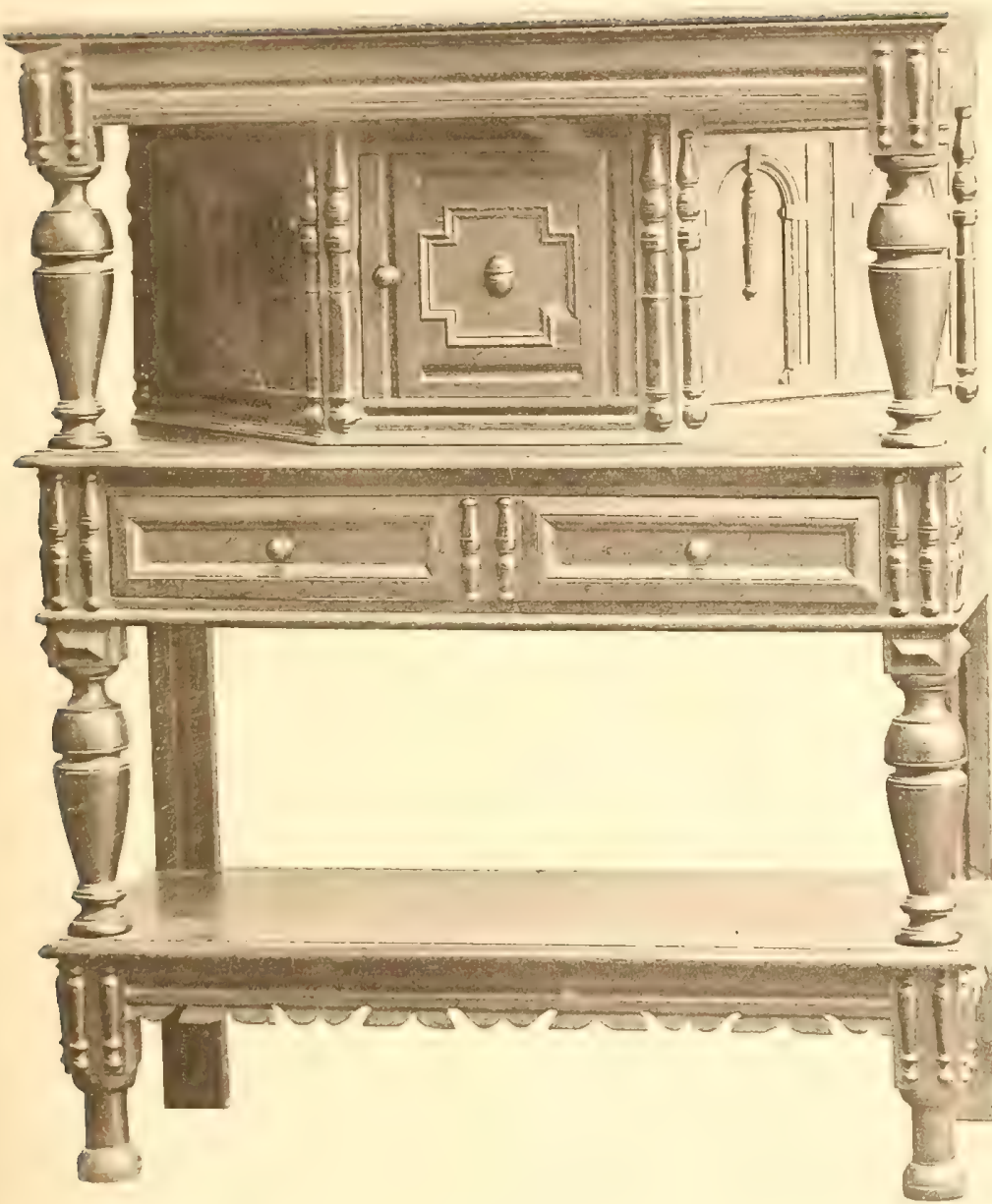

COURT-CUPBOARD 

ware on it, $£$ I Ios." - Inventory of Christopher Gibson, Boston, I674.

Are there to-day any old pieces of furniture which answer to the history and descriptions here given, and which were probably called court-cupboards in the sixteenth and seventeenth centuries?

We think that this question may be answered affirmatively, and that the open cupboard illustrated by Shaw (Plate XXVII.), to which reference has already been made, and also the one in the Hall of Christ Church College in Oxford, here given, are two such examples.

The only difficulty in classing these pieces as courtcupboards is in the matter of price. Both are early examples, and belong to the period in which we find court-cupboards valued in the inventories at a few shillings only. But this objection, which will probably disappear, should not have great weight in the presence of such specimens, which were clearly intended for the display of plate and other precious vessels of glass and earthenware.

As the cupboards in Stationers' Hall in London were called court-cupboards more than a hundred and twenty years ago by so good a scholar as Steevens, and as we find them open and "high-standing," and well adapted for the display of plate, it seems quite likely that we have in them one of the forms of the court-cupboard. They are doubtless larger and bet- 
ter than the average of their type, because designed for a guildhall in which a great number were to dine together.

We do not believe that the style of the court-cupboard in England was regulated by etiquette or any other arbitrary rule, but that from the prices given, the early specimens were, in most cases, very plain and simple affairs, consisting probably of an open frame with stages or shelves. Under one of these shelves a box or drawer was sometimes placed. Occasionally a larger or finer specimen was enriched with carving. Some of these latter, on account of their beauty or value, have been preserved, but the cheaper and less ornate pieces seem to have disappeared.

There are no cupboards remaining in New England, as far as we know, like the one in Christ Church Hall, though there can be but little doubt that such were in use in this country. There is, however, here as in England, a style of cupboard differing from the above only in having its upper part inclosed. One is shown in Fig. I5. It belongs to Mr. William C. Waters, of Salem, Mass.

We are strongly inclined to believe that these pieces were called court-cupboards in the seventeenth century. The part below was left open, like the French and Flemish dressoirs of similar construction, to receive the precious vessels of silver, glass, 


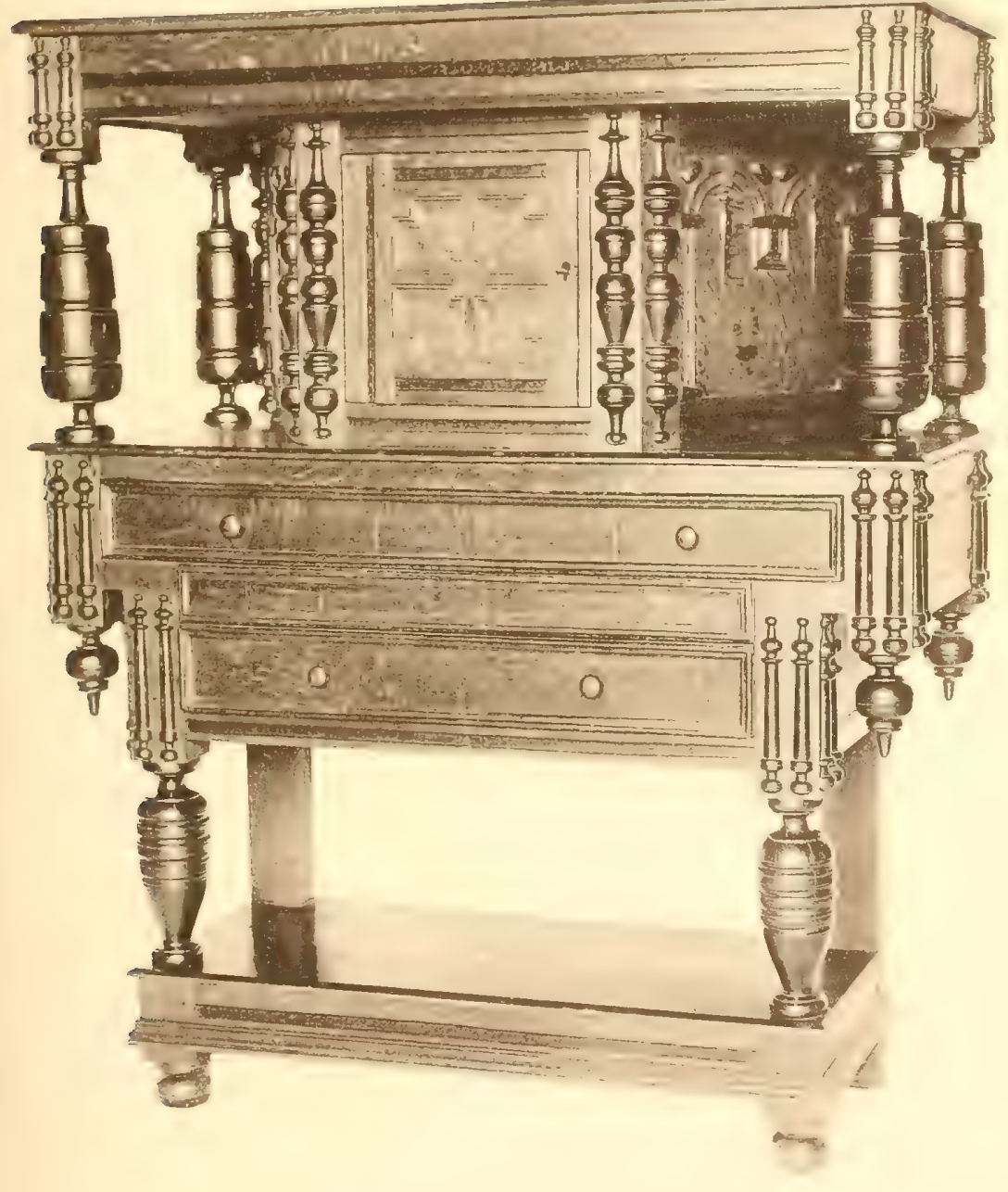

Fig. 16

COURT-CUPBOARO

SECOND HALF SEVENTEENTH CENTURY 

and faience, which were also displayed from the cupboard's head. On the continent of Europe such pieces were called dressoirs, and that they answered the same purpose in England and in this country seems altogether likely. Unless we suppose them court or livery-cupboards, - which, as we shall see, were probably the same, - it will be difficult to classify them. The only other articles of furniture mentioned in our inventories which could have referred to such pieces as these are side cupboards, or, as they are sometimes written, sideboard cupboards. We have notes of fifteen of these cupboards from the New England inventories of the seventeenth century, and are inclined to think that the words side cupboard and sideboard cupboard were only other names for the court and livery-cupboard, though in two instances we have found them mentioned in the same estate with a livery-cupboard, and once with a court-cupboard. In the inventory of Sir Henry Woddrington, dated I 593, and published by the Surtees Society, "iij syde cupbordes" are mentioned.

Another example of the court-cupboard is shown in Fig. I6. It is a very quaint and interesting specimen. There are two drawers below the central stage. This piece belongs to Mrs. Charles Haddock, of Beverly, Mass., in whose family it has descended from some time in the seventeenth century.

Livery-cupboards are mentioned in the English 
records as early as the year 1538 . In one of the items of the Hengrave contract made in that year, and published in Gage's "History and Antiquities of Hengrave," above cited, it is specified that, " $y^{\mathrm{e}}$ said hall to have ij coberds; one benethe, at the sper, $\mathrm{w}^{\text {th }}$ a tremor; and another, at the hygher table's inde, $w^{t}$ out a tremor; and $y^{e}$ cobards, they be made $y^{e}$ facyon of livery, $\mathrm{y}^{\mathrm{t}}$ is $\mathrm{w}^{\mathrm{t}}$ out doors."

Another item in this contract calls for "two parlors to be seelyd, to the heyght of the floor, and eche of them a livery cobard." Besides these, ten other livery-cupboards for the chambers are mentioned.

In the notes of the forty-five livery-cupboards which we have gathered from the English records, the prices are given separately in only nine, all these being between the years 1582 and I588. Two shillings six pence is the highest price named, and eighteen pence the lowest. The only information that we have found relating to the prices of livery-cupboards in England in the seventeenth century is contained in the item, "Livery cupboard and carpet, I 5 s.," from the inventory of William Bullock, recorded in 1667 in the Lichfield District Probate Registry. According to these facts the value of livery-cupboards in England, like that of court-cupboards, was very low.

We have notes of fifty-three livery-cupboards collected from the New England inventories from 1650 
to I694. The prices of the cupboards alone are given in thirty-one cases. One was valued at $£ 316 \mathrm{~s}$. in 1663; two at $£ 3$ each in 1664 and 1666 ; five at £I Ios. each in I650, I666, I672, I690, and I69I; seven were valued from $£ \mathrm{I}$ to $\oint_{\mathrm{I}} 5 \mathrm{~s}$., and sixteen between three and eighteen shillings. The prices of livery-cupboards in New England are thus seen to be about the same as for court-cupboards.

The livery-cupboards at Hengrave, according to the terms of the contract, were to be made without doors; indeed the contract defines a livery-cupboard to be one without doors. The cupboard in the hall, "at the sper," had "a tremor," which was a hood, or head-piece, possibly resembling those seen upon the early Flemish dressoirs. From the fact that the location of this and the other cupboard in the hall was provided for, it would seem that these two pieces might have been stationary.

While it was undoubtedly the rule that livery-cupboards were open structures, there are, nevertheless, a few facts which show that in some cases they were more or less inclosed. In an inventory made in 1626 , and published by Halliwell in 1854 , in his work above referred to, "I winscott livery cupboard with lock and key" is mentioned. In the inventory of Nicholas Upsall, of Boston, taken in 1666 , "a small livery cubberd $\mathrm{w}^{\text {th }}$ drawers" is valued at ten shillings, and in that of Jonathan Mitchell, of Cambridge, 
dated I668, we find the item, "By a liverey cubbard and drawer and old cloth, 6 s. 8 d." Again, in the inventory of Mary Lusher, of Dedham, dated 1672-73, a livery-cupboard in the parlor is valued at $f_{1} \mathrm{IOS}$.; on the second line below, "Smale things within the cubbard" are mentioned. As no other cupboard occurs in the parlor, the livery-cupboard in this instance was inclosed.

The following quotation from the translator of Comenius is, so far as we know, the only record cotemporary with these cupboards that has any reference to their use. In treating of the dining-room it reads : -

"Golden and gilded beakers, cruzes, great cups, crystal-glasses, cans, tankards, and two-ear'd pots are brought forth out of the cupboard and glass-case, and beeing rins'd and rubb'd with a pot-brush are set on the liverie-cup-board." - Janua Linguarum. Edition 1643 .

Here, then, in our first view of the livery-cupboard in use we find it set out with golden and gilded beakers, plate, and precious glasses. That this was the use to which it was put in other instances is rendered probable by the fact that it is the only kind of cupboard found in the halls and dining chambers of many estates, as, for example, that of William Glaseor, Vice-Chamberlain of Chester, inventoried in I589, and published by the Chetham Society, and of William Lee, a wealthy gentleman of Brandon, 


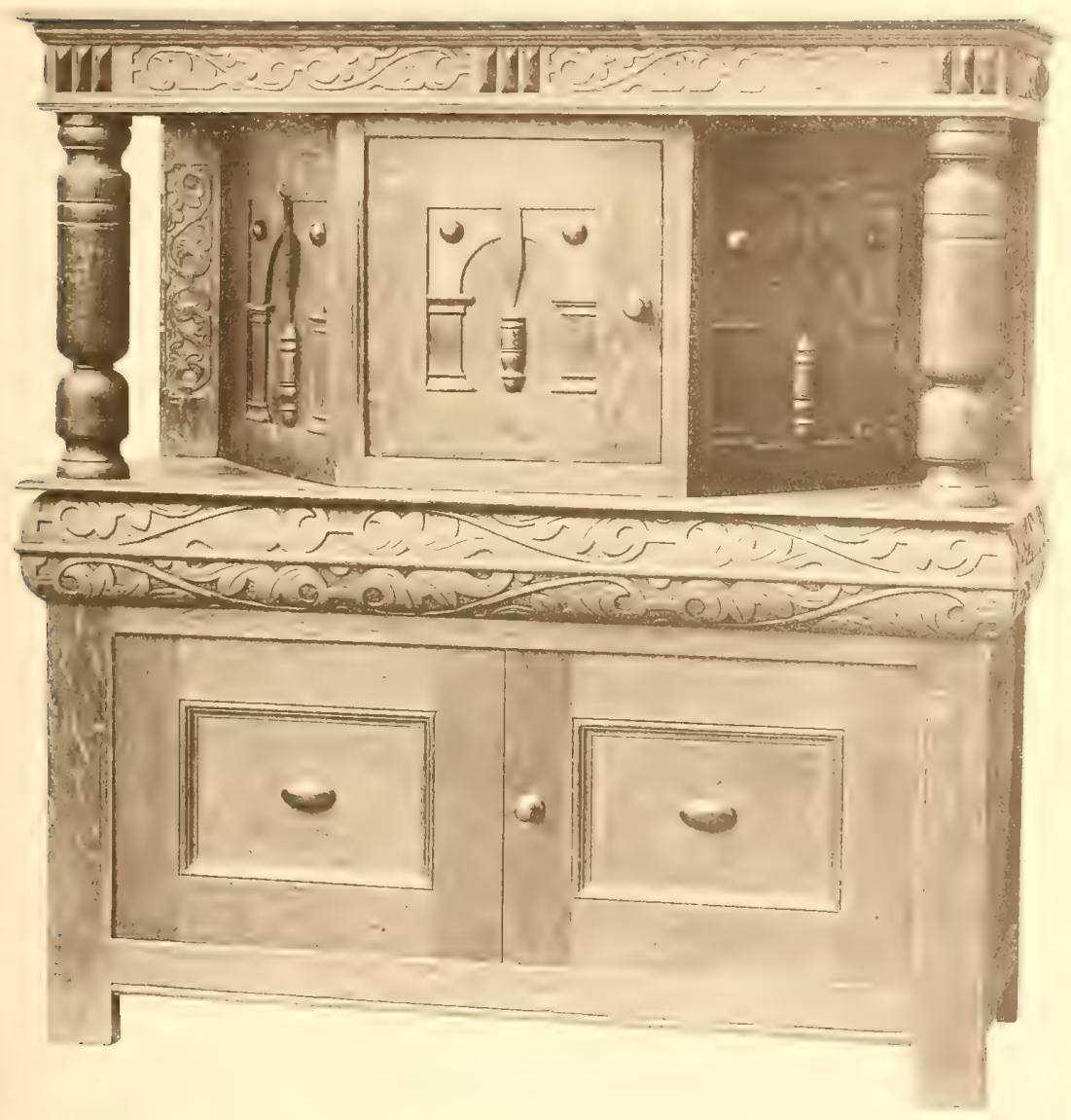

F G. 1 ;

PRESS CUPBOARD

AB.SLT 1660 

whose inventory, dated 1582 , is published by the Surtees Society. Both of these gentlemen had plate, the former a large amount, but neither had other than livery-cupboards in the hall or dining chambers. It is reasonable, therefore, to suppose that the plate in these houses was displayed upon their livery-cupboards.

It is a rule, to which we have found but three exceptions, that court-cupboards and livery-cupboards do not occur together in the same estate. These exceptions occur in the inventory of Bishop Bellot, before mentioned; in that of the Right Honorable Lettice, Countesse of Leicester, dated I634, and published by Halliwell in the work cited, and in the inventory of John Haynes, Governor of Connecticut, dated 1653 . But in none of these instances is a livery-cupboard found with a court-cupboard in the same apartment.

From the facts now set forth relating to court and livery-cupboards, - that they extended together over the same period; that both were mainly open structures, with a parallelism in price; that their uses seem to have been the same; that they occur in the halls, parlors, and chambers of the same people, but never together in the same apartment, and very rarely in the same house, - it would appear that one readily took the place and served the purposes of the other, if indeed they were not identical structures which 
went sometimes under one, and sometimes under the other name.

It is not at all improbable that court and livery-cupboards were used in some instances in parlors and in chambers, like the modern what-not and étagère, to hold a great number of miscellaneous objects, just as, according to Viollet-le - Duc, little dressoirs were sometimes used in France in the fifteenth century.

We cannot refer to any historic example of the livery-cupboard, to any particular piece or illustration that we know was called a livery-cupboard in the sixteenth or seventeenth century. There can be, however, scarcely any doubt that the descriptions and illustrations which have already been given in the study of court-cupboards are equally applicable to the livery-cupboard. A piece which was supposed to be an old livery-cupboard was sold at Christie's in London a few years ago, and is described by Mr. George $T$. Robinson, in his very valuable and interesting papers on furniture, published in "The Art Journal " during the year I88r, as follows:-

"It was of rude construction, consisting of three stages, supported by four legs, and having beneath its middlemost shelf a shallow drawer for table linen."

The court-cupboard with a drawer, which we have cited from an English inventory dated 1610, was colored red. There was also a red table in the same chamber. We often find certain parts of old cup- 


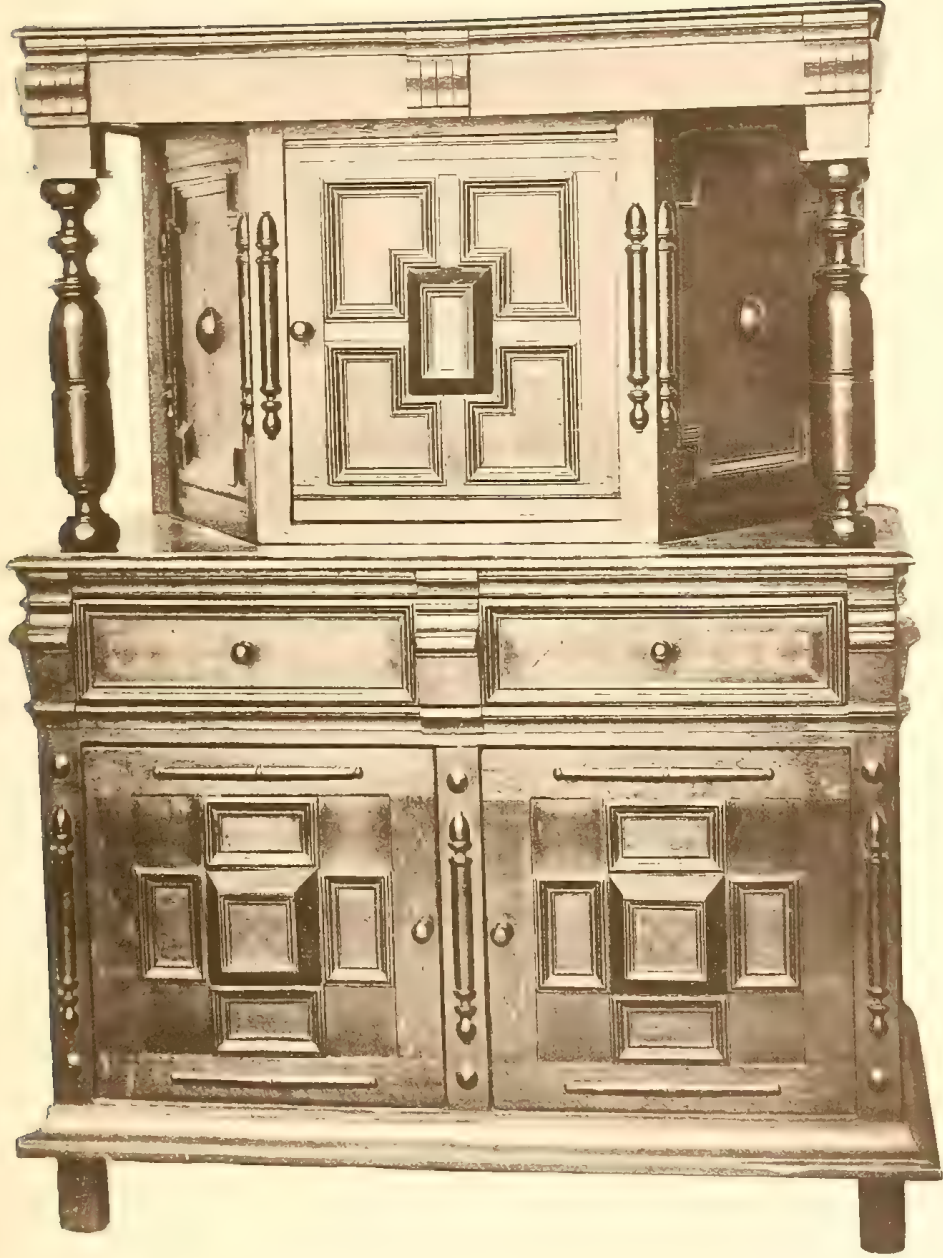

A PRESS CUPBOARD

1650-175 

boards colored black, such as their turned pillars, mouldings, and applied ornaments. But a red cupboard and a red table in the same apartment suggest that they were made to go together.

A similar instance is found in the Boston records (Suffolk. Deeds, Lib. I. I 36). The house known by the sign of the "Kings Arms" was sold in $165 \mathrm{I}$, with certain portions of its furniture. In the inventory of the latter is the following item:-

"Imprimis in the chamber called the Exchange one halfe headed bedsted $\mathrm{w}^{\text {th }}$ blew pillars, one livery Cupbord coloured blue, one long table, benches two formes, \& one carved chaire."

We come now to a class of cupboards wholly inclosed. These were by no means so rare in New England as those inclosed in their upper parts only, which, as we have shown, were probably called court and livery-cupboards.

Inclosed cupboards are variously referred to in the inventories as cupboards, great cupboards, press cupboards, presses, cupboards with a press, joined cupboards, and wainscot cupboards. When the New England inventories began to be written in the third decade of the seventeenth century, those pieces of furniture which stood up from the floor to various hights, with doors and shelves, were called cupboards and presses. Cupboards were very numerous, and like the old almeries held almost anything that 
could be put into them, while the presses proper were designed as receptacles for clothing, but were probably used to some extent for other purposes. It is quite likely that the words cupboard and press were used somewhat loosely in the inventories of those days, and that different apprizers have recorded the same or similar pieces under different names, sometimes as a cupboard, sometimes as a press, and sometimes as a press cupboard.

We show in Fig. I 7 one of the larger and finer cupboards to which reference has just been made. It belongs in the Hosmer collection. It is made in two separate parts, the upper and lower, which are fitted together at the top of the drawer so as to conceal the joint. The upper part represents three faces of an octagon, its sides sloping from behind to the door in front, the same as in the two court-cupboards in Salem, here illustrated. Just below this part is a large drawer extending across the front, with its face moulded and carved, and its ends mitered with the carved mouldings at the sides. The part below the drawer is opened into by two doors. The piece is plain below, but more or less enriched above with carving, paneling, and applied ornaments. This cupboard was bought a few years since near Colchester, Conn., very much out of repair, and with some of its parts missing. These have been carefully restored with strict regard to the original de- 
sign. It is fifty-four and three quarters inches high, fifty and a half inches long, and twenty inches wide.

In Fig. 18 is seen another specimen of the same type, but with differences enough in the ornamental details to render it a desirable piece to illustrate. It belongs to the estate of Burgis P. Starr, late of Hartford, Conn., and was valued very highly by this gentleman because of its descent from his Starr ancestors. It measures fifty-seven inches in hight, forty-three and one half inches in length, and twentytwo inches in width. There is no carving on it, but the front of the drawer and the raised panels on the doors are inlaid with colored woods. The columns, the turned ornaments, and the sunken mouldings are here, as in other specimens of the kind, colored black. Besides these two specimens, we have seen four others like the first, and have knowledge of four more, ten in all, which have been owned and used in Connecticut probably from some time in the seventeenth century.

Sometimes a piece is found with its upper cupboard made as in the preceding examples, but with two or three drawers in place of the lower cupboard.

Another style, differing from the foregoing mainly in the shape of its upper part, is shown in Fig. I9. The upper story is rectangular and divided into two cupboards, which are set back under the entablature 
about five and a half inches. The columns at the sides are good examples of the turner's art. The large cupboard or press below has but one door. The carving, applied ornaments, and drawer front closely resemble those on the chest shown in Fig. 9. This cupboard, now in the possession of the writer, had been owned in an old Connecticut family for several generations. It is of oak, fifty-six inches high, forty-nine inches long, and twenty-two inches wide. We have seen five others just like it, all from Connecticut, where, like the chests of the same style, they were doubtless made in the last half of the seventeenth century. One of these belongs to Yale University, a bequest from the late Charles Wyllys Betts.

Cupboards of this style, with plain panels and without carving, are occasionally found in New England. We have seen two such pieces.

Besides the above, at least two other varieties of this style are found here. One of these is shown in "The House Beautiful," by Clarence Cook (Fig. 75). In the other the lower cupboard is shaped like the upper cupboards in our illustrations Figs. I5 to 18 inclusive. It has also four turned columns, two for the upper, and two for the lower cupboard.

Cupboards like the preceding and their varieties were in general use in England during the seventeenth century. The style came into England from 


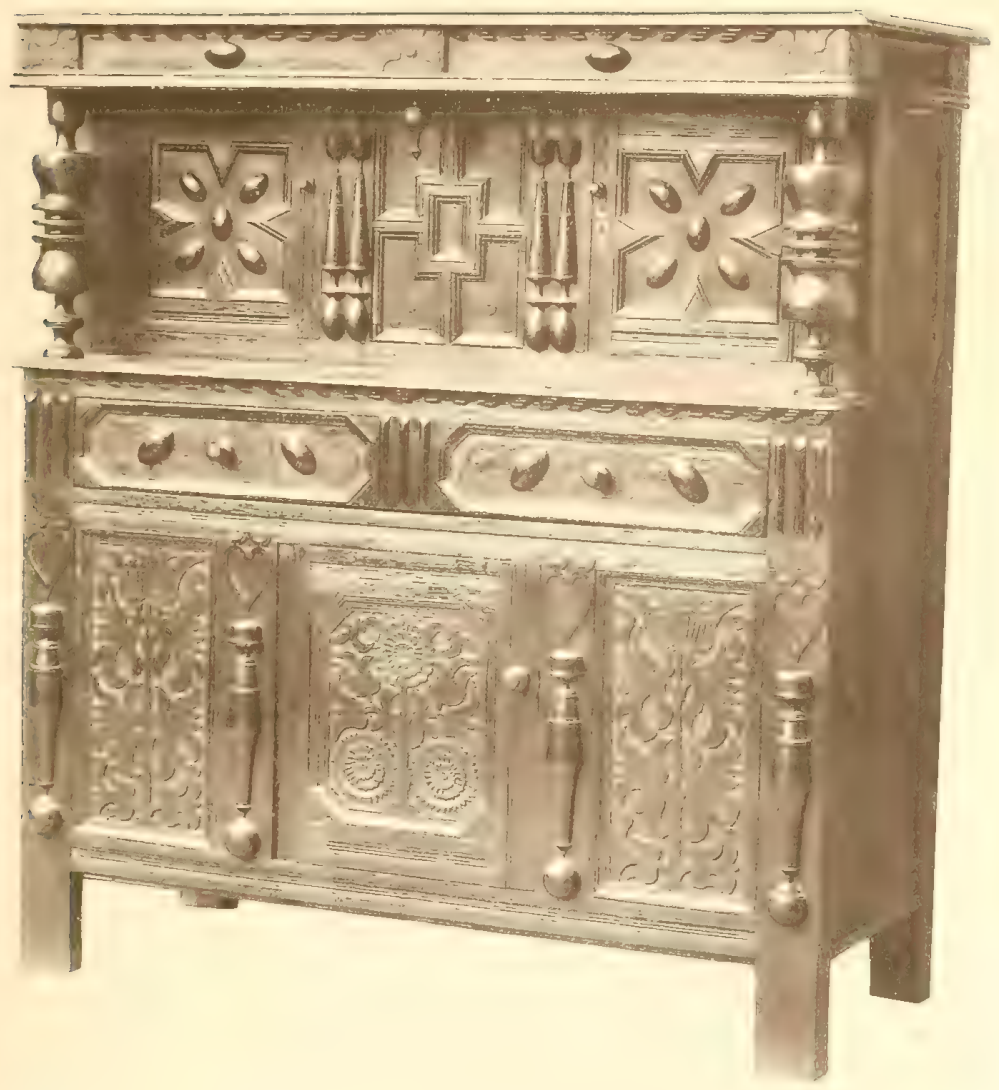



Germany and the Netherlands, and its details may be easily traced back to the designs of Hans Vredeman de Vries and his cotemporaries in the sixteenth century. The pieces we illustrate are indeed very modest representatives of the elaborate armoires designed by these celebrated artists, but it needs only the most casual comparison to discover the striking resemblances between them. This is especially apparent in the architectural treatment of their upper parts.

The cupboard of the seventeenth century in the Thaulow Museum at Kiel, referred to in the chapter on chests, is an exact counterpart of those in use in England and in her American colonies during the corresponding period.

We have made several attempts to trace certain of these cupboards in the inventories of the families to which they had belonged, for the purpose of discovering what they were called in their day, but have not succeeded except in a single instance, and here the success was only partial. One of very large size, six feet five inches high, five feet long, and twenty-six inches wide, - with the turned columns and upper cupboards, as in Fig. I9, was referred to, in a will made in $I_{7} 6_{3}$, as "my great cupboard." The cupboard and the will were shown us in the same house, by the descendants of the testatrix, and from the history of the former there could be scarcely any 
doubt that it was the piece mentioned in the document.

It would appear exceedingly probable that these inclosed pieces went under the general name of cupboard, with such prefixes as we have already pointed out, namely, great, joined, press, or wainscot, according to the facts in the case or the usage in the family or neighborhood. They were certainly not called cabinets, as some recent writers have misnamed them. Cabinets are not infrequently found in our records. One is mentioned in the following extract from the inventory of Richard Lord, of Hartford, made in I662, namely, "A cabbinet \& cupboard that it stands on, $£^{2}$ Ios."

"A turn pillar cuberd" is mentioned in the inventory of Rear Admiral Thomas Graves, of Charlestown, made in 1653. This is the only reference to these turned columns that we have noted, showing, as has already been pointed out, that decorative details, such as carving, applied ornaments, etc., were seldom employed in the old records to designate particular pieces. As a court-cupboard also occurs in the inventory, we may infer that it did not have turned columns, and that the "turn pillar cuberd" was probably an inclosed structure.

A cupboard was described in 1668 in the inventory of Thomas Hett, of Charlestown, as "A large Cuberd wherein a press and drawer, $£$ I $5 . "$ 

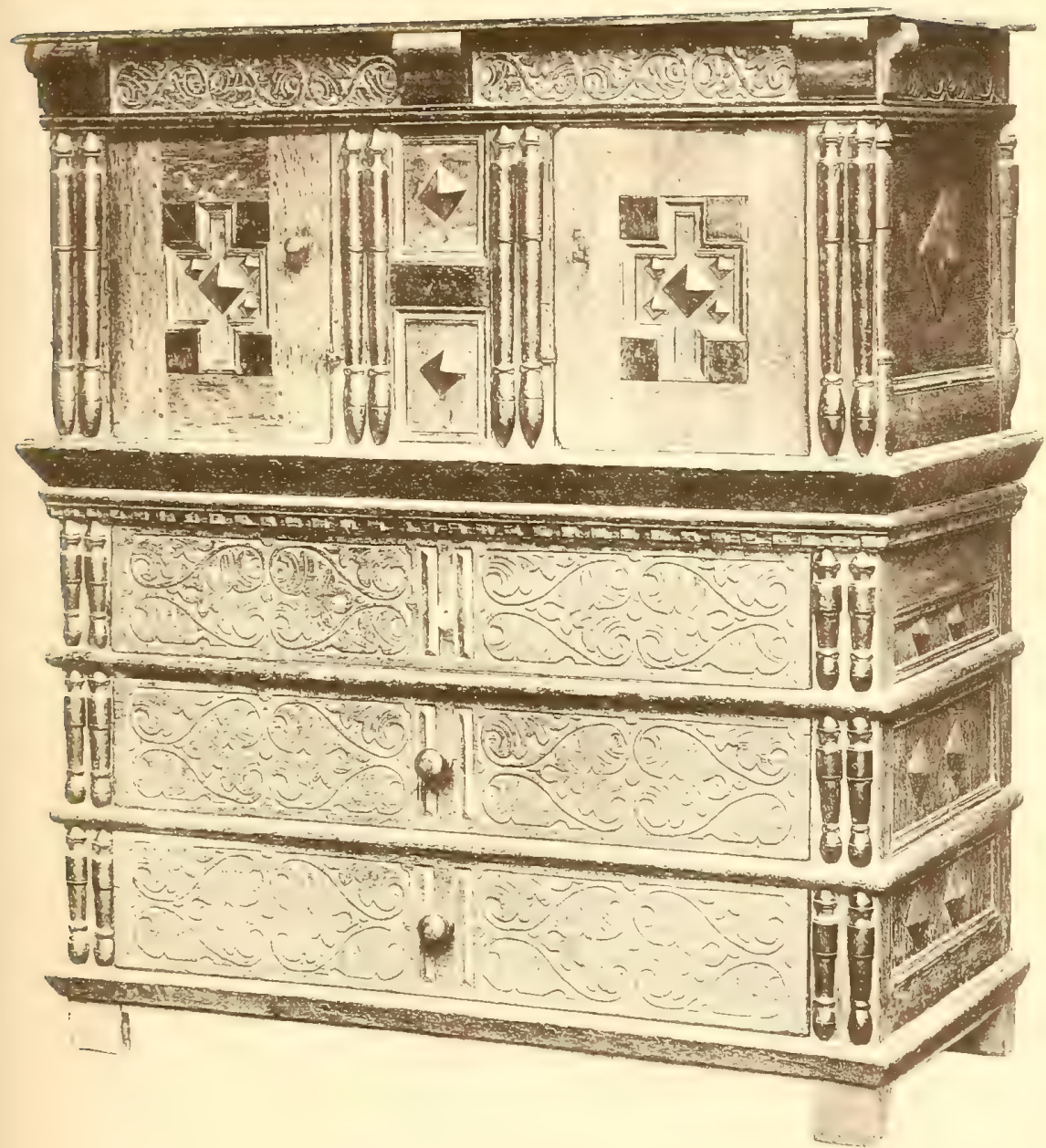

FIG. 20

CUPBOARD WITH DRAWERS 

A cupboard with drawers has been mentioned as a variety of the style represented in Figs. 17 and 18 . Another kind of cupboard with drawers is found in New England, an example of which is shown in Fig. 20. It is now the property of Yale University, and one of the several pieces of furniture of the seventeenth century period devised to that institution by the late Charles Wyllys Betts. It is made of oak, with the exception of the bottoms of the drawers, which are of pine. It measures about fifty-seven inches in hight, fifty-one and a half in length, and twenty-three and a quarter in width. The upper part, or cupboard, is made separate from the lower, and has two doors. Its front is on a line with the fronts of the three drawers below, instead of being recessed and flanked with turned columns in the usual manner. This cupboard was bought a few years since in Durham, Conn. One almost exactly like it, in the possession of the writer, was purchased in the town of Madison, Conn., in I883, from a family in which it had descended for many generations.

Cupboards with drawers appear quite early in our records. The item already quoted in the chapter on chests, from the inventory of John Cotton, made in I653, namely, "I chest and I little cupboard, both with drawers, $£ 3$ los.," contains the first mention of them that we have noted.

In 1657 two cupboards with drawers, valued re- 
spectively at $£^{2} 5 \mathrm{~s}$. and $£_{36 \mathrm{~s}}$, are mentioned in the inventory of Governor Eaton, of New Haven. In I666 the item, " 2 cubberds with drawers, $\mathcal{E}_{4}$," is found in the inventory of John Baker, of Boston. They continue to recur in the probate records, but do not appear to have been numerous. In 1684, "a cuboard with three drawers," valued at thirty shillings, was inventoried in the estate of Samuel Sendall, of Boston.

The specimens now illustrated, and their varieties described in the text, include all the larger and finer cupboards of the seventeenth century found in New England of which we have any knowledge.

Cupboards here as in England, as far back as they can be traced, were furnished with cupboard cloths of various materials and colors. All kinds of cupboards, the court, the livery, and the inclosed, were provided with these draperies, and, on occasion, doubtless depended chiefly on them and the plate, Delft, and glassware of the house for their beauty and comeliness. A few extracts from the inventories will give the reader very valuable information as to the materials and prices of these textiles:-

"One Sempiternum cubbord cloth $\mathrm{w}^{\text {th }}$ silke frenge, £I. O. o." - Inventory of William Clark, Salem, 1647 .

"I blue cubberd cloath."

" 2 plaine Holland cubbard cloaths, $£$ I 6 s." 
" 3 laced cubbard cloaths, $£_{2} 3$ s." - Inventory of Governor John Haynes, Hartford, 1653.

"I greene wrought cubbard cloth $\mathrm{w}^{\text {th }}$ silke fringe, \&2." - Inventory of Mrs. Ann Hibbins, Boston, 1656.

"I cambrick \& 3 holond cupboard cloaths $£$ I I 7 s." - Inventory of Richard Lord, Hartford, I662.

" Two cupboard cloths of pantado, I 2 s." - Inventory of John Eliot, Junior, Cambridge, I668.

"Two cubburd cloath yallo: one at Ios., $y^{\mathrm{e}}$ other at $5 \mathrm{s."}$

"One kallico cobert cloath Lased [laced] i 5 s." Inventory of Rev. Nathaniel Collins, Middletown, 1685.

Besides cupboard cloths, cupboard cushions are frequently mentioned in the New England inventories. The following items have been selected from notes of sixty-five cupboard cushions, and contain most of the details that relate to the stuffs, colors, and uses of these cushions:-

"One Cubberd cuishion, 2 s."

" 2 Cubberd cuishions of dammaske \& one needle worke one, £I." - Inventory of William Clark, Salem, I647.

"A liverey cuberd w $^{\text {th }}$ a cloth and cushin, $£$ I. 6. 8."

- Inventory of John Johnson, Roxbury, I659.

"I corute cobbord: chusion: cubbord cloth, $\delta \mathrm{I}$ 5 s." - Inventory of Jacob Sheaffe, Boston, I659. 
"I livery cubbard, cubbard cloth I velvet cushen, £2." - Inventory of Henry Webb, Boston, I660.

"By two small cushins to set on a cubbards head, L2." - Inventory of Nathaniel Upham, Malden, Mass., I66I-62.

"I Cushion for Cubbard head, I s." - Inventory of Thomas Sallows, Salem, I663.

" 3 cubord head cushins." - Inventory of Richard Hicks, Boston, I 666.

"A sid Cubbord with cloath \& cushing, £ I 6 s." - Inventory of Robert Lemon, Salem, I667.

" 2 wrought cushens ffor cubberd, I 2 s." - Inven. tory of Benjamin Richards, Boston, 1667 .

"Too cushens for a cuberd, $£$ I Io s." - Inventory of John Jeffs, Boston, I67o.

"I Cubbard with 2 Covers of Cushens on it, and smale potts in it, Ios." - Inventory of Richard Jackson, Cambridge, 1672.

"One cowt cubbard a cushen \& cloth, $£ 2$ Io s." - Inventory of Stephen Talby, Boston, I673-74.

"One cupboard with drawes \& a cushin, $£$ I 5 s." - Inventory of Christopher Gibson, Boston, I674.

"A press \& quision \& cuberd cloth, £I." - Inventory of Gregory Wolterton, Hartford, 1674 .

"A livery cubbard $\mathrm{w}^{\text {th }}$ cushion \& cloth, $£_{2} 5$ s." Inventory of Fathergone Dinely, Boston, 1675.

"Ffive cupboard cushions, $\mathscr{E}$ I Io s." - Inventory of John Warren, Boston, I677. 

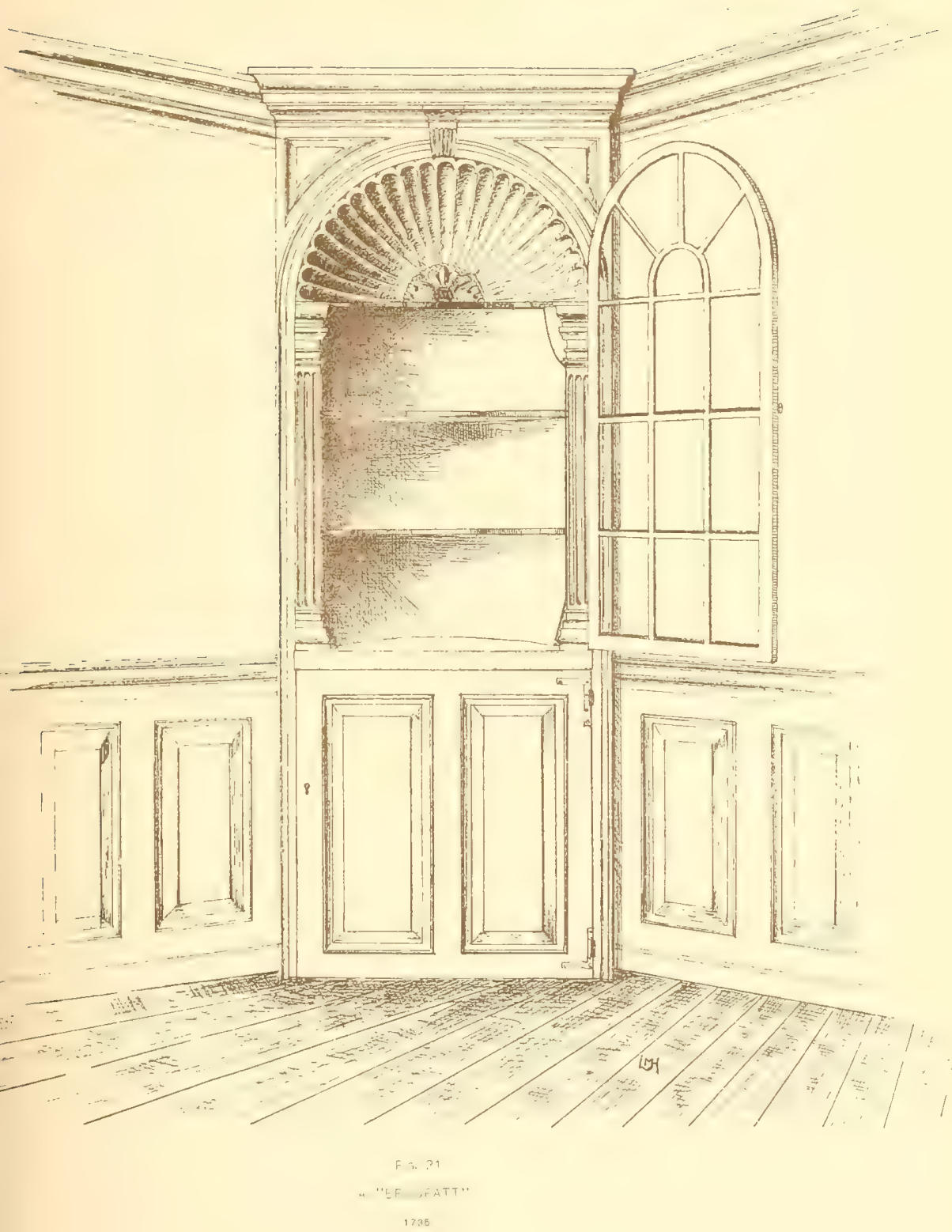
"I needle work cupboard cushion, Io s." - Inventory of Robert Wakeham, Boston, I677.

"4 wrote sideburd Cushions." - Inventory of Samuel Hale, Charlestown, I679.

"A Cuberd head cloath and cushin, $£ 3$ ro s." Inventory of Jonathan Avery, Dedham, I69I.

"One cupboard, cloth, \& cushion to it, \&2." Inventory of Jacob Eliot, Boston, I693.

The cushions, like the cloths, are here seen on all kinds of cupboards. They were placed on the head or top of the cupboard, but whether on the shelves of open livery and court-cupboards it does not appear. The relation of the cloth to the cushion, whether used together or not; and, if together, which belonged over the other, is left undetermined by the records that we have studied.

Much more space has been allowed for these extracts than would have been given had the fashion of cupboard cushions in the seventeenth century been more widely known, and their uses better understood.

The old cupboards of all kinds that we have described began to lose favor in Boston about the year I680, and by the close of the century were practically thrown aside by people who followed the European fashions. No cupboards whatever are mentioned in the inventory of Sir William Phips, made in I696. Inclosed cupboards, however, continued in use, espe- 
cially among the rural classes about Boston, for some time longer, and in Connecticut till the middle of the eighteenth century. As before mentioned, we have found no court or livery-cupboards in the records after the year i 704 .

The piece of furniture that had the most to do in displacing the old cupboards was the chest of drawers. These, as we shall see in the next chapter, now began to be valued higher than formerly, to be furnished with cloths and cushions, and, a little later, to have earthen and glassware placed upon their tops. Another fashionable place for glass and earthenware was the manteltree, which from about the year I 700 is frequently mentioned in the best houses as a resting-place for these objects. Sets of manteltree wares, especially designed to decorate this piece, were now also in vogue.

Two new styles of cupboards appeared with the Queen Anne architecture, the corner cupboard and the buffet. According to Mr. George T. Robinson, of London, one of the best authorities in matters pertaining to old furniture, the corner cupboard in England was a small piece usually suspended or bracketed in a corner, but sometimes reaching to the floor. Corner cupboards, he says, were not called buffets in England; the two pieces were separate and distinct from each other.

The correctness of this view is sustained by old 


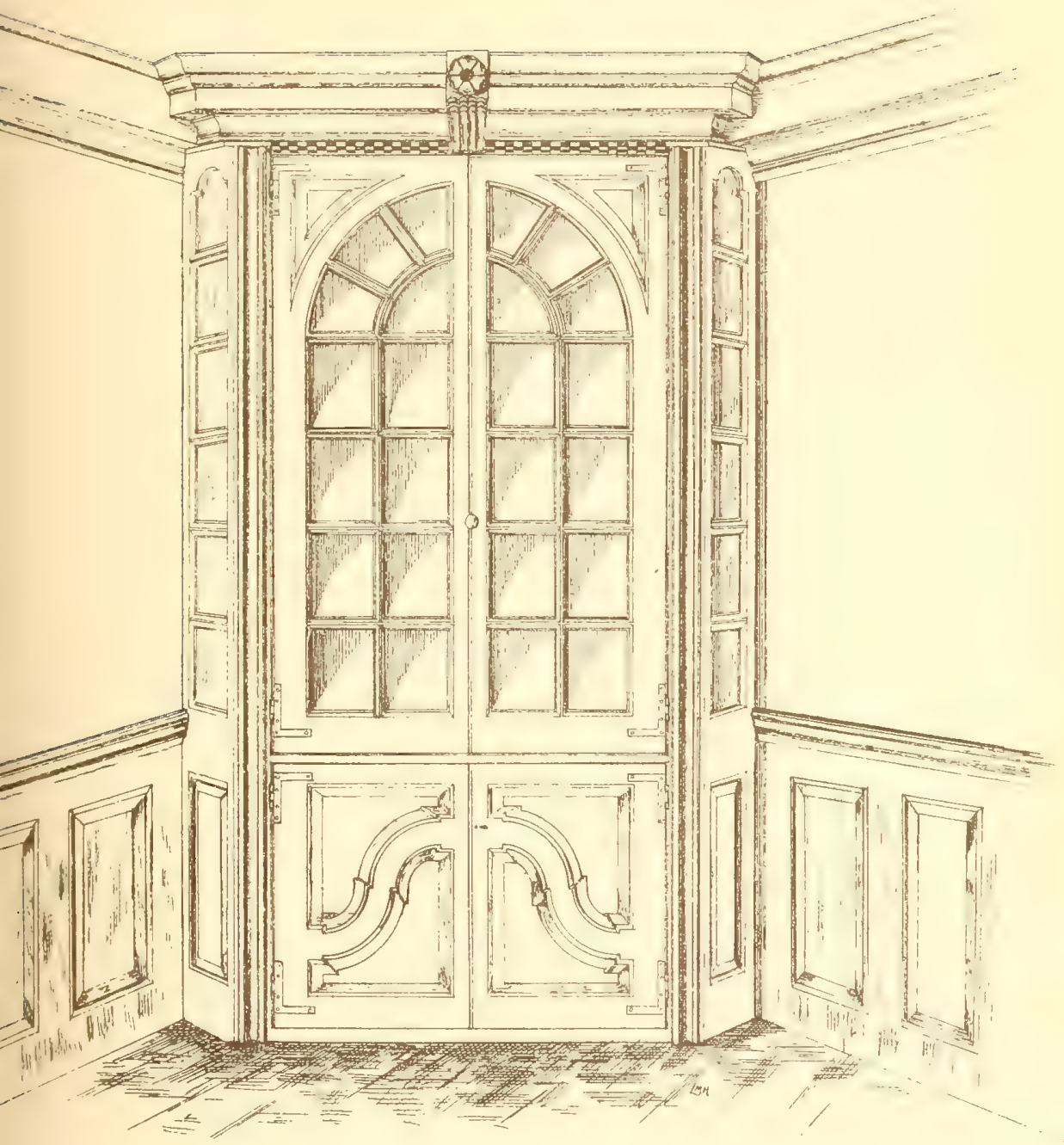




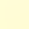


London newspapers, in which buffets and corner cupboards are separately mentioned in the same advertisement. One of these advertisements appears in the "Daily Courant," November 4, I 7 I9, another in the "Daily Post," March I8, I723. Examples of these little corner cupboards may be seen in England in private collections, and in the shops of the dealers in old furniture. The first record of them in England that we have seen is in the advertisement of Isaac Van den Helm, a Dutch table-maker, found in "The Post Man," of London, March 8-10, I 7 II.

The first mention of buffets in New England that we have run across occurs in the following advertisement from "The Boston News-Letter," No. 576, April 25 to May 2, I 715:-

"Looking-Glasses of all sorts, glass sconces, Cabbinetts, Escrutoires, Chests-of-Drawers, Tables, Beaufetts, Writing Desks, Bookcases with Desks, old Glasses new Silvered, and all sorts of Japan-work, Done and Sold by William Randle at the Sign of the Cabbinett \& Looking-Glass Shop in Queen-Street near the Town House, Boston."

The earliest use of the word in England known to us is in the advertisement above referred to in the "Daily Courant," of London, November 4, I 7 19, in which "Beaufets" are mentioned. But that buffets of the style now under consideration were in use in London before I7 5 , we may well believe from the 
proof which we have of their presence in Boston in that year.

In the inventory of John Mico, of Boston, made March 7, I718-19, "glasses \&c in the Bouffett" of the dining-room are mentioned. After this time buffets were of common occurrence.

That they were here oftener built in as part of the house, instead of being movable pieces, is rendered tolerably certain by the great frequency with which they are referred to in the inventories without being themselves apprized. That they were often movable pieces of furniture, like the old cupboards, we should know from such advertisements as the above, and from their occasional valuation in the inventories, if, indeed, we had to-day no surviving examples.

In New England at the present time, the words corner cupboard and buffet are synonymous terms, applied indifferently to the triangular cupboards found in the corners of the rooms of houses built in the eighteenth century. How long this has been the case we cannot tell, but that a distinction was made between these pieces when they first came in use is evident from the difference in their prices, and from the fact that both are occasionally mentioned in the same inventory.

The first "corner cupboard" in our notes, from the inventory of Mary Lidgett, of Boston, I7 I9, is valued at $7 \mathrm{~S}$. Another in 1725 was valued at $5 \mathrm{~s}$, 
one in 1736 at $15 \mathrm{~s}$, and one in 1745 at $12 \mathrm{~s}$. But these prices are given in the depreciated paper money of the period, and if reduced to the silver standard would be respectively 4 s. 8 d., 2 s. 4 d., 4 s. 6 d., and $2 \mathrm{~s} .8 \mathrm{~d}$. In 1760 , after the currency had returned to a silver basis, "I small corner cupboard "was valued at $2 \mathrm{~s}$., in the inventory of James Clark, of Boston, and in $\mathrm{I} 770$, a corner cupboard in the estate of Captain John Coleman, of Hartford, was apprized as low as one shilling. Surely, these corner cupboards could not have been the pieces which are known to-day in New England as buffets or corner cupboards.

On the other hand we find, in 1738 , the item, "I Buffett, $£ 6$," in the inventory of John Parker, of Boston, and "I bofate with a parsall of chine som broken, $£ 8$," in 1745 , in the inventory of Captain David Allen, of Boston. These prices in silver would have been $£$ I I 5 s. 6 d. and $£^{2} 5$ s. 8 d. In I 76 I, "a Bofett in $\mathrm{y}^{\mathrm{e}}$ lower Room "was valued at $£^{2} \mathrm{I} 3 \mathrm{~s} .4 \mathrm{~d}$., in silver, in the inventory of Henrietta Maria Cane, of Boston.

The marked disparity in value here shown between buffets and corner cupboards justifies the notion that these pieces may have been as separate and distinct from each other in this country as in England at this time.

An instance in which both are mentioned in the same inventory occurs in I 752 , in the estate of David 
Evans, of Boston, as follows: "A corner Japann'd cupboard, 4s." "A Bofatt, 20s."

The first "corner Beaufatt" that we have noted is in the inventory of Mary Walker, of Boston, dated I734. Another is mentioned in $175^{2}$, and another in 1754 .

So far as we can ascertain, the movable buffet in New England was always placed in a corner of the room. Buffets that were fixed were usually built in the corners, but sometimes at the sides of the apartment, and when in the latter situation did not project into the room, but were recessed like closets, and opened into by doors on a line with the wall. Buffet doors were sometimes single and sometimes double. They were usually divided horizontally below the middle, making an upper and a lower part. The upper doors were often glazed. Occasionally the upper part was made without doors. It was then either left open or closed with a curtain.

The interiors of the better pieces were often finished with a shell-like hood or dome richly carved. Below this were dainty shelves beautifully shaped, with circular projections from their centers. A good example of these, from an old house in Middletown, Conn., built about the year I 735, is seen in Fig. 21 .

In our next illustration (Fig. 22) is shown a very fine buffet, from a house in Wethersfield, Conn., built about I 750 . 


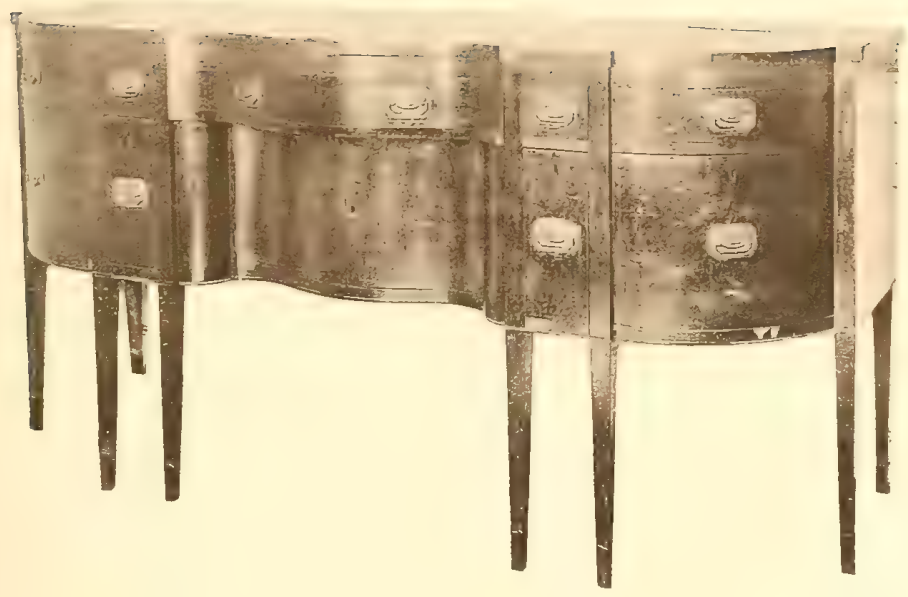

FIG. 23

SIDEBOARD, STYLE OF HEPPELWHITE

MACE $\because: 1: 0$ : 
It was the fashion in Philadelphia to make movable buffets of mahogany. Many fine examples are yet to be seen in the shops of the dealers. Some of them are of the same style as the one that is represented on page 256 of "The House Beautiful," before cited.

After the buffet the next movable pieces answering somewhat to the old cupboards were the sideboards of Heppelwhite and Sheraton. Sideboards are mentioned in the English inventories as early as 1553. In this year "ij longe syttebordes" are recorded in the inventory of Thurstan Tyldisley, published by the Chetham Society. In I $_{5} 63$, "a syde bord " is found in the inventory of Ralf Huton, published by the Surtees Society, and in 1573, "twoo longe tables or syddebordes in the hall $\mathrm{w}^{\text {th }}$ ffoure fformes accordingelye," are put down in the inventory of Dame Anne, widow of Sir Thomas Langton, published by the Chetham. Society.

These English sideboards were probably not sideboards in the modern sense of the word, but, as may be seen from the item last quoted, were merely side tables.

Sideboards are occasionally met with in the New England records of the seventeenth century. "One Chest \& a side Board " are together valued at $£$ I 2 S., in the inventory of Henry Ambrose, of Boston, in I658, and in I66I, "I Cubberd \& a side board," at $£^{2} 5 \mathrm{~s}$., in that of Abiel Everill, of the same place. 
What these sideboards were it would now be very difficult to tell with any certainty, but that they were possibly something more than simple tables is, at least, suggested by the occurrence in the inventories of two other similar names of rather indefinite meaning, namely, the side cupboards and sideboard cupboards, to which we have before referred.

In "Paradise Regained," published in I67 I, Milton speaks of "a stately sideboard;" and in 1693 , in his translation of Juvenal, Dryden says: "No sideboards then with gilded plate were dress'd." In an advertisement in "The General Advertiser," of London, September I 3, I 746, "A large marble Sideboard Table with Lavatory and Bottle Cistern" is mentioned. This is the earliest instance of a sideboard with these accessories that we have noted.

In I 753, and again in I 760, Chippendale published designs for "sideboard tables." They were tables five to six feet long and two feet eight, to two feet ten, inches high, to be made with wooden or marble tops, but without any drawers or closets underneath. The designs are very naked and inhospitable looking affairs. The notion that Chippendale made sideboards inclosed below the table with drawers and cupboards is incorrect; these belong to a later date.

We have seen no mention of sideboard tables in our inventories before the year i 769 , when " I Marble Side Board \& Frame" is valued at $£ 2$, in the 


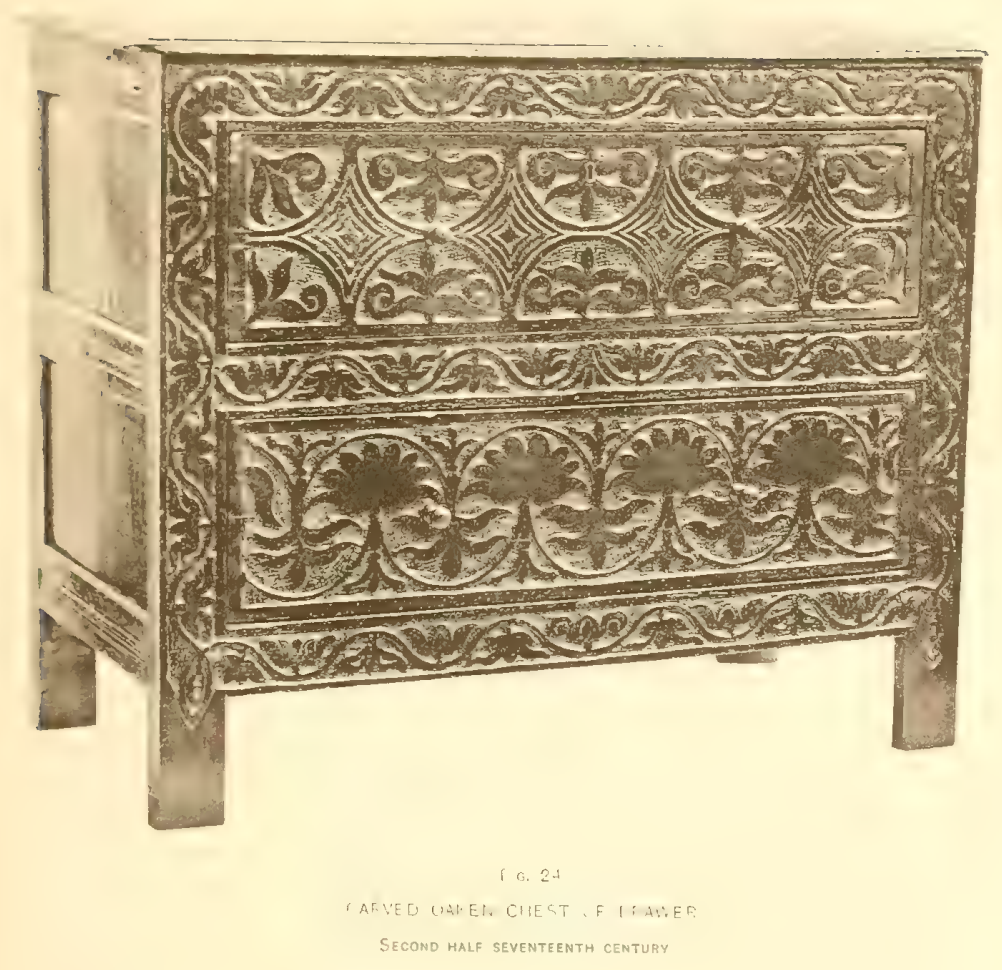



inventory of Joshua Winslow, of Boston. Marble tables are found in many fine estates, and are sometimes valued at a high figure; some of them may have been used as sideboards or side tables.

In 1787 , "A. Heppelwhite and Co., Cabinet-Makers," of London, published two designs for sideboards with a deep drawer at each end, and one long and shallow one in the middle. They also published in the same year four designs for sideboards without drawers. These were really sideboard tables after the style of Chippendale.

In I791, '92, and '93, Thomas Sheraton, another celebrated cabinet-maker of London, published designs for sideboards with cupboards and drawers underneath, and in I 794, a plan for a sideboard without any drawers or cupboards whatever, simply a sideboard table. These plates are found in his work entitled, "The Cabinet-Maker and Upholsterer's Drawing-Book," London, I 794. In his "Cabinet Dictionary," published in 1803 , besides a cellaret sideboard with cupboards and drawers, he again publishes a design for an entirely open "Side Board Table," and says: "The most fashionable sideboards at present are those without cellarets, or any kind of drawer, having massy ornamented legs, and moulded frames."

Heppelwhite and Sheraton sideboards made of mahogany or cherry, with inlays of lighter colored 
woods, such as holly and satinwood, are quite common in New England.

In Fig. 23 is seen a very good example, made in I804, after the style of Heppelwhite, by Aaron Chapin, an excellent cabinet-maker, who settled 'in Hartford from East Windsor about I7 $_{3}$. It is made of mahogany with inlays of satinwood. It now belongs to the estate of the late Walter Robbins, of Rocky Hill, Conn., who was a son of its first owner. The original bill is preserved by the family, and reads as follows:-

1804. Mr. Frederic Robbins

Nov. 22 .

Bou $^{t}$ of Aaron Chapin

I Mahogany fashiornerd 8 leg Sideboord . . \$68.00

I Candle Stand ro/ . . . . . . . ז.67

Recd Pay in full for Aaron Chapin

$$
\$ 69.67
$$

LAERTES Chapin.

These sideboards came in use here very soon after their adoption in England, and remained in fashion until about I 820 to I 830 , when they were succeeded by much inferior and often very clumsy looking pieces called lockers. 


\section{CHAPTER III.}

CHESTS OF DRAWERS.

Chests of drawers are not mentioned in the English inventories of the sixteenth century published by the antiquarian societies to which reference has so often been made in these pages. They therefore did not come into use in England until some time in the first half of the seventeenth century.

They appear in the New England records as early as 1643 , in which year one chest of drawers, valued at $£ 2$ IOs., is found in the inventory of John Atwood, of Plymouth. Though not numerous in these early days they were by no means of rare occurrence, as between this date and 1675 we have notes of fifty examples from the inventories of Suffolk County, Mass., alone. The prices of these are given in thirty-six instances. Their aggregate is $£ 76$, making an average of a little over $£^{2} 2 \mathrm{~s}$. apiece. Three of these were valued at $£ 3$ each, in 1658,1665 , and I670; one at $£ 3$ Ios. in 1667 ; three at $£ 4$ each, in 1662, I669, and 1674; one at $£ 4$ Ios. in 1671 ; and one as high as $£ 7$, in the estate of Martha Coggan, of Boston, inventoried in I660. It will be seen from 
this summary that the chests of drawers of this early period were even more valuable than the cupboards, which we have just studied.

Examples of the earlier types which have descended to us from the seventeenth century are now very scarce. Two such are shown in Fig. 24 and Fig. 25. The first consists of a frame and two deep drawers. It is thirty-two inches high, forty and one half inches long, and twenty inches wide. Its front and ends are made of oak; the top and the back panels of yellow pine. The entire front is carved. It was found a few years since in Essex, Conn, and now belongs to the writer.

The second piece measures the same as the first, except that it is five inches longer. It has four drawers, but their fronts are divided into eleven panels, giving the appearance of as many little drawers. It is made of oak. It was lately bought in Middlefield, Conn, and is now the property of Mr. Walter Hosmer.

We believe that certain characteristics of the New England chests of drawers from the first settlements down to the latter part of the century are fairly represented in these two pieces; that is to say, that during this period they were of about the size here shown, were in most cases made of oak, and, like the cotemporary cupboards and chests, were decorated with carving, paneling, and applied ornaments. 


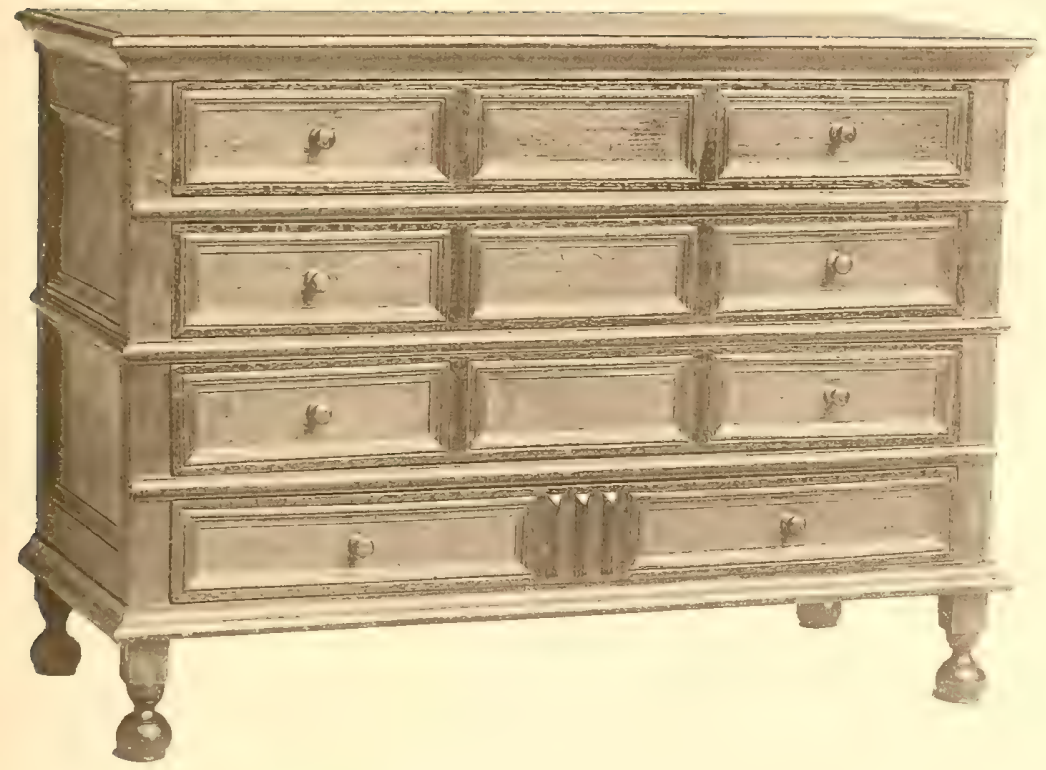

OAKEN CHEST OF DRAWERS

SECOND HALF SEVENTEENTH CENTURY 
There is, however, hardly enough difference between the chests of drawers here shown and the carved and paneled chests of the same period to account for the marked difference in their valuation.

We have seen that the average price of thirty-six chests of drawers, taken just as they came, without any selection, was about forty-two shillings. The highest price for any chest that we have found in the inventories of this period is thirty shillings, and the average price for the eleven chests with the highest valuations is twenty-five shillings. It is evident from these facts that many of the early chests of drawers, especially such as were valued above the average, were either made of more costly woods than the two here illustrated, or that they were finished with much more elaboration and detail.

That the earlier chests of drawers were not made high is strongly indicated by two facts: first, that no carpets, cloths, or cushions were provided for them; second, that their tops were not used as places of safety for valuable objects, such as earthen and glassware. If they had been high, like the cupboards, they doubtless would have been furnished with these draperies, and their tops utilized as shelves. This, as we shall see, actually took place with later chests of drawers when it became the fashion to build them higher. As far as we know the chests of drawers 
(commodes) made in France during the seventeenth century were low, from thirty-three to thirty-four inches in hight.

About the year 1680 we find numerous indications in the inventories that chests of drawers had begun to take on important changes. Down to this time they had been mentioned alone, without any accessories. In I675, a chest of drawers makes its appearance with a carpet and cushion. From I680 to 1683 , looking-glasses, dressing-boxes, tables, and cupboard cloths began to be associated with chests of drawers and to be apprized with them in the same item. Such entries as the following soon became very common: "A chest of drawers and a lookingglass," I68I. "I chest of drawers and dressing box," I683. "I Chest of drawers and table," I683. "A chest of drawers and cupboard cloth belonging to it," I683. "A chest of drawers cloth and cushion upon it," 1690.

The significance of these cupboard cloths and cushions has been pointed out. The tables which from this time were made en suite with chests of drawers, may have had their origin quite as much from the tendency to build the latter higher as from mere fashion and the desire for more furniture. As long as the chest of drawers remained low it could itself be used as a dressing-table, but when from its increasing hight it was no longer available for this 


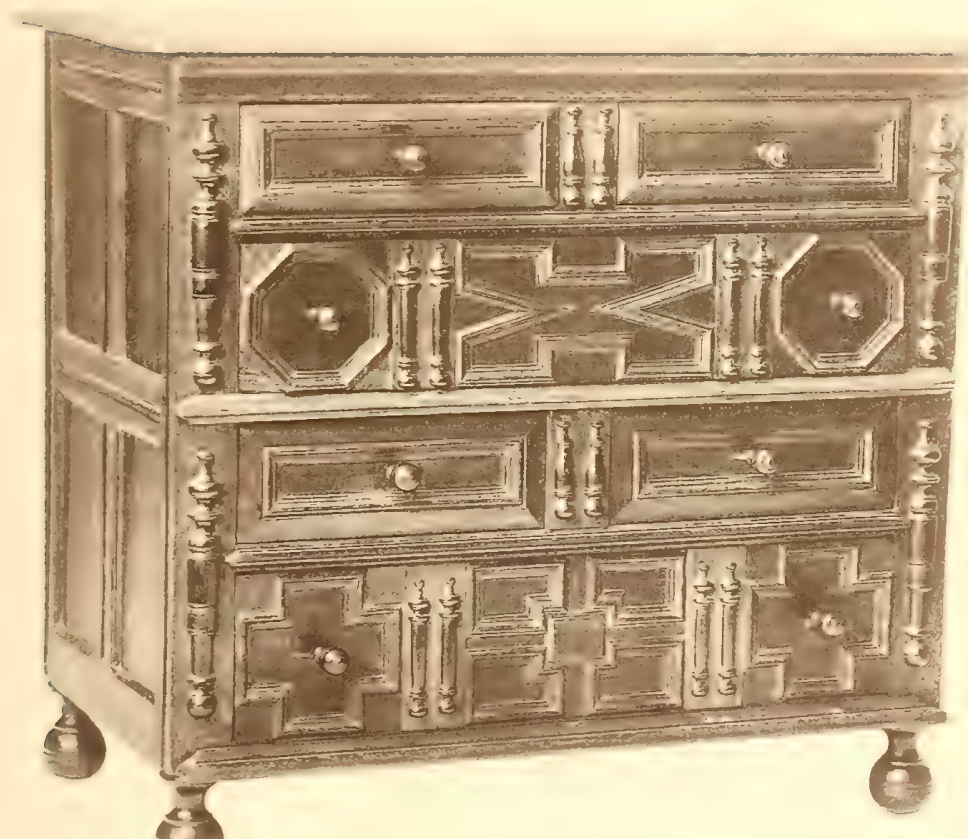

FIG ?:

A CHEST OF OFAVIFR

, $6 \approx n-1>30$ 

purpose something else had to be provided. The advent of these tables may therefore mark the epoch when it became the fashion to build higher chests of drawers.

An example of one of the styles of this period, from the collection of Mr. Henry F. Waters, is shown in Fig. 26. It was found in Peabody, Mass. Its hight is thirty-nine inches, and its length fortytwo inches. . It is made of oak, excepting the drawer fronts which are paneled with cedar. Several other specimens of this kind are known.

We have seen in another chapter that chests with two drawers underneath, forty to forty-two inches high (Figs. 7, 8, and 9), began to be used as early as 1690 , and probably somewhat earlier. We return to these chests to call attention to the fact of their close resemblance in size and general appearance to the chest of drawers here illustrated.

It seems altogether likely that the single drawer which began to be placed under the parent chest toward the middle of the century was a suggestion derived from the new piece of furniture called chest of drawers, which had lately come in fashion. The chest with this addition was partly a chest and partly a chest of drawers. Indeed, some of these pieces were made to look like chests of drawers by having the face of the upper or chest part broken into panels resembling drawer fronts. 
Later in the century the chest made further departures from its original state by adopting the increasing hight of its fashionable rival and by taking on still another drawer. In this form, though strictly speaking a chest with drawers, it was in fact a-modified chest of drawers, and was doubtless so regarded. The similarity in construction between it and the regulation chest of drawers probably led to some confusion in the nomenclature, and we are inclined to think that these chests with drawers were sometimes referred to in the conversation of the day as chests of drawers, and sometimes so recorded in the inventories. They were very numerous in and about Hartford, Conn., where it is quite uncommon to find a chest of drawers like the one illustrated in Fig. 26.

The chest with three drawers, forty-six inches in hight, shown in Fig. 10, belongs to the same hybrid class. It is the only example of its kind made of oak and carved known to the writer. It was made toward the close of the seventeenth century. Old chests with two and three drawers underneath, of about this hight, cheaply made of cherry or pine, are not infrequently met with in New England, and were made throughout the eighteenth century.

In addition to the draperies, tables, and dressingboxes, which began to appear about I680, we soon find mention of chests of drawers made of various 
woods, such as cedar, olive, and walnut, also japanned and inlaid chests of drawers. At the same time the prices advanced from three and four, up to six, eight, and ten pounds. In 1702 we begin to find mention of "old fashioned" chests of drawers, and in the following year, of glass and crockery upon their tops. These facts, which are of considerable interest, are shown in the following items:-

" 2 cedar chests of drawers and table, $\mathscr{L} 68$." Inventory of William Harris, Boston, I684.

"I fine large chest of drawars, $£ 6 . "$ - Inventory of Leonard Dowden, Boston, I686.

"A chest of drawers, $£ 8 . "-$ Inventory of James Butler, Boston, I689.

"One Jappan Case of draws, £ Io."

"One Olivewood Case of draws \& table, $£ 8 . "$

"One inlaid Case of draws \& looking glass, $£$ Iо." - Inventory of Captain Andrew Craty, Marblehead, Mass., I695.

"I walnut chest of draws, $£ 4$." - Inventory of John Tenney, Boston, I699.

"I old fashion chest of drawers, $£$ I." - Inventory of Robert Bronsden, Boston, I yo2.

"A Chist of Drawers, £ I Io."

"To Glass ware \& Cupps on the Chist of draws, Io s." - Inventory of Captain Richard Sprague, Charlestown, I 703 .

"A mantletree set $7 \mathrm{p}$. $6 \mathrm{~s}$, a sett of Glasses on a 
Chest of Drawers 9 p. 4 s." - Inventory of Zachariah Long, Boston, I 703-4.

It was during the period of transition that we have traced in the last two decades of the seventeenth century that chests of drawers mounted upon legs were introduced into New England.

A careful study of all the old chests of drawers of all kinds that still exist discloses the fact that those mounted upon legs were the immediate successors of such as we have hitherto illustrated and described in this chapter. No intervening styles are found.

The next step is to fix the date of the first appearance of these high chests of drawers. This is approximately determined by the facts that have been already cited from the inventories, and which cannot be satisfactorily explained by the chests of drawers which preceded the style now under consideration.

It is quite possible that cloths and cushions were placed upon chests of drawers of intermediate hight, - thirty-nine to forty-six inches, - because it is not certain that all the cupboards with cloths and cushions that figure in the old inventories were as high as those illustrated in the chapter devoted to cupboards. But in addition to the probability that these draperies were reserved for the larger and finer cupboards, we have the very significant fact that the fashion of using them upon chests of drawers did not spring up till late in the century, during the 


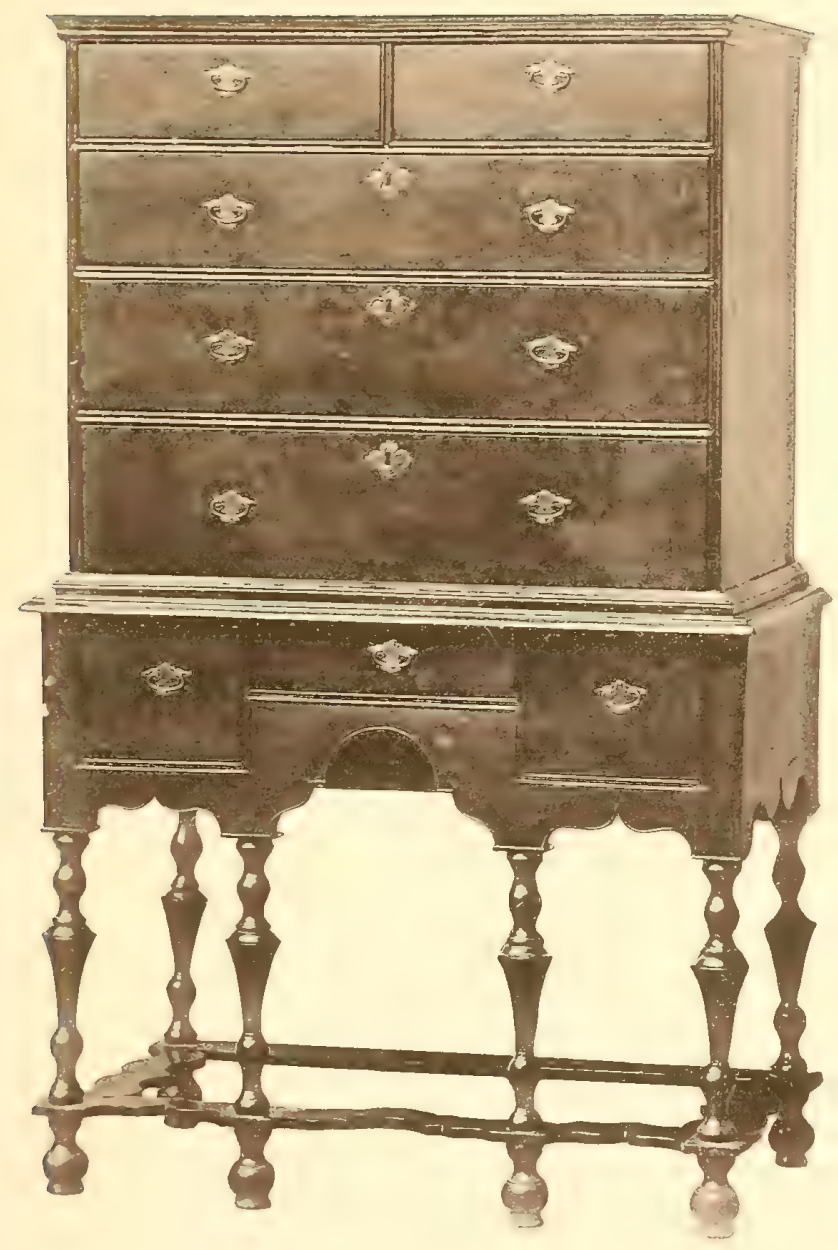

FIG, 27

A SIX-LEGGED CHEST OF DRAWERS 

period in which we find many other indications of the existence of high chests of drawers.

One of these indications is found in the prices given. With a single exception the highest price noted for any chest of drawers inventoried before the year I 686 is five pounds; but from this date to the end of the century they were valued in the inventories of estates as high as at any time during the next fifty years. Indeed, we have seen but three instances between $I 700$ and $I 750$ in which the valuation of any specimen exceeded ten pounds in silver money.

But though we find chests of drawers with cloths and cushions; chests of drawers with their tables; "fine large chests of drawers;" chests of drawers made of cedar, olive, and walnut woods; chests of drawers japanned and inlaid; chests of drawers valued at six, eight, and ten pounds; and reason from these facts that they were probably high, like the chests of drawers made of the same materials and inventoried at the same prices in the next century, yet satisfactory proof of this conclusion is not obtained until the year 1703 , when a chest of drawers, with glassware and cups on its top, is found in the inventory of Richard Sprague. The custom of putting earthen, glass, and china ware on chests of drawers continued from I 703 into the last quarter of the century, and perhaps later, and became so fashionable that special contrivances called steps were used for the better accommodation and display of these objects. 
These chests of drawers must have been high, as otherwise the habit of depositing fragile objects upon them would not have become so prevalent; and that they were made with legs is rendered exceedingly probable by the fact already pointed out, that no other style of sufficient hight belonging to this period has been discovered.

It may be that some of the earlier high chests of drawers were made of oak with paneled fronts, like the pieces represented in our last two illustrations, but instead of going down to within a few inches of the floor, were elevated upon frames with legs. Such specimens are found in England. One is illustrated in "The Cabinet Maker and Art Furnisher," of London, for September, r88r. Another in the “ Building News," London, May 23, I 884.

The high chests of drawers first used in New England were of two kinds, - those made with turned legs, usually six in number, united by stretchers running all the way around just above the floor; and those mounted upon four bandy-shaped legs.

A very good example of the first variety is shown in Fig. 2\%. Its hight is sixty-four inches. It is made of the wood of the plane or sycamore tree. It consists of two parts, the upper and the lower or table part. These are fitted together just above the moulding that projects from the top of the table. There are three drawers in the table. The piece 


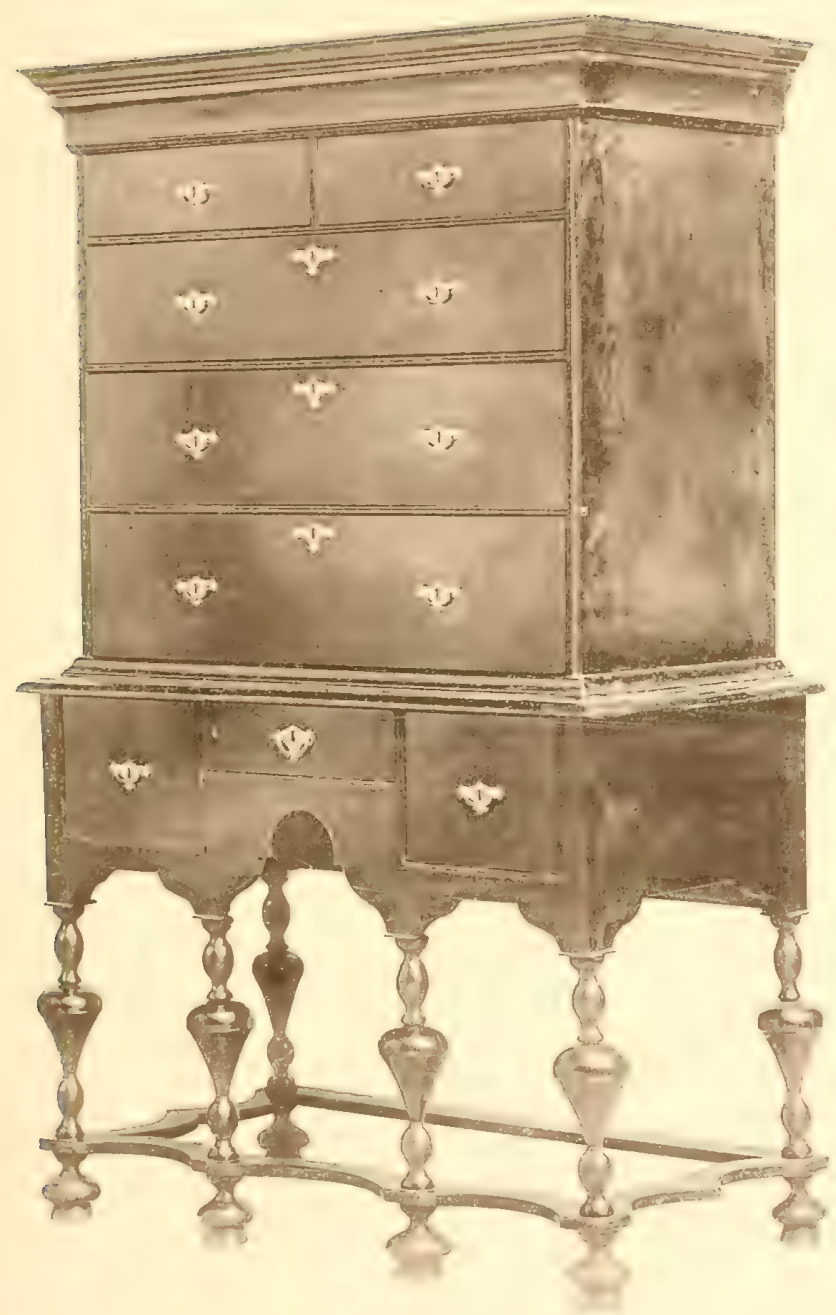

Fis. $2 \%$

A SIX.LEGGES CHEST PF TAAHE: 

taken as a whole is a composition made up of the old-fashioned low chest of drawers raised upon a table. It belongs to H. S. Fuller, M. D., of Hartford, Conn. It was bought a few years since in Wethersfield, Conn.

The second example (Fig. 28) is shown on account of its pleasing symmetry and the beauty of its richly turned legs. It has a shallow drawer in its cornice. It is made of maple. Its hight is sixty-seven inches, the increase in this respect being due to the cornice drawer. Its brasses are of a pattern somewhat later than those on the preceding specimen. It was bought a few years since in Lynn, Mass., and now belongs to the writer.

These two pieces are good examples of the sixlegged chests of drawers found in New England. They are, however, not put forward as pieces made as early as the latter part of the seventeenth century, but only as representatives of a style which began to be used at that time in New England. They were probably made in the first quarter of the eighteenth century.

Chests of drawers of this style are Dutch and Flemish in their origin, and may have been introduced into New England directly from the Netherlands, as they appear to be very rare in England. One can judge how scarce they must be there from the facts that well-known English connoisseurs have 
not met with an example, and that the upper parts of two specimens were illustrated in "The Cabinet Maker and Art Furnisher," of London, December I, I 887, without the knowledge that their legs were missing.

The peculiarity of the style lies in the construction of the lower part or table, which evidently took its character from the French knee-hole bureaus made during the reigns of Louis XIII. and Louis XIV.

The tables, usually called chamber tables in the inventories, but sometimes dressing-tables, which were made to go with these chests of drawers, appear to have had four instead of six legs. They were also a size or two smaller than the lower or table part of the main piece. One is shown in Fig. 29. It was bought from a dealer in Lynn, Mass, and is owned by the writer.

Some of these chests of drawers were furnished with five instead of six turned legs, three in front and two behind. There is in the Hosmer collection the under part of such a piece. From the top of the central to the top of each lateral leg in front there is an arch, and above them one long drawer with drop handles. The upper part of this piece is unfortunately missing.

The fact that ornamental details are seldom mentioned in the inventories has already been pointed 
out. One would suppose, however, that objects so obtrusive as the triple rows of brasses on chests of drawers would have proved an exception to this rule, especially when they first came in fashion, which in this country must have been as early, at least, as the first appearance of the high chests of drawers. But the first, and indeed the only, chest of drawers with brasses that we have noted occurs in the inventory of Elisha Webb, of Boston, made in I 710. Brasses were probably referred to in the item, " 2 I doz $\frac{1}{2}$ of scutcheons drops and rings, £I. 10. 8.," recorded in 1696 in the inventory of John Dyer, a Boston merchant. In the inventory of John Ffellows, joiner, of Philadelphia, Penn., made October I 2, I694, we find the item, "To a pcell of Brass-work for Drawers, \&I. 4."

We show in Fig. 30 a brass handle with its plate, and in Fig. $3 \mathrm{I}$ a scutcheon, both from a veneered six-legged chest of drawers in our possession. They are of the same pattern as those seen on the chest of drawers shown in Fig. 27, and are not at all uncommon in New England.

Drop handles are also found on these old chests of drawers, and with their plates vary somewhat in different specimens. The handles are of two kinds, those cast solid and those hollowed out behind. The plates are sometimes circular and sometimes of other shapes. Examples of these brasses are seen in Figs. 
32, 33, and 34. Fig. 32 has the hollowed handle, the other two the solid.

These brasses, given here in their full size, are believed to be Dutch in design, and are of the oldest types found in New England. The plates and scutcheons were cast very thin, and their surfaces stamped with dies. The handles are fastened on with looped wires.

In Fig. 35 is shown a stamped plate with its handle of a style later than the preceding, from a maple six-legged chest of drawers belonging to James Campbell, M. D., of Hartford, Conn. The drawers in this instance have overlapping edges. This fact coincides with the brasses in indicating that this piece is one of the latest of the chests of drawers of this style.

The six-legged chests of drawers found in New England are, we believe, invariably furnished with the brass mounts now described, and, in most instances, with those of the older types. Moreover, they seem to have been always made with flat tops. They, therefore, ceased to be made before these old brasses went out of fashion, and before the introduction of the arched top.

Chests of drawers with flat tops, and mounted on four bandy-shaped legs, are also of Dutch and Flemish origin. They appear to have reached this country at about the same time as the six-legged variety, 


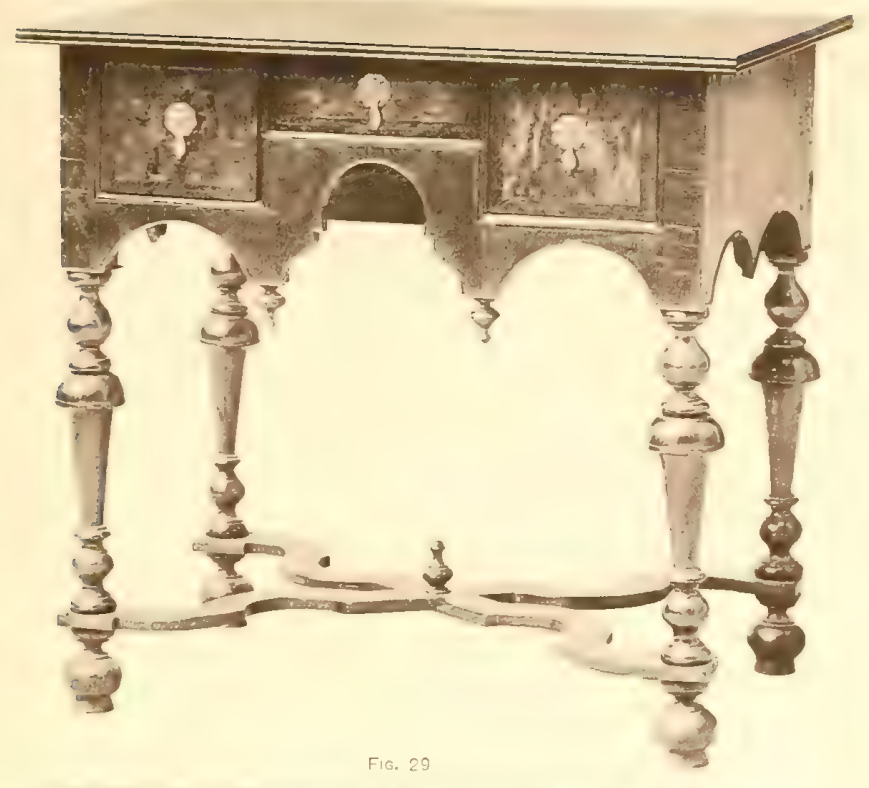

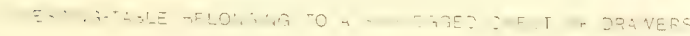

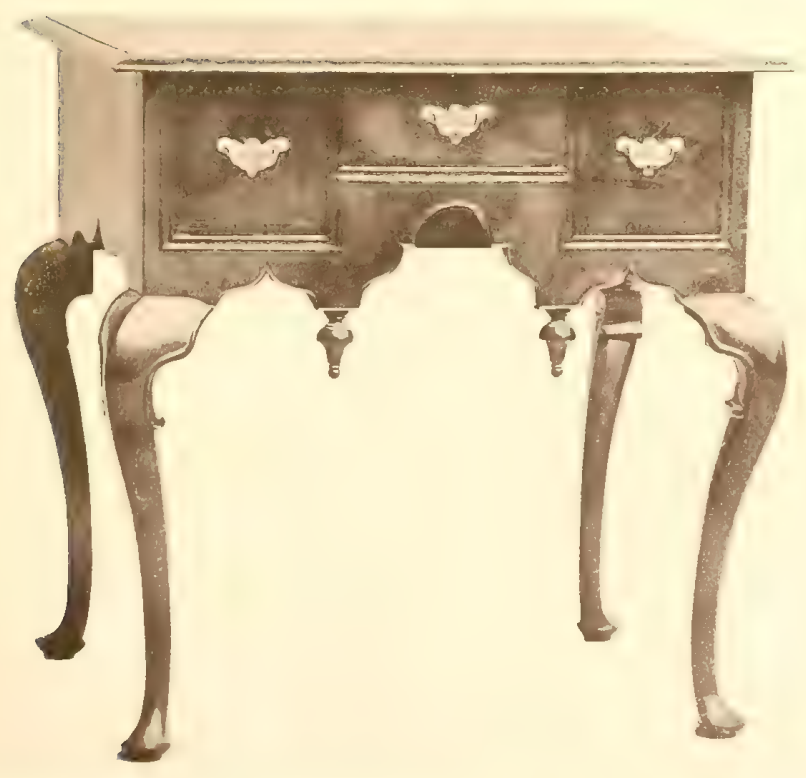



from which they differ in respect to their lower parts only. The shape and construction of the upper parts, the woods, the veneers, and the brasses, are alike in both. Their tables even do not differ except in the number and shape of their legs.

A very old and quaint example of this style is shown in Fig. 36. It came from Windsor, Conn., and, with the dressing-table made to accompany it, is the property of Mr. Edwin Simons, of Hartford. The wood is maple. The legs are boldly cut out, and the feet, which are unusually large, show the influence of the preceding style. Its decoration is of the "flowered" variety, that is, with flowers and other objects painted in colors. In this instance there are trees and flowers, and figures representing hunting and other scenes crudely painted in dull yellow on a black ground. Flowered furniture is occasionally mentioned in the inventories of the early part of the eighteenth century. This kind of decoration was probably suggested by the japanned work then in fashion.

In Fig. 37 is seen a dressing-table with veneered front and carved legs. It is one of the finest examples of the dressing or chamber table found in New England. The original brasses are missing. It was bought by the writer in Lebanon, Conn., ten or twelve years ago. Its chest of drawers, which, in all probability, had a flat top, is lost. 
The tops of these four-legged chests of drawers seem to have been made flat down to about 1730 , when pieces surmounted with the interrupted arch and "bookcase heads" made their appearance. A very good specimen, crowned with the interrupted arch, and dated 1737 , is in the possession of $\mathrm{Mr}$. L. M. Solon, the celebrated pâte sur pâte artist at Stoke-on-Trent, in England. The figures of the date are inlaid on the front of the piece above, and are undoubtedly genuine. In the inventory of Robert Davis, made in Boston in 1739 , we find the item, "I case of Draws \& Table bookcase head, £ I 2."

It is quite possible that chests of drawers with the interrupted arch were made before the year I 730 , as we know that clocks with arched dials appeared in the reign of Queen Anne. This question has proved a difficult one to settle, but our studies have led us to adopt the date I 730 as not far from right.

That they were later than the four and six-legged chests of drawers hitherto considered is shown by the absence in their construction of the details that mark these older pieces. These details are very characteristic, and consist of the older stamped brasses of small size with handles, or drops, held in place by looped wires, the double-beaded mouldings around the drawers, and the thin strip fastened with wrought iron nails to the under edges of the table, forming by its projection a delicate bead or moulding very 
pleasing to the eye. Of these features, the typical brasses have been wanting in every arched top chest of drawers that we have seen, the nearest approach to them being. stamped brasses of larger size, with turned handles similar to those shown in Fig. 35 . The two kinds of mouldings referred to, when seen at all on these arched top pieces, occur on the older specimens, and then rarely together on the same piece. These facts are well brought out by the beautiful chest of drawers shown in Fig. 38. Its brasses are of the stamped variety, but of large size. The delicate moulding on the under edge of the table is present, but the drawers are finished with overlapping edges, instead of being surrounded by the double mouldings above described. This piece is richly japanned, and with its dressing-table and dressing-box, shown in Fig. 39, belonged to the late Dr. George B. Loring, of Salem, Mass. It was made in England, or Holland, and dates from about the year I735. In England a chest of drawers of this kind is sometimes called a tall-boy, in this country sometimes a tall-boy, but oftener a high-boy.

Chests of drawers of this general style, with bandy legs, with flat as well as arched tops, and with dressing-tables to match, were the ones most in vogue in New England from about I 730 till toward the close of the century. A few of the earlier pieces were either japanned or veneered, but most specimens 
will be found plain and without the two kinds of mouldings referred to, with plain instead of stamped brasses, and with handles terminating in bolt heads, instead of being secured with looped wires. After the middle of the century the brasses became larger and more showy, and the legs sometimes terminated in ball and claw feet.

In some instances, instead of the bandy-legged table below, the lower part of both the flat and the round top varieties is made up of drawers, which go down nearly to the floor. They must have been rare in this country before the middle of the eighteenth century, if we may judge from the great scarcity of old specimens. It is not at all uncommon to find such pieces made after the middle of the century.

In England these double chests of drawers, as they were called, were sometimes made with one of the drawer fronts to let down at a suitable hight for writing. Watson, in his "Annals," says that chests of drawers with a writing-desk at the center were in use in Philadelphia and New York before the Revolution. We have not seen these combinations in New England, but the following extracts leave little doubt that such or similar specimens were in use here:-

"A Japan'd chest drawers Cabinet in one. A Looking Glass and table varnished with red, $£ 50 . "$ - Inventory of Henry Guineau, Boston, I 730. 

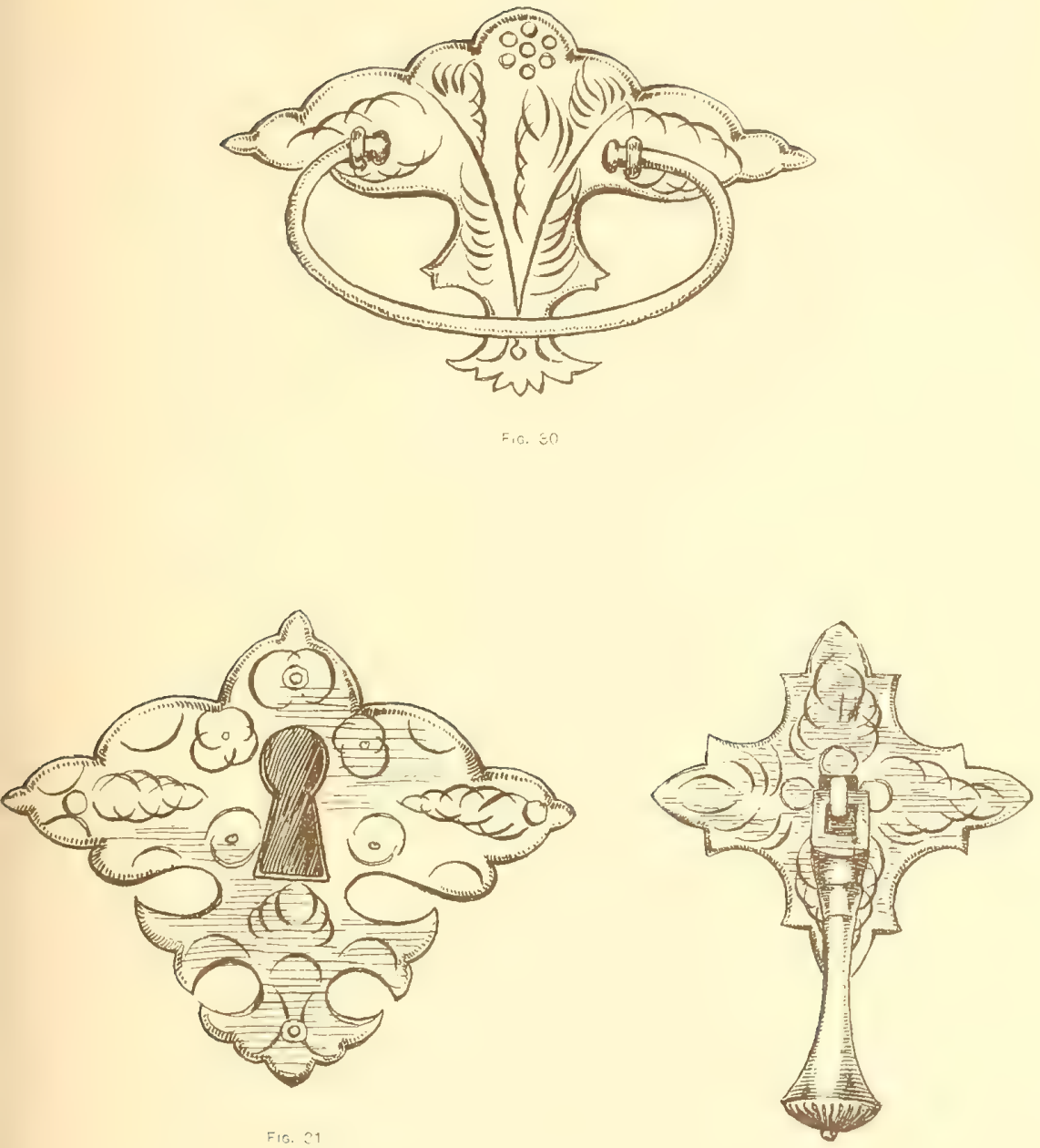

OLD BRASSES

CLOSE OF SEVENTEENTH AND BEGINNING OF EIGHTEENTH CENTURY 

"A writen Daske or chest of Drawers, £2. I3. 4." - Inventory of James Orr, Boston, 1752.

A very beautiful double chest of drawers, with shaped front and with ball and claw feet, is shown in Fig. 40. It is made of cherry. It is the property of Mrs. Thomas G. Talcott, of Hartford, Conn.

We know from records, as well as from an occasional specimen, that low chests of drawers did not become wholly extinct during the supremacy of those mounted on legs. The item, "I Low Case of Draws, I8s.," is found in I7I7 in the inventory of William Howel, a cabinet-maker of Boston. Between this date and 1756 we find in our notes mention of three other low cases of drawers, and of four low chests of drawers, a goodly number, if we take into account the infrequency with which such descriptive terms as high and low are used in the inventories. Low cases of drawers are also mentioned in the schedule of prices adopted by the joiners of Providence, R. I., in 1756 , and published in the Appendix of this work. Among the finer examples of the low chests of drawers found in New England may be mentioned those with richly mottled veneers, and with the old stamped brasses. The writer has seen three such specimens, made in the first half of the eighteenth century. They had bracket feet, and were from thirty-three to thirty-five inches in hight.

As already indicated, it is probable that most of 
the chests of drawers in use in New England down to the latter part of the seventeenth century were made of oak. During this period oak was the wood most in use for furniture in England, where, according to Pollen, the marquetry so extensively employed on the Continent did not become a fashion until the reign of William and Mary.

It is difficult to understand why the valuation of oaken chests of drawers should have exceeded so greatly that of the oaken chests of the same period. The amount of material in each was about the same, and the extra labor in making the drawers could hardly explain the difference in the prices. It is, therefore, not at all unlikely, as we have before pointed out, that some of the higher priced pieces were made of other woods, and with more costly decoration than is seen on the first two illustrated in this chapter.

Chests of drawers had been in use in Italy, France, Spain, and Portugal for some time before they were introduced into England. They therefore received the impress of the art of these countries, and their decoration doubtless followed that of the chests and cabinets of the day. Indeed, they were, so to speak, a cross between these two pieces, better than the chest, but not as good as the cabinet.

Very good examples of early French chests of drawers, before the time of Boule, finished in mar- 

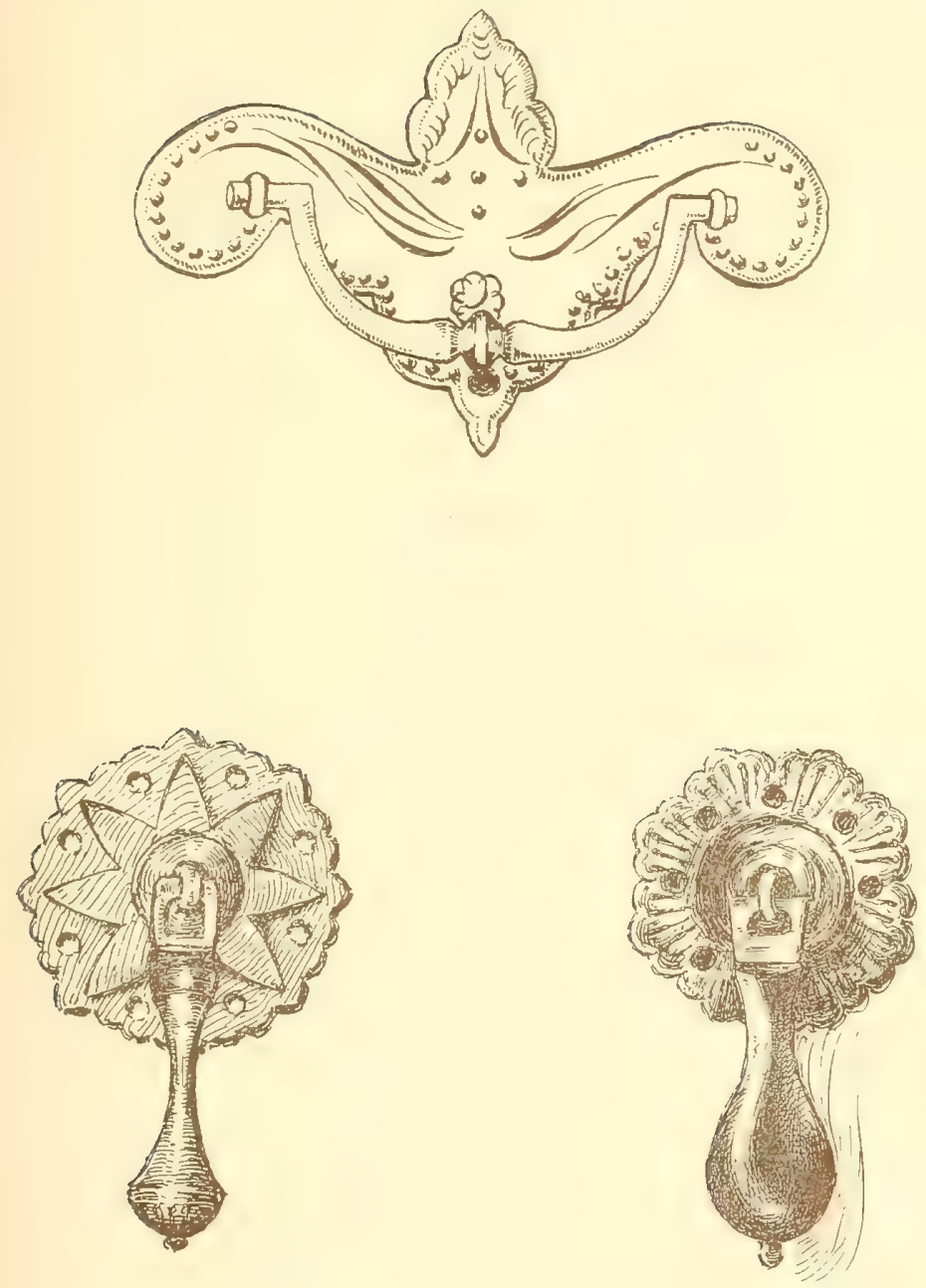

quetry of colored woods, are to be seen in the South Kensington Museum and in the Musée du Mobilier National, in Paris. Two of the latter are illustrated (Plate No. VI., Deux Commodes, Genre Hollandais) in "Les Meubles D'Art Du Mobilier National," by E. Williamson, Paris, $1883-85$.

When the chest of drawers reached England it was probably made of oak, and plainer than on the Continent, but doubtless its front retained more or less of the decoration which it had been in the habit of receiving in other countries. In this condition it was brought to the American colonies, and finding its way into the inventories has left proof that it was a piece on which more than ordinary care was bestowed.

We have noticed the two cedar chests of drawers in the estate of William Harris, of Boston, in I684. Cedar was used to some extent for furniture, probably in most instances, like cypress, to keep away moths. Three cedar chests are mentioned in the inventory of Captain Samuel Scarlet, of Boston, made in 1675 . That it was also used for its color and grain is indicated by the fact that "a rownd cedor table "was inventoried in I676, in the estate of Obadiah Walker, of Boston.

The earliest mention of olivewood noted in our records is in the item, "I Looking glass small Olive frame," in the inventory of Thomas Thacher, made 
in Boston in 1686. Comparatively few pieces of olivewood furniture are found in the New England inventories.

The japanned case of drawers in the inventory of Captain Andrew Craty, made in 1695, is the first mention of japanned furniture that we have found in New England. In the advertisement of Tho. Hulbeart, "at the Ship and Anchor over-against GunYard in Hounsditch, London," contained in the "London Gazette," January I6-20, I689, "Several sorts of Screwtores, Tables, Stands, and LookingGlasses of Japan and other work," are mentioned. In the same journal, April I4-17, I690, he advertises "Chests of drawers, Tables, Stands, and LookingGlasses of right East-India Japan, and other work."

This is the first record of japanned furniture found in a rather rapid look through the files of several of the old London newspapers. But from the objects mentioned, as well as from the fact that the textiles, porcelains, and lacquered wares of the Orient had, in large quantities, been regularly imported into Holland all through the seventeenth century, it is probable that japanned furniture had been in use in London for some time previous to this date. The words "Fapan Cabinets, Indian and English," found in the advertisement of John Gumley, in the "London Gazette," March I to March 5, 1693, will be accepted as proof that japanning was then prac- 
ticed in England. Havard has shown in his admirable work, the "Dictionnaire de L'Ameublement," that lacquered furniture was manufactured in Paris as early as I69I.

The final sentence in the following advertisement shows that japanning was done in Boston in I 7 I2, three years earlier than by William Randle, whose advertisement is given in full in the chapter on cupboards : -

"There is lately come from England an Engine, which grinds Cocholat very well. If any Person would have Cochoa ground, or Chocholat ready made, they may be accommodated on reasonable and moderate Termes by Mr. Nehemiah Partridge, at Mistress Pordage's in Treamount Street, Boston near the Orange Tree, where all Sorts of Japan Work are also done by him." Boston News-Letter, March 3I to April 7, I 7 I2.

Japanned chests of drawers were fashionable and comparatively numerous in Boston down to I 730-35, after which they were found in the inventories less and less frequently till about I775. It is probable that most of the pieces that figure in the probate records after I 750 were old specimens. At the present time they are so scarce in New England as seldom to be seen. It is not at all improbable that many of these old pieces exist to-day in plain wood, their japanning having been scraped off as it became unfashionable or out of repair.

The wood of which much of the best furniture in 
and about Boston was made in the eighteenth century was the American black walnut, the Fuglans nigra of Linnæus. The rich color and grain of this wood early attracted the attention of cabinet-makers. We find furniture made of it as early as 1668 , in which year "one box of black walnettree" is mentioned in the inventory of John Eliot, Junior, of Cambridge. In 1676 " a square table of Black Wallnutt" is valued at $\ell^{I} 5 \mathrm{~s}$, in the inventory of Obadiah Walker, of Boston, and in 1680 , "one black walnut table" at 30 so, in the inventory of Samuel Winslow, of Boston. After I.700 it was very extensively used for all kinds of furniture.

Black walnut chests of drawers are frequently found in the Boston inventories from the beginning of the century down to about I760. The drawer fronts of many of these pieces were finished with walnut veneer of richer grain, derived from the burr of the tree. After I 760 black walnut chests of drawers, like all other kinds, are mentioned much less often, but this can be partly explained by the fact that fewer descriptive terms were used in the inventories of these days than formerly.

The celebrated London cabinet-maker, Thomas Sheraton, tells us in his "Cabinet Dictionary," published in London in $\mathrm{I}_{80}$, that there are three species of the walnut tree, "the English walnut, and the white and black Virginia. Hickery is reckoned to 


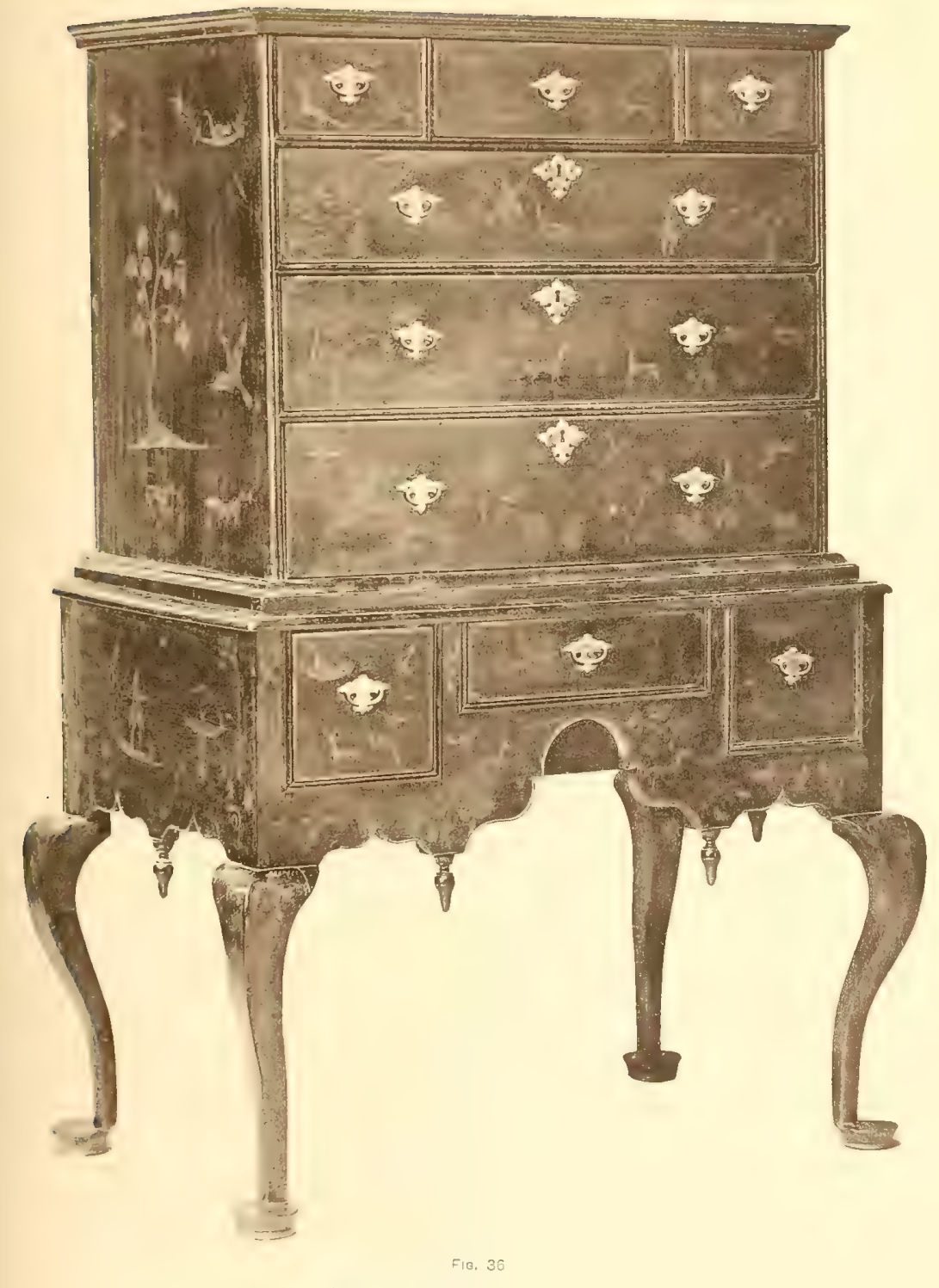

A BANDY-LEGGED CHEST OF DRAWERS 


$$
\text { . }
$$


class with the white Virginia walnut. The black Virginia was much in use for cabinet work about forty or fifty years since in England, but is now quite laid aside since the introduction of mahogany."

It was used in England for furniture considerably earlier than Sheraton supposed, as we find "Virginia wallnut-tree Chairs" mentioned in an advertisement in "The Daily Post," of London, August 30, I 73 . "Virginia Wallnut-tree, and Mahogony in the plank" were advertised in "The London Evening Post," June 2 I-23, I 750, and "a Virginia Wallnut-tree Tea Chest with a drawer," in "The Public Advertiser," of London, August I, I 757 .

As reference has been made to veneered chests of drawers, it may be of interest to note that the first mention of veneer that we have found in our records occurs in the inventory, before cited, of William Howel, made in I 7 17. We here find the items, "To Walnut Fenere, £8. I8. 7," and "I Fenereing Hammer \& Pinchers." These items, besides showing the use of veneer at this time, tend to show that William Howel, by trade a cabinet-maker, had not only made veneered furniture, but, from the amount of veneer on hand, that this with him was not altogether a new art. Moreover, as "I 2 pillers for a chest of drawers," and "drups \& Scutcheons" to the value of $£ 2.5$. Io, are also found among his effects, it is reasonably certain that chests of drawers were among his produc- 
tions, and that his walnut veneer was designed to enrich the fronts of such pieces.

Walnut was undoubtedly the veneer most in use in New England in these early days. It is the only veneer that we have seen in the inventories, and is the one oftenest found upon furniture which has come down to us from the first half of the eighteenth century. Other veneers, however, are occasionally met with, especially upon the older and finer pieces. It is sometimes quite difficult for the most competent judges to agree upon the woods of these veneers.

The first mahogany chest of drawers that we have noted in the New England records occurs in the inventory of Thomas Dickinson, made in Boston in I748. But as mahogany furniture had been in use in Boston since 1732 , it is of course quite possible that mahogany chests of drawers began to be made there considerably earlier than the year 1748 . They are not frequently mentioned in the inventories, and existing specimens are comparatively scarce. The most that are found to-day are double chests of drawers, sometimes with shaped fronts and arched tops, as in the specimen shown in Fig. 40.

It is believed that mahogany began to be used for furniture in London about the year I720. The history of its introduction there is told by Mr. Robinson in "The Art Journal," May, I881, as follows:-

"Its introduction was somewhat curious, mahogany being first 



$$
\text { . }
$$


sought for as a medicinal substitute for the 'Jesuit's bark,' and many treatises on its therapeutic virtues were written. About the year 1720 some planks of it were brought to Dr. Gibbon by his brother, a West Indian captain, and the doctor, thus having more than he would be likely to want for medicine, proposed having some of these planks used in a house he was then building in King Street, Covent Garden. The carpenters, however, found the wood too hard, and the planks were laid aside as useless. Soon afterwards Mrs. Gibbon wanted a candle-box, - an article of household furniture now extinct, - and Dr. Gibbon called in his cabinet-maker, one Mr. Wollaston, to a consultation. The planks were examined in the garden where they had lain some time, and he too declared he could make nothing of them, as the wood was too hard for his tools. 'Get stronger tools, then,' said the doctor, who fortunately was an obstinate man, and the result was a beautiful candle-box, the like of which had never before been seen. Indeed, so beautiful was it that the doctor immediately ordered a bureau made from the new discovery, and invited his friends to come and see the wonder. All fashionable London came, and the Duchess of Buckingham begged some of the wood which was left: of it she made at once both furniture and a fashion, and thus mahogany became duly installed in the English home."

One of the items in the following advertisement, from the "Daily Courant," of London, December 3, $\mathbf{1 7 2 4}$, tends to confirm the story of the rapid progress made by mahogany as a new wood in furniture:-

"To be Sold by Auction, On Thursday the roth Instant, the Shop Goods of John Cracherode, at the Tea-Table in HenriettaStreet, Covent-Garden, being all new, and consisting of PeerGlasses, Chimney-Glasses, and Sconces, Indian Skreens and 
Chests, Tea-Tables, Hand-Boards, Bottle-Stands, Burows, Tables of several Sorts both Wallnut-tree and Mahogany, Lanthorns for Halls and Stair-Cases, with all other sorts of Cabinet-Maker's Goods."

Mahogany furniture is mentioned in American inventories somewhat earlier than the date given for the manufacture of Dr. Gibbon's candle-box, as may be seen from the following extracts:-

"I broaken Mahogony Skreen, 2s." - Inventory of John Jones, of Philadelphia, merchant, taken 8th, 9th, and Ioth of June, I 708.

" 2 Mohogany Planks $36 \frac{1}{2}$ feet at $16 \mathrm{~d}$., £2.8.8. 3 Inch board Ditto 48 feet at $6 \mathrm{~d}$., $£$ I. 4." - Inventory of Charles Plumley, of Philadelphia, "Joyner," taken December I 5, I 708.

"I Mehogeney Chest of Drawres, \&4." - Inventory of Bartholomew Penrose, of Philadelphia, shipwright, taken November IO, I 7 I 2.

"Feather bed bolster pillow Sheets 3 blanketts 2 Coverlids Curtains rods \& mohogany bed stead, $£ 6$. 5. o." - Inventory of Thomas Coates, of Philadelphia, merchant, taken October 3, I 7 I9.

"In the best Parlour, Mohogany Chest Drawers and Table, $£ 7$. Io. 6 foot Table ditto, $£ 5.4$ foot ditto, £2. 5."

"Front Parlour, 5 foot Mohogany Table, £4. 4 foot Ditto, $£ 2$. 5. Mohogany Clothes press, $£ 5 . "$

"Front Chamber, Mohogany Table \& Chest Drawers, £7. ıо." 
"Best Chamber, Mohogany Chest Drawers and Table, \&7. Iо."

"Chamber Over Upper Kitchin, Mohogany Chest Drawers and Table, $£ 5$. I0."

"Red Room, Mohogany Chest Drawers and Table, $£ 4$. 10."

"Stair head, Mohogany Clothes press, $\mathscr{E}$."

"Upper kitchin, Mohogany Oval Table $a b^{t} 4 \mathrm{ft}$. £2. Ditto abt 3 foot, £I. 7. 6."

"Shop or Ware house, Mohogany Oval Table, £. Iо."

"Lower Stores," besides a quantity of "hewed Staves," "Cedar posts," "Cedar Scantling," and other lumber, there were "I I Mohogany planks Each I I foot long 5 Inch thick and 2 foot wide," valued at £24. 4. - Inventory of Jonathan Dickinson, of Philadelphia, merchant, taken May 20, I722.

The original inventories from which these extracts are taken are preserved in the office of the Register of Wills in Philadelphia, Penn.

Mahogany furniture was therefore in use in Philadelphia as early as the year I 708, and from the fact that mahogany lumber was found among the stock of a joiner in 1708 , and that a mahogany screen was part of the household furniture of a person who had died in that year, it is probable that mahogany furniture had been made in Philadelphia somewhat before the year 1708 . 
The fashion of displaying glass, earthen, and china wares from the heads of chests of drawers has already been touched upon. These articles were usually placed directly upon the flat tops of the chests of drawers, but sometimes upon steps provided for their reception. In addition to the two items previously given, the following extracts have been selected from a great many, and embrace most of the information relating to this subject to be gleaned from the inventories:- -

"A Chest of Drawers, table \& looking glass, Earthen ware on $\mathrm{y}^{\mathrm{e}}$ Chest of Drawers." - Inventory of John Wharton, Boston, I 7 I 2-I 3 .

"I Japan Chest Drawers \& Steps for China \&

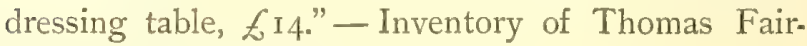
weather, Boston, 1734 .

"I Chest of Drawers, $£ 7$. "

"Chani Earthen \& Glass Ware on Do, \&I. 5." Inventory of John Foster, Boston, I 735 .

"I Steps for China Ware, 2 s." - Inventory of Abraham Blish, Boston, I735.

"I black walnut Draws \& Table, £ I6."

" 55 peices small coarse China on ye Draws, $£ 5$. Io." - Inventory of Captain John Welland, Boston, 1737.

"I Chest Drawers \& Table, $£$ I 7 ."

"A Parcel of Glass \& China Ware on Chest Drawers, $\&_{3}$." - Inventory of Samuel Greenwood, Boston, I 742. 


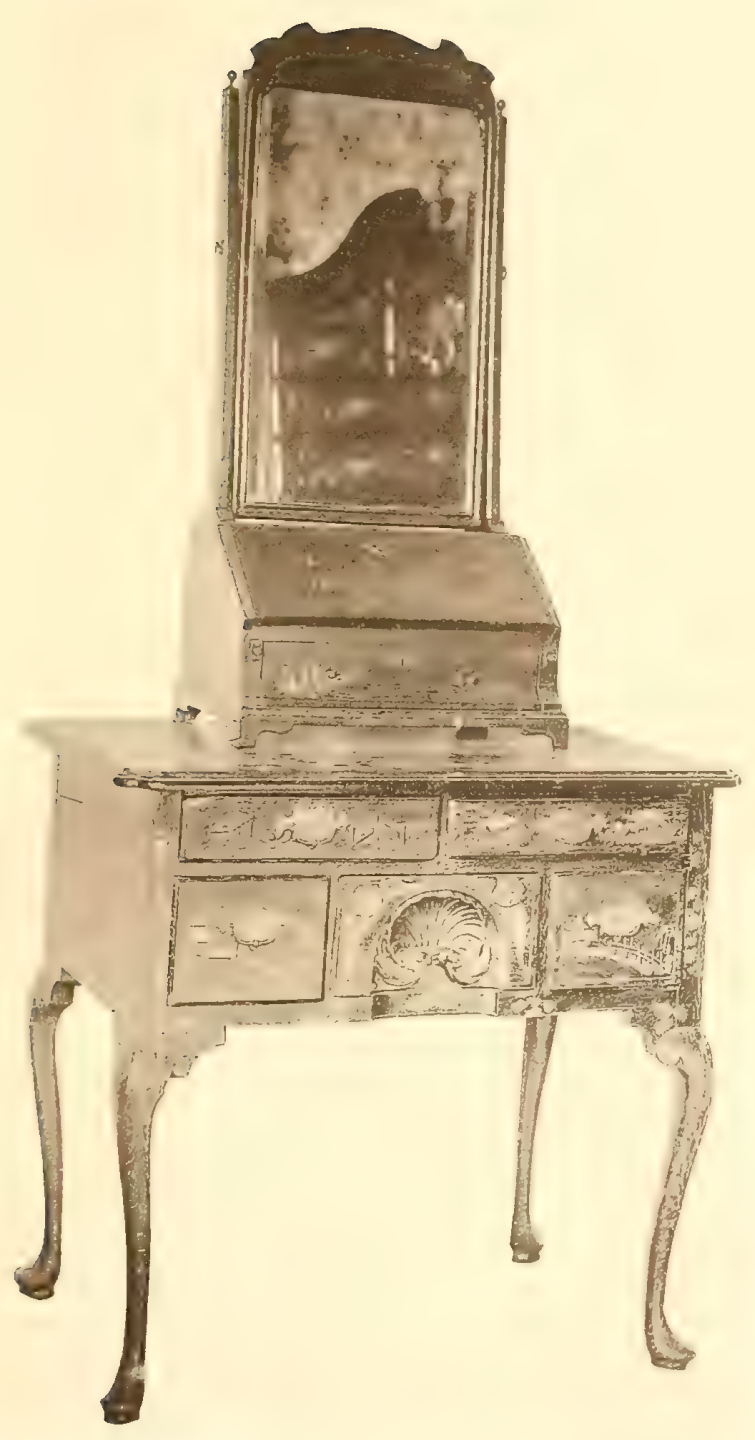

F.G. 39

THE CHAMEEF TABLE AND IRESSIN BO A BELONGING TO 38 

"I Japan'd Chest of Drawers \& Table, £7.6. 8."

"A parcell of China Bowls on ye Chest of Drawers, £3." - Inventory of Rev. William Welsteed, Boston, 1753 .

"Case of draws Veneered, £2. I 3. 4."

"The steps \& some small China thereon, all $5 \mathrm{~s}$. 4 d." - Inventory of John Proctor, Boston, I 756.

It is probable from the phraseology of the inventories that the fictile wares placed on chests of drawers were those designed for household use rather than for the special decoration of these pieces. It may be, however, that sets for chests of drawers were made and used the same as for manteltrees. The item already quoted from the inventory of Zachariah Long possibly refers to such a set. So may the following, from the inventory of Captain Thomas Thacher, made in Boston in I 723:-

"I Japand Chest Drawers, £4."

"Furniture for Chest Drawers, Ios."

"Furniture for mantel pe, 6 s."

The earliest mention of steps noted in the New England records occurs in I733, in the inventory of John Jekyll, of Boston. As these objects were of the simplest construction and had no other value than as appendages to chests of drawers, and have been out of fashion for about a century, it is probable that existing specimens are very scarce, and that knowledge of their former use has for the most part been lost. 
Through the kindness of Mrs. Thomas G. Talcott we are able to present in Fig. 4 I a veritable specimen that has descended in her family. It is cheaply made of soft pine boards from one half to three quarters of an inch in thickness, nailed together, and stained a chocolate brown. It has three stages, each about four and a half inches in hight. The lower stage has a front of twenty-eight inches, and a depth of fifteen and a half inches. The second and third stages are made to recede so as to leave steps in front and on each side about four and a half inches in depth. They also run back as far as the first stage, and all are left open behind.

To complete the historical picture, this piece, with china on its steps, is shown in Fig. 42 on the chest of drawers, also in possession of Mrs. Talcott, to which it originally belonged.

Mr. George R. Curwen, of Salem, Mass, has described to the writer a piece of furniture almost identical with the one here illustrated, which he had seen in Salem about fifty years ago, and which he remembers very distinctly. He was then told that such pieces were made to go upon the tops of chests of drawers, and that they were called steps.

As a rule they seem to have been movable pieces that could be put on or taken off the chest of drawers at pleasure. This was, however, not always the case. We have seen at least two chests of 

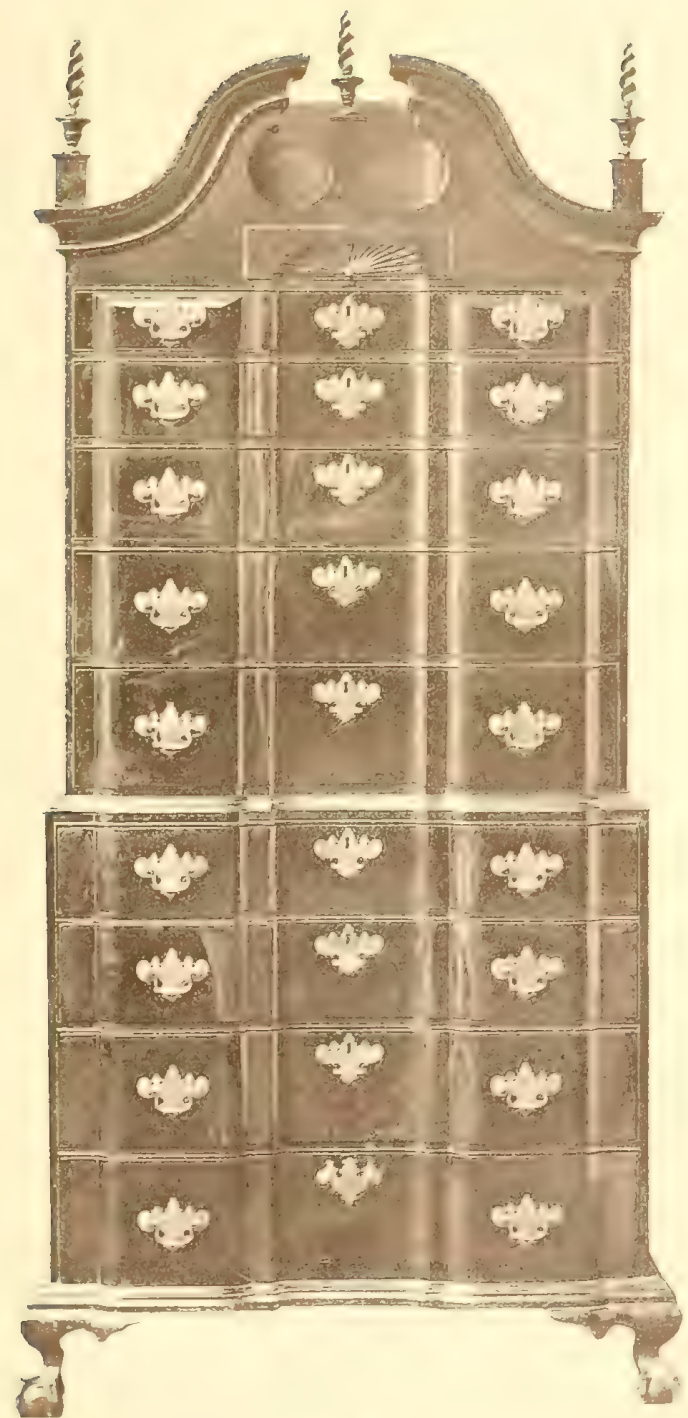

$\vec{F}$... H 

drasvers with stationary steps upon them. One of these is now in our possession. In this connection it is also noteworthy in respect to its hight. It is reasonably certain, as we have hitherto assumed, that steps were intended for high chests of drawers. But in this instance the top upon which the steps are fastened is but forty-nine inches from the floor. The use of steps upon pieces of this hight was, we believe, altogether exceptional.

The steps on this chest of drawers have but two stages, in each of which there is a drawer. The fronts of these drawers are on the line with those of the drawers below, so that the steps have gradations on their sides only. The drawer fronts are made of maple, the ends of the piece of whitewood. The feet are turned, and are very large and globular in shape. The brasses are of the older stamped variety, but the drawers have the overlapping edges. The piece was made in the third decade of the eighteenth century.

During the seventeenth century the article of furniture which is the subject of this chapter was usually written chest of drawers in the New England inventories, the expression case of drawers being but seldom seen. In the next century we meet with cases of drawers in the records much oftener than before, though chest of drawers continued to be the standard name. Felt, in "The Customs of New 
England," Boston, I 853, supposes that there was a difference between chests and cases of drawers; that the former had flat, and the latter shaped or rounded tops. It must be admitted that there are grounds for this belief, such as the more frequent use of the expression case of drawers, which we find in the records toward the middle of the eighteenth century, at the time when it is supposed that the round tops made their appearance. Another fact of similar import is the occurrence in several instances of chests of drawers and cases of drawers in the same inventory, as though the apprizers intended thereby to express a difference. In a few of these instances the cases of drawers are valued much the higher, which again would seem to point to the more fashionable and expensive pieces with wrought tops.

There are, however, two or three historical facts opposed to this view. The expression case of drawers is found in our records as early as I654, long before the arched tops made their appearance. Moreover, glass and earthenware and steps are frequently found upon their tops, which must, therefore, have been flat, as in the following instances:-

"I black Walnut Case of Drawers \& Table, $£ 7$."

"A parcel Glass Ware on ye Case of Drawers, EI. Io." - Inventory of William Welsteed, Boston, I 729.

"Sundry Sorts of flint Glass ware upon the man- 
the peice \& Case of draws, $£ 4$. Io." - Inventory of Captain Edward Cruft, Boston, I735.

"Case of Drawrs, $£ 3$. ro. Chaney glass and Earthen ware on it, $£ 4$. Io." - Inventory of Jacob Williams, Roxbury, I 736.

"I Case draws \& table theirto, $£$ I 5."

"Other Glass \& Earthen on ye Case draws, I 5 s."

- Inventory of Sampson Mason, Boston, I738.

"Case o' Drawers \& Table, \& Io."

"A parcel of Glass on ye Case o' Draws, $£ 4$." Inventory of Josiah Langdon, Boston, 1743 .

"I Case of Draws Steps \& Table, £ Io." - Inventory of Captain William Warner, Boston, I 746.

"I Case Draws \& Chamber Table \& glass on $\mathrm{s}^{\mathrm{d}}$ Draws, £3. 5." - Inventory of William Beers, Boston, 1760 .

Low cases of drawers are sometimes mentioned in the same inventory with high cases of drawers. Now the low cases of drawers always had flat tops.

From all these facts it is very probable that chest of drawers and case of drawers were terms that were used interchangeably.

Chests of drawers continued in use down to the close of the eighteenth century. In I 794 we find the following items in the inventory of Elisha Wolcott, of Wethersfield, Conn.:-

"I high Case of Draws, 25 S., I low Ditto, I 5 s., I Dressing Table, $5 \mathrm{s."}$ 
The writer has lately seen a chest of drawers made in the year I800, in Wethersfield, Conn., by Edward Shepard. The wood is cherry. The drawers go nearly to the floor, and rest upon bracket feet. The top is flat, but at its front is surmounted by a pediment made up of a scroll and fret on each side of a central urn-like ornament. The scutcheons are small and elliptical in shape. The handles are large, and are each furnished with two small discs through which the bolts are passed to be secured on the inside of the drawer. The hight of this piece to the top of its pediment is somewhat over seven feet.

Heppelwhite in 1787 published designs for high chests of drawers reaching to the floor, but gave none mounted upon legs. We find no mention of chests of drawers in Sheraton's work, published in I 793, which shows how completely they had gone out of fashion in England at that time.

The dressing-tables and dressing-drawers or bureaus that began to appear in New England soon after the revolutionary war were chiefly made after the designs of Heppelwhite. They appear to have immediately followed the old-fashioned chests of drawers and dressing-tables which have been the subject of this chapter. 


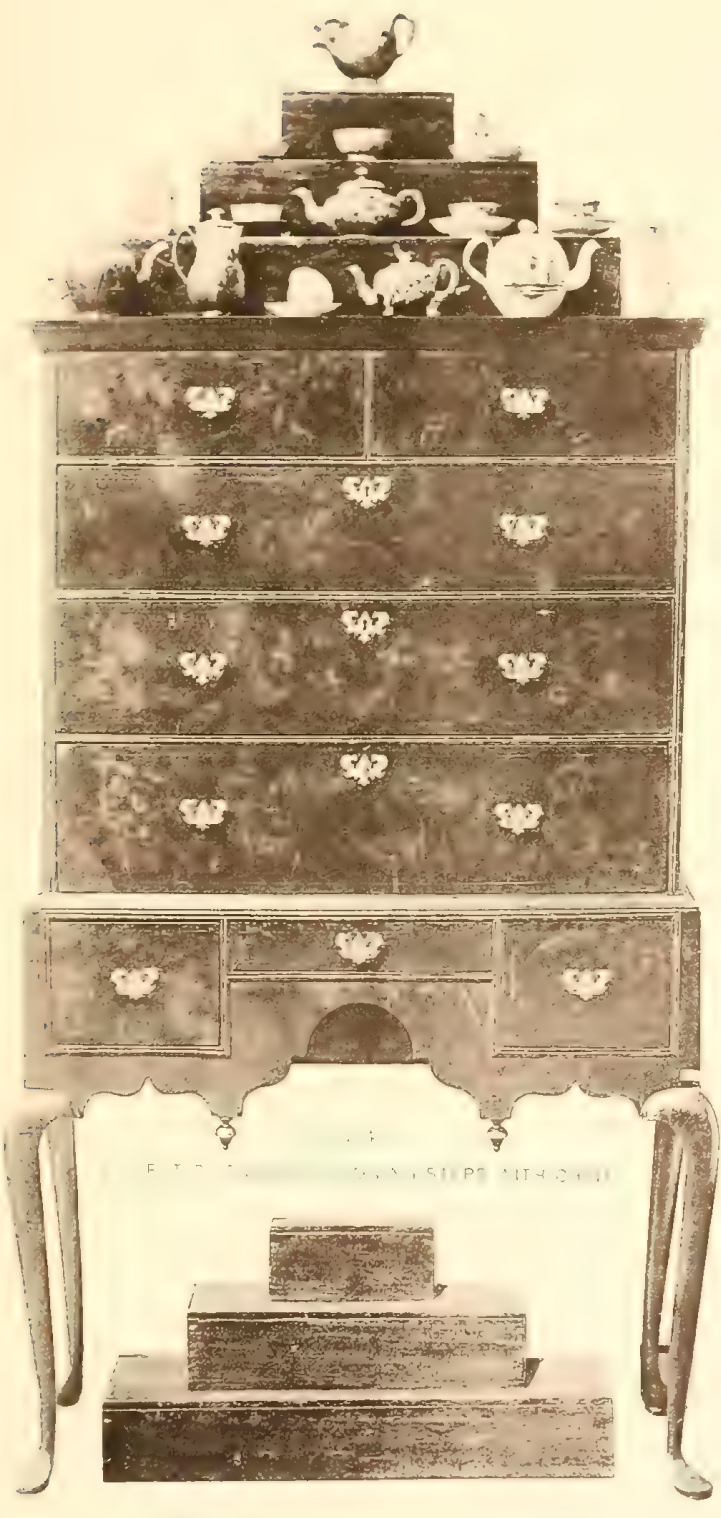

FiG, 41

STEPS FOR TOP OF CHEST OF DRAWERS 



\section{CHAPTER IV.}

DESKS.

THE desk in some form was probably coeval with the art of writing with pen and ink. They are found in Greek and Latin manuscripts as early as the ninth century. Examples of writing and reading desks from the ninth to the fifteenth century have been published by Viollet-le-Duc, Willemin, Strutt, Shaw, and others. Some of these were mounted on feet, others were made small and portable so as to be carried about and used on the lap of the writer.

The word desk appears in the "Court of Love" formerly attributed to Chaucer. It is also found in the first English-Latin dictionary, the "Promptorium Parvulorum," written about I440. Its etymology is the same as that of dais, dish, and the German word tisch, which seems to show that the primitive idea to be expressed was that of a raised plane or table.

English lexicographers have from early times accorded to this word two rather distinct meanings. One, a piece of furniture used for reading, - a reading desk, a lecturn, or pulpit. The other, a piece used rather to write on, or to inclose books and 
papers. It is mainly desks of the second kind that we shall here consider.

The desks found in the New England inventories, from those first noted in I644 down to I669, range in price from one up to twenty shillings, the average, carefully ascertained, being about six shillings. Most of the descriptive details relating to these desks that one is able to gather from the probate records are included in the following extracts :-

" I little desk, I s." , "I desk, I s." - Inventory of William Brewster, Plymouth, I644.

"In the great Chamber, His Deske, $£$ I." - Inventory of William Clark, Salem, I647.

"I desck box, 3s." - Inventory of Robert Day, Hartford, 1648.

"In the Study, I Greene desk for a woman, $6 \mathrm{s."}$ - Inventory of Major-General Edward Gibbons, Boston, I654.

"I covered deske, Ios." "For the deske \& Standish, I4 s." - Inventory of Nathaniel Souther, notary, Boston, I655.

"In the hall, A standing deske standish \& Box, $£_{\text {I }} 5$ s." - Inventory of John Brackett, merchant, Boston, I666-67.

These early pieces no doubt differed from each other in shape and size to a considerable extent. The greater number, however, were probably boxes, either plain or carved, with sloping lids, and, not hav- 


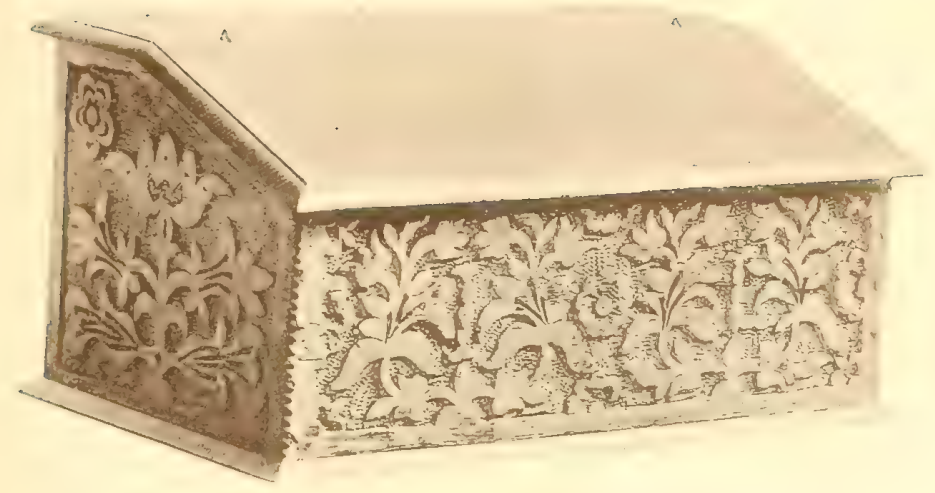

FIG. 44

CAR IED FAKEI. [EST

$$
A=-j, \ldots
$$

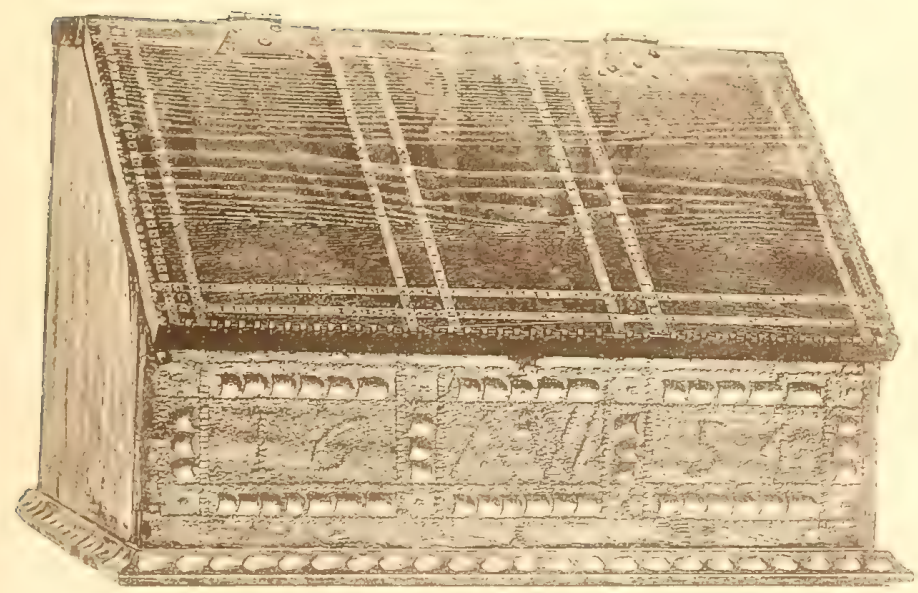

FIG. 43

CARVED DESK

DATED I6SA 


\section{.}


ing legs, were brought to the proper hight for use by being placed on some other object, as a table or chest. This is the traditional conception of these old desks. It is also consistent with the definitions of the word found in the dictionaries of the early part of the seventeenth century, and is further sustained by the presence among us to-day of actual specimens which have come down from these early times.

One of these from the Waters collection is shown in Fig. 43. It is twenty inches in length by thirteen and a half in width. Its hight behind is thirteen and a half, in front six and a half inches, making the lid altogether too steep to be used for writing. It is made of a wood resembling butternut. In the inside, at the back, are supports for a narrow shelf that had run from end to end. Its front is carved, and bears the date 1654 , and the initials A. W. It was bought in Danvers, Mass. A much smaller desk in the same collection is made entirely of oak and carved with acanthus leaves. Its lid is not so sharply inclined as in the one here illustrated, and there is a little till running along its back on the inside.

A very beautiful carved oaken desk box belonging to Mr. Henry W. Erving, of Hartford, Conn., is shown in Fig. 44. Its dimensions are: length, seventeen and a quarter inches; width, ten and a quarter inches; hight behind, eight and a quarter 
inches, in front, six and an eighth inches. On the inside, at the back, is a shelf three and a quarter inches wide, running lengthwise. The top, including the lid, and the bottom are restorations, the wood of the original top and bottom being too much decayed to admit of repair. The parts restored have been copied from the original design with the greatest care. The carving is very good, and the oak undoubtedly European. This piece was picked up a few years ago in the town of Essex, Conn.

The habit of covering desks with cloth is very old. Strutt, in his "Dresses and Habits of England," has reproduced from a manuscript of the twelfth century a reading desk with drapery thrown over it. In the inventory, made in February, 1534-35, of the effects remaining at Baynard's Castle of Katharine of Arragon, published by the Camden Society, we find the item, "a deske covered withe blacke velvette, and garnysshid withe gilte nayles," and Antipholus of Ephesus, in the "Comedy of Errors," being in urgent need of money, dispatches his servant to Adriana, his wife, commanding him to

"Give her this key, and tell her, in the desk

That's cover'd o'er with Turkish tapestry

There is a purse of ducats ; let her send it."

The writing table in France (bureau) derived its name even from the woolen cloth which had long been in use to cover its top. 
With these facts in view it is easy to see that the "covered deske," which we have cited from the inventory of Nathaniel Souther, and the "greene desk for a woman," - probably covered with green cloth, - from the inventory of Edward Gibbons, were desks treated according to a custom that had been in existence for many centuries, and which to-day is perhaps more widespread than ever.

There is much uncertainty as to the type of the "standing deske," mentioned in the inventory of John Brackett. It was probably a mounted desk, but at what hight, and whether on an open frame, or inclosed below, are questions difficult to decide.

Desks inclosed from the table nearly to the floor reach back to very early times. One is shown in the view of a Norman school, given by Wright in his "Homes of Other Days" (cut No. 89), from a manuscript of the early part of the twelfth century. Viollet-le-Duc has illustrated a very interesting example belonging to the thirteenth century (Lutrin, Fig. 7). In the frontispiece of "Cicero's Tusculan Questions," printed in Venice in I5 IO, five desks are seen with writers seated at them. Two of these, at least, have sloping tables, and all are inclosed at their ends and backs.

There are, however, two very good reasons for supposing that the desk in question was one mounted on an open frame made to hold it. First, this seems 
to be the most natural and probable meaning of the word standing as here used. Second, desks with frames were then in use, as the following extracts from the inventory of William Whittingham, merchant, made in Boston in I672, will show:-

"In the parlor Chamber, 2 Standers \& a desk w w $^{\text {th }}$ a fframe, $\mathscr{E}$ I. 8."

"In the porch Chamber, I desk \& fframe, ros."

We show in Fig. 45 an oaken box enriched with carving and applied ornaments, and dated i668. It is thirty inches long, twenty-four and a half wide, and ten and a half high. It is of European oak, and belongs to the Hosmer collection.

Whether these boxes with flat lids were called desks in the seventeenth century is an interesting question. If so, they were desks mainly in the sense of receptacles for books and papers; for while it was possible to write on them when brought to the proper hight, it would have been more convenient to use the top of any ordinary table for this purpose.

The use of the word scob at Winchester College in England, to designate the boxes with flat lids used there as desks, is a fact opposed to the idea that such pieces were called desks in the seventeenth and eightcenth centuries. If, as is supposed, this nickname arose from spelling the word box (bocs) backward, it would tend to show that these pieces had previously been called boxes instead of desks. 


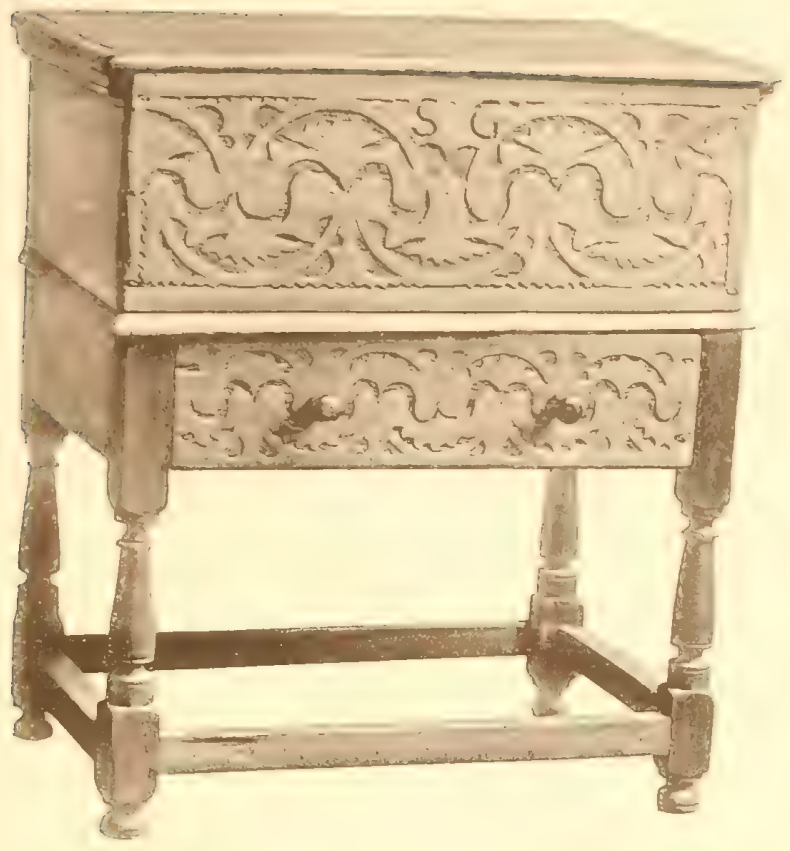

FIO. 46

CARVED BOX WITH DRAWER

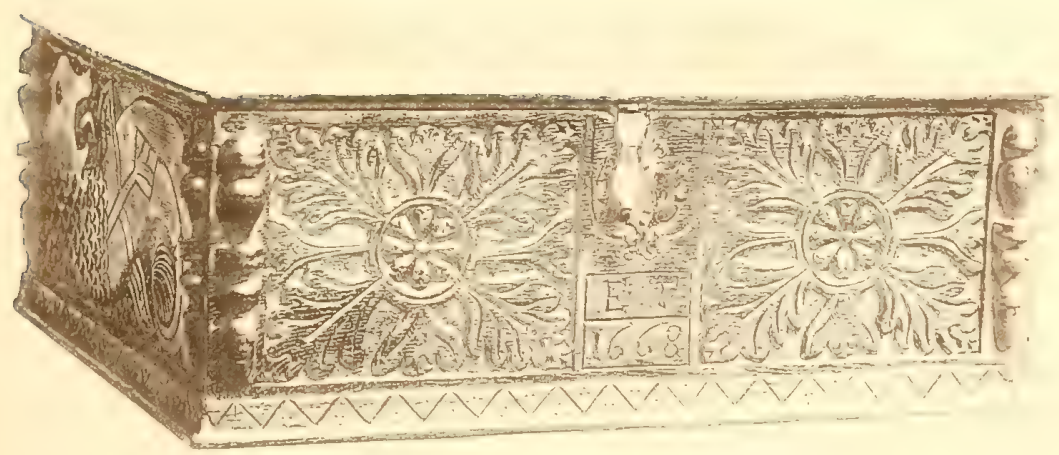

FIG. 45

CARVEO OAKEN BOX 

That some desks were made solely to inclose books and papers is apparent from the following facts:-

Barrett's "Alvearie," London, I 580, gives " a deske to write upon, or to keepe bookes in." In the inventory of Henry Brickwell, made in I 589-90, and published by the Surtees Society, "ii desks for books" are mentioned. In the English-Latin part of Littleton's Dictionary, published in London in 1684 , the difference between a desk for books and one for writing is thus recognized:-

"A Desk for Books. Pluteus.".

"A Desk to write on. Abacus, scrinium scriptorium."

The fact that the Waters desk, shown in Fig. 43, could not have been used for writing on, owing to the steepness of its lid, renders it highly probable that it and similar pieces were made, not to write on, but only to hold the materials for writing.

If, then, certain desks were made solely to inclose papers, books, etc., they could have been made with flat as well as with sloping lids. The etymology of the word desk is certainly in favor of a flat top, and we may add that nothing at all opposed to it has been found in the dictionaries of the seventeenth century which we have consulted.

A piece of furniture belonging to the seventeenth century is found in New England, concerning whose use there is much doubt. A specimen is shown in 
Fig. 46. It is a box with a drawer under it mounted on legs. The box is twenty-six inches long, sixteen and one half inches wide, and its top is thirty inches from the floor. If boxes with flat lids were ever called desks, could this have been a mounted variety? It has been suggested that such pieces belonged to the dining-room, and were used for holding table linen. This may have been its design. This piece is owned by the writer, who has seen three other examples.

The desks now described include all the varieties that were in fashion in New England down to about i669, of which we have knowledge. Good specimens are now very scarce, especially of those with frames, or mounted on legs.

A style new and altogether different from the desks which had preceded it now made its appearance. It was called the scrutoir. We give here, from original sources, notes of a few of the earlier examples :-

"In the little Chamber, I Scritore \& desk, £ Io. 6." - Inventory of Antipas Boyes, merchant, Boston, I669.

"In $\mathrm{y}^{\mathrm{e}}$ porch Chamber, I desk \& some devinity books and some knives and one scredoar, $\mathscr{L} 3 . "-$ Inventory of Nathan Rainsford, merchant, Boston, I 676 .

"In the Parlor, One screetor \& frame, £2." - Inventory of Richard Sharp, Boston, 1677 . 


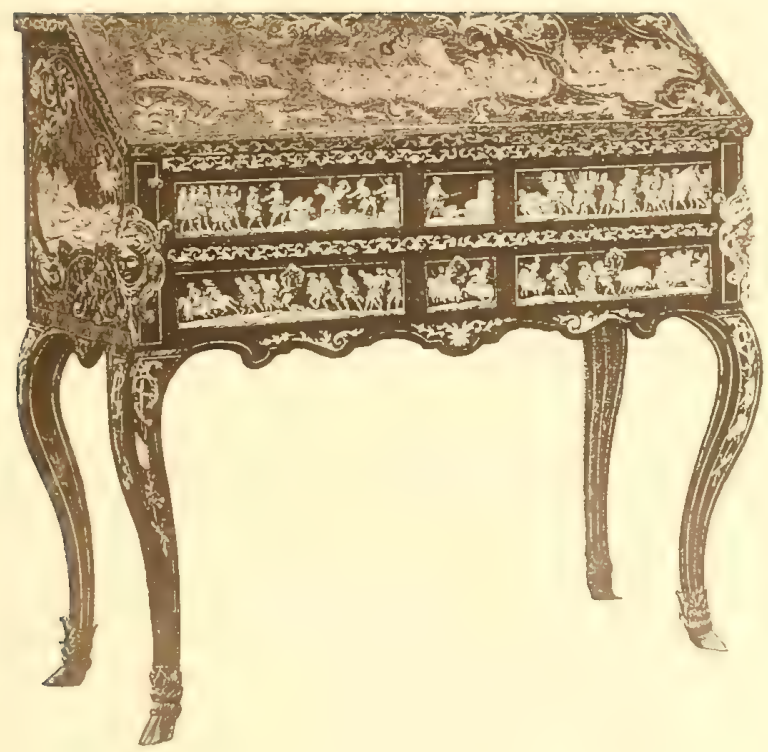

FIG 47 

"In the Hung Chamber, A Scrittore, £ $12 . "$

"In the Great Chamber, A Scriptore, 5os." - In. ventory of Benjamin Gibbs, merchant, Boston, I678.

From this time down to about I 7 IO they are occasionally met with in the inventories; after I 7 ro they become more and more numerous and are found in many good estates. The latest scrutoir that we have noted is in the inventory of Rev. Nathaniel Hooker, of Hartford, made in I 770, though no special search has been made for a later mention.

That they were rather fine structures is evident enough from the prices given, which, prior to I 710 , ranged from ten shillings up to $£ \mathrm{I} 2$, the average being somewhat over $£ 5$. After ryio they were valued considerably higher, in some instances up to twenty, and even thirty pounds, but this was mainly due to the inflation which the currency underwent during the first half of the eighteenth century.

The earliest description of this new piece of furniture that we have been able to find is the following, which occurs in Phillips' "New World of Words," fifth edition, I696:-

"Scrutoire, a sort of large Cabinet, with several Boxes, and a place for Pen, Ink and Paper, the Door of which opening downward, and resting upon Frames that are to be drawn out and put back, serves for a Table to write on."

In the sixth and seventh editions of the same dictionary, published respectively in 1706 and 1720 , the 
wording of the definition, which is the same in both, varies from that of the preceding as follows:-

"Scrutoir, or Scritory, a sort of large Cabinet with several Drawers, and a place for Pen, Ink and Paper, the Door of which opening downwards, and resting upon Frames or Irons, serves for a Table to write on."

In the first edition of Bailey's Dictionary, published in I72I, a scrutoir is defined to be "a sort of large Cabinet, with a door opening downwards for the Conveniency of Writing." This definition, which is essentially the same as those given by Phillips, is repeated in all of Bailey's dictionaries down to the close of the eighteenth century.

With these clear and detailed definitions in hand, it is comparatively easy for the student of old furniture to identify the scrutoir, which sprang up in the latter part of the seventeenth century, with the writing-desk, which became so fashionable and popular in the first half of the eighteenth century, and which continued in use considerably over a hundred years.

A scrutoir said to date from the close of the seventeenth century is illustrated by Havard in his "Dictionnaire de L'Ameublement" already cited (Fig. 324), and is here reproduced in Fig. 47.

It is a very beautiful specimen, and, if as old as it is supposed to be, it is the earliest example of the scrutoir to which we can refer, and as such is very 
interesting from the mode of its construction. It is quite likely that many of the earlier scrutoirs were mounted, like this, upon legs. It is also very probable that others were made with drawers extending nearly to the floor.

The oldest New England scrutoir that we know of is shown in Fig. 48. It has several features which indicate that it was made in the first quarter of the eighteenth century. These are its fine old drop handles, with their delicate stamped plates and scutcheons; the mouldings, instead of lips or overlapping edges, around the drawers; the long compartment opened into from above by a sliding cover at the back part of the table, and the globular shape of the feet.

The period to which such brasses and mouldings belong, and their value in determining the age of a specimen, have been fully set forth in the preceding chapter. The compartment referred to is an indication that the piece was made early in the eighteenth century, if not before, though exceptions to this rule are not unknown. Later in the century its place was usually occupied by one long, or two short drawers which drew out in front just below the level of the table, as in the specimen next illustrated.

The feet which support this scrutoir were made for it when it was new, and are the only ones that it has ever had. This statement is made because their 
genuineness has been called in question. But the history of this piece and an examination of the parts concerned leave no doubt that the present feet are those which have always belonged to it. Moreover, turned feet of large size, similar to these, are occasionally found on chests and chests of drawers made at the close of the seventeenth and in the beginning of the eighteenth century. They are seen on the chest of drawers shown in Fig. 26 of the preceding chapter. They occur also on three pieces - one chest and two chests of drawers - belonging to the writer, who, besides these, has seen several other examples.

The turned feet of the six-legged chests of drawers and of the dressing-tables made to accompany them become very interesting when compared with those found on this scrutoir. They all belong to the same period; they are, in general, of the same style and shape; all are fastened to the main piece in the same manner; in short, they differ from each other in point of size only.

One of the quaintest of the old scrutoirs found in New England is shown in Fig. 49, with its lid closed. It was picked up in Glastonbury, Conn., in I888, and is now the property of Horace S. Fuller, M. D., of Hartford, Conn. It is made of maple. The measurement from front to back of the main part, at and below the level of the table, is but fifteen and 


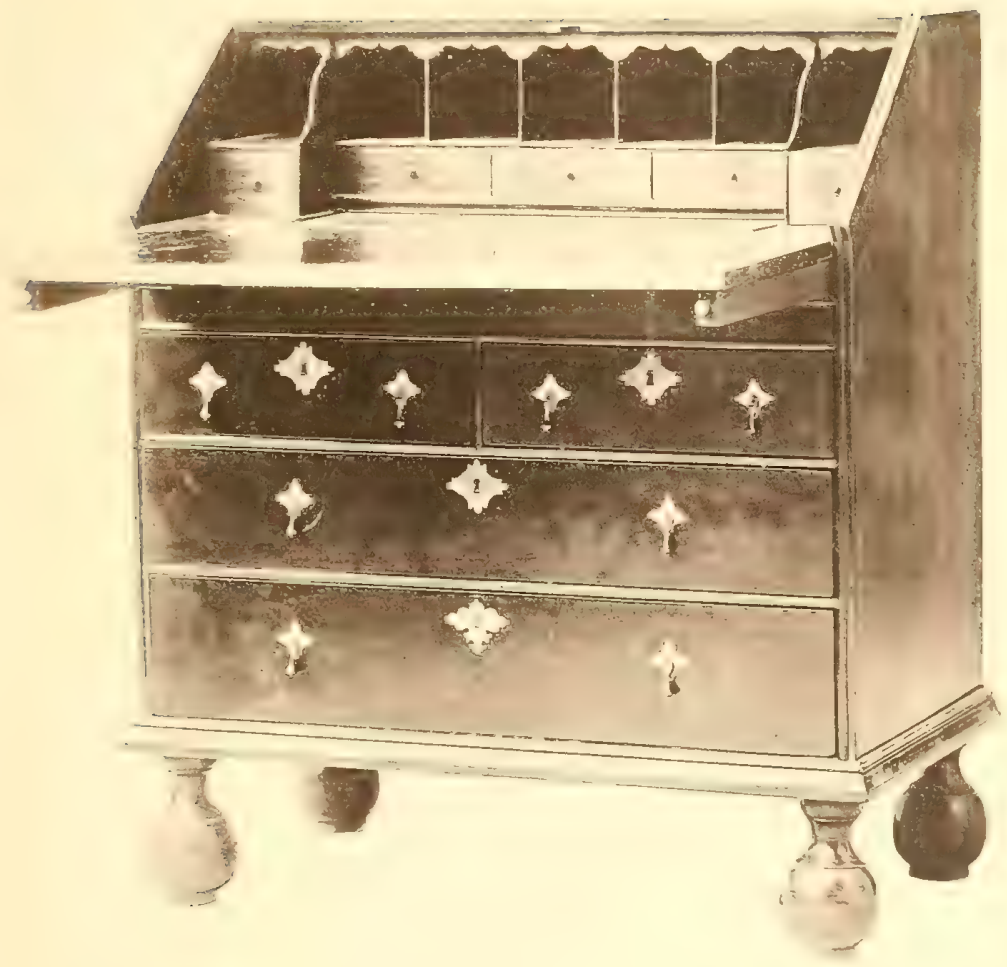

FIG. 48

SCRUTOIR 

a half inches, which is about three inches less than the average. This, with the steepness of the lid and the gracefulness of its legs, gives to this piece an unusually light and airy appearance. The overlapping edges of its drawers and the absence of the compartment above described show it to be later. than the preceding specimen. The original brasses are missing, but were, no doubt, one of the transition types which have been described in the chapter devoted to chests of drawers.

After the middle of the century scrutoirs, like chests of drawers and dressing-tables, were sometimes richly made with shaped fronts and with ball and claw feet. A very fine example of this style is shown in Fig. 50. In size it is considerably above the average, having a front of forty-one inches and a width of twenty-two and a half inches. It is made of cherry, with inlays of ebony and light-colored woods upon the lid. The little drawers in the upper part are twenty-nine in number, and in arrangement remind one somewhat of an amphitheater. The following inscription, having all the appearances of age and genuineness, is written in ink on its bottom: "This desk was made in the year I 769 by Benjamin Burnham who sarved his time in Philadelphia." It was lately bought from an estate in Hartford, Conn., and is now a part of the Hosmer collection of that city. 
It is hard to tell how early scrutoirs with cases upon them for books began to be made. Writing desks of other styles, with cases or cabinets upon them, were sometimes made during the seventeenth century, such as the large secretary, nearly six feet high, in the second room on the ground floor of the Plantin-Moretus Museum in Antwerp, and the Maréchal de Créqui bureau in the Musée de Cluny in Paris. Such pieces as these make it possible that scrutoirs with similar additions were made in the latter part of the seventeenth century. Other sug. gestive facts are the high prices at which some of the earlier scrutoirs were valued, and that they so often belonged to merchants.

On the other hand, no mention of an upper part is made by Phillips in his first definition of scrutoir in I696; and as we have been unable to find any proof in the inventories or elsewhere of its existence in the seventeenth century, and because we have not met with the word bookcase till the year I 710 , we are inclined to think that the writing desks now under consideration were not surmounted with cases for books till after the beginning of the eighteenth century.

The following items bearing upon this point are cited from the inventory of John Mico, a Boston merchant, made March 7, I 7 8-I9:-

"In the Hall, I Scriptore, £6." 


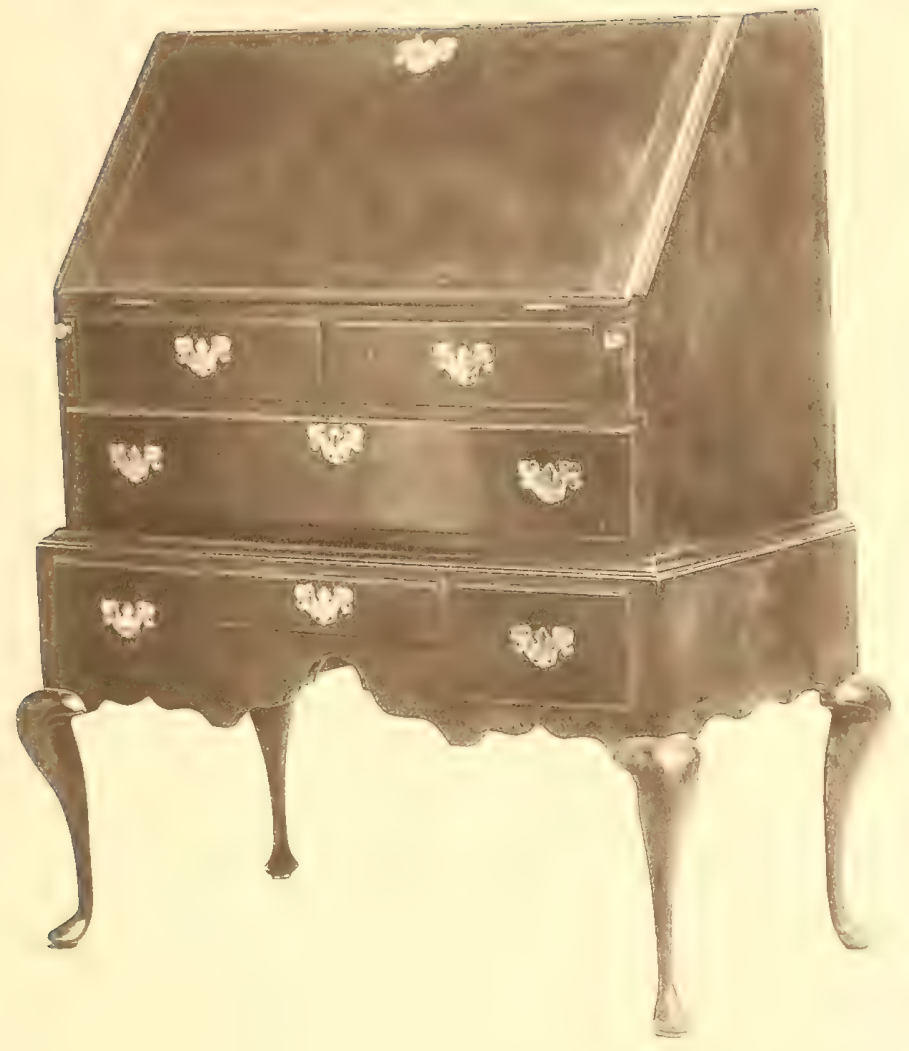

FIG. 49 



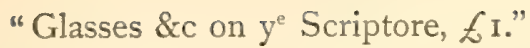

The scriptore in this instance probably had an upper part with a flat top, upon which glass and china ware were placed according to the fashion of the day.

It is quite likely that the bookcases upon the earlier scrutoirs had flat instead of arched tops, following in this respect the rule which governed the construction of the high chests of drawers. Bookcases with flat tops, however, did not cease to be made after the introduction of those with the arched top.

As a rule the bookcase doors were made wholly of wood; occasionally they were glazed, as in the following instances:-

"In the Front Chamber, I fine Glass Escrutore the Glass broke, $£ 8 . "-$ Inventory of Henry Frank. lin, merchant, Boston, I 725 .

"Scriptoree with Glass doors, $£ 20 . "$ - Inventory of Governor William Burnet, Boston, I 729.

"In $y^{\mathrm{e}}$ Middle Room, I Scrutore \& Book case $\mathrm{w}^{\text {th }}$ Glass doors, $£ 26 . "$ - Inventory of Matthew Bond, merchant, Boston, I 737 .

A very fine example of the scrutoir with an upper part is shown in Fig. $5 \mathrm{I}$. It belongs to Mr. William G. Boardman, of Hartford, Conn. It is made of mahogany, and dates from about the middle of the eighteenth century. 
In I683 "I small Scriptore, in the Lower Bed Roome," was valued at ten shillings in the inventory of Thomas Kellond, merchant, of Boston; and in I 7 I "I Small Scritore," at thirty shillings, in that of Captain Walter Roswell, mariner, of the same place. These facts show that the early scrutoirs were sometimes small as well as cheap pieces. They were probably made above in the usual manner; but instead of reaching to the floor, possibly terminated just below the supports for the flap. In this condition they were more or less portable, and, like the pupitre desks, were placed upon tables or other objects for use. The "screetor \& frame" which we have cited from the inventory of Richard Sharpe was probably one of these small pieces mounted upon a frame made to receive it.

The scrutoir mentioned, in 1669 , in the inventory of Antipas Boyes is the first that we have noted either in this country or in England. It was, undoubtedly, an early specimen of its kind. But as the scrutoir originated in Europe it is probable that it had been in use for some time before the fashion reached Boston. We may, therefore, expect that the word will be found in the English records somewhat anterior to this date.

In his work already cited, Havard informs us that the first use that he has been able to find in France of the word escritoire, to designate a writing desk, is the 
following, which occurs in I680, in the inventory of Henri de Béthune, Archbishop of Bordeaux: "Un grand escritoire en pupitre d'ébène noire." Among others, he also cites from the inventory of the furniture of the Crown, made in 1697: "Une table-escritoire qui s'ouvre par-dessus, ayant 4 pieds de long sur 2 pieds 4 pouces de large, couverte de velours rouge cramoisy;" and "une petite table en écritoire, de marqueterie étain et cuivre, et par-dessus de panne verte," from an inventory made in Paris in I7I8. The last use that he has been able to find of the word écritoire in the sense above given is in the year 1770.

In New England the scrutoir held its name securely for a period of fifty years. During all this time the word desk continued to be used in the records in its old sense, and to be inventoried at its old prices.

In I7I9, "one Pine Writing Desk" was valued at $£ 2$ IOs. in the estate of Joshua Roberts, a japanner, of Boston, and in I $72 \mathrm{I}$, "I Oak Desk" at $£ 5$, in that of James Scollay, of Boston. From this time it is not an uncommon thing to find desks apprized as high as scrutoirs.

At the same time that the New England scrutoir began to be called a desk it received still another name. In I72I, "A Burow Desk" was valued at $£ 3.10$. in the inventory of David Craigie, mariner, of Boston, and in I 725, "I Buroe" at $£ 5$, in that of 
Henry Franklin, of Boston. "Beuroes" are men. tioned in an advertisement in the "Daily Courant" of London, June 14, I 7 IO, seven to ten years earlier than the use of the word by Swift in "Sandy's Ghost," so often cited by the lexicographers.

The additional names, desk and bureau, were probably not given to the scrutoir, because the latter had undergone changes that required special designations. When the scrutoir appeared in England and in her American colonies it had received its name, which, as we have seen, was retained for half a century. By this time it had become a well-known object, and began to be called a desk mainly through a tendency to revert from a foreign to an old and familiar English word.

It is quite possible that in France the éritoire began to be called a bureau through a similar process of reversion, the word bureau being in that country the national or generic name for writing desks of all kinds. In the first or French part of his FrenchEnglish dictionary, published in 1699, Boyer defined the word bureau as follows: "Bureau, (Espèce de Table à plusieurs tiroirs \& Tablettes) a Chest of Drawers, a Scrutor." Boyer was familiar with both French and English furniture, having lived in France until he was twenty-one, and in England long enough to acquire the language thoroughly. This definition may therefore be accepted as evidence that pieces 


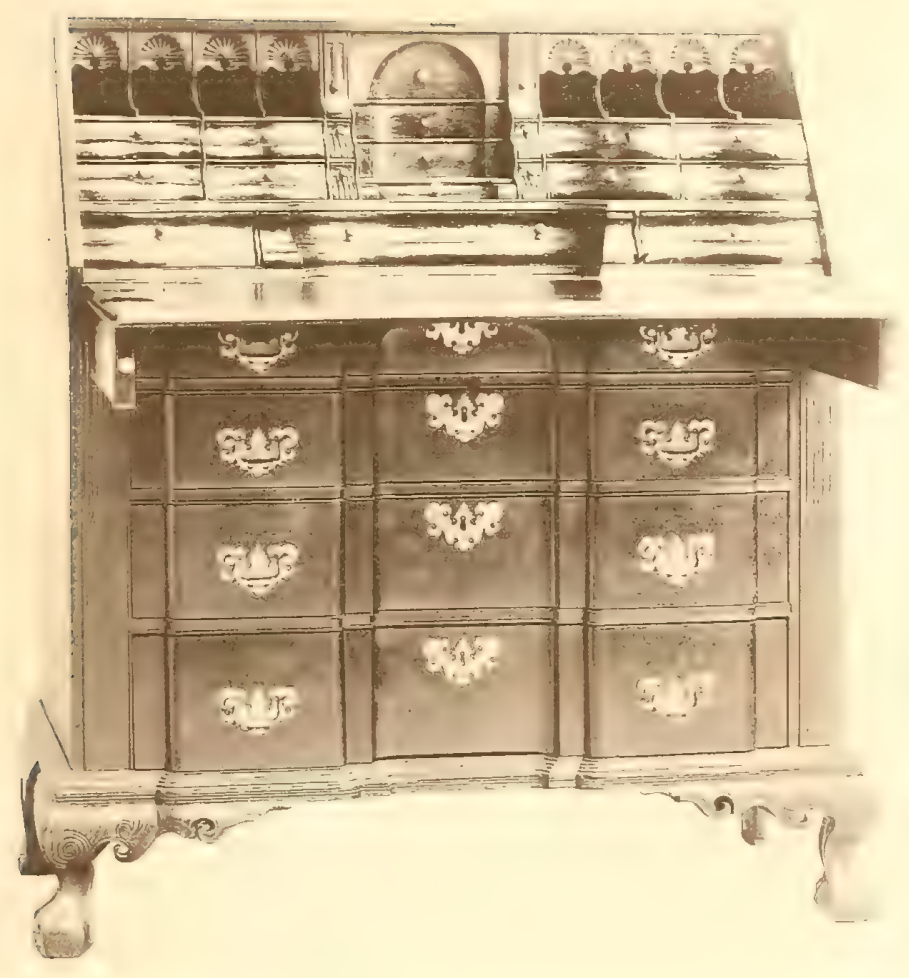

FIG. 50

SCRUTOIB 

of furniture like the scrutoir were called bureaus in France as early as 1699.

The new French name for the scrutoir, in whatever manner received, soon found its way to England and this country, and into the records as above described.

Were, then, these three names, scrutoir, desk, and bureau, used interchangeably and applied without discrimination to pieces which had hitherto been called scrutoirs? This was undoubtedly true of such examples as are represented in Figs. 48, 49, and 50, that is, with drawers below the level of the table, and without bookcases above the main part. That is to say, that in a community where all did not understand and use these terms alike, such pieces would be correctly called scrutoirs by one, desks by another, and bureaus by a third person. We are led to this conclusion by the following facts :-

The prices at which scrutoirs, desks, and bureaus, without tops, were inventoried in New England run about the same.

The scrutoir as described in this chapter was, we believe, about the only writing desk in New England in the first half of the eighteenth century to which these names, with the prices given, could have been applied. Some of the high-priced "desks" of this period may have been of the pupitre variety, of large size, and mounted on frames, such as are seen to- 
day in shops and counting-houses. These, however, would not have been called scrutoirs, or bureaus.

In Bailey's "Dictionarium Britannicum," second edition, London, 1736 , Bureau is defined to be "a Cabinet or Chest of Drawers or Scrutoir for Depositing Papers of Accounts; also a Buffet for setting Plate, China Ware, \&c." In this definition bureau and scrutoir are made convertible terms.

The words desk and scrutoir were also used interchangeably, as in the following instance, from the inventory of Anthony Stoddard, made in Boston in I748: "In the Front Room, I Desk or Scrutore, $£ 15$."

In 1753 , and again in I 760 , Chippendale published designs for scrutoirs with bookcases on them, like the one shown in our illustration, Fig. 5 I. These, however, he did not call scrutoirs or bureaus, but desks and bookcases.

Finally, in defining the word bureau in 1803 in his "Cabinet Dictionary," already cited, Sheraton says:-

"In England it has generally been applied to common desks with drawers under them, such as are made very frequently in country towns. They run from 3 to 4 feet long, and have three heights of common drawers under them, the upper one divided into two in length. The desk flap turns down to 30 inches perpendicular height from the ground, or a little less, for sitting to write at. The inside of the desk part is filled up with small drawers and holes for letters. These pieces of furniture are 


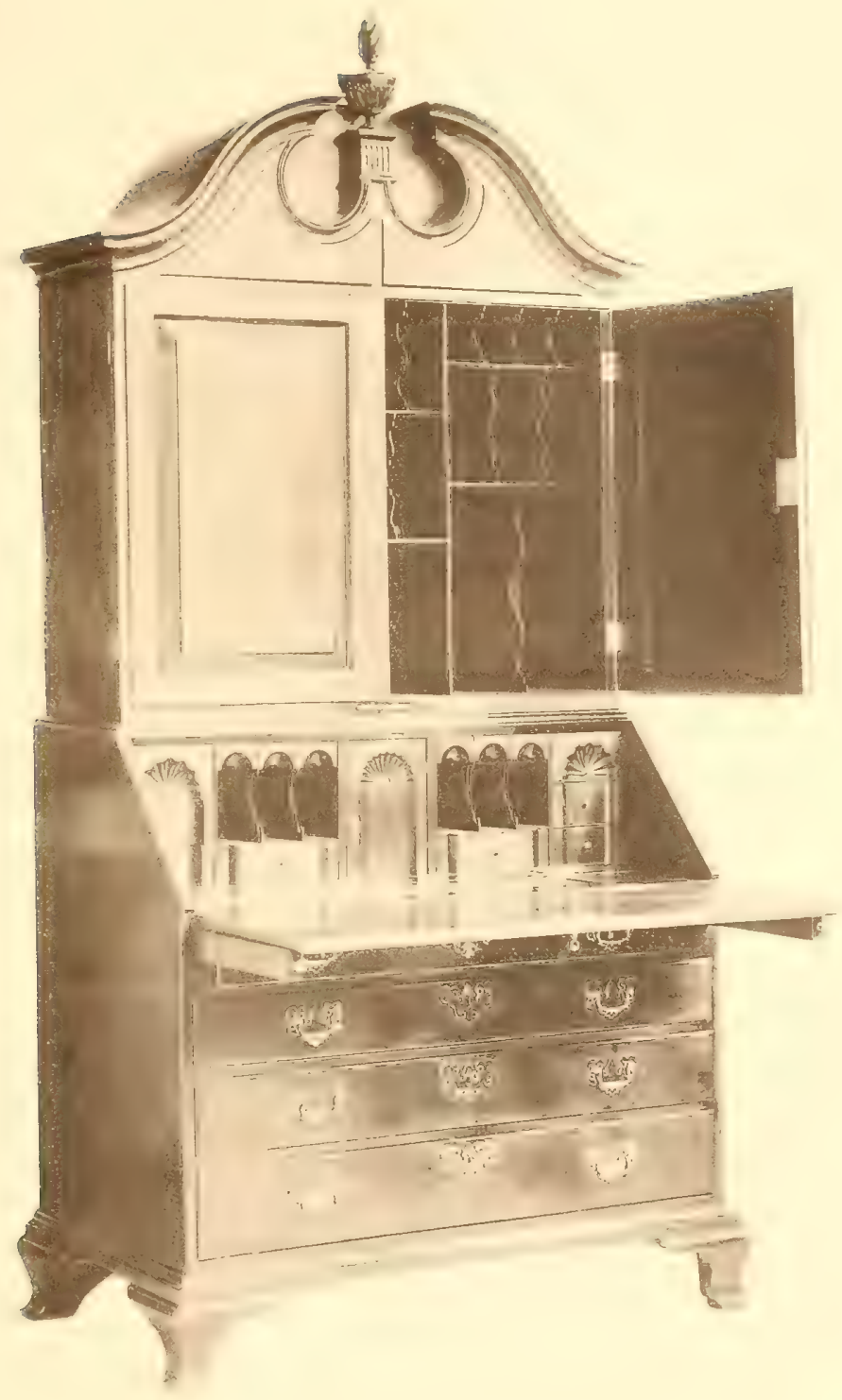

FIG. 51

SCRUTOIR WITH BOOKCASE 

nearly obsolete in London; at least they are so amongst fashionable people. I have, however, endeavoured to retrieve their obscurity, by adding to them an open book case, and modernizing the lower part, as in plate 23 , where they are called Bureau Bookcase."

It will be seen from this description and the cut to which it refers, which represents a desk with a sloping lid when closed, that in England the word bureau had been in quite general use as one of the names for the scrutoir.

We will now present a few facts which seem to show that the words scrutoir, desk, and bureau were sometimes used to designate objects different from each other.

In the advertisement referred to in the "Daily Courant," of London, June I4, I7IO, "Scrutores, Cabinets and Beuroes of Wallnut-Tree" are mentioned.

In William Randle's advertisement in "The Boston News-Letter" in I7I5, to which reference has twice before been made, we find mention of "Escrutoires," "Writing Desks," and "Bookcases with Desks."

Indeed, it is not an uncommon thing for scrutoirs and bureaus, or bureaus and desks with bookcases, to appear together in advertisements in the London newspapers during the first half of the eighteenth century. 
If now we turn to the inventories, we shall occasionally find facts of similar import, as shown in the following extracts : -

"In the Front Chamber, I fine Glass Escrutore the Glass broke, $£ 8$. I Buroe, $£ 5$." - Inventory of Henry Franklin, Boston, I725.

"I Desk, \&4. Iо. A Scretore \& Table, $\mathscr{L}$ Iо."Inventory of Daniel Willard, ship chandler, Boston, I 728 .

"A Buro, $£$ I5."

"An Escruitore, \&IO."

"A Desk with book Case, $£ 30$." - Inventory of Lewis Vassall, gentleman, Braintree, Mass., I 743.

It is doubtless true, as already intimated, that much confusion prevailed in the use of these words. Dictionaries were scarce, scrutoir and bureau were foreign terms, and the latter was not defined in the English vocabularies till I736. Moreover, the scope of the word desk had been extended so as to include styles that were also known by other names.

It must, however, be admitted that when two or more names, such as bureau and scrutoir, or bureau, desk, and scrutoir, are found in the same advertisement or inventory, the pieces which these words were used to represent were, in all probability, more or less different from each other. What explanation of this can be given consistent with the supposed identity of the scrutoir, the desk, and the bureau? 
It has already been shown that the term scrutoir stood for pieces without, as well as with, the bookcase above. By attention to the prices given it will also be found that when the word desk or bureau was used in the inventories, a desk or bureau without a bookcase was ordinarily meant. When the bookcase was present the valuation was nearly double, and the piece was called either a scrutoir, or a desk and bookcase, or, more rarely, a bureau and bookcase.

It seems, therefore, exceedingly probable that the use of the words scrutoir and desk, or bureau and scrutoir, in the same inventory, was because one of the pieces referred to had an upper part or bookcase upon it, while the other had not.

There is still another way in which such instances as we have cited may be explained. Some of these early bureaus were "bureau tables," that is, chests of drawers with flat tops, instead of being finished above, like the scrutoir, with a desk, flap, and pigeonholes. A few facts relating to these pieces are here presented.

"Buerow Tables" are mentioned in an advertisement in "The Daily Post," of London, January 4, 1727. This is the earliest notice of them that we have seen. The following are examples from the inventories: -

"In the Easterly Chamber, I Buro Table, $£$ I I." Inventory of Pyam Blowers, merchant, Boston, $x 739$. 
"In the Front Chamber, I Buro Table with Drawers, $£_{15}$." - Inventory of John Phillips, merchant, Boston, 1747 .

"In the Back Chamber, I Buroe Table, £3.6. 8."

"In the Back Room, I desk black walnut Buroe, £2. I3. 4." - Inventory of Thomas Palmer, 'Esq., Boston, I 752 .

"In the front Chamber, A Buro Chamber Table, £2." - Inventory of William Clark, physician, Boston, I760.

"A mohogany Chest of Drawers \& Beaurow Table, EI 3. 6. 8." - Inventory of Daniel Malcom, merchant, Boston, I 769 .

What was the use of these bureau tables? Were they writing or dressing-tables?

We are informed by Bailey that in 1736 a bureau was "a cabinet or chest of drawers or scrutoir for depositing papers of accounts." We also know that the word bureau was used in England and in her colonies in the eighteenth century to designate a chest of drawers for clothes; but how early it was employed in this sense it is very difficult, if not impossible, to tell from the dictionaries.

That the bureau tables now under consideration were of the latter kind is probable from the following facts :-

That whenever the apartments in which they were found have been mentioned in such inventories as 


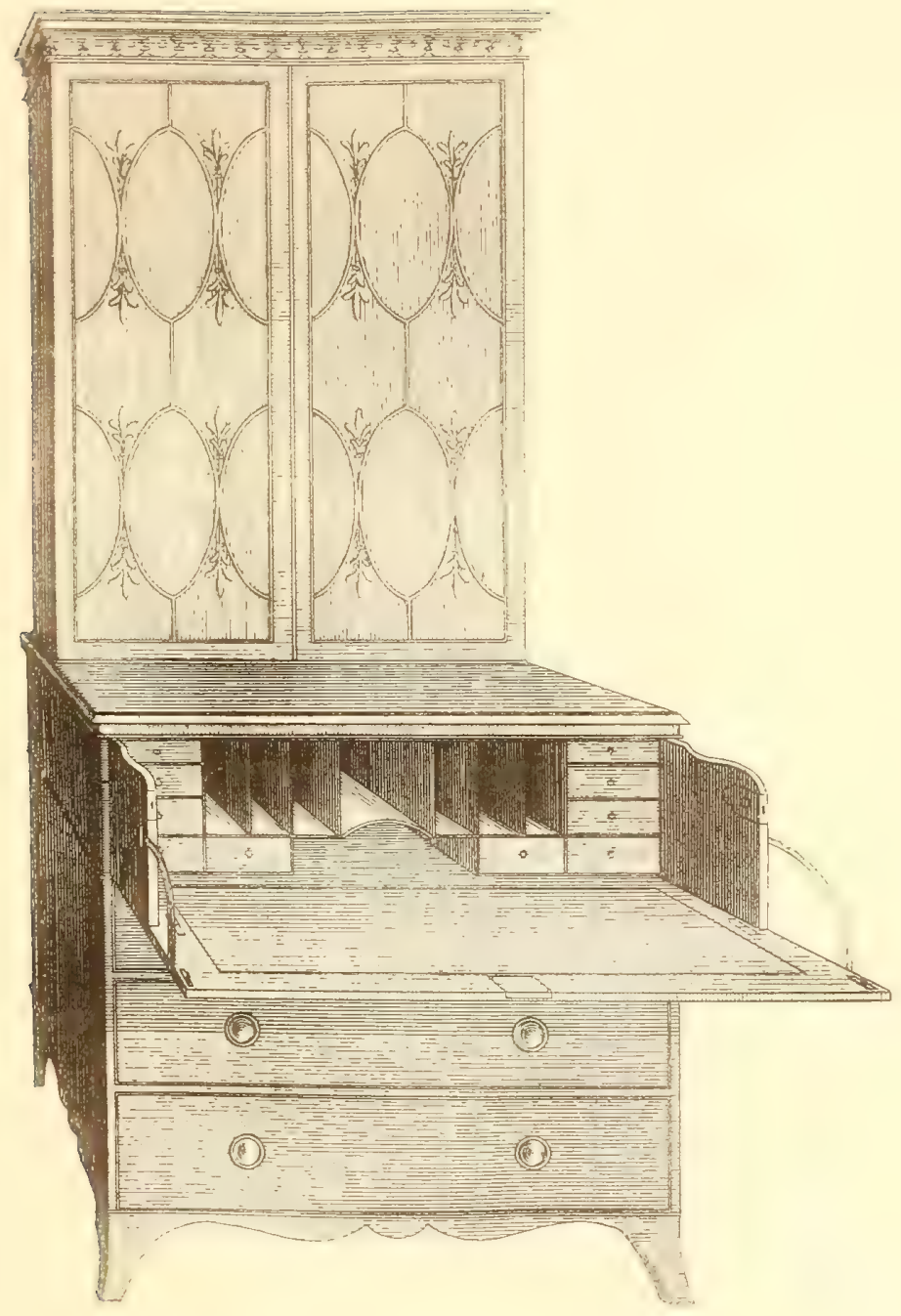



we have examined, they have invariably proved to be bedchambers.

That in some of these instances the bedroom contained no other piece that could have been used as a bureau or dressing-table. This is found to have been the case in the houses of Pyam Blowers, John Phillips, and Thomas Palmer.

That though Chippendale's designs for "Commode Bureau Tables," and "Bureau Dressing Tables" are dated I760, yet his "French Commode Tables," published in I753, were chests of drawers such as in later years were defined as bureaus.

That the "Buro Chamber Table" in the inventory of William Clark and the "Beaurow Table" in that of Daniel Malcom were indisputably bureaus in the modern acceptation of the term. From the known character of these two pieces, and from Chippendale's designs for "bureau dressing tables," it is reasonable to infer the character of the bureau tables which we find in our inventories of earlier date.

There were, therefore, bureau tables, as well as bureau desks, and when these different expressions are found in the inventories we know that different objects were meant. When, however, the word bureau alone is found, which is about as frequently as the other expression taken together, the nature of the piece must often remain in doubt. If it were in a room where there was no bed, it was presumably a 
desk; if in a bedchamber, and the only piece that could be so used, it was probably a chest of drawers.

In some of the instances, then, in which the words scrutoir, desk, and bureau are found in the same inventory or advertisement, the bureau may very well have been a chest of drawers for clothes, instead of a desk or scrutoir for writing and for holding papers of accounts. If we may trust to indications derived from the inventories, the word scrutoir had nearly run its course by the year 1770 . It probably fell into complete disuse soon after this date.

The term bureau in the sense of a secretary gradually gave way during the last quarter of the eighteenth century to the word desk. In some places, however, its use was extended well into the present century; and, according to information received from Mr. George R. Curwen and Mr. Henry F. Waters, of Salem, Mass., desks like the ones shown in our illustrations, Figs. 48, 49, and 50, are sometimes called bureau desks in Salem to this day.

The writing desk with a deep flap, vertical when closed, which came in fashion in France about I 750, did not obtain any foothold in New England during the eighteenth century. Examples of this style are occasionally seen here at the present day. Many of these were made in Europe in the present century.

In 1787 Heppelwhite published designs for "Secretaries and Bookcases," one of which is reproduced 


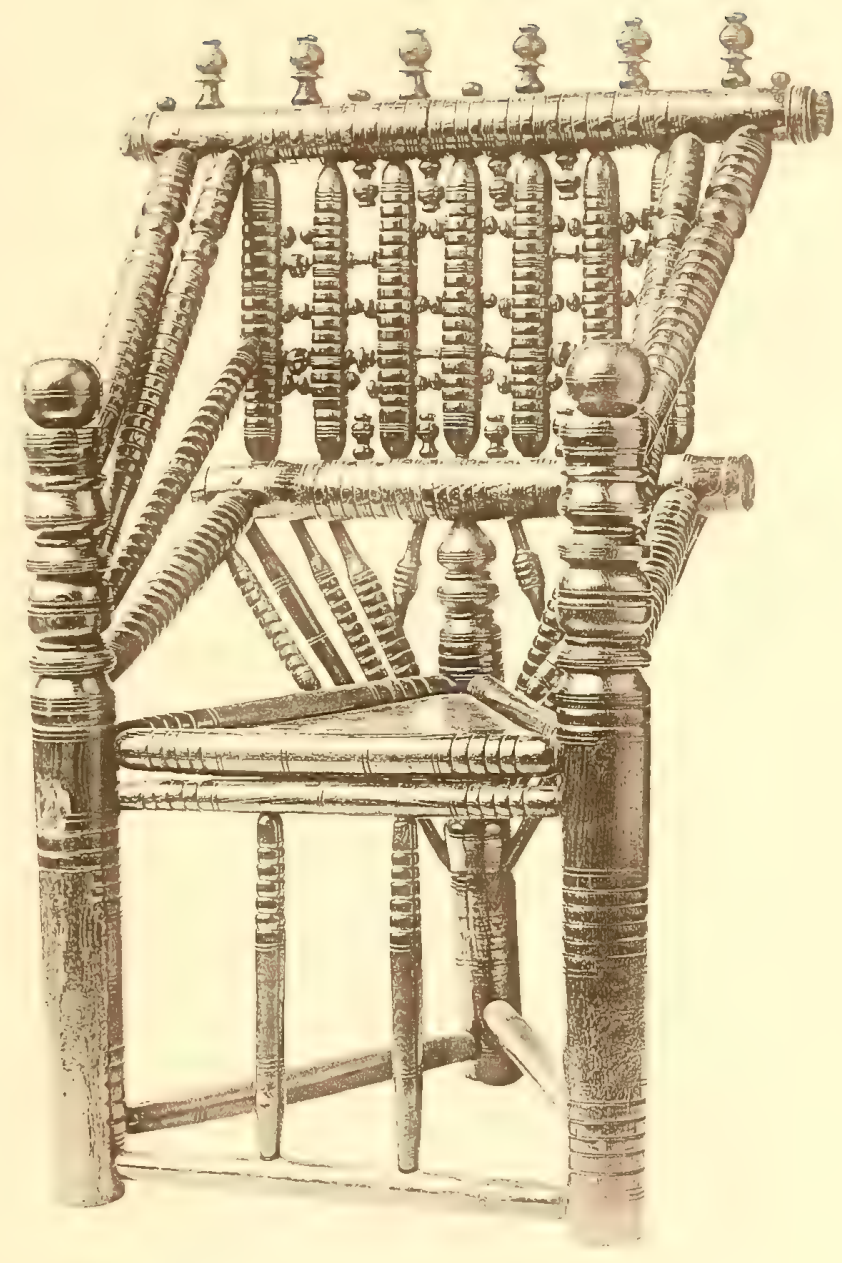

FiG. 53 

in Fig. 52. They differ from the desk and bookcase, he says, "in not being sloped in front. The accommodations therefore for writing are produced by the face of the upper drawer falling down by means of a spring and quadrant, which produces the same usefulness as the flap of a desk." Pieces of this description, belonging to the close of the eighteenth and the beginning of the nineteenth century, are quite common in New England.

The secretaries with sliding covers for the desk, the bureau à cylindre, which sprang up in France about I750, apparently did not reach New England until the close of the century, and then in a form modified by Heppelwhite, and named by him "Tambour writing Tables." The tambour cylinder desks of Heppelwhite have been seen here, but they are certainly very rare.

Standishes are sometimes mentioned in the records, as we have seen, especially in those of the seventeenth century. They were made of wood as well as of metals. "A woodden standish" was ap. prized at ten shillings in the inventory of Robert Keayne, made in Boston in I657. Another "wooden standish" was valued at five shillings in I660 in the estate of Henry Webb, of Boston; and in 1672 "I pewter standish" at $2 \mathrm{s.} 6 \mathrm{~d}$. in that of William Whit. tingham of the same place.

In an advertisement in the "London Gazette," 
November 3O-December 4, I 7 I 4, "one round silver standish with silver boxes for ink and sand" is mentioned; and one that belonged to Dean Swift is thus described in his will made in I740:-

"I bequeath to Deane Swift, esq., my large silver standish, consisting of a large silver plate, an ink-pot, a sand-box and bell of the same metal."

The stand dish was of various shapes and sizes, the essential part being a dish or tray in which were set boxes or stands for ink and sand. There was sometimes a little drawer under the dish. Havard, in his work before cited, has illustrated seven very interesting examples under the word écritoire. 


\section{CHAPTER V.}

CHAIRS.

Chatrs were very scarce in early colonial times. Only fifty-six are mentioned in the first sixty-one inventories of Plymouth, Mass., made from 1633 to 1654 , and but one hundred in the first seventy-nine inventories, from 1639 to 1653 , in Boston. The inventories of the first fifty-six householders of New Haven, Conn., recorded from I647 to 1662 , show one hundred and forty-six chairs, while only one hundred and fifty are found among the chattels of the first seventy-five householders of Hartford, Conn., from I64 I to I659.

In many of these inventories no chairs at all are mentioned, while in others the number much exceeds the average, ranging from six to twenty-four.

This scarcity of chairs was not mainly due to distant migration, pioneer life, and lack of wealth, but rather to the use of stools and forms for seats, a custom which the colonists had brought from the mother country. In England stools and forms were yet in common use, and chairs, which during the sixteenth century had been very scarce, did not become at all abundant till after the Commonwealth. 
There were three very distinct types of chairs in New England in the seventeenth century, namely, the turned, the wainscot, and those with seats and backs covered with leather or with textiles of various sorts.

The chair known at Harvard University as the President's Chair (Fig. 53) is one of the oldest and most noted of the turned chairs to be found in this country. It has been sung by Holmes in his "Parson Turell's Legacy," and pictured in the popular magazines.

The following facts relating to this chair, as well as to other old turned chairs which in England were eagerly hunted down by collectors over a century and a quarter ago, are quoted from pages 3 I 2 and $3^{I} 3$ of Pierce's "History of Harvard University," published in Cambridge, Mass., in 1833 :-

"The Chair was brought to the College during President Holyoke's administration. Dr. Holyoke is pretty certain it came from Mystick. He supposed it was brought from England;never heard of its having been made by a Clergyman here. President Holyoke added the round knobs to the chair, which he turned himself. Dr. H. has been asked about it fifty times.

"A correspondent has put into the Editor's hands the following curious extracts from Horace Walpole's Private Correspondence, giving a description of some antique chairs found in England, exactly of the same construction with the College chair; a circumstance which corroborates the supposition that this also was brought from England. 


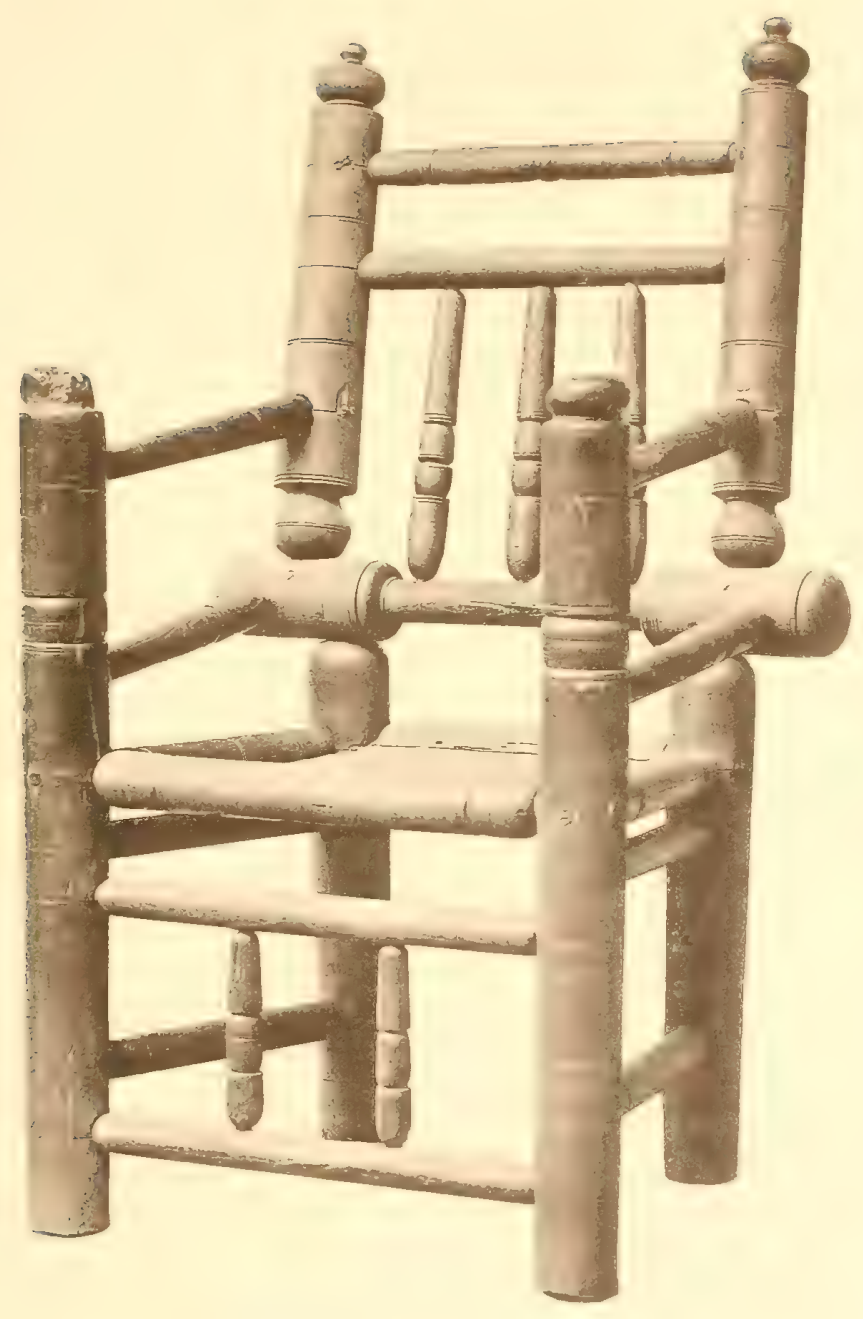

Fis 5 i

TURNED CHAIR

EAG, S TTEEATH CEUT IRY 

"HORACE WALPOLE TO GEORGE MONTAGU, ESQ.

"Strawberry-Hill, Auguest 20, I76r.

"Dickey Bateman has picked up a whole cloister full of old chairs in Herefordshire. He bought them one by one, here and there in farm-houses, for three-and-sixpence, and a crown apiece. They are of wood, the seats triangular, the backs, arms, and legs loaded with turnery. A thousand to one but there are plenty up and down Cheshire too. If Mr. and Mrs. Wetenhall, as they ride or drive out, would now and then pick up such a chair, it would oblige me greatly. Take notice, no two need be of the same pattern. - Private Correspondence of Horace Walpole, Earl of Oxford, vol. ii. p. 279 .

"HORACE WALPOLE TO THE REV. MR. COLE.

"Strawberry-Hill, March 9, I765.

"When you go into Cheshire, and upon your ramble, may I trouble you with a commission? but about which you must promise me not to go a step out of your way. Mr. Bateman has got a cloister at old Windsor furnished with ancient wooden chairs, most of them triangular, but all of various patterns, and carved and turned in the most uncouth and whimsical forms. $\mathrm{He}$ picked them up one by one, for two, three, five, or six shillings apiece from different farm-houses in Herefordshire. I have long envied and coveted them. There may be such in poor cottages in so neighbouring a county as Cheshire. I should not grudge any expense for purchase or carriage; and should be glad even of a couple such for my cloister here. When you are copying inscriptions in a church-yard in any village, think of me, and step into the first cottage you see - but don't take further trouble than that. - Ibid., vol. iii. pp. 23, 24." 
These interesting letters prove that very old chairs with triangular seats, and with backs, arms, and legs loaded with turnery "in the most uncouth and whimsical forms," could be picked up in English farmhouses in the last century at about the same time that the President's chair was brought to Harvard University. They also show that such chairs were sufficiently rare at that time to be coveted by one of the most noted of English collectors.

A chair very similar to the President's chair is preserved in the Ashmolean Museum at Oxford, England, where at present no more is known of it than in 1836 , when it was catalogued as "a chair said to have been part of the furniture of Windsor Castle in the time of Henry VIII." A cut (No. 307) of this chair may be seen in Wright's "Homes of Other Days," London, I87 I. There are eight holes through the top rail of its back for ornamental pegs, like the ones seen in the Harvard chair, but the pegs themselves are missing.

Another example of this style, resembling the Ashmolean chair, was found and purchased in Chester, England, in I886, by Mr. Henry F. Waters, the celebrated genealogist, from whose collection of old and rare furniture in Salem, Mass., we have drawn so freely to illustrate this volume.

A well-known chair belonging to the Connecticut Historical Society, of Hartford, is represented in 


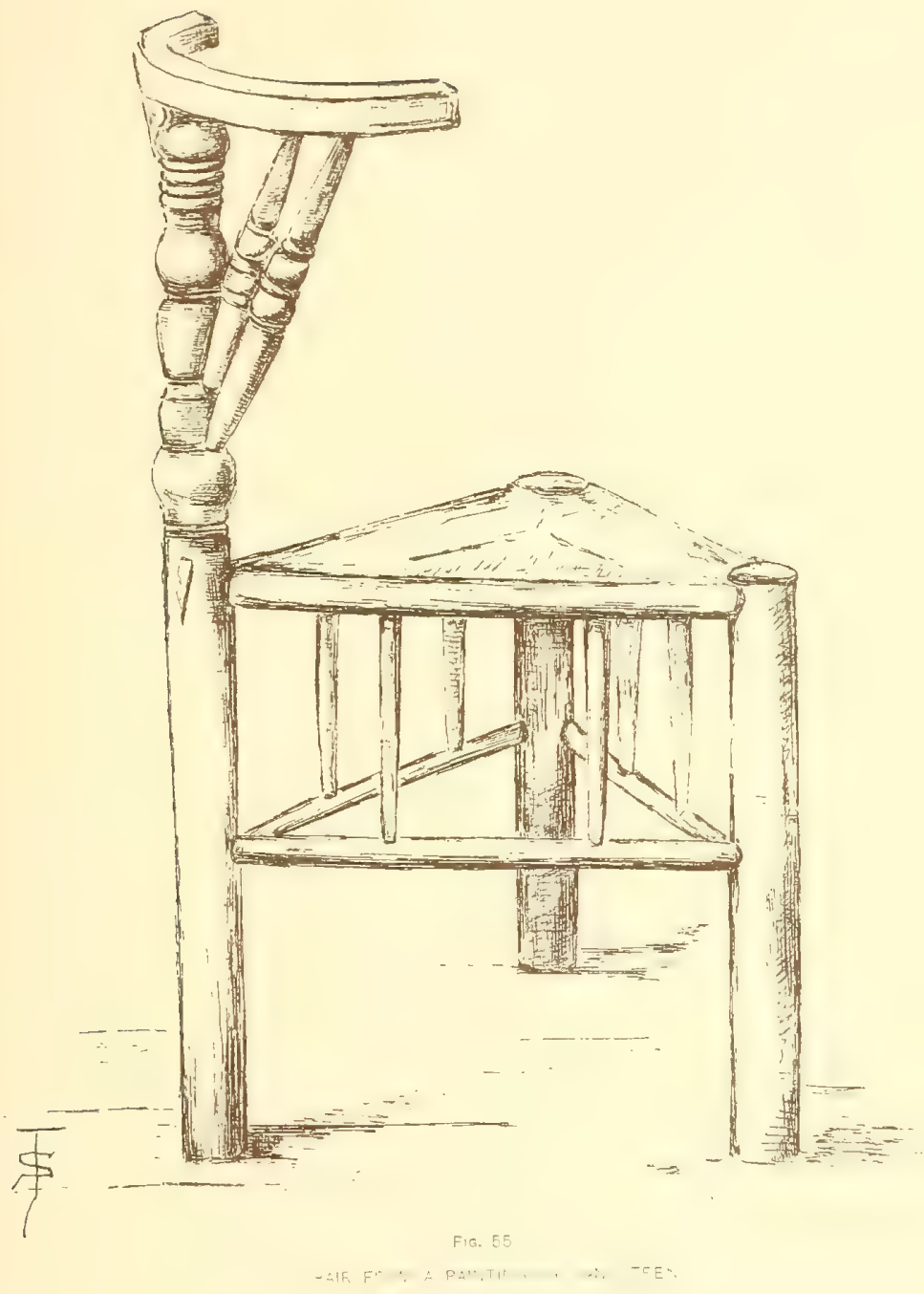



our next illustration (Fig. 54). Cuts of this chair have been published by different writers with histories and dates widely at variance with one another. Its period is probably the same as that of the Harvard chair, which it closely resembles, the departures from that type being chiefly due to its quadrilateral shape. Two of the three vertical pieces in the back of this chair are restorations faithfully copied from the third, which is original.

Turned chairs of triangular shape of the same general style as the Harvard chair, but of much simpler construction, were in use in Germany in the latter part of the fifteenth century, and in Holland and Flanders down to the middle of the seventeenth century. This, for the early period, is attested by Israel Von Mecheln's engraving of "The Virgin ascending the Steps of the Temple;" and for the later, by such pictures as "Le Parabole de l'Enfant Prodigue," by Sebastiaan Francken, the "Tableau de Famille," by Jan Steen, both in the Musée Van Der Hoop, in Amsterdam; by the "Portrait d'tn Peintre," by Zacht Leven, dated I629, in the Louvre, and by "The Lord's Supper," by James Jordaens the elder, in the Antwerp Museum. In each of these pictures there is a chair like the one shown in Fig. 55, which has been drawn for us from the painting by Jan Steen above mentioned. These simple threecornered chairs were developed from the three-legged 
stools of precisely the same pattern that are found in the paintings and. illuminated manuscripts of the fifteenth century.

It is, however, somewhat unlikely that chairs of the Harvard type were made as early as the Von Mecheln example, on the general principle that time is required for so much development and elaboration. It is more probable that they began to be made in the first half of the sixteenth century, and we know that some specimens remained in use well into the seventeenth century.

Turned armchairs of the style represented in Fig. 56 appear to have been much used in New England during the first seventy-five years of its colonial life. They are already familiar to many through the socalled Carver and Brewster chairs kept in Pilgrim Hall at Plymouth, Mass., cuts of which have been published from time to time; and the chair of the apostle John Eliot, in the First Church at Dorchester, Mass., which is pictured in the first volume of Winsor's "Memorial History of Boston." Besides the four now referred to the writer has seen nine other examples, has knowledge of eight more, making twenty. one, and believes that many more will yet be brought to light.

In the inventories they are included in such entries as "turned chairs," "great chairs" (chairs with arms), and "flag bottomed chairs." They cannot, 


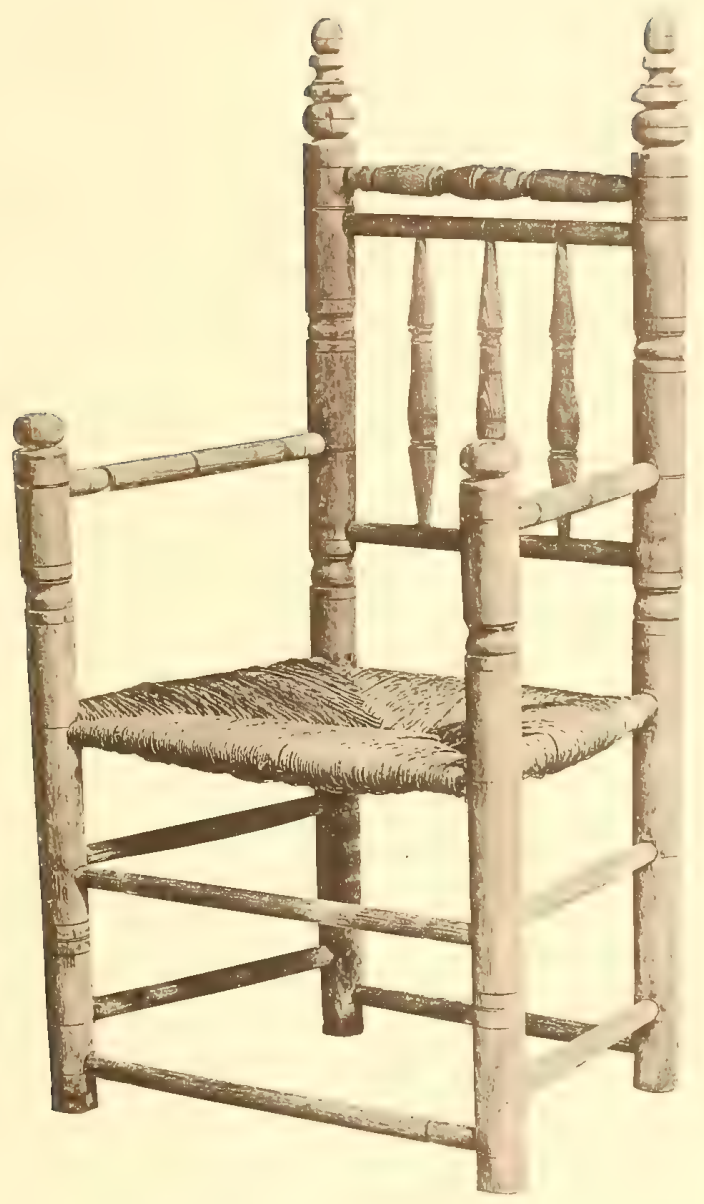

Fin.. 5 3

TURNED CHAIR

Firat half SEVENTEENTH CENTURY 

therefore, be accurately traced and identified in these records because there were other turned, great, and flag-bottomed chairs in use at the same time. The posts, which are very large in the older specimens, are almost invariably made of ash, the arms and stretchers usually of hickory, while the light turned work in their backs is often made up of two or three different woods, as hickory, ash, and birch. Only a momentary comparison is needed to show that these chairs are the lineal descendants of the type shown in Fig. 54. It is generally supposed that they date from about the beginning of the seventeenth century. The specimen here illustrated belongs to the writer. It was lately picked up in Hartford, Conn. The seat is new, but the frame is the original in every particular.

Another type of turned chair much in vogue in the seventeenth century was that with horizontal slats in the back. A very old example of this style is shown in our next illustration, Fig. 57. It was bought in Killingly, Conn., in 1889, and is now in the Hosmer collection. The feet, which had been cut off, have been restored and a new seat put in, so that the chair is presented as nearly as possible in its original state. It will be noticed that the only essential difference between this chair and the one preceding it is in the substitution of the horizontal slats for the turned work in the back.

A second specimen of this type, rather quaint and 
unique from the shape and inclination of its arms, is shown in Fig. 58. It was bought in Lebanon, Conn., in 1878 , from a family in which it had been for sev. eral generations, and now belongs to the writer.

Chairs with these backs seem to have been in use in Germany and the Netherlands in very early times. In the picture of "St. John the Evangelist, and His Disciples," painted in the latter part of the fifteenth century, and attributed to Israel Von Mecheln, there occurs a chair, apparently triangular in shape, with a transverse slat running between two of its turned posts. Also in the "Two Episodes in the Life of St. Benedict," by John Mostaert (I 474-I555), in the Musée de Peinture, in Brussels, there is seen a clumsy chair with heavy hewn posts with such slats in its back. Turned chairs, with and without arms, with transverse pieces in their backs, very similar to the two here illustrated, are frequently found in the paintings of the Dutch and Flemish masters of the seventeenth century. Chairs of this style, without arms, and usually with two slats in the back, were in common use in New England all through the seventeenth and well into the eighteenth century. They were made much smaller, and lower in the back than those with arms, which, as we have said, were called great chairs.

Chairs with flag bottoms are often mentioned in the inventories of the seventeenth century, but doubt. 
less many of these seats were made from the inner fibrous bark of various trees. The bark of the bass or linden tree was much used for this purpose. " 4 basse chaires" are mentioned in John Cotton's inventory, made in Boston in 1652-53. After the beginning of the eighteenth century "bass bottomed" chairs are frequently met with in lists of household furniture. Many of the turned chairs above described have, when found, remnants of old seats in them which at first sight appear to be made of flags or rushes, but when the strands are untwisted and examined their material is discovered to be the inner bark of some kind of tree. Besides the linden, it is known that the bark of the elm tree was also used for bottoming chairs.

The wainscot chairs which figure in the early records were doubtless those made up - backs, seats, and all - of wood, the wood being almost invariably oak. The back is the part on which the most ornamentation was bestowed. It was usually paneled, and sometimes carved and dated. But few are mentioned in the inventories, and specimens have become very scarce. One said to have belonged to Edward Winslow, who came in the Mayflower, is now in Pilgrim Hall at Plymouth, another, the Rector Pierson chair, is kept in the library of Yale University; a very good specimen belongs to the Waters collection in Salem, but the best that we have seen in this 
country is the one preserved in the Essex Institute at Salem, and shown in our next illustration, Fig. 59. A cut of this same chair is given in Bryant and Gay's "History of the United States," and also in Cook's "House Beautiful." It was given to the Historical Society (now merged in the Essex Institute) of Salem, Mass., June 27, I82 I, by Robert Brookhouse, of Salem. He had obtained it through his first wife, Martha Farley, whose parents, Major John Farley and Sarah Dennis, natives of Ipswich, Mass., removed to Newcastle, $\mathrm{Me}_{\text {., }}$ in $\mathrm{I}_{772}$ or $\mathrm{I} 773$. This chair and another, said to be a complete counterpart to it, a carved chest dated I634, and a tape loom, all belonging to Sarah Dennis, were then taken from Ipswich to Newcastle. There is traditional evidence that the age of the chairs and the tape loom corresponds to that of the chest, and that these articles were brought over from England by the first emigrant of the Dennis family. The other chair was owned in 1872 by E. W. Farley, of Newcastle, Me., but he has since given it to Bowdoin College, where it is now used as the President's chair.

Wainscot chairs were quite common in England and Scotland in the seventeenth century, and may now be seen in many of the old manor houses. There are two in the great hall at Hardwick, dated respectively $\mathrm{I} 662$ and $\mathrm{I} 688$, and one recently brought from Scotland to Hartford, Conn., bears the date I648, carved in relief on its back. 


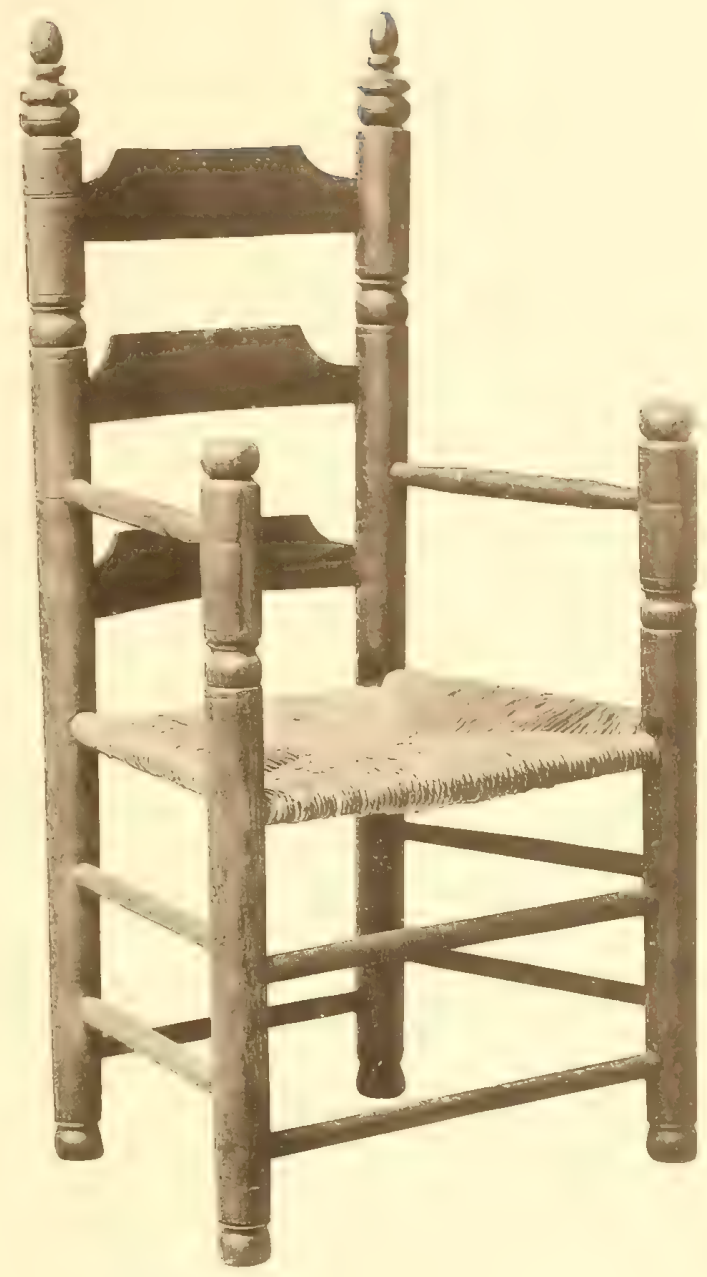

Fic. 57

TURNED CHAIR

EARLY SEVENTEENTH CENTURY 

In some of these chairs the space below the seat is inclosed by means of panels let into the framework, and panels also fill the spaces between the seat and the arms on each side. An example of this kind, dated $165^{2}$, is now preserved in the Old South Church of Boston.

Leather chairs, that is, chairs with leather seats and backs, were comparatively common in New England in the seventeenth century. They often occurred in sets, and usually belonged to people of wealth or of high social standing. Some interesting facts relating to them are shown in the following items:-

"In the Hall, Three leather chaires and 3 smaller leather chaires, $£$ I. IO." - Inventory of John Atwood, Plymouth, I643.

"In the Hall, 3 red Leather chaires, I 3 s. 4."-Inventory of William Clark, Salem, I647.

"In $\mathrm{y}^{\mathrm{e}}$ great Parlour, 7 leather Chaires, $£ 3.0$. o." - Inventory of John Cotton, Boston, 1652-53.

" 4 lether chaires, $\mathscr{L}$ I. I 2."

"I great lether chaire, Io s." - Inventory of William Bradford, Plymouth, 1657.

"I I Rusha Lether chaires in the hale at II s., £6. I s."

" 5 Rusha lether chaires, $£ 3.5$ s." - Inventory of William Paddy, merchant, Boston, I658.

"In $y^{\mathrm{e}}$ Halle, I 2 Red Lethered chares at $£ 5$." Inventory of Jacob Sheaffe, Boston, I659. 
Some of these chairs were doubtless made in England, and some in this country, but in both cases in accordance with the fashion then prevailing in Western Europe. One finds from the chairs in the paintings of the old masters, as well as from the numerous specimens preserved in European museums, that the leather chairs of the period now under consideration were almost invariably made with rather low rectangular backs. Rubens's chair, which is shown in Fig. 60 as a very good example, is about nineteen and a half inches high from the seat to the top of the back between the posts. The seat is twenty and five eighths inches high, seventeen and a half inches wide, and fourteen and three quarters inches deep. This chair is kept in the Royal Museum in Antwerp. It has its original leather seat and back, and on the latter is the name Pet. Paul Rubens, and the date I633.

In Fig. $6 \mathrm{I}$ is shown an old chair with its seat and back of stamped leather in a very fair state of preservation. The leather in both places was drawn over the wooden frame, without padding underneath, and fastened with large and small copper nails which are still in place. Indeed, the only noteworthy loss that this valuable specimen has sustained is in its feet, which, from wear, decay, and mutilation, have been shortened from two to three inches. This chair belongs to Trinity College, at Hartford, Conn., and 


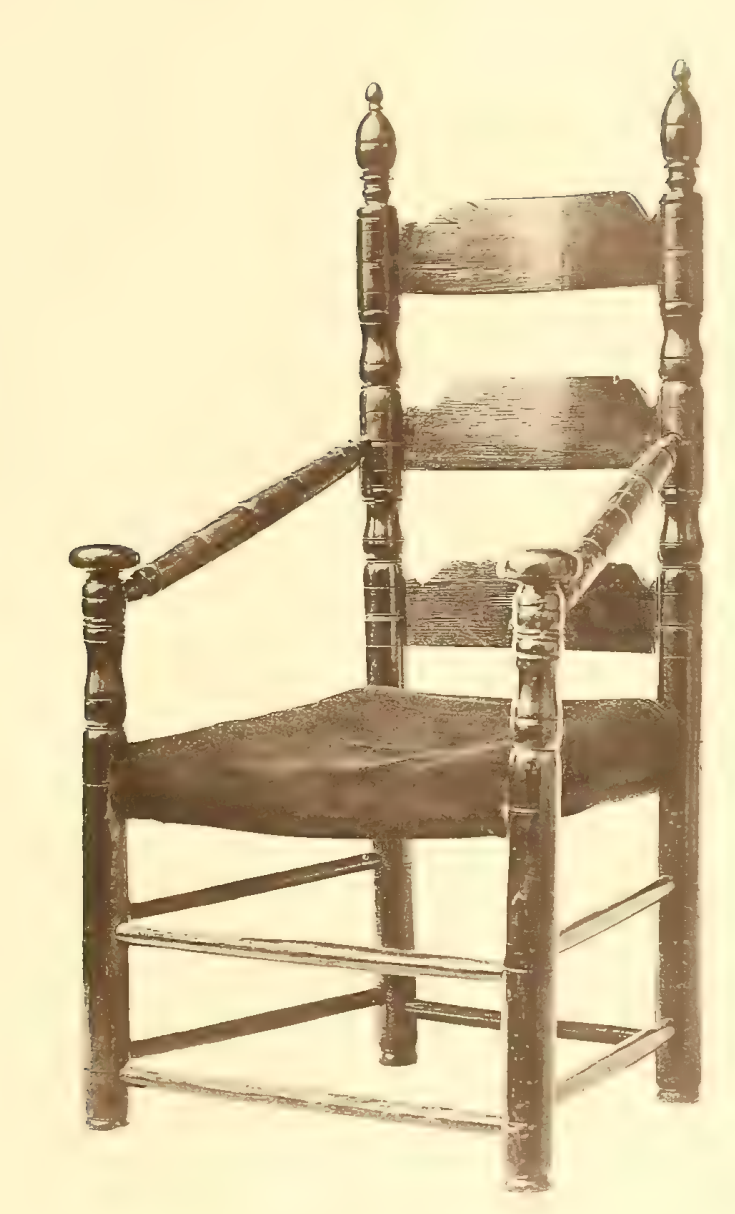



is kept in the library. It was presented to the college about forty years ago by the late Thomas Winthrop Coit, to whom it had descended from Governor Joseph Wanton, of Rhode Island, one of his ancestors.

Another very good chair of this period is represented in Fig. 62. It was picked up a few years since in Essex County, Mass., and is now in the Waters collection. It has a stuffed seat and back, but the original leather covering was too much damaged by time to admit of repair. The new covering is put on in the same way as the old. The feet, which were probably turned, are missing, but the remainder of the frame is in an excellent state of preservation. The seat is now eighteen inches high to the top of its frame, and, with the feet, was fully two and a half inches higher. The hight of the back, measuring from the frame of the seat, is seventeen and five eighths inches, and from the top of the stuffed seat, sixteen and a half inches. The seat is large, its frame having a front of nineteen and three eighths inches, and a depth of sixteen and three eighths inches.

Leather chairs with low backs are occasionally mentioned in the New England records down to the middle of the eighteenth century, if not later. There is, however, much uncertainty as to whether these chairs had leather backs or not, for we know that 
chairs with leather on the seats only were frequently put down in the inventories of the eighteenth century as "leather chairs." If they had leather backs and seats they were probably old chairs that had been made in the preceding century, and though out of fashion, were kept in use because they were considered too good to throw aside.

Besides leather, the stuffed chairs of the seventeenth century were also covered with fabrics of different kinds. Some idea of the richness of these stuffs and of the variety of their colors may be obtained from the following extracts:-

"In the parlour, 2 velvett Chaires \& 2 velvett Stooles, £3. 6."

" 3 turky wrought chaires, 24 s."

"I blue chaire, $6 \mathrm{s."} \mathrm{-} \mathrm{Inventory} \mathrm{of} \mathrm{Governor} \mathrm{John}$ Haynes, Hartford, I653.

" 2 turki worked chaires, $£$ I. I 2."

" 2 turkie bottoms and backs for chayres, $£$ I. 2."

" 4 wrowght covers for stooles Irish stitch, I5s." - Inventory of William Paddy, merchant, Boston, I658.

" 6 branch silke stoole covrs \& 3 such for chayres, £. о. о."

" 2 purple brancht silke covers for stooles \& 2 such for great chayres, I4 s." - Inventory of Henry Dunster, I659. Records Middlesex County, Mass.

"In the hall chamber, 4 red stooles 2 red cloath 


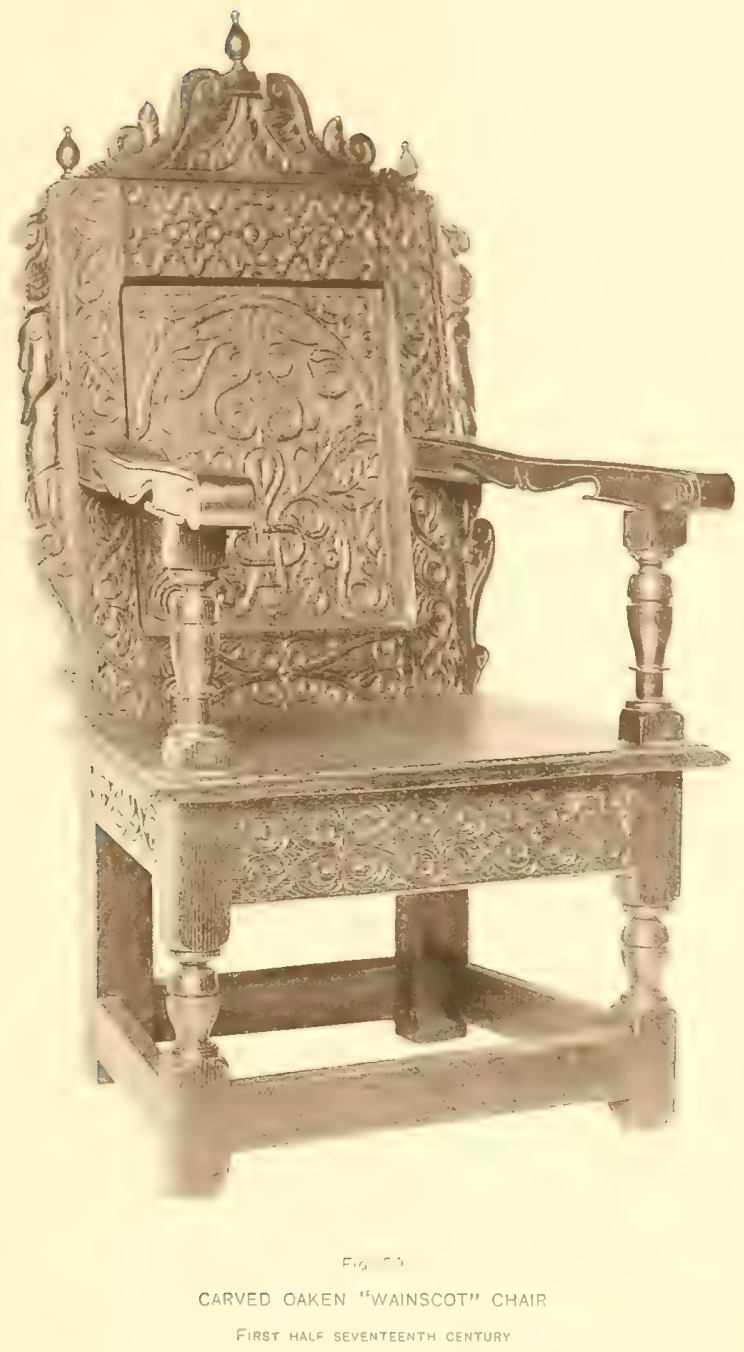


chaires with fringe." - Inventory of William Paine, Boston, merchant, 1660. Inventory in Essex County Records, Salem, Mass.

"In ye Hall Chamber, 7 Greene chaires \& stooles, 4 with fringes \& three $w^{\text {th }}$ gallowne, $£ 3$. Io." - Inventory of Henry Webb, merchant, Boston, I660.

"In the chamber, 6 Turkie worke chayres, $£ 3$ " Inventory of Benjamin Richards, merchant, Boston, I667.

"I4 Turkie workt chaires, $£ 5$. Iо." - Inventory of John Freake, merchant, Boston, I675.

" 7 couers for chairs \& one cuberd cushin, all of neadle work, £2. I5." - Inventory of Joseph Farnum, shopp keeper, Boston, I678.

"In the Hall, one dozen of Turkey work Chayrs, £5." - Inventory of Rev. Thomas Shepard, Charlestowne, 1678 .

Two Turkey work chairs, with their original covers, are represented in Figs. $6_{3}$ and 64 . The first is said to have belonged to Roger Williams, who died in 1683 . It is now owned by one of his descendants, Mr. Henry M. Schmuck, of West Springfield, Mass. The seat is high, as was often the case in these old chairs. It is twenty and one half inches to the top of the front rail, and the upholstering raises it fully two inches higher. The back is low, its top being only sixteen and three quarters inches above the frame of the seat, and thirty-seven and one 
quarter inches from the floor. The seat measures nineteen and three quarters inches from side to side, and seventeen inches from front to back.

The second chair, now belonging to the writer, was lately found in a very rickety condition in an old house in the town of Harwinton, Conn. No history of it could be obtained. Its dimensions, which vary somewhat from those of the preceding, are as follows: Frame of seat, nineteen and seven eighths by sixteen and five eighths inches. Hight of seat to top of frame, seventeen inches; to top of the stuffing, nineteen and one half inches. Hight of the back from the frame of the seat, twenty-four inches; from the floor, forty-one inches.

Both of these chairs are made of maple, and both are stuffed with salt marsh grass, a material often found in the seats of old chairs. The four Turkey rugs with which these chairs are covered, two backs and two seats, are each made in separate pieces with closed or selvedged borders on all sides. This fact, with the two "turkie bottoms and backs for chayres," mentioned in the inventory of William Paddy, would seem to show that patterns for the seats and backs of chairs were regularly made in the Orient for the European market in the seventeenth century.

The Irish stitch found in the inventory of William Paddy was one of the embroidery stitches then in vogue. "The Needle's Excellency," by John Taylor, 
London, I640, contains a poem entitled the "Praise of the Needle," in which the Irish stitch, Spanish stitch, Fine Ferne stitch, Brave bred stitch, Queen stitch, Rosemary stitch, and many others, are mentioned as the favorite stitches of the day.

By the close of the seventeenth century chairs had become quite abundant in New England. In Boston, the average number for thirty-nine consecutive inventories in which the number of chairs is mentioned, from 1698 to 1 yor, is about nineteen. The lowest number is four, the highest seventy-two; two estates show forty each, one forty-two, and another fifty-one. The leather, Turkey wrought, and flag-bottomed chairs still appear in the inventories, but begin to be made with higher backs in accordance with the fashion then prevailing in Europe.

In Boston cane chairs in sets of from six to twelve began to appear in lists of household furniture as early as I689. They became very fashionable and with cane couches en suite continued in favor till about the middle of the eighteenth century. The finest examples were richly turned and carved, and had tall and stately backs. Some interesting facts relating to these chairs are here given from their original sources: -

"Six Cane Chairs, $\mathscr{L}^{2}$. 8." - Inventory of Giles Masters, Boston, r688-89.

"Six Kane back chares \& six bas chares, £3. Iо." - Inventory of John Ragland, Boston, I6gI. 
"In the Lower Roome, To 6 Cane chears, $£ 5.2 . "$ - Inventory of Thomas Pemberton, Boston, I693.

"I 3 Caine Chaires, $£ 6 . "$ - Inventory of Daniel Royse, merchant, Boston, I693.

"In the Hall, One doz: of cane chairs, $\mathscr{L}^{\mathrm{I}} \mathrm{2}$." Inventory of Capt. John Ware, mariner, Boston, 1694-95.

"In the Chamber over the great Hall, One doz: of Lackerd Kane Chaires, $\mathcal{E}$ I2." - Inventory of Captain Andrew Craty, Marblehead, I695.

"In the Hall, I 2 cane chaires and I couch, $£ 7 . "$

"In the Hall Chamber, I looking glass and twelve Cane Chairs and Squabb, £I 8." - Inventory of Sir William Phips, Boston, I696.

"In the Parlour, A Cane Couch and Squab, $£ 3 . "$

- Inventory of Peter Butler, mariner, Boston, I699.

" 7 cane chairs I couch \& squab." - Inventory of Sarah Harris, widow, Boston, I 702.

"In $y^{\mathrm{e}}$ Dining-Room \& Chamber, I doz Cane Chairs Black frames, at $16 /$ \&9. I 2."

" I Couch Ditto, $£ 2$."

"6 Cane Chairs $w^{\text {th }}$ Carved frames oak, $\mathcal{L}_{4}$. 4." Inventory of Joseph Pulsifer, mariner, Boston, I 7 I 2.

"6 Leather Chairs with Cain backs, $\mathscr{E} 3 . "$ - Inventory of George Worthylake, mariner, Boston, I 7 I 8 .

" 3 Cain back Chairs w bass bottoms, 9 s." - Inventory of Thomas Gilbert, innholder, Boston, I7!8I9. 


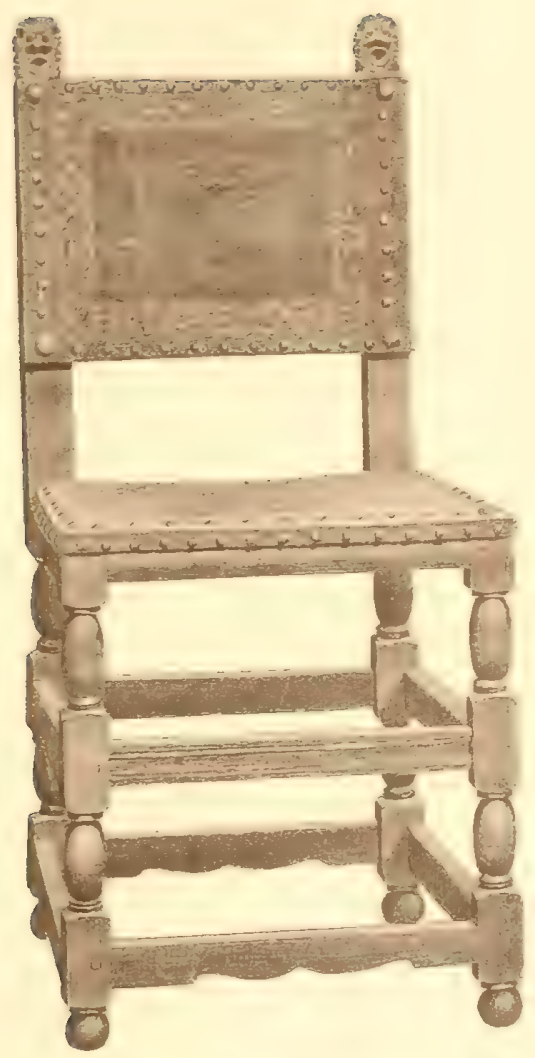

RUBENS'S CHAIR

DATEO 1633 

Very fine examples of the cane chairs in use in New England at the close of the seventeenth century and in the beginning of the eighteenth are shown in our next four illustrations.

The first (Fig. 65) belongs to Mrs. Thomas G. Talcott, of Hartford, having descended to her late husband from one of his Wyllys ancestors. Several other chairs of the same set are preserved in the hall of the Connecticut Historical Society of Hartford. The second (Fig. 66), which serves as the frontispiece to this book, is owned by W. A. M. Wainwright, M. D., of Hartford, Conn. It belonged to his father, Bishop Jonathan Mayhew Wainwright, to whom it had come from the Mayhew family in Martha's Vineyard. Its original seat was of cane. The third and fourth (Figs. 67 and 68) are in the Hosmer collection. According to their history they were part of the household furniture of Richard Lord, of Hartford, Conn., who died in the year I 72.

Cane chairs are mentioned in the inventory of Christopher Taylor, of Philadelphia, April 4, I686. The item is, " 5 Caine Chaires at 9 s., $£ 2.5$."

It is difficult to determine when cane began to be used for the seats and backs of chairs in Europe. In the opinion of Mr. George T. Robinson it was introduced into England with the Indo-Portuguese furniture, which came from Portugal with Catharine of Braganza, the wife of Charles II. Mr. Robinson 
says that "Charles made presents of the richly carved ebony chairs and divans or couches which the new fashion brought in to many of his friends and adherents," and cites as an example the chair now in the Ashmolean Museum at Oxford, said to have been given by the king to John Evelyn, it originally having had a cane seat.

The earliest record of cane chairs in England that we have found is contained in the following items from the inventory of Elizabeth Throckmorton, of the Parish of St. Margaret, Westminster, dated December 8, I679:-

"Dining room, 2 cane chairs, 5 s."

"My lady's chamber, 2 cane bottom chairs, 5 s."

In the "London Gazette," April I6-I9, I694, "John Horne, living at the Cane Chair in DruryLane," advertises for a stolen horse.

In the inventory of John Hodson, gentleman, recorded in New Haven in I7II, "Six high backed Leather Chaires at I5/" each are mentioned. Just the type of these chairs it would now be very hard to tell, but it is not at all improbable that they were similar to the chair represented in Fig. 69. This chair was lately bought in Windsor, Conn., from a family in which it had been owned through several generations. The feet were missing and have been restored. The leather seat and back are also new. The top of its back between the posts is twenty-four 

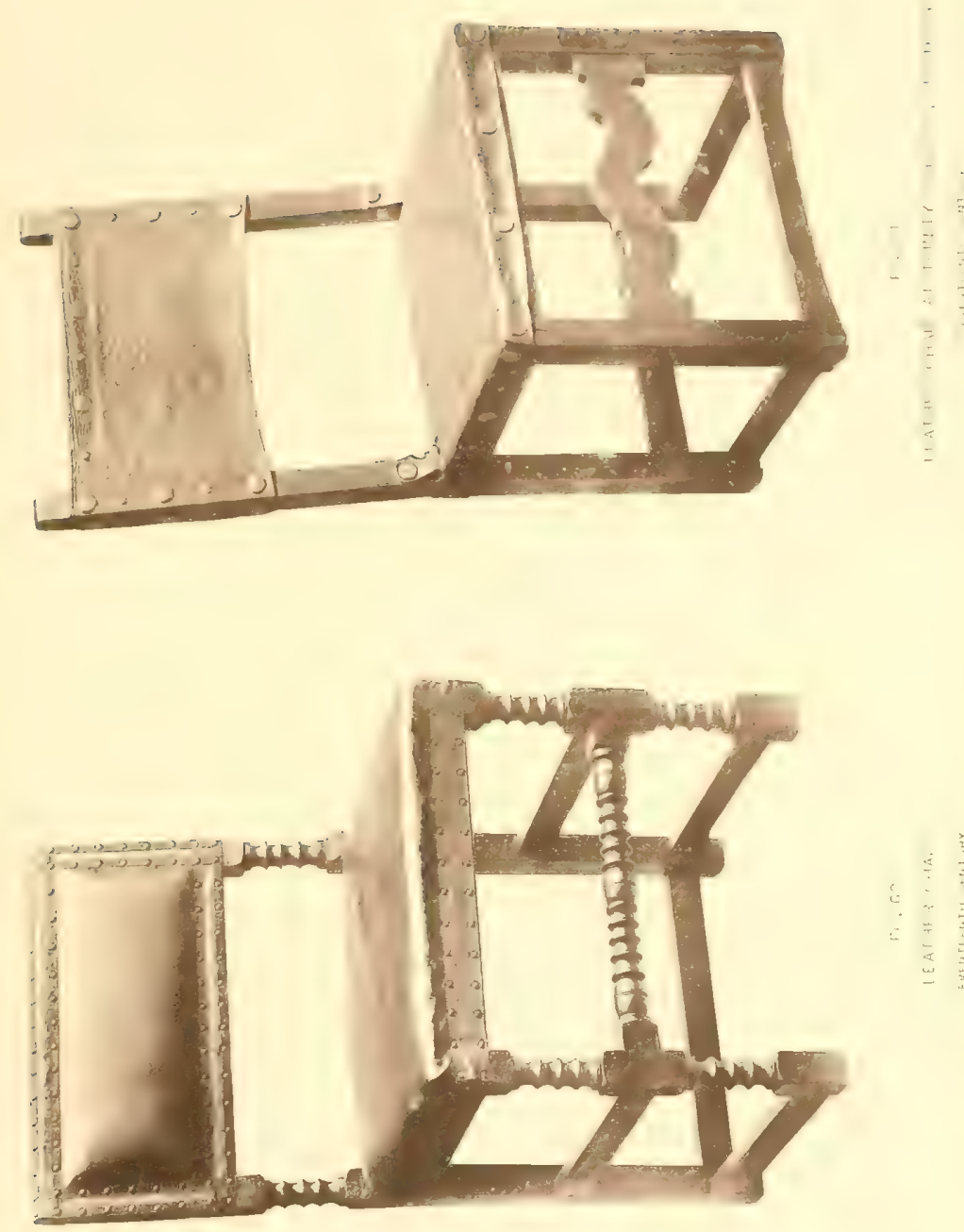

and one half inches from the frame of the seat, and forty-three and one quarter inches from the floor. It is now the property of Mr. Edwin Simons, of Hartford, Conn.

It is held in England by some of the best students of old furniture that high-backed leather chairs, like this, date back to the time of Cromwell. In his admirable papers in "The Art Journal," already cited, Mr. Robinson, in writing of furniture at the beginning of the reign of Charles II, says :-

"The low-relief carving, partly perforated, which had always played so large a part in Eastern Art, was also seized upon with avidity; and though the low-backed divans and the chairs made to agree with them did not quite accord with the ideas then prevailing in England, yet a similar character of decoration was immediately applied to them. It is indeed curious to note that although both in France and Holland, whence most of our fashions in furniture were derived, the height of the chair back was gradually being reduced, yet in England the mediæval feeling in favour of the high-backed chair seemed to be too strong to be influenced even by fashion. The visible proportions of the old friend of the fireside were retained, and only in its mass of construction and its ornamentation did it undergo a radical change."

There are those, on the other hand, who do not fully agree to this early date for these chairs, but who are inclined to the opinion that they made their appearance toward the close of the century, when it became the fashion to make chairs of many kinds higher in the back than formerly. 
In favor of an early date for high-backed chairs are the following facts:-

That while the most of the chairs in Abraham Bosse's plates are low in the back, there are a few in a plate dated 1633, whose backs are as high as the shoulders of the men seated in them. This, by careful measurement and calculation, is found to be about twenty-four inches.

That some of the early wainscot chairs had high backs. This is the case with the "scrowled" chair illustrated by Mr. Robinson, in "The Art Journal," August, I881, and also with the chair dated 1652 , in the Old South Church, in Boston, to which we have already referred. The back of this chair rises thirtyone and one half inches above its seat, and forty-six and one eighth inches above the floor.

That "high chairs" are sometimes mentioned in the inventories of the seventeenth century in this country and in England. Thus, among others, may be cited the " 12 Leather chaires 6 Low \& 6 high," found in the inventory of Henry Webb, made in Boston in 1660 , and the " 2 high leder chayers" in the inventory of John Brackett of the same place, made in 1666-67.

In England, in the inventory of Thomas Child, gentleman, of Abbot's Langley, County of Herts, made February 4, I642-43, we find the items, "I I high chairs Turky work," " 2 low chairs," " 4 high 
chairs, 2 low chairs;" and in the inventory of Timothy Cotes, of the Parish of St. Margaret, Westminster, made October 29, 1667 , we find in the "Low Room, 4 high chairs, 3 low chairs," and in the "High Chamber, 7 high chairs, 2 low chairs."

That in the inventory of Captain William Tyng, of Boston, merchant, made in 1653 , high-backed chairs are mentioned. The record is as follows: "In the Hall of the dwelling house at Boston, I great greine chaire \& 6 high backe chaires \& 2 loe backe stooles all greine and 2 turky worke high backe chaires \& I old greine elboe chaire all cased, $£ 6.0$. o." This is the only mention of high-backed chairs that we have noted in the inventories prior to the year I 709; after this date they are frequently found in the New England records.

The high chairs mentioned in the third proposition were not necessarily high-backed chairs. "High stools" are frequently met with in the inventories of the same period, and sometimes in the same inventory with high chairs, making the inference perfectly natural and legitimate that the expression high applied to these chairs referred to the elevation of their seats rather than to that of their backs.

The chairs cited from the inventory of William Tyng had, in all probability, stuffed seats and backs, as eight were green, two were of Turkey work, and all were cased. But as the words high and low are 
relative terms there is no certainty that the backs of the eight "high backe chaires" were very high, or, indeed, that they were much higher than those of the " 2 loe backe stooles." The backs of the two Turkey work chairs illustrated in this chapter are sixteen and three quarters and twenty-four inches high respectively. If these two chairs had belonged to William Tyng's estate the difference between them might have been very well expressed by inventorying the first as a low-backed, and the other as a high. backed chair.

Allowing for these possibilities we have remaining the facts that wainscot chairs at the middle of the seventeenth century were made with backs thirty-one and a half inches high, and that Abraham Bosse's chairs in 1633 had backs about two feet high, the same as the Turkey work chair shown in Fig. 64, made probably somewhere between 1650 and I680. There appear, therefore, to be no historical objections to the belief that leather chairs as high in the back as the one shown in Fig. 69 were made in England in the time of Cromwell, or even earlier in the century.

But we are here confronted with another difficulty. The division of the back of this chair into a middle portion, with spaces on each side, is a style which is supposed to belong later in the century, and is often seen in cane chairs. Backs of this description are 

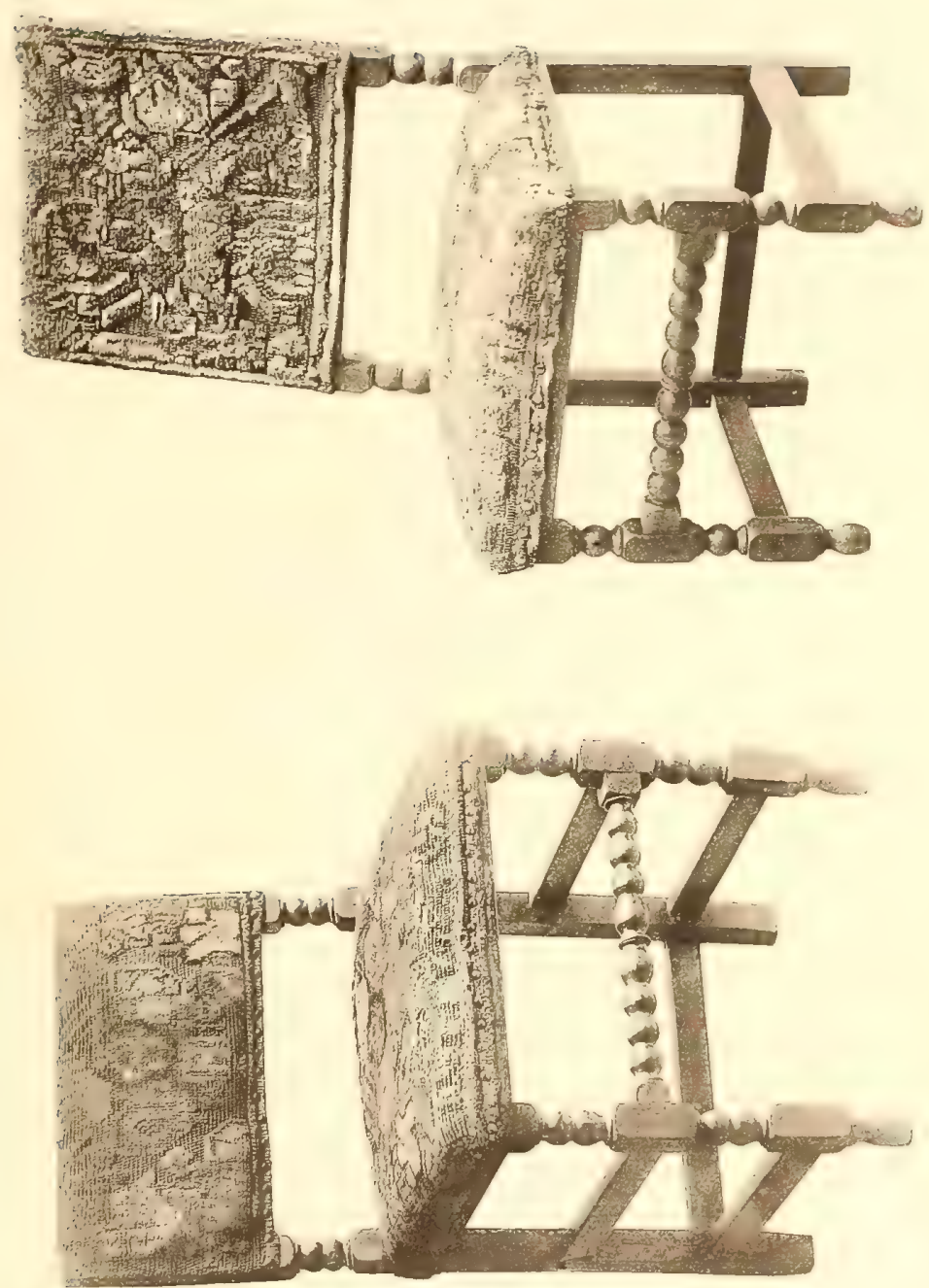

not found on the chairs painted by the Dutch and Flemish masters from I650 to I680, and this, with the fact that the Dutch and Flemish chairs of this period are seldom as high in the back as twenty-four and a half inches, is sufficient to cast doubt on the existence of such chairs in England during the Commonwealth.

A high-backed leather chair, somewhat different from the preceding, is shown in Fig. 7o. This style probably made its appearance in England in the reign of William and Mary, and in this country about ten years later. The frame is maple. The hight of the back is forty-five and five eighths inches from the floor. The leather covering is the original. This chair belongs to the Hosmer collection.

Bandy-legged chairs began to be used in New England early in the eighteenth century. Some of the older examples have leather backs, like the one shown in the last illustration. But the regulation back, so to speak, for these chairs is here shown (Fig. 7I). Toward the middle of the century they were sometimes made with ball and claw feet, and with more or less carving. Seven chairs with "Eagles foot \& shell on the Knee" are found in the inventory of Theodore Wheelwright, upholsterer, made in Boston in 1750 . A chair in the Hosmer collection, answering very well to this description, is shown in Fig. 72. It is made of black walnut and was bought 
a few years since in Hartford, Conn. The bandylegged style was introduced into England from Holland by William and Mary when they ascended the English throne.

In the summer of I88 I Mr. George T. Robinson expressed to us his opinion that the bandy-shaped leg was of Chinese origin, and in support of this view showed us in his house in London a Chinese vessel with bandy legs, which he considered an antique.

Prompted by this suggestion we have sought further information on this point, and through the kindness of Yung Wing, LL. D., late assistant minister from China to the United States, we are enabled to state that the bandy leg, moderately crooked, with the ball and claw foot, was in use in China in the Chow dynasty, I I 22-254 .B. C., and that the bandy leg with the typical crook and with the ball and claw foot, as represented in Fig. 73, was in use in China as early as $254 \mathrm{~A}$. D. The claw and ball represent the claw of the Dragon clasping the pearl.

This illustration and these facts are taken from the Chinese work entitled "Hwang Chao Li Khi Tú Shih," or "Drawings and Descriptions of Implements and Equipages of the present Imperial Dynasty," published under Imperial order in Peking. Preface of the work written by His Chinese Imperial Majesty, Kien Lung, July, r8 I 9.

Such pieces as the Bernward candelabrum in St. 


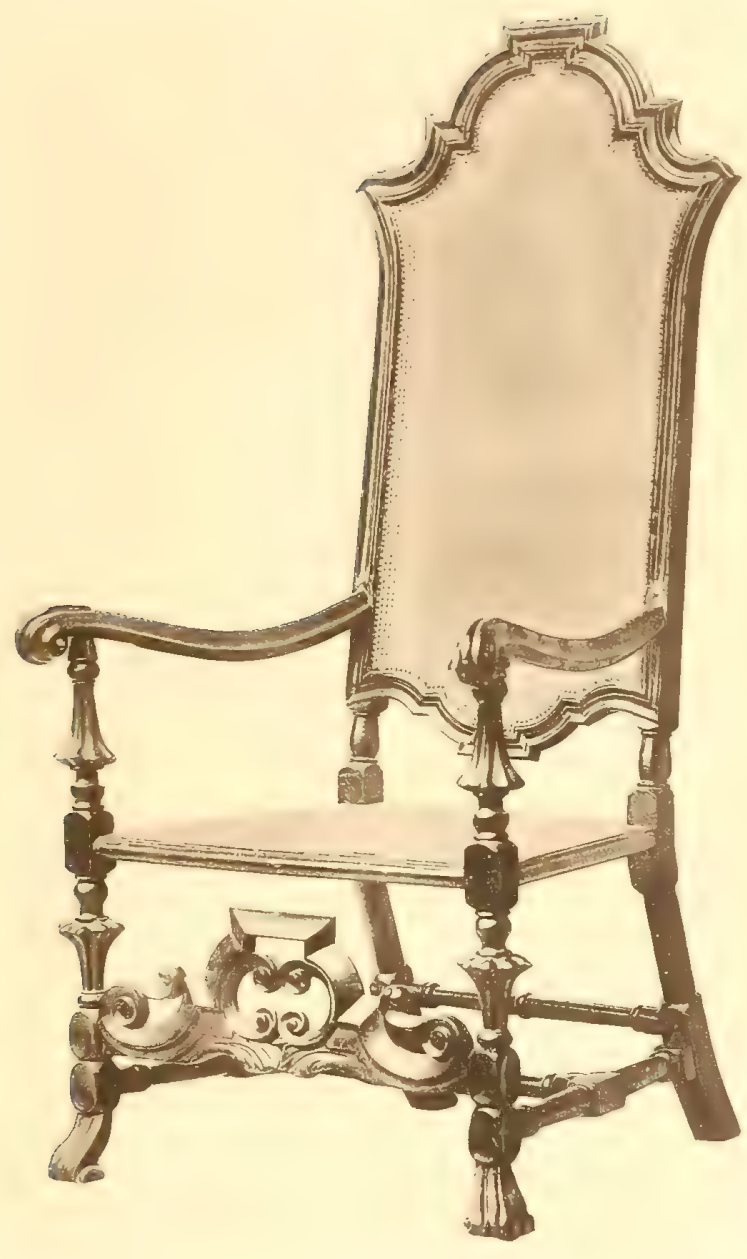

Fig. 65

CAME CHAL: 

Magdalene's Church at Hildesheim, and the Romanesque candelabrum in the Musée de Cluny, in Paris, show that the bandy leg was in use in Europe in the Middle Ages. It is, however, highly probably that the fashion of bandy legs for furniture, which started up in Europe in the seventeenth century, was a recent importation from the Orient.

In the inventory of Benjamin Ivory, of Boston, made in 1737 , " 6 Crowfoot chairs" are mentioned. This is the first reference to the ball and claw foot that we have found in the New England records. The Dutch marquetry chairs, which were to be seen in the state dressing-room at Chatsworth in I88I, had small ball and claw feet. Such chairs date back to the reign of Queen Anne, which is, perhaps, about the time when the ball and claw began to be used in England.

We do not remember to have seen the expression ball and claw in the American inventories. Besides, the "crowfoot" and "eagles foot" chairs above mentioned, we have notes of a mahogany bedstead, a large mahogany easy-chair, and a mahogany teatable, each "with eagle claws," found in the inventory, made in June, I758, of Abraham Lodge, Esquire, attorney at law, of New York city. Mahogany high cases of drawers, "with crown and claws," are mentioned in the table of prices for joiners' work in Providence, R. I., in I 757, published in the Appendix to these chapters. 
In Fig. 74 is shown one of the descendants of the style represented in Figs. 57 and 58 of this chapter. The greater elevation of the back was the principal change that this family of chairs underwent at the close of the seventeenth or in the beginning of the eighteenth century, when they began to be designated in the inventories by the number of horizontal pieces in their backs, which were from two to five and sometimes, though very rarely, six. Those with two slats were called "two back" chairs, those with three slats, "three back," and so on. A few extracts from the records referring to these chairs are here given :-

"To 6 forebacke chairs, I 2 s." - Inventory of John Goodwin, Jr., carpenter, Boston, I $70 \%$.

" 6 Flagg Chairs, 3 backs at $\mathbf{I} / 4,8$ s."

" 6 ditto white, 2 backs at I/ 8 , Ios."

" 6 ditto, 4 backs, I 8 s." - Inventory of George Worthylake, mariner, Boston, I 7 I8.

" 6 Chares with 5 backs."

" 16 Chairs, 2 backs." - Inventory of Josiah Mountjoy, innholder, Boston, I 7 I 9.

" $\frac{x}{2}$ Doz of five Back Cheairs, $3 / 6, \mathscr{L}$ I. I s." - Inventory of Ephraim Wheeler, feltmaker, Boston, I 72 I-22.

"Three Bla: 6 backt Chairs at 6/, I8 s." - Inventory of Mary -Walker, Boston, I735.

These chairs were made of the harder woods, such 


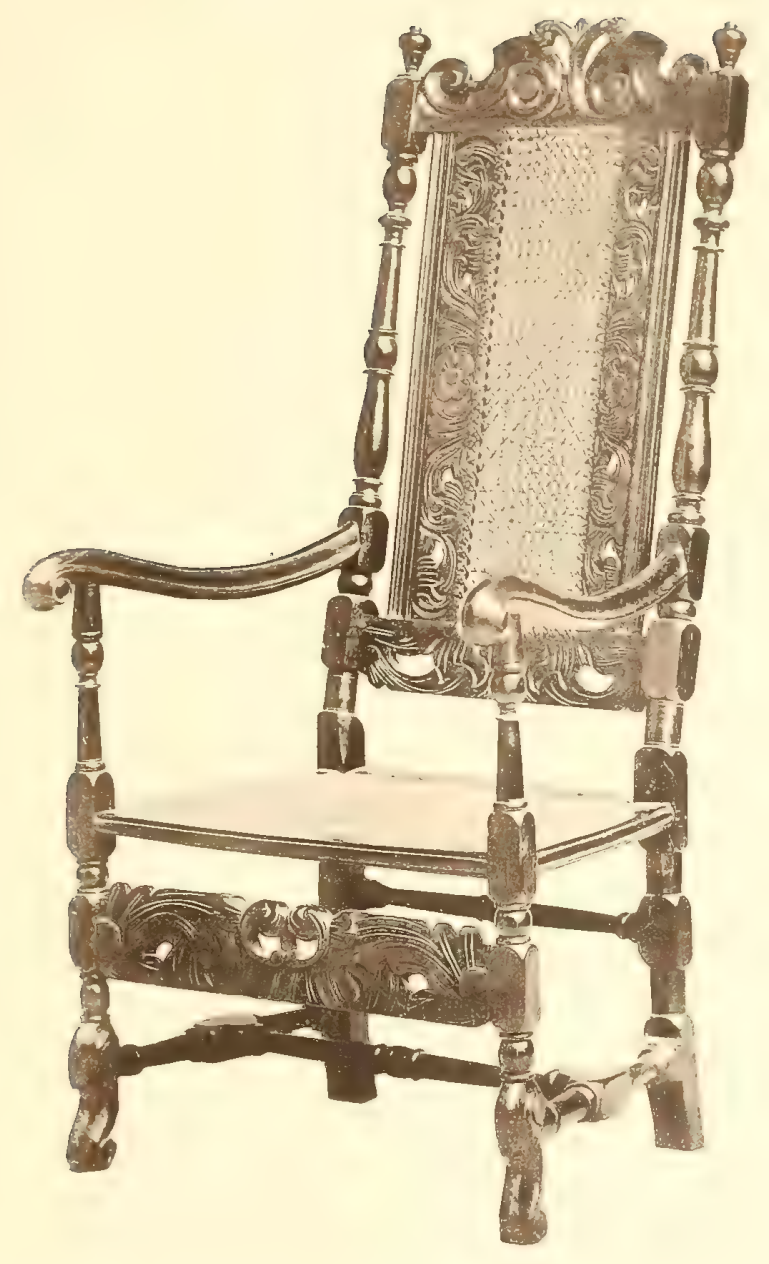

FIQ. 67

CANE CHAIR

-ATE REVENTEENTH OR EARLY EIGHTEENTH CENTURY 

as maple, hickory, and beech, were admirably put together, and have been remarkable for their strength and durability.

Another style much in vogue in the last century is shown in Fig. 75. They were made, some with three, others with four vertical pieces in their backs. These pieces were usually turned on one side and flat on the other, and were put in, sometimes with the flat, but perhaps oftener with the turned surface to the front. Sometimes they were not turned at all, but were flat on both sides, with their fronts either plain or a little grooved. They were called in their day "banister back," "split back," "slit back," and sometimes "slat back" chairs.

The earliest reference to these chairs that we have found in our records is in 1727 . It is quite possible, however, from the altitude of their backs, and because they are supposed to date from the beginning of the century in England, that they began to be used here some time before their first appearance in the inventories. From many references to these chairs in the records the following items have been selected as representative:-

"In the Parlour, 23 Leather Chairs, Banister Backs, £8. I." - Inventory of Thomas Selby, "Tavenor," Boston, 1727 .

"Fore flat Backt Chares: Io/ \& six slett Back Ditto, 30\%"- Inventory of David Eustis, mariner, Boston, I 73 I. 
"9 Split Back Chaires, f2. I4, 6 Four Back Do., $£$ I. Iо." - Inventory of Caleb Winchester, mason, Boston, I 736.

"In the West Room, 6 slitt back Chairs carv dops flagg bottoms, $\&$ I. Io." - Inventory of Sampson Mason, "Glasyer," Boston, I 738.

"In the Hall, Six Slat bannister Chairs, 66/." Inventory of Stephen Trowbridge, New Haven, I 744. " 5: 3 banister back Chairs, 20/."

"I arm 4 back do, IO/." - Inventory of Jonathan Gatchell, shipwright, Boston, I745-46.

" 6 Split Bannester Black Back Chairs, I I s." Inventory of Mary Bennett, Boston, I $75 \mathrm{I}$.

Easy chairs began to appear in the New England lists of household furniture early in the eighteenth century. They were part of the bedroom furniture of wealthy people, and were sometimes covered with the same stuff as that of which the bed and window curtains were made. The cost of the cloth and the large amount required to cover these great chairs will help to explain the relatively high figures at which some of them were apprized.

It is believed by the best English and Flemish connoisseurs that chairs of this style sprang up in Europe in the last years of the seventeenth century, - by some that they were of Dutch, by others, that they were of French origin. They remained in use till the close of the eighteenth century. Heppel- 
white published a design for one as late as 1787 , and in his text referred to it as an "easy chair," and also as a "saddle cheek chair."

Good specimens of this style are by no means uncommon in New England. In Fig. 76 is shown one belonging to the writer that was bought a few years ago from a dealer in North Beverly, Mass., who had picked it up in the neighborhood.

The following items descriptive of these chairs have been selected from original sources:-

"In the next Chamber [to the "Great Chamber"], An Easy Chair, £I." - Inventory of John Rainsford, mariner, Boston, I 7 I 2-I 3 .

"In Chamber, I Easy chair, $£ 4 . "$ - Inventory of Adam Beath, Boston, I 716-I7.

"In the Front Chamber, I fine Green Camblet Bed Curtains \& silk Quilt, £I5."

"A large Silk "easy Chair, £Io." - Inventory of Henry Franklin, merchant, Boston, I 725.

"In the Great Chamber, I New Coach Bed green Cheney, £30. I Easey Chair Ditto, £ I I." - Inventory of James Pecker, wharfinger, Boston, I734.

"In the Front Chamber, I Red China Easey Chair Broken, \&5." - Inventory of Captain Edward Pell, painter, Boston, 1737 .

"In ye Hall Chamber, I Easy chair $w^{\text {th }}$ Calico covering, $£ 8$." - Inventory of Captain John Welland, distiller, Boston, 1737 . 
"In the best Chamber, I Green China Easie Chair, £Io." - Inventory of James Townsend, wine cooper, Boston, 1738.

"In the Front Chamber, I Harrateen Easey Chair, £ Iо." "I Cornish Bed, Harrateen Curtains, Headcloth Teaster, \&c., $£ 30 . "$ - Inventory of Captain John Hill, mariner, Boston, I 739.

"An Easey Harrateene chaire, $£ 20 . "-$ Inventory of John Dennie, merchant, Boston, I 748.

"In Front Chamber, I Red Easy Chair, Ł3.6. 8. Suet of red curtains \& rods, $\mathcal{E} 2.8 . "$ - Inventory of John Proctor, innholder, Boston, I 756.

The first appearance of "round about chairs" in the New England inventories, of which one can feel reasonably certain, is in 1738 . They are recorded under quite a variety of names of which the following are the principal, namely: "round chair," "threecornered chair," "triangle chair," "round about chair," "half round chair." But of all these and similar designations, the one the most frequently met with is the fourth, namely, "round about chair."

They were made, some very plain and cheap, of the commoner woods, with flag bottoms: others much better, of black walnut, mahogany, or cherry, with leather or cloth-covered seats, while occasionally a specimen is found quite elaborately finished with carving, ball and claw feet, and fenestrated panels after the style of Chippendale. Sometimes, though 


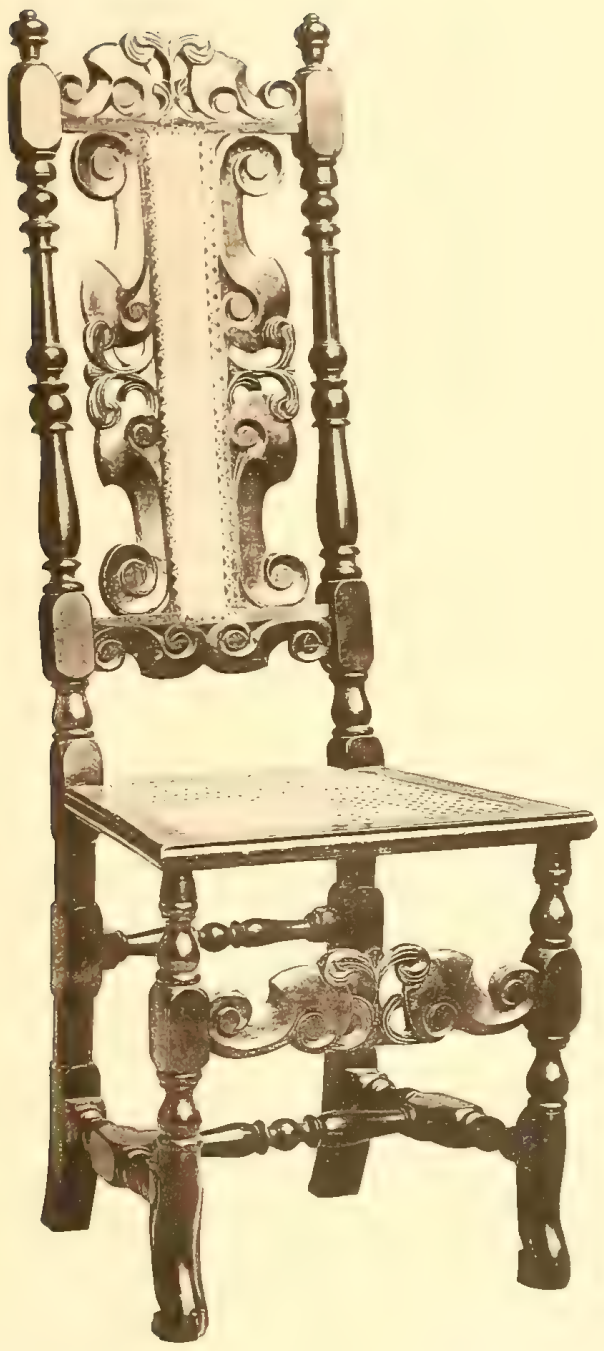



rarely, one is seen with a piece rising from its back as far above the arms as these are above the seat. This back piece is in open work, and gives to such chairs a very picturesque appearance.

Roundabout chairs were desirable as comfortable armchairs for daily use, and as quaint pieces of . furniture. Some specimens were designed for invalid chairs, and these had the upper part of the space beneath the seat inclosed. There are those in England who are inclined to think that chairs of this style sprang up there as early as the time of Queen Anne.

A roundabout chair of very good pattern, belonging to Mr. William G. Boardman, of Hartford, is represented in Fig. 77.

In 1748 , " 6 mehogeny chairs" belonging to the estate of John Dennie, of Boston, were inventoried at $£ 42$ in the paper money of the day. These are the first mahogany chairs that we have found in the Boston records. A mahogany table is mentioned in the inventory of Captain John White made in Boston, March 20, I 73 I-32, and this is the earliest date for mahogany in New England of which we have knowledge. After I 732 mahogany furniture is mentioned in our inventories with increasing frequency.

Let us return to the six mahogany chairs and inquire concerning their style. Could they have been Chippendale chairs? 
Chippendale's earliest plates are dated 1753. If we add to this the time required for a new fashion to cross the Atlantic it will appear quite improbable that these chairs were made by Chippendale or after his style, even if we suppose that he was established in business and in reputation for several years prior to the date of his first designs.

There is, however, scarcely any doubt that the elegant style of Chippendale found its way to this country within ten years after the publication of his first plates, so that the "ten mahogany chairs with yellow bottoms," which we find valued at $£ \mathrm{I} 6$ in I 759 in the estate of Charles Apthorp, of Boston, may very well have been Chippendale chairs.

The Chippendale chairs found in New England are almost invariably those with openwork backs of various patterns, with interlacing lines which sometimes remind us of the flowing tracery in the heads of decorated Gothic windows. They are usually plain or a very little carved, but sometimes the carving is more elaborate and extensive. His Chinese chairs and chairs with "ribbon backs" are very seldom seen in this country.

The beautiful chair backs of Chippendale were developed from the solid wooden piece which, in connection with the chair shown in Fig. 7I, we have described as the regulation back of the bandy-legged Dutch chairs. The first departure from this old 


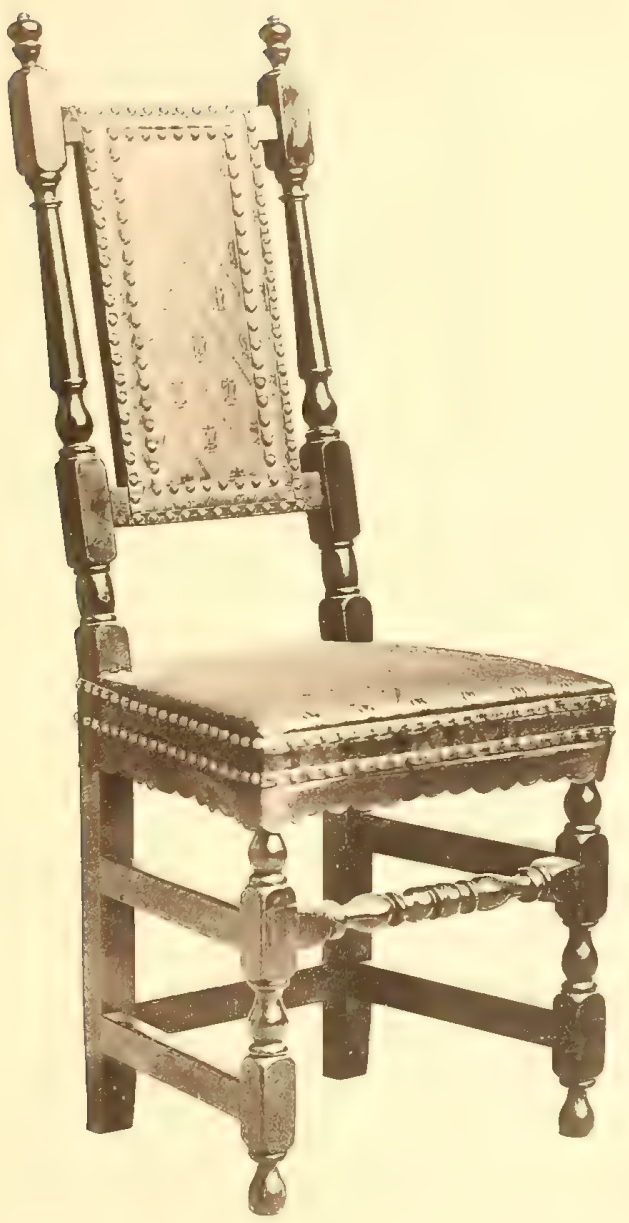

Fic. 69

HIGH-BACKED LEATHER CHAIR 

form was a single perforation of this back piece with a heart, or, perhaps, a diamond-shaped opening. Such chairs are occasionally seen. Next, the back was widened and two or more openings made. It was from the hints afforded by these primitive fenestrations that Chippendale worked out the fanciful designs that characterize the backs of his chairs.

Many of the older examples of these chairs were made in New England of black walnut; later the wild cherry was much employed. The seats were covered, as in England, with leather, silks, and other rich stuffs, and after I 770 "black horse hair" was added to the list. "A Sopha" covered with this material was inventoried in the estate of Nathaniel Rogers, of Boston, in the year last mentioned. They remained in fashion here down to the arrival of Heppelwhite's chairs, which, as we shall see, took place in the last decade of the century. The writer is familiar with a set of Chippendale chairs with ball and claw feet made by Eliphalet Chapin, of South Windsor, Conn., as late as the year $\mathrm{I} 78 \mathrm{I}$. The price paid for them at that time was $f_{\mathrm{I}}$ apiece.

We show here three chairs and a double chair or settee, after the style of Chippendale. The first, Fig. 78 , is one of the set of the well-known chairs in daily use in the library of Yale College. They are made of mahogany, and with them is preserved the story that they were brought from England to Bos- 
ton by Governor William Burnet, in 1727 , and that after his death, in 1729 , they became the property of his successor, who owned them till his death in I 757 .

They are very beautiful examples of the style now known as Chippendale's, and there is scarcely anything about them to criticise, except their reputed age. The date of Chippendale's first designs is I 753, and though it is possible that such chairs were made somewhat before this time, yet we have no authority for the belief that they were so made. The probabilities are, therefore, very great that these chairs were not manufactured till after the middle of the eighteenth century.

The second, Fig. 79, which is about as old as the preceding, is made of mahogany, and now belongs to the writer. It is one of six chairs formerly owned in Hartford, Conn. Mr. Edwin Simons of that city, who also has one of the set, can remember them as far back as fifty years.

Chippendale chairs with straight legs in front, and with backs resembling the one shown in Fig. 80, are those the oftenest seen in New England, and, we believe, elsewhere in the older parts of this country. This chair was lately picked up in Middlesex County, Conn. It is made of mahogany, and belongs to the Hosmer collection.

The beautiful double chair, represented in Fig. 8I, 


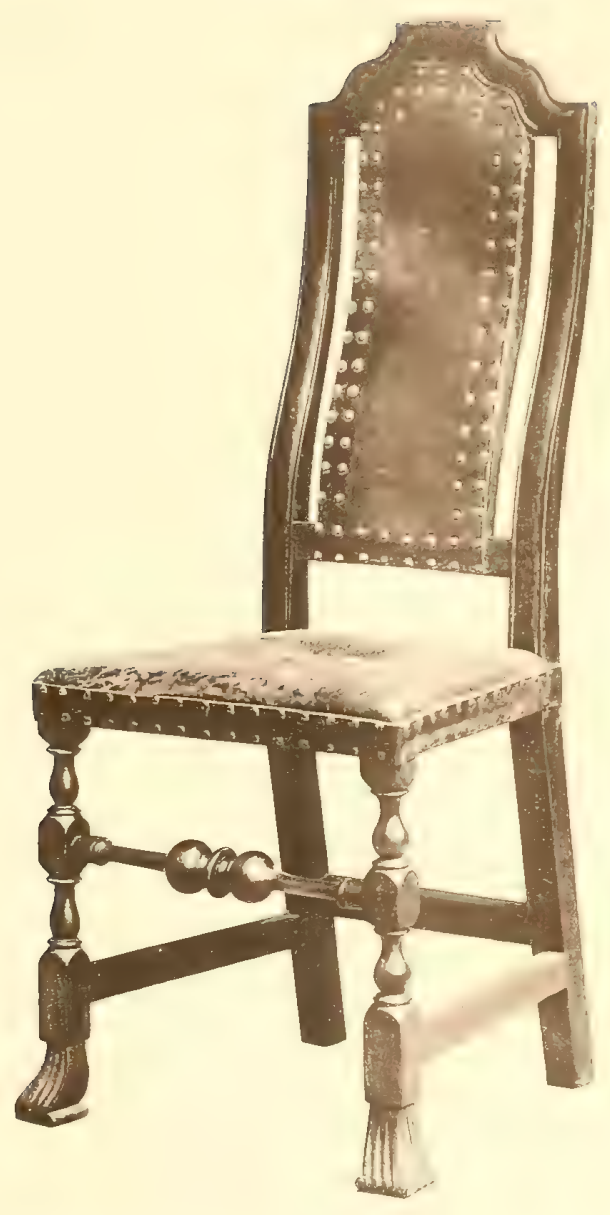

FIG 70

HIGH-BACKED LEATHER CHAIP 

is the property of the American Antiquarian Society at Worcester, Mass. It is said to have been part of the household furniture of Governor John Hancock. It was presented to the Society in July, I8 38 , by John Chandler, Esq., of Petersham, Mass. Double Chippendale chairs are very rare, in this country, at least. One in England, belonging to Lord Dover, is illustrated in "The Magazine of Art" for October, I 88 I.

While the name of Chippendale is now known to collectors and to many other people all over the civilized world, but little has yet been gathered of his personal history. That little, however, is interesting and is here given.

In his Introduction to the "Ancient and Modern Furniture and Woodwork in the South Kensington Museum," London, I 874, Mr. John Hungerford Pollen says:-

"In England we had, about the middle of the century, a school of carvers, gilders, and ornamenters following the extravagant style of the French. The most prominent name in this field is that of Thomas Chippendale. He worked from the middle till towards the end of the century. He was descended from a family of carvers, and inherited the skill which had been general in his craft since the days of Gibbons," (p. cxlv.) "The dates of his birth and death are not known. . . Thomas Chippendale was son and father of furniture makers. A collection of Chippendale's unpublished designs is extant in the hands of a private collector," (p. ccxxii.) 
Mr. Robinson, in "The Art Journal," December, I 88 I, says: -

"Foremost amongst these establishers of a British style of furniture was Thomas Chippendale, of St. Martin's Lane, a fanciful artist, an excellent workman, and especially an excellent chairmaker.

"Of course he did not create the style which now bears his name; no one man ever does create a style. The style rather creates the man who ultimately governs it. Thomas Chippendale the chairmaker was begotten of the times and born in the craft, for his father had distinguished himself as a cabinet-maker before him, and St, Martin's Lane was then the head-quarters of Art in London. It was there the Royal Academy was born, and it was, in fact, the nursery of English Art, so Chippendale lived in the very center of the youthful movement."

Chippendale's earliest plates are dated, as has already been said, in 1753 , and the first edition of his book, entitled "The Gentleman's and CabinetMaker's Director," was published in 1754. On the title-page of "the third edition," dated I 762 , he styles himself "Cabinet-Maker and Upholsterer, in St. Martin's Lane, London," and mentions, besides two places in the Strand, that the book is to be "sold at his House, in St. Martin's Lane." His residence and shop were, therefore, both in St. Martin's Lane.

The name "Thomas Chippendale, Upholsterer, 60 St. Martin's-lane," is found in the list of the "Master Cabinet-Makers, Upholsterers, and Chair Makers, in and about London, for 1803 ," appended to "The 


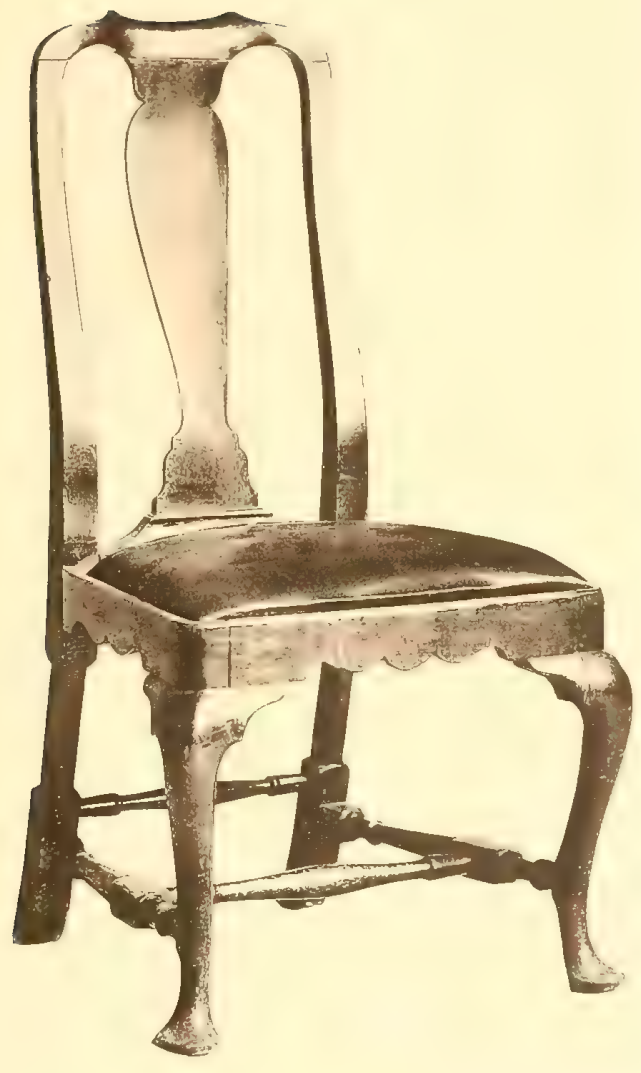

DUTCH BANDY-LEGGED CHAIR 

Cabinet Dictionary," by Thomas Sheraton, London, 1803. This is the only Chippendale found in the list, and he was probably a son of the famous cabinetmaker.

It is interesting to note that the name Chippendale does not appear in the inventories in connection with furniture. No Chippendale chairs, or tables, or other objects, are mentioned in these records. The principal explanation of this lies in the fact pointed out by Mr. Robinson, that Chippendale was not the creator of the style that now bears his name. He was certainly one of the most able and skillful makers and designers of his time; but there were so many clever cotemporaries working on the same lines and in the same style that probably nobody in London thought of calling it by Chippendale's name. But after the lapse of a century, when this style had become historic, and specimens of it were eagerly sought by collectors, it received the name of the maker who had published and left behind him its best designs. While, therefore, Chippendale was one of the ablest, perhaps the ablest, exponent of the fashion that prevailed in his early manhood, it is not at all improbable that his greatest reputation was posthumous, and not reached till after the style which he did so much to elaborate had finally received his name.

"One Windsor Chair" is mentioned in the inven- 
tory of Hannah Hodge, widow, of Philadelphia, taken the 7 th day of July, I 736 . This is the earliest date for the Windsor chair that we have yet discovered. We also find in the inventory of Governor Patrick Gordon, of Philadelphia, the item, "Five Windsor Chairs@II/6, £2. I7.6." The inventory is not dated, but he died August 5, I736, and his will was proved August I7, I736. After I 736 Windsor chairs are occasionally met with in the Philadelphia inventories, one, and sometimes two, in an estate, till we reach the inventory, dated March 5, I757, of Lloyd Zachary, "Practitioner in Physick," in Philadelphia, who had " in the Parlor," "at the Plantation," "Ten Windsor Arm Chairs." On Thursday, June 21, I 764, "a parcel of Windsor chairs" is mentioned in a list of household furniture advertised for sale in "The Pennsylvania Journal and Weekly Advertiser." From these two facts - that in 1757 ten Windsor chairs were found in one estate, and that in I 764 "a parcel of Windsor chairs" was to be sold at public auction - it is evident that these chairs had become sufficiently numerous in Philadelphia to be at least well known, if not common.

The following advertisement with a cut of a Windsor chair appears in. "The New-York Gazette, or The Weekly Post-Boy," April I 8, I 765:-

"To be Sold By Andrew Gauteir, In Princes-Street, Opposite Mr. David Provoost's in Broadstreet; A Large and neat Assort- 
ment of Windsor Chairs, made in the best and neatest Manner, and well painted, Viz, High back'd, low back'd and Sackback'd Chairs and Settees, or double seated, fit for Piazza or Gardens. ... Children's dining and low Chairs, \&c.

"N. B. As the above Gauteir intends constantly to keep a large Number of all Sorts of the above Chairs by him for Sale, all Persons wanting such, may depend on being supplied with any Quantity, Wholesale or Retail, at reasonable Rates."

Andrew Gauteir probably made the Windsor chairs that he sold, as he was a joiner who had doubtless learned his trade in New York City, where he was born in $\mathbf{I} 720$, and died in 1784 . He was a grandson of Jacques Gauteir, a Huguenot, who emigrated to this country shortly after the revocation of the edict of Nantes.

The earliest date for Windsor chairs in New York City that we have found is June $8, \mathrm{I} 758$, when " 4 high back winsor chairs, In the Entery," were recorded in the inventory of Abraham Lodge, attorney at law. It is probable that they made their appearance there somewhat before this time, but we have failed to find them mentioned in the very few early inventories of New York City that are preserved in the Surrogate's office in New York, and in the office of the Clerk of the Court of Appeals in Albany.

The fashion of Windsor chairs now spread very rapidly. They were advertised by name in the newspapers of the day in a manner altogether unprece- 
dented, and, judging from the great numbers yet in existence, became very popular. They were made in various styles, as will appear from the descriptions left by the dealers, and the examples that we shall illustrate. They were much more comfortable to sit in than the old-fashioned "two to five-backed" and "banister" chairs, which they largely superseded for common every-day use.

"Windsor chair plank" was advertised for sale in Philadelphia, by Samuel Williams, joiner, in the "Pennsylvania Chronicle," June Ir to June I8, I 770.

In "The Pennsylvania Journal," November 24, I 773, and subsequently, Jedidiah Snowden informs the public that he "has removed from his late dwelling-house in Market-Street to the West side of FrontStreet, opposite Hamiltons wharf, where he carries on his business of Cabinet and Windsor Chair-Making, and sells them at the most reasonable rates."

The manufacture of Windsor chairs, which in this country seems to have started in Philadelphia, did not reach Boston, according to our investigations, till I786, although Windsor chairs are occasionally mentioned in the records and in the newspapers before that date. In 1769 two Windsor chairs are apprized at six shillings each in the inventory of Captain Daniel Malcom, of Boston, and in 1773 , " 2 painted Windsor Chairs," at ten shillings, in the inventory of Mr. Samuel Parker, merchant, of Boston. 

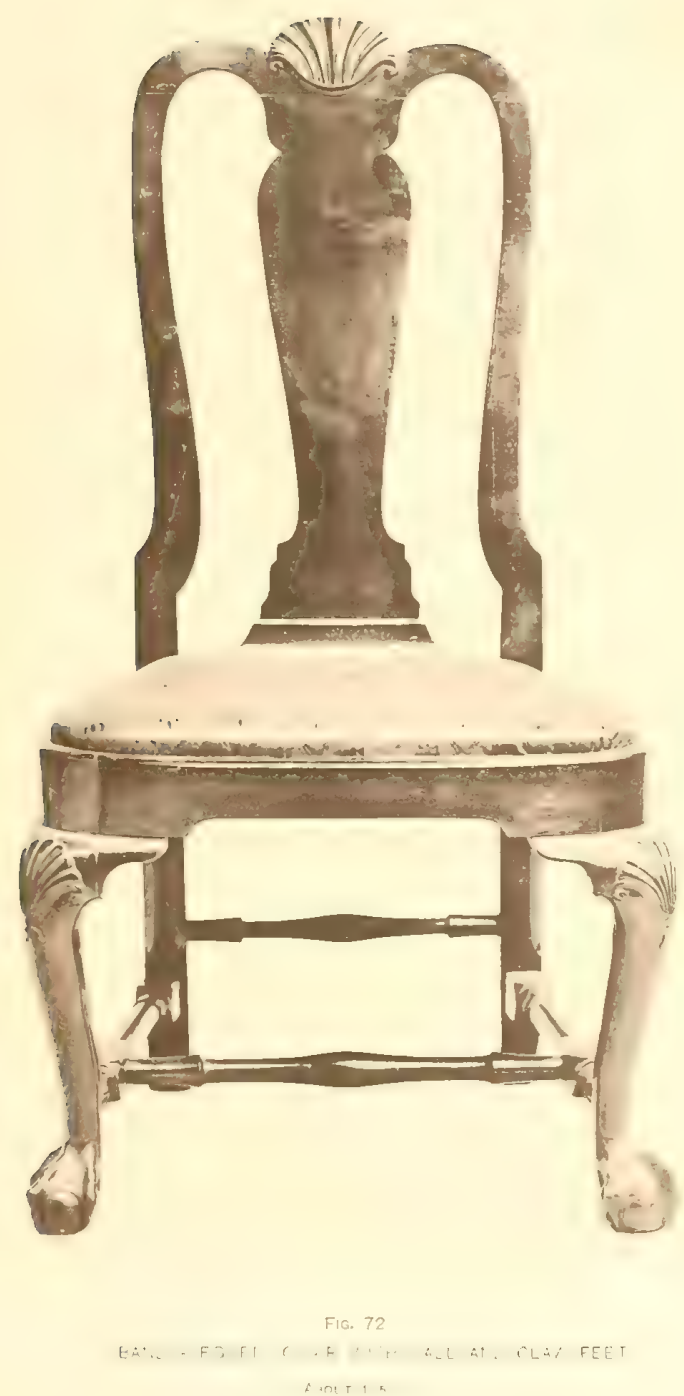

The following advertisement first appears in "The Independent Chronicle," of Boston, April 13, 1786 , with woodcuts of two Windsor chairs of different patterns :-

"Warranted Green Windsor Chairs, may be had at Ebenezer Stone's Shop, on Moore's Wharf, North-End, opposite Dr. Clark's, Where is made, and for Sale, at a low Price, Round-Top chairs, fan-back Garden-chairs, Soffas, stuff-seat Chairs, and a large Assortment of Dining-Chairs, painted equally as well as those made at Philadelphia."

As the closing sentence in this advertisement implies some knowledge on the part of the public to which it was addressed of Windsor chairs made and painted in Philadelphia, it is not at all unlikely that such chairs were then selling in the Boston market, and it may be that the "large assortment of Elegant Windsor chairs" advertised for sale at "Messrs. Skillin's Carver's Shop, near Governor Hancock's wharf," in "The Independent Chronicle," December 29, I785, were chairs that had been shipped from Philadelphia.

The first mention of these chairs in Hartford, Conn., that we have found, is in an advertisement in the "Connecticut Courant," January 30, I786, which reads as follows :-

"Windsor Chairs.

"Stacy Stackhouse, From New-York, Informs the Public, that he has established his business in this City; where he makes 
and sells all sorts of Windsor Chairs in the neatest manner, and on the lowest terms. From the great demand for this kind of manufacture in this State, and the encouragement promised him by a number of Gentlemen in this vicinity, he flatters himself with the prospect of a large run of business, and promises every attention to deserve the favours of the Public."

In the "Courant," June 25, I 787 , he "informs the public, that he continues to make Windsor Chairs, in the best manner, at his House a little north of the State House in Hartford - Those Ladies or Gentlemen who will please to favor him with their Custom, may depend on having their work done in the genteelest manner, and on as reasonable terms for pay in hand, as in New-York." Mr. Stackhouse returned to New York about I 795 .

In "The New-Haven Gazette and the Connecticut Magazine," February 22, I787, under a cut of a Windsor chair, "Alpheus Hews, from New-Jersey, begs leave to inform his friends and the public in general that he carries on the business of Windsor Chair Making in Chapel St. in New Haven, where may be had any Number of Windsor Settees, and Garden Chairs, made in the neatest manner and different fashions, also some very convenient for Children."

In "The United States Chronicle," Providence, R. I., July I9, I787, Daniel Lawrence "informs the respectable Public, that he carries on the chairmak- 


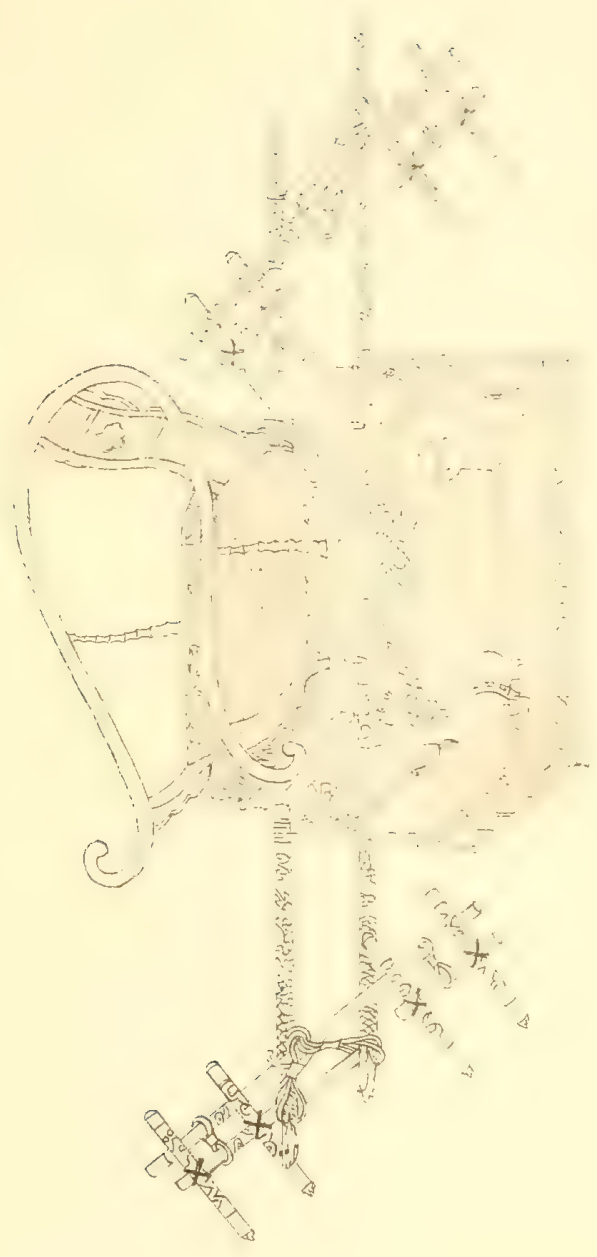



ing Business, at a Building on the next Lot Eastward of the large Three-story Dwelling-House of Dr. Amos Throop, in Westminster-street, Providence, a few Rods West of the Great Bridge, where he makes and sells all Kinds of Windsor Chairs, such as Round-About Chairs, Dining-Chairs, Garden-Chairs, also Sofas, Settees, etc, in the newest and best Fashions, neat, elegant and strong, beautifully painted, after the Philadelphia Mode, warranted of good seasoned Materials, so firmly put together as not to deceive the Purchasers by an untimely coming to Pieces."

In "The Connecticut Gazette," of New London, November I4, I788, "William Harris, Jun, Windsor Chair-Maker, Takes this method to inform the public, that he makes all kinds of Windsor Chairs, Settees and Writing Chairs."

Windsor chairs, like clock cases, were doubtless made by the local cabinet-maker in almost every considerable village. Thus, we find Theodosius Parsons, of Scotland, Windham County, Conn., advertising in the last-named newspaper, January 30 , I789, for a "journeyman to the Windsor Chair and Cabinet business."

The fashion of Windsor chairs had run its course by the close of the century, but that they were made and sold for many years later is proved by the advertisements of John K. Cowperthwaite, and of 
William Brown, Jun., which occur in the "New York City Directory" for the year I8I8. They are men. tioned in the Boston inventories as late as 1820 , and perhaps later.

Where the Windsor chair originated, and how it received its name, are interesting questions. There is a tradition in London that the first chair of the kind was discovered by George III., in a shepherd's hut in Windsor, near the Castle, the shepherd having made much of it with his pocket knife. The king, who was fond of quaint and curious things, liked the chair so much that he had others made after its pattern, and thus the style was introduced and named.

If there be truth in this story it will be necessary at the present stage of the inquiry to substitute the name of Greorge II. for that of his grandson, who was not born till after the Windsor chair was christened and had reached the Western Hemisphere.

This tradition, the existence of old Windsor chairs in England, the name, and, we may add, the probabilities in the case, are the principal grounds for the belief in their English origin.

No mention of Windsor chairs was found in the cursory examination already referred to of the London newspapers down to the year 1765 , nor has any of the English students of old furniture consulted been able to throw any light on the early history of these chairs in England. 


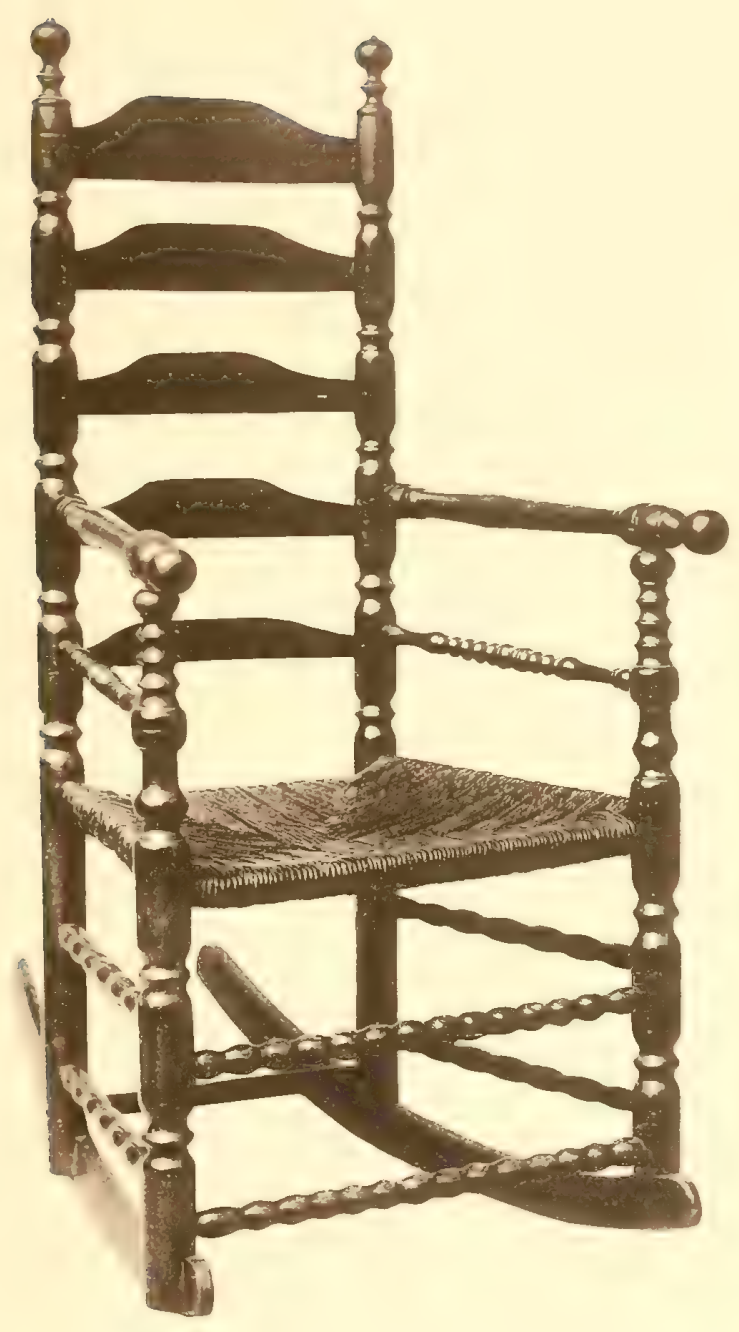

F1G. 74

A FIVE-BACKED CHAIR

BERINAING EIGHTEENTH CENTURY 

In the "New York Gazetteer," February I 7, I 774, we find the following notice:-

"Thomas Ash, Windsor Chair Maker, at the Corner below St. Paul's Church, In the Broad-Way, Makes and sells all kinds of Windsor chairs, high and low backs, garden and settees ditto. As several hundred pounds have been spent out of this province for this article, he hopes the public will encourage the business, as they can be had as cheap and good, if not superior to any imported; he has now by him, and intends keeping always a large quantity, so that merchants, masters of vessels, and others may be supplied upon the shortest notice."

This advertisement proves that Windsor chairs had been imported into New York. It does not, however, prove that these imported chairs had come from Europe. The different American colonies were separate jurisdictions between which jealousies and commercial rivalries existed. Chairs which in I774 had come from Philadelphia to New York would, at that time, be very properly referred to in the latter city as "imported " into " this province."

If the Windsor chair originated in Philadelphia, the probabilities would be very great that it had taken its name from the chairmaker who designed and first made it. But the surname Windsor is not found in the records of Philadelphia during the seventeenth and eighteenth centuries.

From the foregoing facts and considerations we are inclined to the opinion that the Windsor chair is of English origin; that it was brought to Philadel- 
phia not long before the year I 736 , possibly by Gov. ernor Patrick Gordon, who arrived in Philadelphia from England with the royal commission in I726, bringing with him, no doubt, his equipage, and much of his household furniture, among which at his death in 1736 five Windsor chairs were found.

We show here five Windsor chairs of different patterns. The first, Fig. 82, is a very old specimen that was picked up by the writer in Lebanon, Conn., in 1878 . It is of the "high backed" variety. One very similar to it is owned by Trinity College at Hartford, Conn., where it is used as the President's chair. Chairs of this type are very uncommon in New England, at least.

The second, Fig. 83 , is the most common and widely known of all the Windsor chairs. The handles of those made in New England are usually plain. Several chairs of this style preserved in Carpenters' Hall, in Philadelphia, have their handles carved as in this specimen. This is probably the variety described in Andrew Gauteir's advertisement as "sackback'd."

Another very common variety of this family of chairs, sometimes called the "fan backed," is represented in Fig. 84. This kind occasionally, though rarely, was made with arms. One is shown in Fig. 85. It was bought a few years ago in Southington, Conn., and is owned by the writer. 


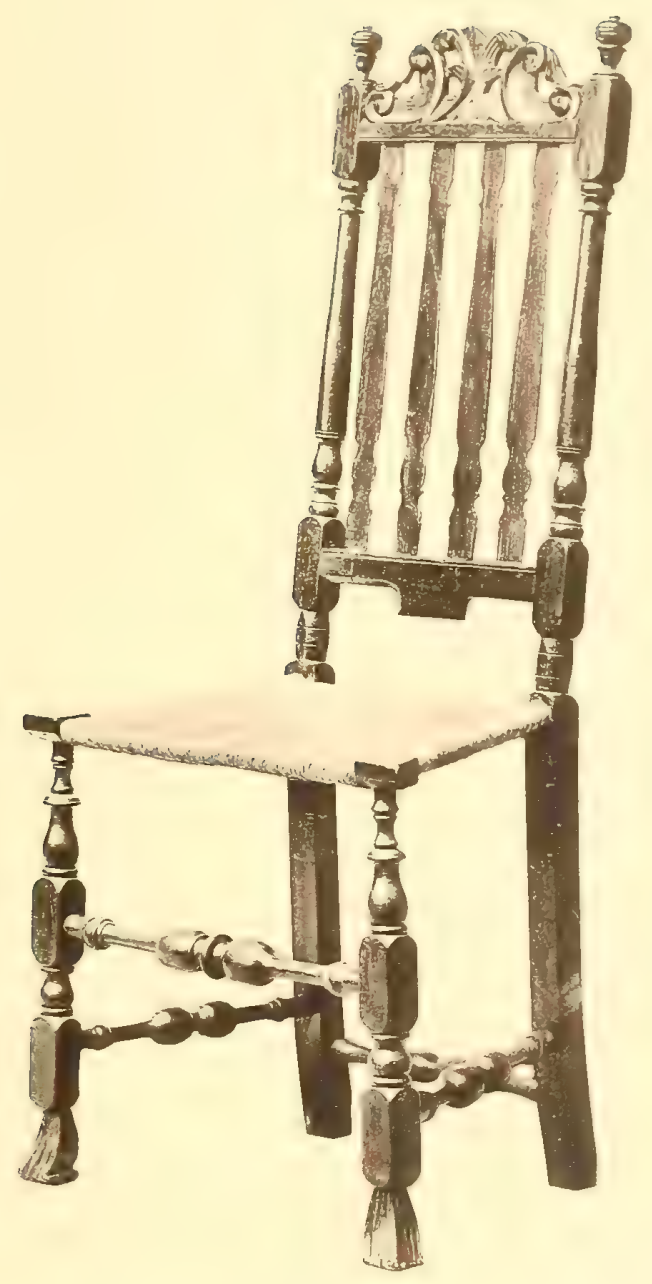



A chair of very light and graceful construction is shown in Fig. 86. These chairs are well known in New England, but are not very common at the present day.

The backs of some Windsor chairs are reënforced by means of pieces which rise from a projection of the seat (Fig. 87). The effect of this arrangement is sometimes very agreeable to the eye.

There are other varieties and modifications of the Windsor chair, but the ones here shown are the best and most pleasing representatives of the style.

It was the fashion to paint the Windsor chair green. Other colors were used to some extent. The chair illustrated in Fig. 86 was yellow when found a few years since in North Haven, Conn., and a careful examination disclosed the fact that it had never been painted a darker hue.

After Chippendale the next most famous London cabinet-maker whose reputation has reached to our times was Heppelwhite. His book of designs was published in I789, and his styles appeared in New England soon afterward.

Chippendale had trusted for his enrichments chiefly to carving, in which he greatly excelled; but Heppelwhite, in addition to carving, made extensive use of marquetry, painting, and japanning to embellish his pieces. His inlays were mostly of satinwood, and such painters as Cipriani and Angelica 
Kauffman were sometimes employed to decorate his more elegant productions.

The Heppelwhite chairs found in New England are fairly represented in Figs. 88 and 89. The first is one of the set formerly in the senate chamber of the old State House at Hartford, Conn. This building was first occupied in 1796 , about which time these chairs were made. They are of Honduras mahogany, and their front legs are inlaid with satinwood. This chair, with others of the set, is kept in the library of the new State House at Hartford.

The second chair, Fig. 89, is one of a set of ten belonging to Mrs. Thomas G. Talcott, of Hartford. She inherited them about thirty years ago from her father, William H. Jones, late of New Haven, Conn. The set consisted originally of twelve, two of which were armchairs. They are made of mahogany, and are very fine examples of their style.

Both these chairs have the shield-shaped back of which Heppelwhite was so fond, and by means of which his chairs may often be told at a glance.

At the close of the century the chairs of another celebrated London furniture maker, Thomas Sheraton, began to come in use in this country. His book of designs was published in I 793. His chair backs are usually rectangular in shape, and the front legs oftener round than square in section. They were made of mahogany mostly, but sometimes of other 
woods painted and gilded. Two examples of his style are represented in Figs. 90 and 9I.

The first is Sheraton as to its back, but the front legs are Heppelwhite rather than Sheraton in style. We have selected this chair for illustration in order to say that chairs with Sheraton backs, but with legs and stretchers similar to those here seen, are oftener met with in New England than those made with the typical Sheraton leg. This chair belongs to Mr. Edwin Simons, of Hartford.

The second example is of later design than the preceding. It is made of mahogany enriched with inlays of lighter colored woods. It belongs to the Hosmer collection, and dates from the early part of the present century.

Settles were more or less common in New England in the seventeenth and eighteenth centuries, but good examples are now becoming rare. One made in I 769 for the house of Colonel Samuel Talcott, of Hartford, Conn., built in that year, is shown in Fig. 92. It was made for the kitchen, and the panels in its back correspond to those found in the woodwork of that apartment. The movable shelf attached to the central panel above the seat was intended for a candle.

The bottom of this piece has undergone some alteration; formerly it was finished plain to the floor. The front below was also made to raise on hinges 
to the level of the seat, so that the settle in this condition could be used as a bed. Bed settles are occasionally mentioned in the inventories. In other instances the space under the seat was utilized as a chest, and sometimes for drawers which slid out and back at the front. This settle was exhibited in Philadelphia at the Centennial Exposition in 1876. Its dimensions are, hight, five feet six inches; length, five feet five and a half inches; width, sixteen and three quarters inches. It belongs to Mrs. Thomas G. Talcott, of Hartford, Conn. 


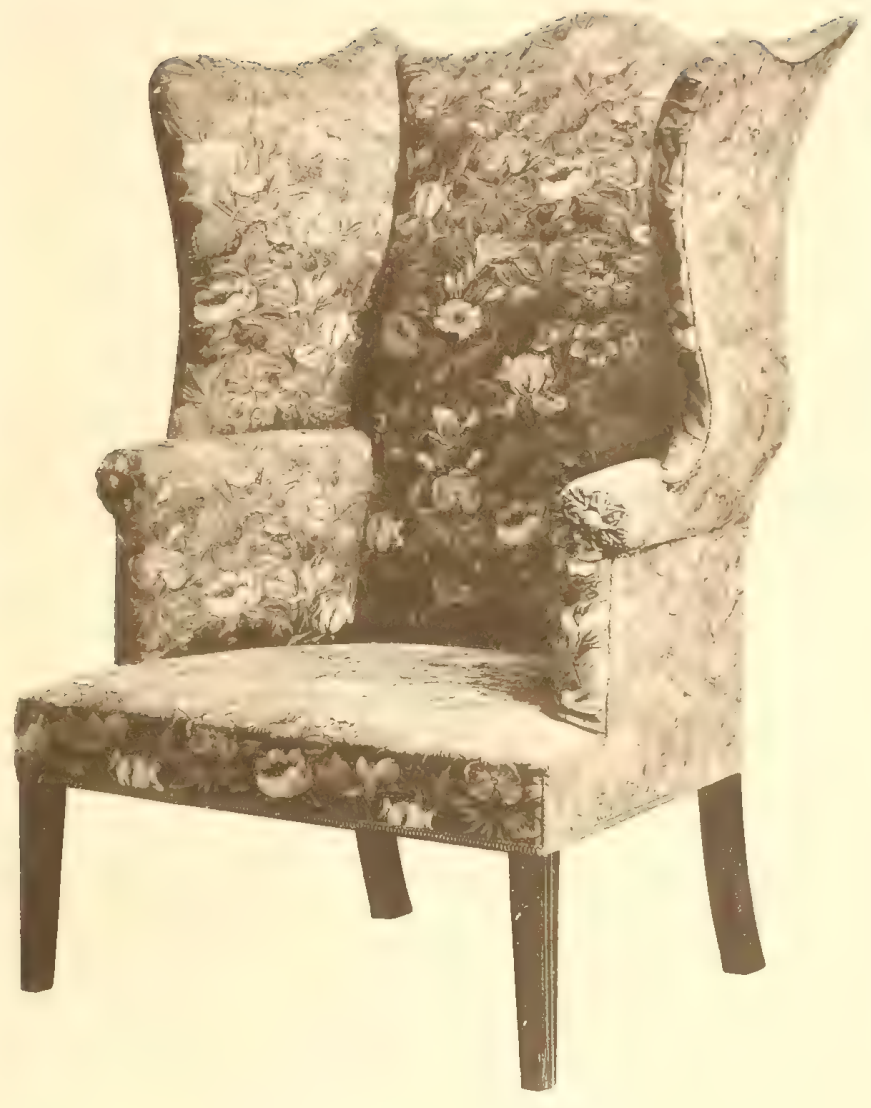

Fis. 75 



\section{CHAPTER VI.}

\section{TABLES.}

IN lists of the household furniture that belonged to our early settlers we occasionally find table-boards mentioned. The items, "In ye hall, One great table bord \& forme, I4 s.; One short Table bord, 2 s.," occur in the inventory of Alice Jones, of Boston, made in 1642. Table-boards are also found in the inventories of Salem, Mass, and in those of Hartford, Conn. They were not numerous. We have notes of them as late as 1738 .

"One table bord" is mentioned in the will of John Bynley, Minor Canon of Durham, made in I 564, and published by the Surtees Society. They are not often found in the English inventories that have been published. We are informed by Wright, in his "Dictionary of Obsolete and Provincial English," that the expression table-board is of Cornish origin.

Now the Anglo-Saxon name for the dining-table was board, derived literally from the upper part of the table which, in these early days, was a movable board, made up of sufficient length and breadth to 
be used, when properly mounted upon trestles, as a table for meals. After the repast the table was cleared away by first removing the board and then its supports.

This simple method of constructing the diningtable with board and trestles is referred to in the early part of the eighth century by the Anglo-Saxon writer Tahtwin, in a verse quoted by Wright in "The Homes of Other Days" (p. 33).

In process of time this important piece of furniture received another name. It was no longer called a board exclusively, but sometimes a table. How early this began we shall doubtless be told in due time by Doctor Murray in his great historical Dictionary now in course of publication. It is certain, however, that this new name for the board had become sufficiently current in the fourteenth century to be used to a considerable extent in "Piers the Ploughman," and by Chaucer, and in the beginning of the fifteenth century it was employed by Lydgate in his minor poems published by the Percy Society oftener, indeed, than the old word board.

During the next two centuries the English dining-table went under one or the other of these two names. But we find in the literature of this period, as well as in the inventories of household furniture, a progressive tendency to use the word table more and the word board less, until at length the latter 


was practically superseded by the former, which thus became the standard name.

Thus in Shakespeare table, in the sense of a place for meals, is written between five and six times as often as the older word board. In Wycliffe's translation of the Bible, made in the time of Chaucer, the word board as a place for meat occurs thirty-two times and table but once; whereas, in the version of King James, made a little over two hundred years later, table is used altogether and board not at all.

One of the influences that contributed powerfully to this change in name was the Norman invasion. When William the Conqueror and his followers came to England they brought with them not only their manners and customs, but also their language; and as they had called this piece of furniture a table in Normandy, so they and their descendants continued to call it in England without any regard to its construction.

Another cause was the habit of allowing the board to stand permanently upon its trestles instead of removing it after every meal. In this way, as Mr. Robinson has explained, less attention was given to the top than when it was moved off and on with every emergency, and so by degrees the board lost its name and the piece in its entirety was called a table.

The table with trestles, however, continued to be 
the regulation table for several centuries after the Norman conquest. We are told by Galfridus Grammaticus, in his English-Latin Dictionary, the "Promptorium Parvulorum," written about I440, that a "table" at that time was a "mete boord that ys borne a-wey whān' mete ys doōn." That even the "table dormant" of the fourteenth and fifteenth centuries was sometimes a board standing upon trestles is shown by the following item recorded in 1509 in the inventory of Martin Collins, Treasurer of York, published by the Surtees Society, namely, "De xviii d. pro iii. dormondes bordes cum tripot"." Following the trend of the inventories we find that tables with trestles were not uncommon down to the middle of the sixteenth century, when "joined" and "framed" tables began to appear. After this time tables with trestles declined in frequency, but that they continued to be used by English people well into the eighteenth century is proved by the "tableboards" that we have cited from the New England records.

A table-board, we are now prepared to explain, was no more nor less than the top of a table which, when brought out and placed upon trestles or improvised supports, made the family board, to be used for the occasion and put away when the meal was over. We have not seen trestles mentioned in our inventories in connection with table-boards, but that 


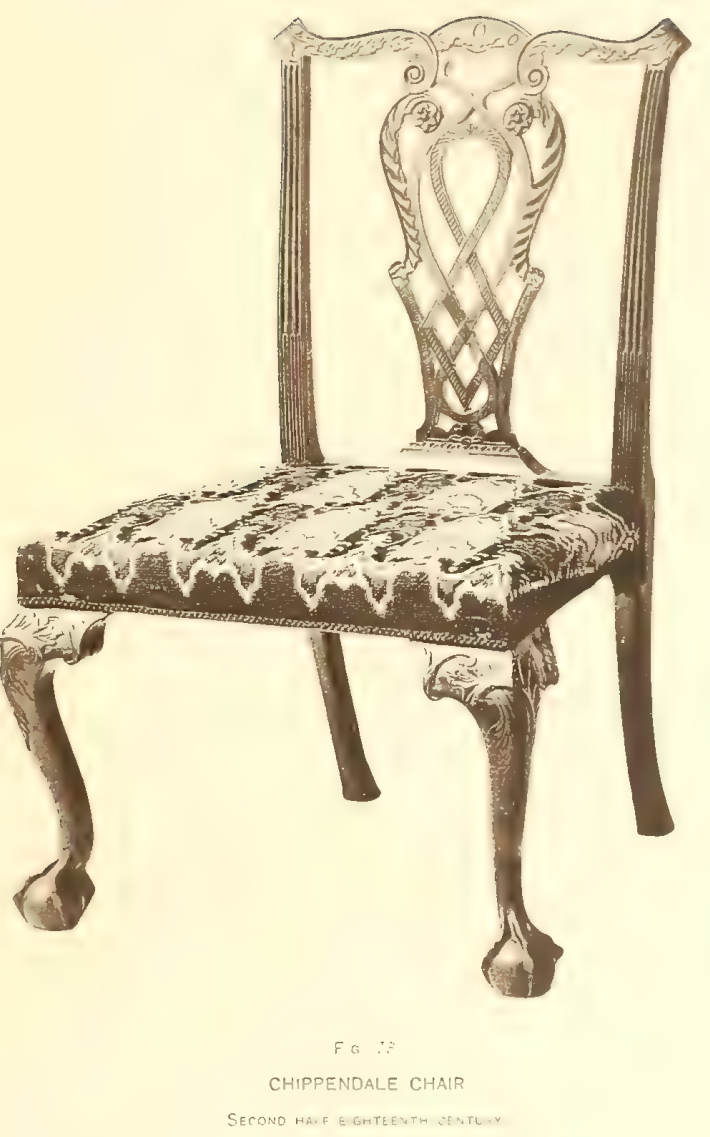



they were sometimes used in New England is shown by the following extract from the inventory of Robert Wing, of Boston, made in i65I, namely, "To tables and trestles and fair benches, 5 s."

The table-boards of our New England ancestors have, therefore, served to remind us of a custom which in their days had become nearly extinct, and of the origin and history of the two names by which the English dining-table has been known as far back as it can be traced.

The ordinary tables in use in New England during the early colonial period were framed structures with square-shaped, round, or oval tops, and with legs usually turned and held in place below by firm rails or stretchers running all around just above the floor.

In examining the inventories from the earliest down to about 1650 the following varieties are those usually met with, namely, framed tables, joined tables, round tables, chair tables, long tables, drawingtables, and square tables.

There is little doubt that the words framed and joined were interchangeable terms and used indifferently in the inventories to describe tables with frames constructed similarly to the one shown in Fig. 93. But when a table with a square frame had a round top it was called a round table; if the top was square, a square table; if the table was convertible into a 
chair, a chair table; if the frame and top were much longer than usual it was called a long table; if made with a top to be drawn out or extended, it was said to be a draw or drawing-table. All these varieties, however, were framed or joined tables, that is, joined or framed together by a joiner, but naturally took the more descriptive names suggested by individual peculiarities of structure or use.

Long tables are found in our inventories as early as I644, and, with the exception of drawing-tables, were then the largest in use for dining purposes. They were made of various sizes, and with more or less ornamentation, and when not in use were often covered with carpets. The item, "In the Hall, I long table \& carpett, \&2. Io," is found in $1652-53$ in the list of household furniture that had belonged to John Cotton, of Boston. They were not very wide, but sufficiently so to be used from both sides, for the custom of sitting at one side of the table which had prevailed in Europe for centuries had now become practically obsolete. "I long fframed Table and 2 Joyned formes by it, In the Parlour," are mentioned in the inventory of Francis Chickering, of Dedham, made in 1658 .

A drawing-table is mentioned in 1647 , in the inventory of George Lamberton, of New Haven, one, "in the hall," in I 657, in the estate of Governor Theophilus Eaton, of New Haven, and two, in 1658 , in 
that of Stephen Goodyeare, the Deputy Governor of the same colony. They are found in the English inventories as early as 1565 .

They usually belonged to people of wealth or station. They were of various sizes, and so made that the ordinary length of the table could be nearly doubled by means of extension pieces at both ends. These pieces when not in use lie under the main top. They are fastened to beveled slides, on which they are raised in extension to the proper level.

The drawing-table, shown in Fig. 93, now belongs to the Connecticut Historical Society of Hartford, having been presented several years since by the late Henry Halsey, of Windsor, Conn. Its history has been carefully obtained by Mr. J. H. Hayden, of Windsor Locks, Conn., who succeeded in tracing it to an old house on the homestead of Matthew Allyn and his descendants, which was pulled down about' 1830. This would indicate that it may have come down in the Allyn family, and that it possibly belonged to Matthew Allyn who died in 1670. A drawing-table, however, is not found in his inventory. Indeed, the only drawing-table that we have noted in the Hartford records is the one mentioned in the inventory, made in 1676 , of Governor John Winthrop. The item reads, "A great draw Table, $\mathscr{E} \mathrm{I}$." This may, therefore, have been his table.

The top of the main table is seventy-three inches 
long and thirty-five and three eighths inches wide. The pieces which were made to draw out at the ends were each thirty and a half inches in length. These with their slides are missing, but the artist, Mr. Robert McKee, has restored them in the drawing in order to show the entire design. The full length of the table in extension was, therefore, eleven feet and two inches. Its present hight is thirty-three and three eighths inches, but to this must certainly be added one and a half inches, the thickness of the lost extension pieces. Calculation must also be made for the feet which have been cut off, according to the careful estimates of competent judges, between five and six inches above the floor. If the lower of these figures is within bounds, the original hight of this old table could not have been less than forty inches.

The wood is oak of a deep brown color, too dark, indeed, to be the wood of the American white oak, after full allowance has been made for the effects of time. For this reason, and because the color corresponds so well to that of old Transatlantic oak, we believe that this table was made in Europe and brought to this country in the seventeenth century.

Drawing-tables disappeared from the inventories in the latter part of the seventeenth century, but long tables, though infrequently mentioned after 1675 , linger in the records till about I 750 . 


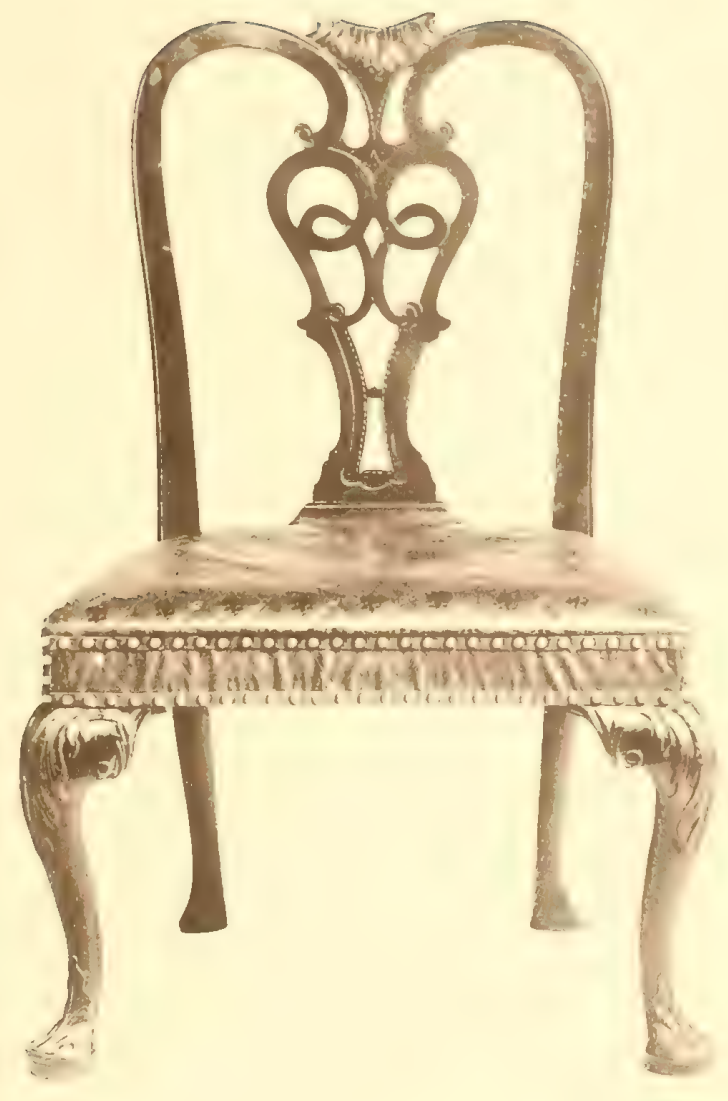

CHIPPENOALE CHAIE 

A chair table is mentioned in the inventory of John Copse, of Watertown, Mass., made in I644. How early they were made in Europe we do not know, but in England certainly as early as I558, in which year a "round chaire table in the plour" is disposed of by Andrew Cranewise, of Bury, in his will published by the Camden Society.

Their principal use was for tables. The tops were perhaps oftener round than otherwise, sometimes square, and occasionally octagonal. The item, "I Joyned Chayer table with the leafe eigh Square, $8 \mathrm{~s} ., "$ is found in 1675 , in the inventory of William Sprague, Sen., of Boston. As chairs their proper place was at the side of the room. The combination enabled the housewife to turn the table from the middle of the floor into a chair against the wall.

The specimen shown in Figs. 94 and 95 was picked up in Hingham, Mass, a few years ago, and now belongs to the writer. The table top is four feet three inches in diameter. The drawer under the seat adds to the quaintness of the piece. The feet are restorations. A very good table chair that belonged to Theodore Hook is illustrated by Mr. Robinson in "The Art Journal" for August, I88I.

An example of the square tables of the seventeenth century is shown in our next illustration, Fig. 96. The frame is of oak and well preserved. The drawer is lost, but was grooved on both sides to receive the 
guards on which it slid out and back, a contrivance of which the joiner of the seventeenth century was particularly fond. Turned frames, similar to the one here represented, belonged to many of the long, round, and square tables which figure in the New England inventories in the last half of the seventeenth and early part of the eighteenth century.

This specimen belongs to Mr. G. H. Hale, of South Glastonbury, Conn., where it has been known for many generations. Its top is forty-two inches square and twenty-seven high from the floor.

A very interesting table belonging to $\mathrm{Mr}$. John Pickering, of Salem, Mass., is shown in Fig. 97. There is no definite history of it, but the tradition in the family has always been that it was brought to this country by his ancestor, John Pickering, who came here about $163 \%$.

The frame of the table under the top has probably undergone some alteration, but the legs and stretchers are believed to be in their original condition. Certain details about the legs and feet remind us of the under parts of the six-legged chests of drawers, and while we have no positive opinion to offer as to the age of this table, we are inclined to think that it was made at the close of the seventeenth or in the beginning of the eighteenth century.

In 1669 " an Ovall Table, In the Hall," belonging 


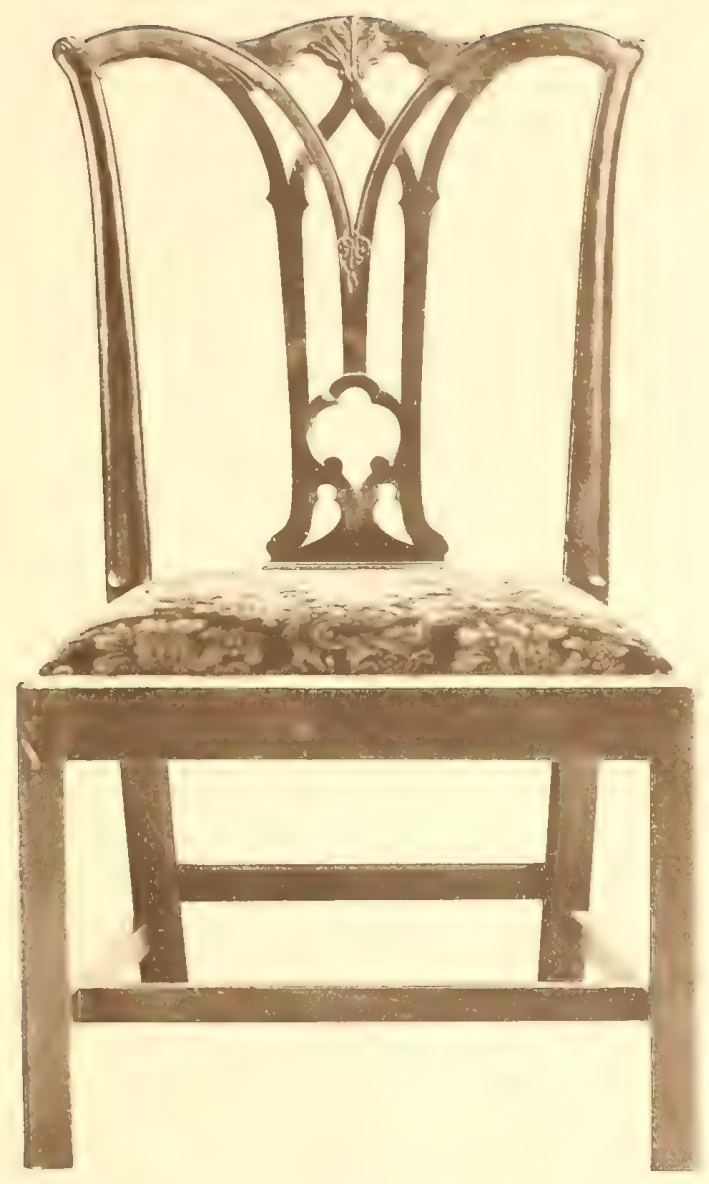

Fis. 80

CHIPPENDALE CHAIB 

to the estate of Antipas Boyes, of Boston, was inventoried at $\delta 3$. Io. The oval top in this instance may have been fastened to a square frame like the one shown in the last illustration, but from the price given it was with greater probability a table with leaves, sometimes called a folding-table, of the style and make represented in Fig. 98. Such tables had already been in fashion in England for one or two decades at least, and during the latter part of the seventeenth and first half of the eighteenth century became very common in this country.

They were made quite narrow in the frame, so that when the flaps were down the table occupied a very small space at the side of the room, but the leaves were often so large that when up a good sized table presented itself.

The framed supports for the leaves give to these tables the appearance of having a great many legs. On this account they are nowadays sometimes called thousand-legged tables. That this, however, is a modern sobriquet is probable from the fact that the expression thousand-legged is not found in the inven. tories, where these tables are referred to.simply as oval tables.

The specimen here shown is of moderate size, measuring about five feet in length, and three feet eight inches in its greatest width. They were sometimes made very large. One in the Heriot Hospital in 
Edinburgh is twelve feet nine inches in length by seven feet nine inches in width. Another of similar size was published by Mr. Robinson in "The Art Journal" for June, r88I. These great tables were supplied with a leaf on each side, and with oval end pieces made separate from the main table. An oval end piece which had belonged to such a table is preserved in the rooms of the Connecticut Historical Society of Hartford. Its framework is very heavy, the legs being three and five eighths inches square between the turnings. The width of the top is seven feet four inches, and this is not quite as wide as the main table of which it was a part.

A little table with a folding frame of this same style, but with a circular top in one piece, is shown in Fig. 99 from the Hosmer collection. The table is made to stand on the floor and to support its top in the horizontal position by placing the two portions of the frame at right angles with each other. By folding these parallel with each other the top falls on a hinge to a vertical line, just as is often seen in stands and stand tables, and the table thus folded being unable to support itself is placed in a closet, or against the wall at the side of the room.

A style of table very common in New England, from about the beginning of the eighteenth century, is shown in Fig. Ioo from the Hosmer collection. The tops were usually round or oval, but sometimes 


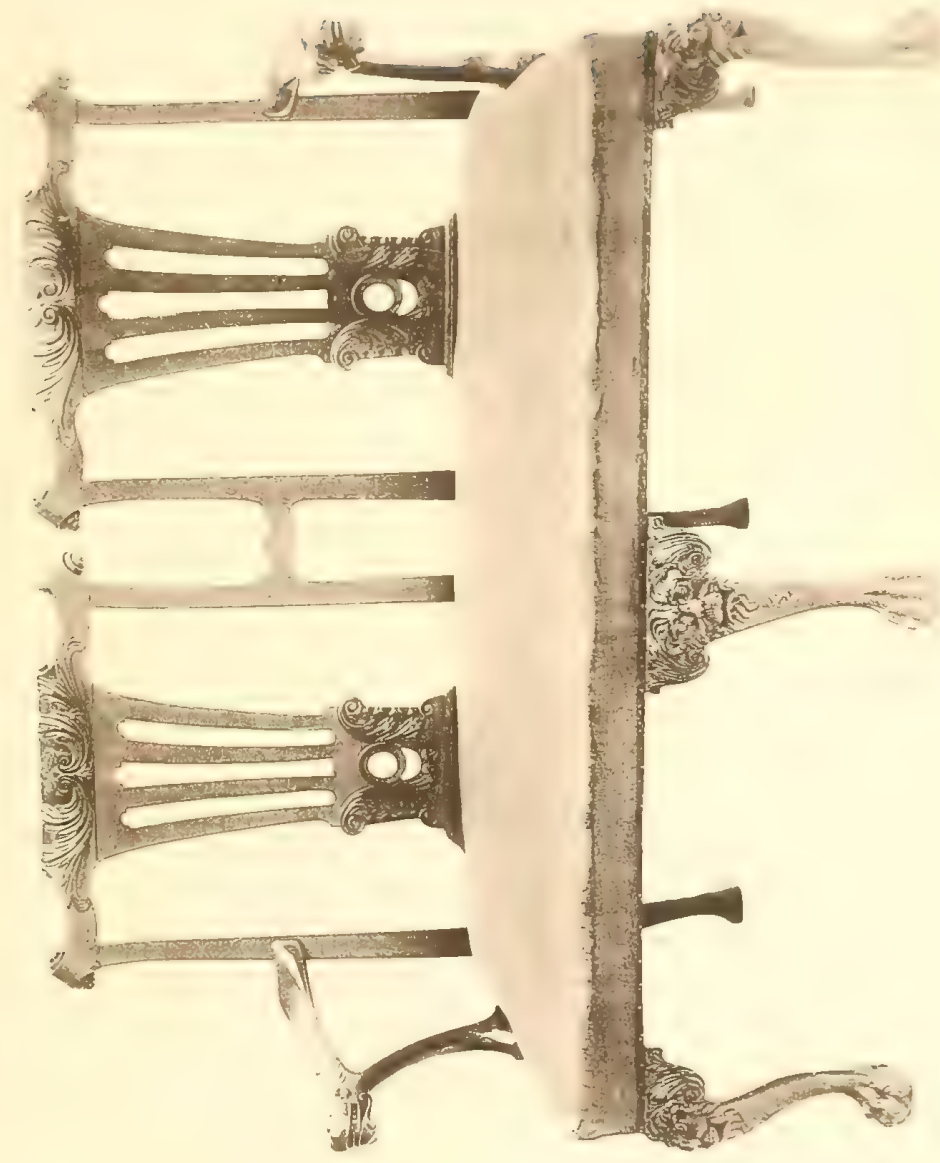



square. Each leaf was kept up by a leg swinging outward to a right angle with the frame. The feet were generally plain, but after I750, in the best tables, were sometimes of the ball and claw pattern, as in the present instance.

A very quaint little table, quite common in Connecticut, but apparently very little known elsewhere, is shown in our next illustration, Fig. IOI. From the spreading of the legs one receives the impression that it may be of German origin; and from its general construction, and the histories and traditions accompanying certain specimens, it is quite evident that the style dates back into the first half of the eighteenth century. Its peculiarities are the spreading of the legs, and the method of supporting the flaps, which is well shown in the illustration. These supports are made to swing either way in putting down the leaves. None of the furniture connoisseurs in England and Scotland, to whom a picture of this table was shown a few years since, had ever before seen one like it. We show in Fig. IO2 a little table made on the same plan, but without flaps. It belongs to the Hosmer collection. Such tables are seldom seen in New England.

A curious table, also belonging to the Hosmer collection, is shown in Fig. IO3. The top turns on the center of a triangular bed. The leaves, when up, are made to rest on the angles, and when down 
to fall at the sides of this triangular frame. These changes are accomplished by the rotary motion of the top. By raising the leaves the piece is changed from a triangular to a circular table. It is made of mahogany, and dates from about the middle of the last century. One just like it was seen by the writer in the shop of a Boston dealer two or three years ago, which he had lately imported from Holland.

Stands deserve a passing notice as being objects of household furniture with which the past generations have been quite familiar, and which date as far back certainly as 1676 , as in that year " 3 stands" are found in the inventory of Freegrace Bendall, of Boston. In 1677 " 2 Stands, In the Hall Chamber," were valued at five shillings, in the inventory of David Anderson, of Charlestown, and in 1686, " 2 Stands, In the Chamber," are mentioned in the inventory of William Condy, of Boston. They did not become numerous till after the beginning of the eighteenth century. Their tops were for the most part round in shape, sometimes square, and were supported by a single column, or pillar, which terminated below in three spreading feet or claws. Such tables with circular tops two or three feet in diameter, and sometimes with a low railing around the outer edge, were called Dutch tea tables early in the last century. Later they were known as stand tables, and these were sometimes of large size. We show 

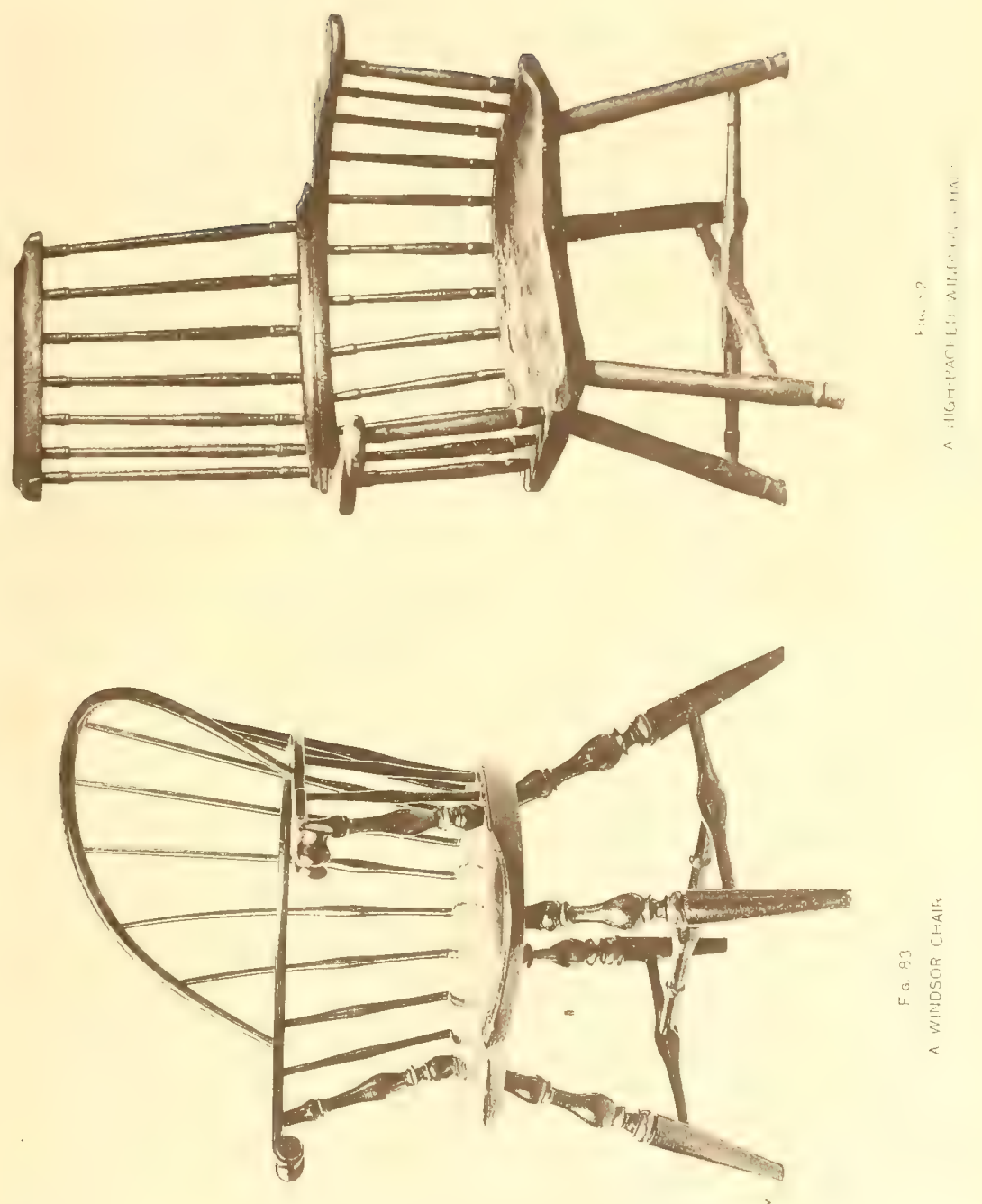

in Figs. I04 and I05 two views of a very fine Dutch tea table, belonging to Mrs. Henry Roberts, of Hartford, Conn.

Slate and stone tables began to appear in the inventories toward the close of the seventeenth century. A few examples are here given:-

"A Stone Table, \&I. Io." - Inventory of Mr. Richard Hooper, Watertown, Mass., I69I.

"In the Lower Roome, A Slate table, $f$ I." - Inventory of Thomas Pemberton, chirurgeon, Boston, I693.

"In $y^{\mathrm{e}}$ hall, I Slate table, $\&_{\mathrm{I}} \mathrm{I}$. IO." - Inventory of Captain Christopher Goffe, mariner, Boston, I699.

"A Table $w^{\text {th }}$ a Stone in the Middle, $£$ I." - Inventory of Captain Zechariah Long, mariner, Boston, I $703-4$.

"In the Hall Chamber, I Slate table, £3. I2." Inventory of John Hodson, New Haven, I 7 II.

"In the front Lower Room, I Stone Table, $£$ I." - Inventory of John Cutler, chirurgeon, Boston, I 7 I $7-18$.

"In the back Chamber, Stone table, 20/." - Inventory of James Le Blonde, merchant, Boston, I 7 I 9.

"One inlayed Slate table Leaff, $£ 3$. Io." - Inventory of Deacon Samuel Shepherd, Middletown, I 750.

It does not appear that these tables were very numerous. We have notes of twenty-five from the 
inventories, the date of the latest being I 764. We have also seen two examples. One of these belongs to the American Antiquarian Society of Worcester, Mass., having been presented in 1847 by the late John Preston, of New Ipswich, N. H., with a detailed history of its descent from his ancestor, the Rev. Nehemiah Walter, who was graduated from Harvard College in I684. It has four turned legs united near the floor by four turned stretchers. The top, which is octagonal in form, is forty inches long by twenty-five inches wide. The slate, a part of which is missing, is dark in color and a little over one eighth of an inch in thickness. It is also shaped octagonally, and measured when whole a little over twenty-nine inches in length by fourteen and a quarter inches in width. It occupies the central portion of the table, and is surrounded on the same level by an inlaid border of wood three and a half inches in width. There is a drawer under the top which pulls out at the side instead of at the end of the table. Fastened to the drawer is one of its original brasses. It is of the drop variety hollowed out behind, such as has been described as one of the oldest styles found in this country, and which ceased to be put on new work about 1730 .

The second specimen is owned by Mr. W. F. J. Boardman, of Hartford, Conn. Its style is that of the dressing-tables (Fig. 29) made to go with the 
six-legged chests of drawers. The slate is squareshaped, twenty-nine inches long by fourteen and a half wide, and, like the specimen at Worcester, is surrounded by a border of marquetry. This is five and a quarter inches wide, of a light-colored ground, in which conventional figures of dragons, scorpions, and squares are elaborately inlaid with woods of a darker hue. Its brasses are of the same style as those on the other specimen. It was undoubtedly a table made to accompany a six-legged chest of drawers, but was finished with an ornamental instead of a plain top. Dressing-tables of this kind with tops enriched with inlays of wood, but without the slate, are known to collectors.

According to the language of the inventory the "slate table leaf" that we have cited from the estate of Deacon Samuel Shepherd was "inlaid." We therefore have three tables with slate and marquetry entering into the decoration of their tops. There was also, in all probability, a wooden border of more or less richness to the "table $w^{\text {th }}$ a stone in the middle," which had belonged to Zechariah Long.

From the foregoing facts we may reasonably conclude that the slate and stone tables of the period now under consideration were so called because slate and stone entered into the construction of their tops. That the use of these materials was not restricted to any particular kind of table is shown by the differ- 
ences between the two examples here described, and also by the fact that slate and stone tables were found in the various apartments of the house.

"A marble table, In the Hall," is mentioned in I665 in the inventory of Governor John Endicott, of Massachusetts. This, however, seems to have been an exceptionally early specimen, as the next reference to them that we find in our notes is the item, "A marble Table, $£ 8$," which occurs in 1726 in the inventory of Mrs. Elizabeth Pitts, of Boston. They are frequently mentioned in the London newspapers from about the year I 7IO. Besides the two instances now given some of the most valuable facts relating to these tables, which have been gathered from our colonial records, are contained in the following extracts:-

"In the Chamber, A Marble Table \& Frame, £ro." - Inventory of William Griffith, merchant, Boston, I 740.

" I Large marble Table \& Frame, f8." - Inventory of Captain William Bennett, mariner, Boston, I 74 I.

"In the Hall, I fine marble Table, $£ 70 . "-$ Inventory of William Clark, merchant, Boston, I742.

"I Marble Table, £i 2." - Inventory of Peter Faneuil, Boston, I 743 .

"In the Parlour, I marble Slab \& Table, $£$ Iо." Inventory of James Pemberton, Esq., Boston, I 747 . 

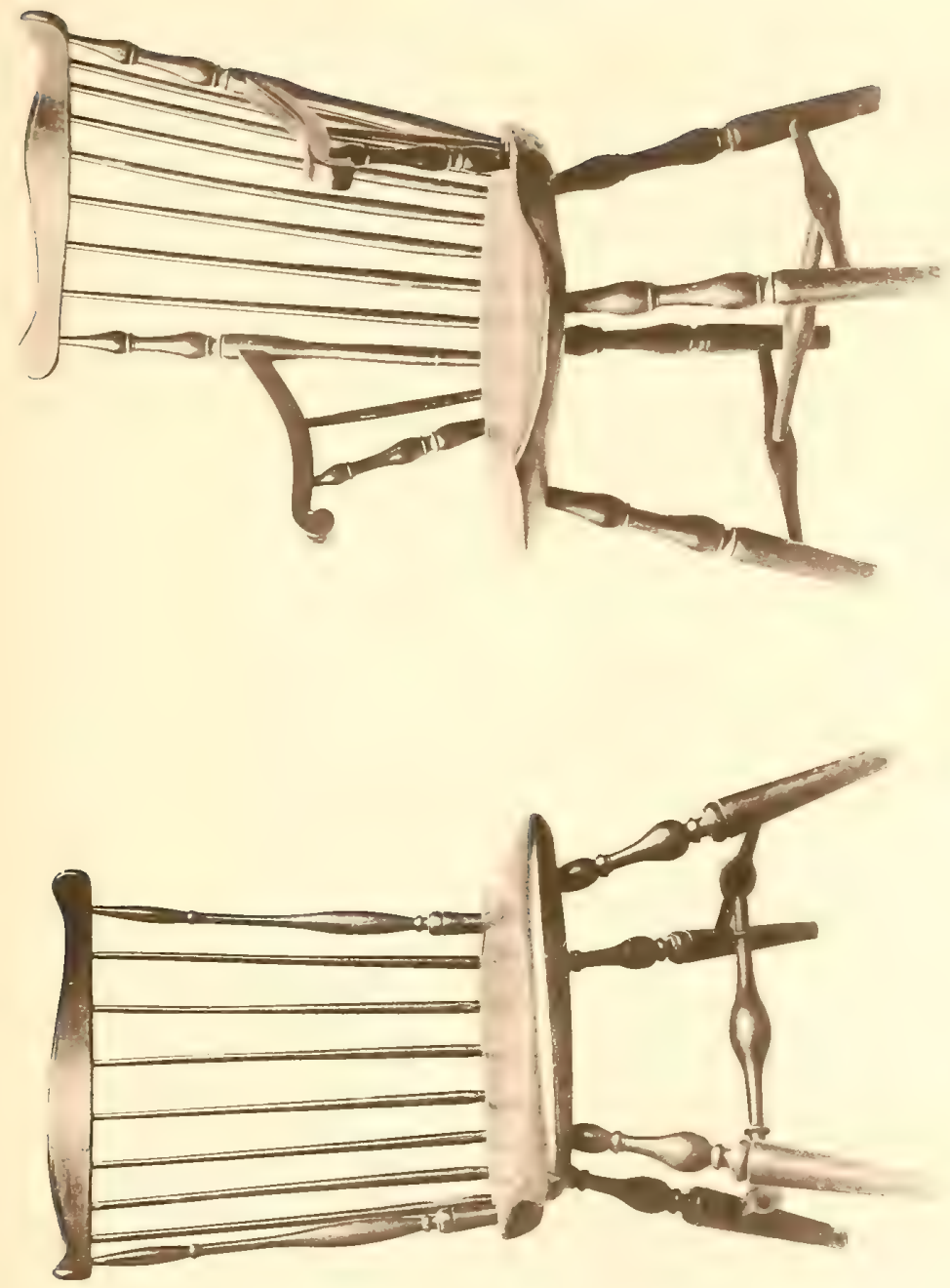

"In the Great Parlour, I Marble Table w $w^{\text {th }}$ Mehogany Frame, $\& 50 . "$ - Inventory of Nathaniel Cunningham, merchant, Boston, I748-49.

"In the Great Parlour, One marble table."

"In Dining Room up Stairs, I Marble Table." Inventory of Charles Apthorp, merchant, Boston, I759.

"I Marble Side Boord \& Frame, £2." - Inventory of Joshua Winslow, Esq., Boston, I 769.

This last item will be recognized as the one previously quoted in connection with sideboards in the chapter on Cupboards.

The prices here given from 1726 to 1750 are in the depreciated paper currency of the day, and are therefore somewhat misleading. Reduced to silver, according to the scale given in Felt's "Historical Account of Massachusetts Currency," they would be, beginning with the table that belonged to Mrs. Elizabeth Pitts, £3. 15. $3 ; £ 2.17 .1 ; £ 2.5 .8$; $£ 20 ; £ 3.8 .6$; 2.2 .1 ; and $£ 6.13 .4$, respectively.

As marble tables were found all over the house, it is probable that their uses were various, like the slate and stone tables just considered. They differed from the slate tables in respect to size, being as a rule larger; in having, so far as we know, marble only, and no wood in their tops; and in being used more or less for sideboard tables. In the chap- 
ter on Cupboards we have cited from a London newspaper of 1746 " a large marble sideboard table," and also mentioned that Chippendale made sideboard tables from five to six feet long with marble tops.

The Heppelwhite tables found in New England are chiefly of the card and Pembroke styles figured in his book of designs published in I 789 . They are made of wild cherry, mahogany, and sometimes of rosewood, and are inlaid with satin, holly, ebony, máple, sumach, and other woods. Indeed, the beauty of these tables consists mainly in their inlays, which are sometimes very rich. The table, Fig. I06, in the possession of Mr. Edwin Simons, of Hartford, Conn., is a good example of the card tables made after the style of Heppelwhite. The Pembroke tables are small, with two leaves and with square or oval tops. According to Sheraton the name was derived from "the lady who first gave orders for one of them."

Having treated of the various kinds of diningtables used by our ancestors, it may not be wholly out of place in concluding this chapter to say a few words about the rooms in which the meals were eaten, as well as certain articles of table furniture which are now of historic interest.

The dwelling-houses of New England in the seventeenth century were usually divided into the following apartments, namely, the hall, one or more parlors, the kitchen, the chambers over these rooms, 

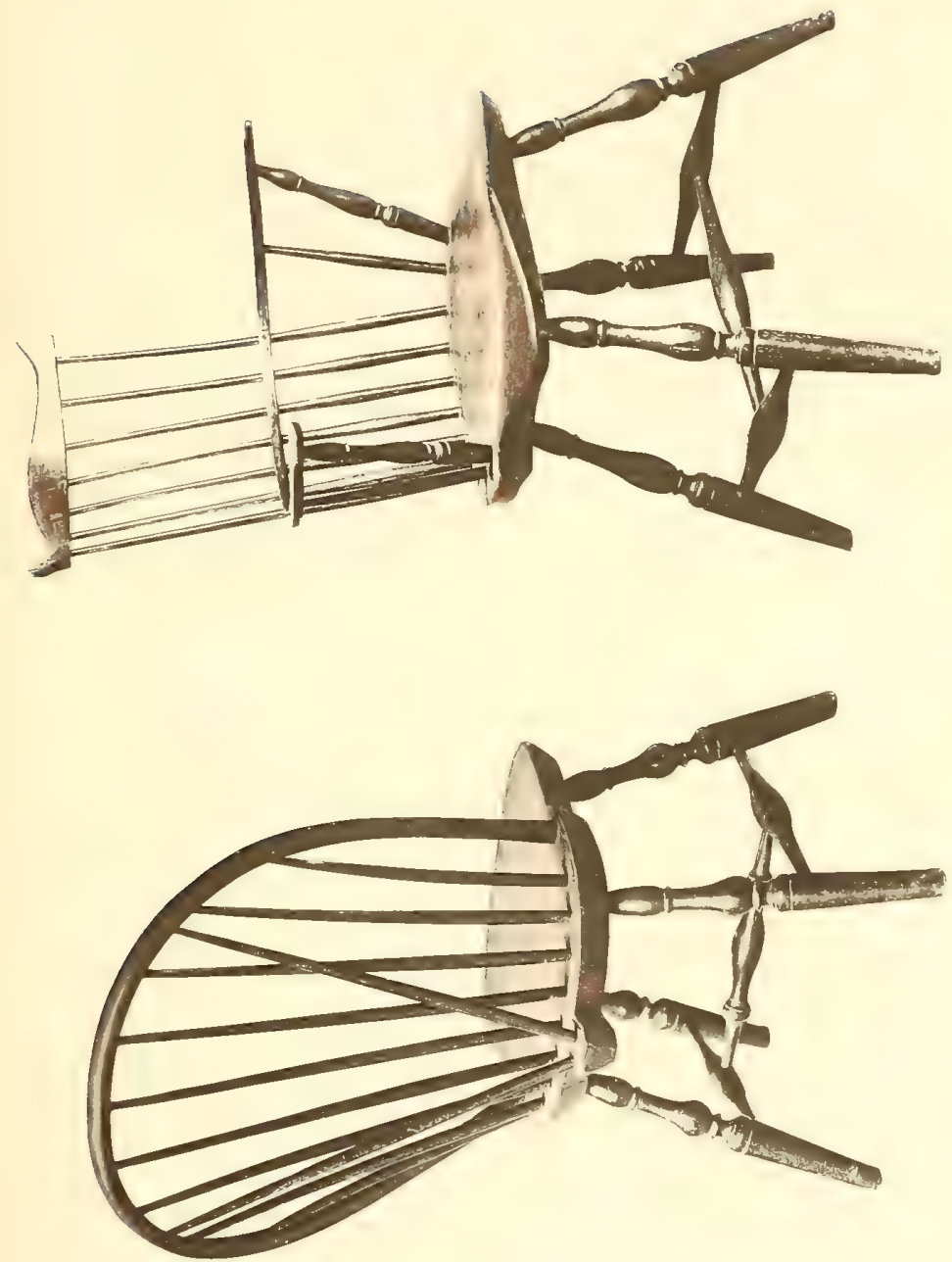

and the garrets. Other rooms are occasionally mentioned in the records; some of these will be referred to as we proceed. Of these apartments the hall and the parlor were those used by the well-to-do as diningrooms.

It must be remembered here that the hall of these early days had nothing in common with the hall of our modern houses. Instead of being a mere entrance way it was the principal living room of the family, just as it was in England at the same time and among the same people, and just as it had been there for several centuries.

The place in the houses of the seventeenth and eighteenth centuries that corresponded to what we now term the hall was then called the entry. The word entry in this sense is found in the Boston inventories from about I 650 to I 835 , after which these records are no longer available for this inquiry, as the ancient custom of mentioning each room by name and apprizing its contents item by item was then discontinued.

The word hall in its modern sense was in use in England as early as the beginning of the eighteenth century, when spacious entrance halls became architectural features of the palaces and manor houses built after the Anglo-Palladian style then in vogue. Such halls are to be seen in Marlborough House in London, and in Blenheim in Oxfordshire, built in 
I709 and I7I5 respectively. The name hall was given to such entrances as these on account, probably, of their great.size. But the style with its nomenclature soon reached the houses of the middle classes, who found little difficulty in calling their new and greatly enlarged entries by the new and fashionable name.

The evidence furnished by the Boston inventories is sufficient to show that a much longer time elapsed before the entrance ways of New England houses were called halls. Corroboration of this is also found in the definition of hall given by Webster in his folio dictionary published in 1828 . By comparing it with the earlier definitions of Bailey and Johnson, it will be seen that Webster did not then recognize the more modern use of the word to designate the entrance way of an ordinary dwelling-house.

There is proof, however, that some New England people called the entrances to their houses halls long before the custom was fully established. The earliest instance of this that we have met with is in 1754 in the inventory of John Salmon, of Boston, merchant. The record is as follows: "In the Hall, I glass Lanthorn, $5 / 4,5$ pictures or maps, $8 /$." There can be no question that the hall here referred to was the front entry, as its contents, which are here given in full, are such as are almost invariably found in the front entries of the Boston houses of this period. 

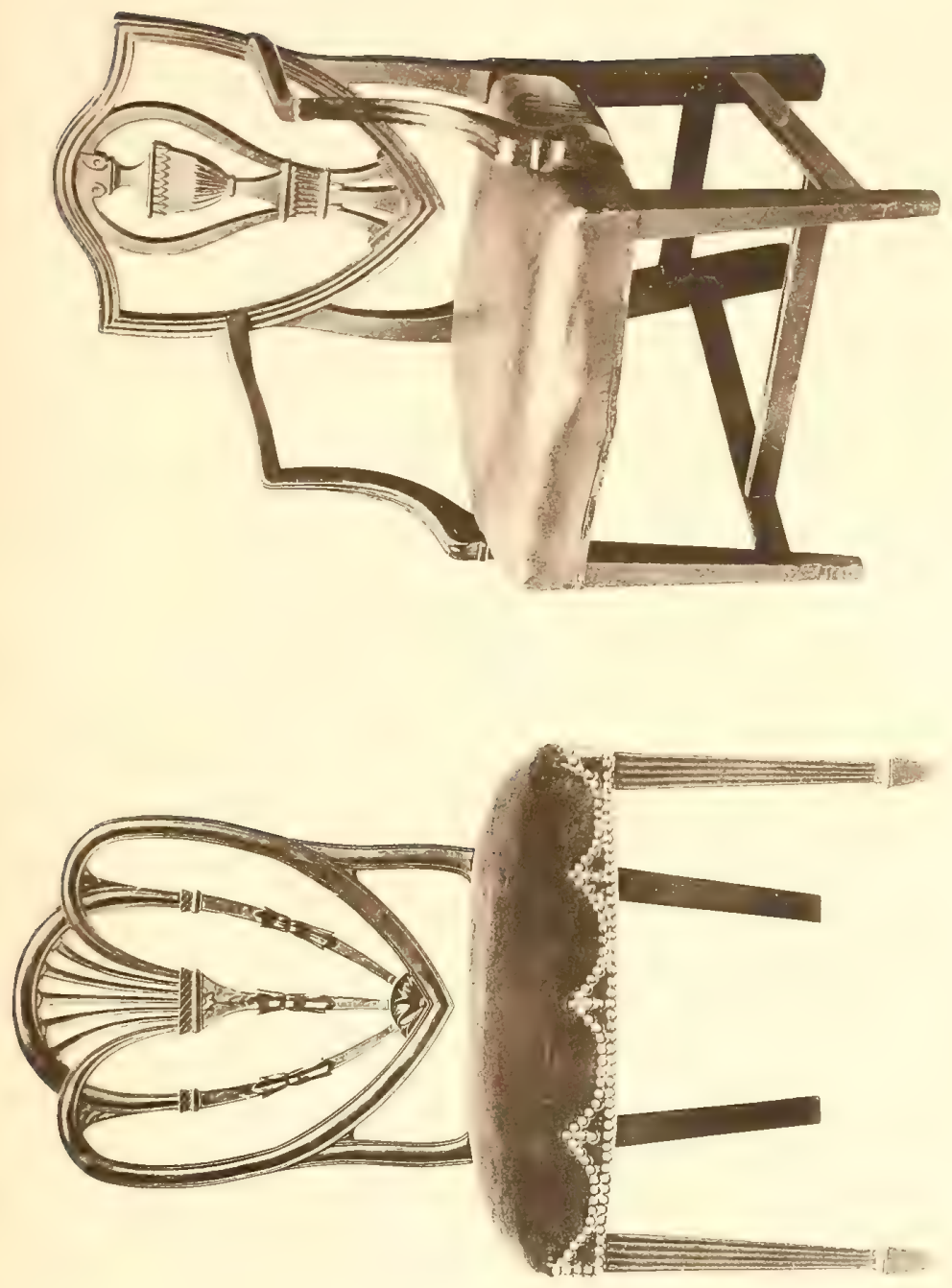

Another fact bearing on this point has been communicated to the writer by Mr. George R. Curwen, of Salem, Mass. This gentleman remembers perfectly well an incident that occurred about the year 1833, in which his aunt, the late Mrs. James Cushing, of Salem, spoke of the front entry of her house as the hall. She was then about sixty years old, and as this habit continued through life, it is altogether probable that it was acquired considerably before the year I 833 .

As a rule, the front entry of a New England house made before I 750 was built in front of the single central chimney and contained, besides the staircase, but little more than space enough for the front door to swing open. Most of these entries had no furniture whatever in them, and this is why they are so seldom mentioned in the inventories.

Let us now return to the Puritan hall of the seventeenth century. The reader has doubtless noticed in the quotations from the inventories given in the preceding pages that many different kinds of furniture have been mentioned in connection with the old colonial hall. A better idea of this apartment and of its uses can be obtained by studying its contents together. For this purpose all the items of furniture found in two of these halls are here given:-

"In the Hall, a drawing Table \& a round table, £I. I8.

A cubberd, \& 2 long formes, I4s. 
A cubberd cloth, \& cushions, I3 S. ; 4 setwork cushions, I2 S., $£$ I. 5 .

6 greene cushions, I2 S。; a great chaire with needle worke, 13 s., $£$. . 5 .

2 high chaires setwork, 20 s. $; 4$ high stooles setworke; $26 \mathrm{~s}$. 8 d., E2. 6. 8 .

4 low chaires setworke, 6 s. 8 d., $£$ r. 6.8 .

2 low stooles set worke, ro $\mathrm{S}$.

2 Turky Carpetts, £2 ; 6 high joyne stooles, 6 s., £2. 6 .

A pewter cisterne, \& candlestick, $4 \mathrm{~s}$.

A pr of great brass Andirons, £2. 0. o.

A prof small Andirons, $6 \mathrm{~s} .8 \mathrm{~d}$.

A pr of doggs, 2 s. 6 d.

A pr of tongues, fire pan, \& bellowes, 7 s."

Inventory of Theophilus Eaton, Governor of New Haven Colony, Connecticut, I657.

"In the Hall, 2 brasse Andirons, Doggs, fyrepan and tonngs, £2. 10.

I2 Red Letherne Chaires, $£ 5$.

I pewter Cesterne, I paire of brasse snuffers, $5 \mathrm{~s}$.

6 Turkie Quishons \& 3 wrought, £2. 5 .

I drawing Table \& Carpet, \&2. Io.

I Round Table, $£$ I. 5 .

6 Joyne stooles, $\mathrm{I} 2 \mathrm{~s}$.

I Courte Cubbard \& Cubbard cloth, $£ \mathbf{r}$.

I Scollop Candlesticke, $3 \mathrm{~s}$.

3 screwes, 6 Roles, 2 wicker baskets, 8 s.

I Curtane \& Rod, I lb $\frac{1}{2}$ tourtell shell, 5 doz timbres, I3 s. 6 d. I 8 oz of plate at 5 s. Ounce, $£ 29$. Io."

Inventory of Jacob Sheaffe, merchant, Boston, I659.

It will be admitted that the presence of a drawingtable in each of these halls is sufficient to identify them as apartments used for dining. 

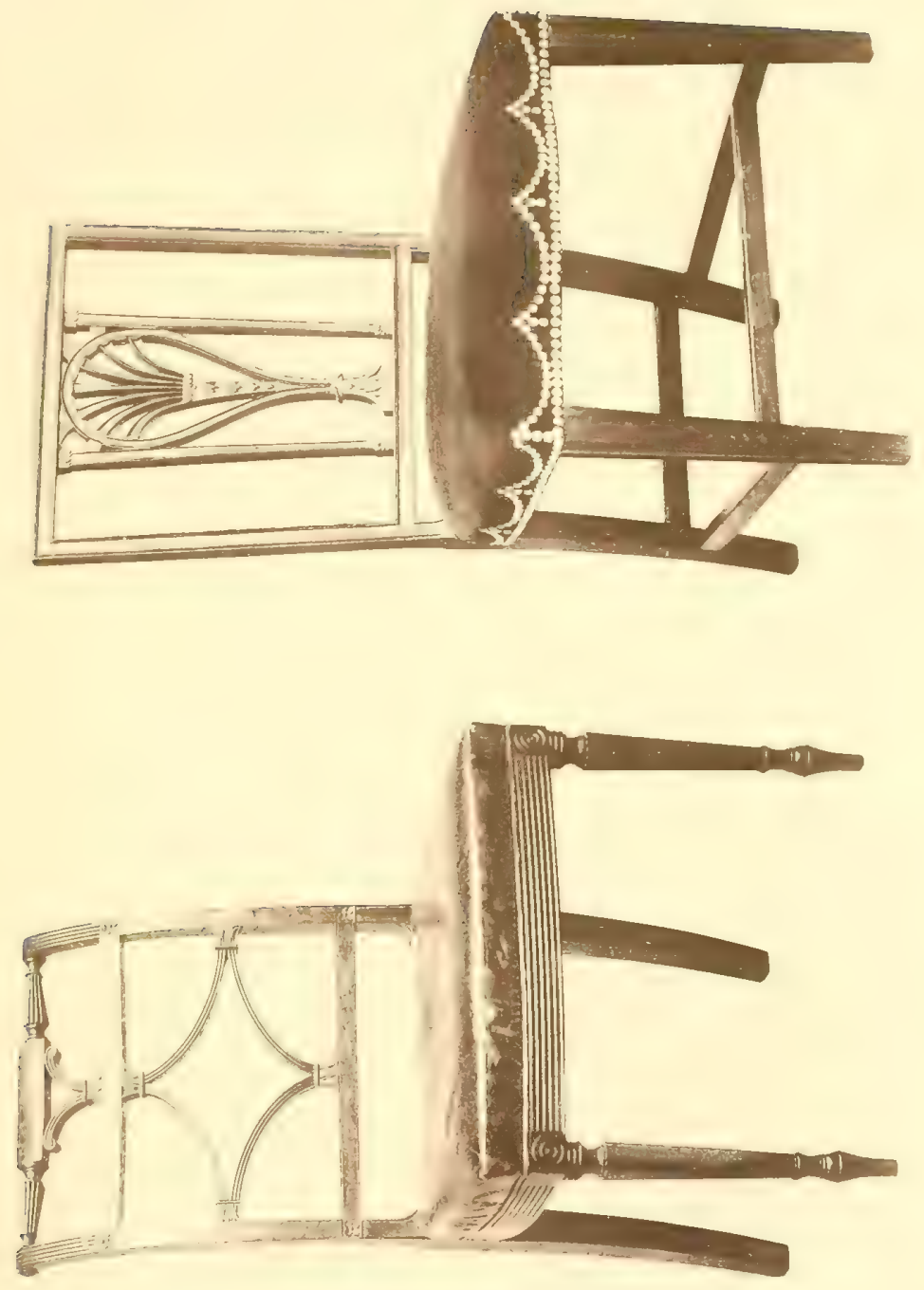


$$
\text { . }
$$


The history of the parlor in England as a place into which the family could retire for conversation and for meals, and thus escape the publicity of the mediæval hall, has been carefully traced by Wright and others from its beginnings at the close of the fourteenth century until it became the English dining-room.

In New England, from the first, it seems to have been the custom for many of the chief magistrates, the clergy, and wealthy gentlemen to make use of one of their parlors as a dining-room, either daily or on occasion. This is inferred from the character of its furniture. John Cotton evidently used " $y^{\mathrm{e}}$ great Parlour" of his house in Boston for this purpose, as it contained, among other things, a long table and carpet, a court-cupboard, cloth, and voider.

We give here the entire furnishings of one of these parlors belonging to Captain William Tyng, a Boston merchant, copied from his inventory made in I653:-

"In the parlour, a drawing Table, $£ 2$.

A Cipresse chest, $£ 5$.

8 red leather Backe chaires \& 2 loe leather Backe stooles, $£ 3$.

4 loe stooles \& 2 high Turky worke, £I. 8.

ro old cushiones, $16 \mathrm{~s}$.

A paire Brasse andirons $\&$ an iron hoope, $£$ I. Io.

2 pewter Stills, $£$ I. Io.

A Brasse clocke, $£^{2}$.

I old greine cubord cloath, $2 \mathrm{~s}$. 
I cluest of drawers, $£ 2$, I 0 .

Stript hangings 2 picktures \& a mapp, £I. Io.

2 dozen layd worke napkins, $£ 2.8$.

2 dozen $\frac{1}{2}$ of Course napkins, $£$ I. 5 .

4 paire large sheats, $£ 5$.

4 paire course sheetes, $£ 3$.

7 pillow beers, $£ 2$.

ro Table cloathes, $£$ I. 1 о.

Old iron $63 \mathrm{lbs}, 15$ s."

Captain Tyng had also a well furnished hall. In order to show that it was probably the chief living room of the family, and that it was used for meals also, we reproduce the record of its contents in full :

"In the Hall, 2 tables and a forme at $£ 2$.

I longe $\&$ I short stript carpetts and a greene Cubboord cloath with a Voyder, £I. IO.

I plaine Livery Cubard, sos.

I greine Couch layd with a case, $£ 2$. Io.

I velvett Window Cushion, I 2 S.

I great greine chaire \& 6 high backe chaires \& 2 loe backe stooles all greine and 2 turky worke high back chaires \& I old greine elboe chaire all cased, $£ 6$.

I great paire of brasse Andirons, I paire brasse creepers, I paire brasse tongs \& a brasse fireshovell, I pr of carved Bellowes, $\&$ an Iron hoope \& a brasse branch, $£_{3}$. ro.

1 Drum with drumsticks \& a case, $£^{2}$.

I great lanthorne \& an old paire Bellowes with a brasse pipe, $10 \mathrm{~s}$.

7 picktures, $7 \mathrm{~s}$.

I truncke covered with seale skins, $6 \mathrm{s."}$ 
Shortly after the middle of the century, diningrooms began to be mentioned in the Boston records. The first instance of this that we find in our notes is in the inventory of Antipas Boyes, whose estate was apprized in I669. The furniture of this room, which differed but little from that in the halls and parlors which we have already studied in detail, is here given in full:

"In the dyning Roome, a pr of Cast Andirons \& back, $£ 2$.

4 leather chayres, $£ \mathrm{I} .8$.

I long ceder table, $£ \mathrm{I}$. I5.

I3 joynt Stooles, $£$. 6 .

I small Table $w^{\text {th }}$ drawers, $6 \mathrm{~s}$.

A carpet, I5 S.

A wine Cisterne, I s. $6 \mathrm{~d}$.

A glass case with 9 peeces of earthenware, Io s."

As it is interesting to compare the furniture of one of these early dining-rooms with what was in the hall of the same house, the contents of the latter apartment are here subjoined :-

"In the Hall, 12 Turkey worke chayres, $£ 7 \cdot 4$.

A standing Cubbert, $£$ I. 10 .

An Ovall Table, $£_{3}$. ro.

A Round Table, $£$ r. ro.

A looking glass, $f$ I. ro.

A Cubbert cloath with a border, $£$ I. 5 .

2 Tinn branches, $3 \mathrm{~s}$.

A Round wicker voyder or charger, 2 s. 6 d.

A large pr of Andirons, $25 \mathrm{~s}$. 
A lesser pr wh brass heads, Ios.

A fyer pann \& tonges of brass, 15 S.

A carpet, I5 s."

One of the rooms in the house of Antipas Boyes was called "The little Parlour." The word little here suggests that there was also a great parlor, but no such apartment is mentioned in the inventory. The great parlor thus referred to by implication was probably the "dyning roome" whose contents we have just displayed. It has already been seen that the parlors of these days were often provided with dining-room furniture, and it is undoubtedly true that when these dining parlors began to be called dining-rooms, the words parlor and dining-room became convertible terms and remained so for a considerable time, until each acquired its more restricted and modern signification.

In Boston the hall, the parlor, and the dining-room were, therefore, the apartments in which the meals of the better classes were eaten. This remained so until about I725, when the hall began to be called the sitting-room by some, and, a little later, the keeping-room by others. In and about Hartford, Conn., it was called the dwelling-room. Under these new names it continued to be the principal living room of the household, and, like the old hall, was used by many as the family dining-room.

The old hall, however, did not at once surrender 


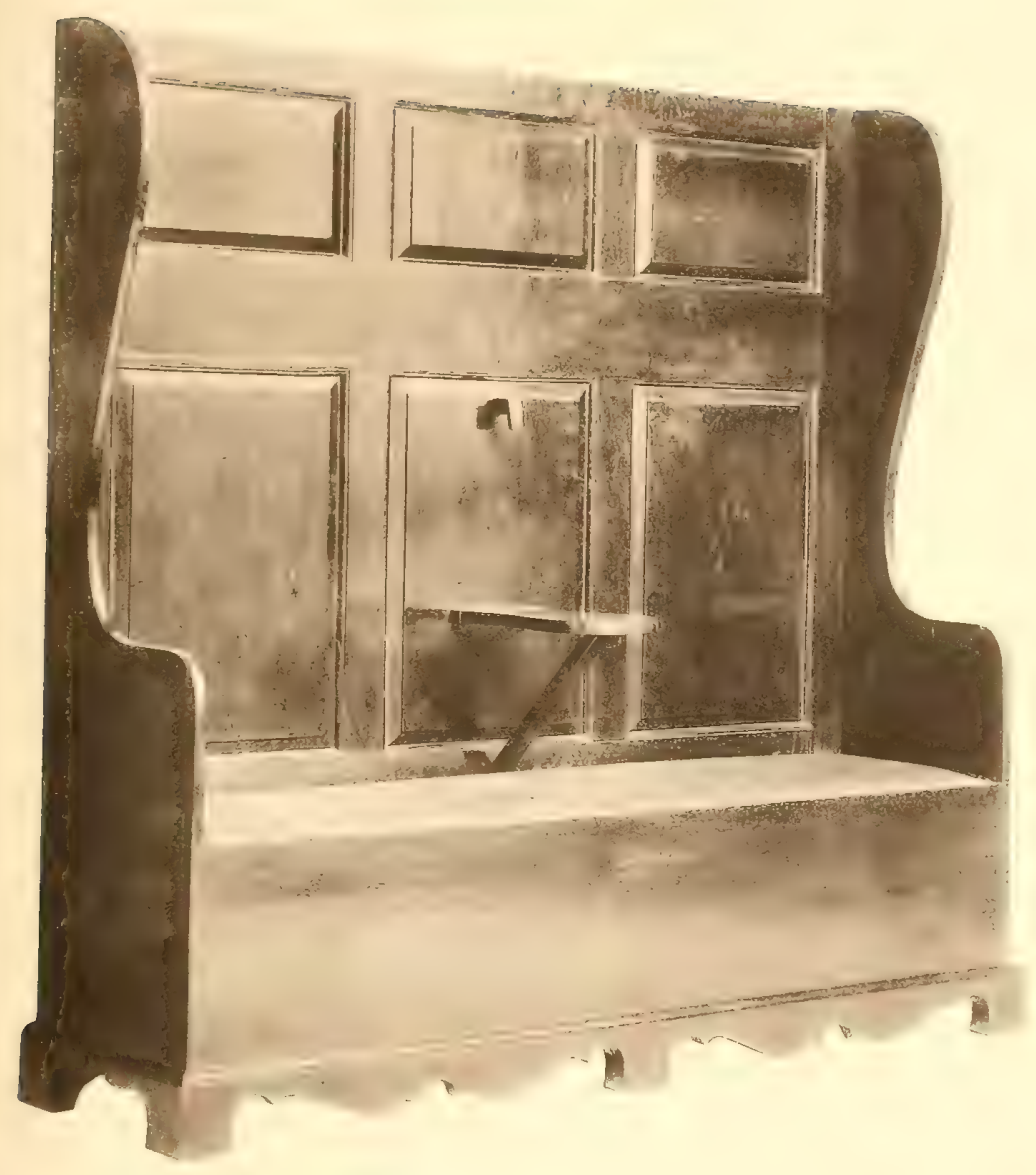

FIG. 92

A SetTle

$\because 1 \%, \ldots$, 

its name. It appears in the estates of many of the best people down to about 1750 , and is mentioned in the Boston records as late as 1770 , if not later. From about 1680 its furniture, like that of all other parts of the house, became more rich and abundant. Here are the contents of the hall of John Jekyll, Esq., of Boston, according to his inventory made in Iร32-33:-

"In the Hall, 2 Couches, Squabs \& pillows, $£ 3$.

I Eight day Clock, $£ 20$.

2 pictures Queen Ann \& Prince George, $£ 8$.

I3 small pictures, @ 7/6, £4. I7. 6 .

6 ffamily Pictures \& a Coat of Arms, $£$ roo.

I Tea Table and Set of burnt China, £I5.

I Large Looking glass, £3o.

4 glass branches, 2 Sconces, $£ 4$.

I walnut Card Table, £6.

2 pr window Curtains \& a painted Canvas for the flloor, $£ z$.

2 burnt China bowls, $£ 2$.

I ditto large Crackt, ros.

2 Slop Bowls crackt, ros.

2 Small Bowls, ${ }_{5} \mathrm{~s}$.

6 Chocolat Bowls (a) 5/, £.r. 10.

I pr Small Bowls, Io s.

12 Coffe cups with handles @ $5 /, £_{3}$.

5 Cups 4 Saucers @ 3/, £I.7.

I pr China Candlesticks Tipt $w^{\text {th }}$ Silver, $£ 4$.

I Tea pot \& saucer, Ios.

I hearth brush, Ios.

I drauft board, $£ \mathbf{I}$.

I doz ${ }^{\text {n }}$ Cane Chaires, $£ z$ o.

4 Stands, Io s." 
The following extracts from the same inventory will serve to mark the difference between the hall and the entry of this house, as well as to show the contents of the latter: -

"In The Entrys, \& on the Stair Case, 9 Painted Pictures, \&5. 2 lanthorns, \&4. 64 Prints @2/, L6. 8 s."

The coverings for the tables of the seventeenth century were tablecloths and carpets. Holland, diaper, and damask tablecloths are the varieties usually mentioned. These were sometimes enriched with colors. The item, "I Holland table cloth edged with blewe, 12 s.," is found in the inventory of Mrs. Ann Hibbins, of Boston, made in I656, and a "table Cloth wrought $w^{\text {th }}$ red" belonged to the estate of Humphrey Davie, Esq., of Hartford, Conn., inventoried in 1689 .

The carpets mentioned in the inventories in connection with tables are, green, green cloth, green broadcloth, Dorneck, Turkey wrought, calico, and occasionally Arras. The item, " 3 Arras Table cloths 20 s. each, $\mathcal{E}_{3}$," occurs in 1654 , in the inventory of Mr. Augustine Walker, of Charlestown. If it should seem a little strange to hear table covers called carpets, it will be interesting to know that in England the word carpet was applied to the coverings of tables, beds, cupboards, and floors from three to four hundred years before it was finally restricted, at 


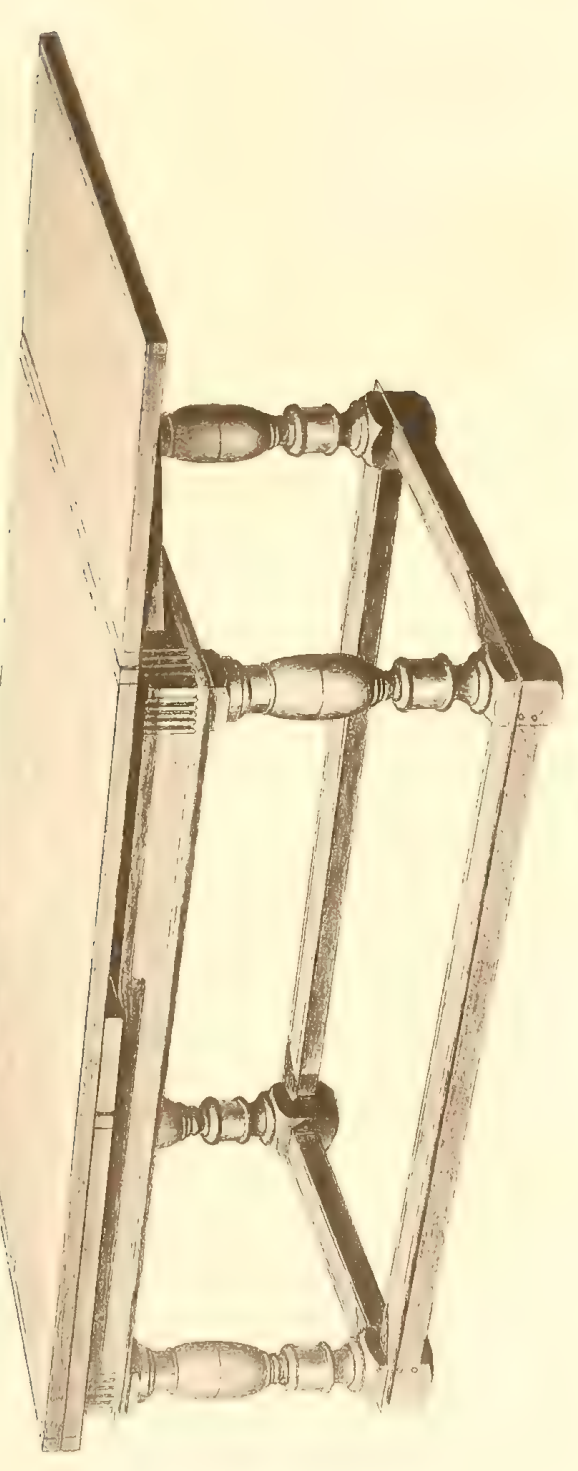



about the middle of the eighteenth century, to the coverings for floors.

The table dishes of our early colonial ancestors were chiefly pewter and wooden, with some alchemy, earthen, china, glass, and silverware. Tin and latten dishes were also in use, but rather for culinary than table purposes. The inventories abound with pewter platters, plates, porringers, flagons, tankards, drinking pots, cups, bowls, salts, and spoons. The range of wooden dishes was less extensive, the articles usually enumerated being trenchers, platters, cups, bowls, and spoons. Alchemy spoons, to judge from their frequent mention, were quite as common as pewter spoons, perhaps more so.

Earthenware begins with the early estates, but after the middle of the century white earthenware, blue and painted dishes are not infrequently met with. The following items relating to these wares are quoted from the inventories of the persons named: "A whit cup;" Joseph Weld, Boston, 1646. "6 small blew dishes, 2s.;" Mrs. Mary Hudson, Boston, I65I. "Io peeces of white earthen dishes, $6 \mathrm{s.}$;" William Blanchard, Boston, I652. "Blew dishe, 8d.;" Abraham Warr, Salem, I654. "6 white dishes," and " 2 white porringers;" Thomas Faulkner, Boston, I656. "In ten Paynted earthen dishes, IO s.; " Peter Bulkely, Concord, Mass., I659. "In white earthenware, $£ \mathrm{I}$;" Henry Webb, Boston, I66o. 
"Painted earthenware, 6s.;" James Davis, Boston, I66I. "Som duth [Dutch] earthen platters and Som other earthen ware, 6 s. 8 d.; " John Betts, Cambridge, Mass., I662-63. "I 7 peecis of blew and $w^{t}$ earth ware, 8 s. 6 d.; " Henry Harwood, Salem, I664. " 5 painted earthen dishes \& I salt, 3 s.;" Thomas Barnes, Hingham, Mass., I672. White and blue earthen dishes are also found in the Connecticut inventories.

The probabilities are very great that the white and blue and painted earthen dishes, as well as the Dutch earthen platters here referred to, were the enameled faïence made at Delft in Holland.

Holland ware is very seldom mentioned in our inventories before the eighteenth century. The only other instance that we have met with, besides the Dutch earthen platters which had belonged to John Betts, is in the inventory of John Cross, of Ipswich, made in I650, in which "Holland jugs" are mentioned.

The first positive mention of the Dutch ware noted in the eighteenth century is in the estate of James Lyndall, of Boston, merchant, inventoried in $\mathrm{r} 720$, in which "a parcell of Duch Tyle Broken" is apprized at $£ 2$. In I $72 \mathrm{I}$ the following items are found in the inventory of Mary Denison, of Wethersfield, Conn., namely, "Three holland earthen platters, 5 s.;" "two holland earthen platters, 2 s." In 


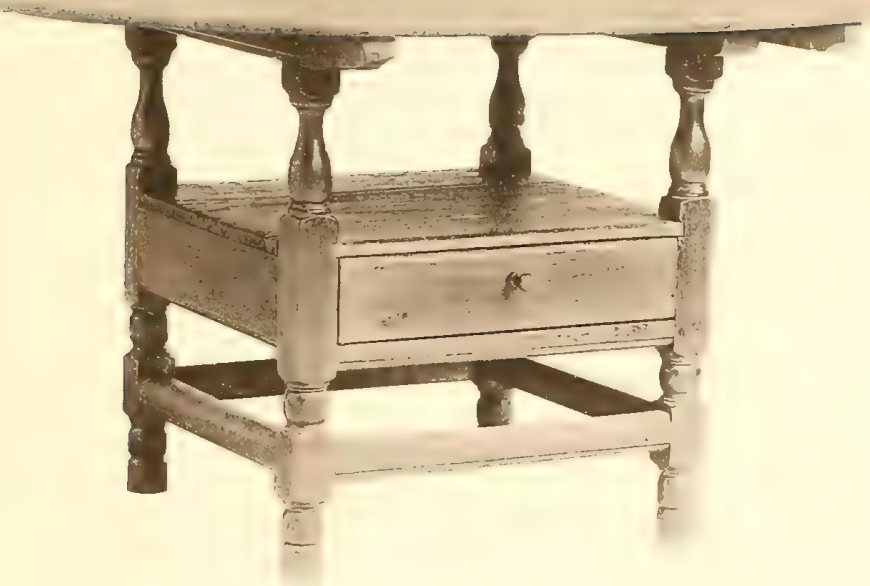



I 724 "A parcell of China \& Delph ware" was inventoried in the estate of Mr. Ambrose Vincent, of Boston, and in 1729 we find "Two large flower pots Delf ware $\& 2$ jars of $\mathrm{D}^{\circ}$. ," valued at $\mathcal{L}^{2}$, in the inventory of Governor William Burnet.

Delft ware had now become common. In the year last mentioned a large amount of it was inventoried from the stock in trade of William Welsteed, a Boston merchant, examples of which are as follows: "I Dozn Delph plates, I8s.;" "6 blue and white delph plates;" "I Dozn blue \& white delph Plates, \&.." “ I Dozn Delph pickle caucers, 8s." In I 734 Dutch fireplace tiles are again mentioned, this time in the inventory of John Ballantine, a Boston sea captain and merchant, as follows: "In the back Garrett, 9 dozen Dutch Tiles, $£$ I. Io." "In the Front Chamber, Io dozen dutch Tiles, $£ 2$. Iо."

The enameled earthenware made at Delft in Holland and the imitation of it made in England were imported into this country in large quantities down to the period of the revolutionary war. Very little, if any, was brought here after the war, as Delft ware had been practically driven from the market by the superior products of the English potters, among whom, at this time, Josiah Wedgwood stood foremost.

The item, "a stone jugg blewe \& white, 2 s.," occurs in $165^{8-59}$, in the inventory of Hugh Laskins, 
of Salem, and, in $1662-63$, "a stone judg tipt with silver" is apprized at $2 \mathrm{~s} .6 \mathrm{~d}$, , in the estate of Jacob Leager, of Boston. These white (gray) stone jugs decorated with blue, though now scarce, are well known to New England collectors. In England it is held by many at the present time that they are of German origin. " 3 fflanders jugs" are mentioned in $1678-79$, in the inventory of Thomas Rix, of Boston.

The history of china ware in New England is very similar to that of the faience of Delft. It begins to be mentioned in the inventories as early as I64I, and continues to reappear at short intervals and in small amounts till the early part of the eighteenth century is reached, when it began to increase rapidly, and soon became comparatively abundant. The following items are from the inventories of the persons named: "I Cheynie Dish;" Thomas Knocker, Boston, 1641. "Cheny ware platter, 20s:;" Thomas Coytemore, Charlestown, I645. "China dishes, I 2 s.;" William Clark, Salem, I647. "I Chany dish;" MajorGeneral Edward Gibbons, Boston, 1654. "I chaney bason;" Thomas Faulkner, Boston, I656. "A cheny bason;" Governor Theophilus Eaton, New Haven, I657. "6 small Chiny dishes, 20 s.;" John Coggan, Boston, 1658. " 3 boxes of east India dishes at $£_{3}$;" Catherine Coytemore, Charlestown, I659. "China Ware;" Rev. Samuel Stone, Hartford, 1663 , and so on. 


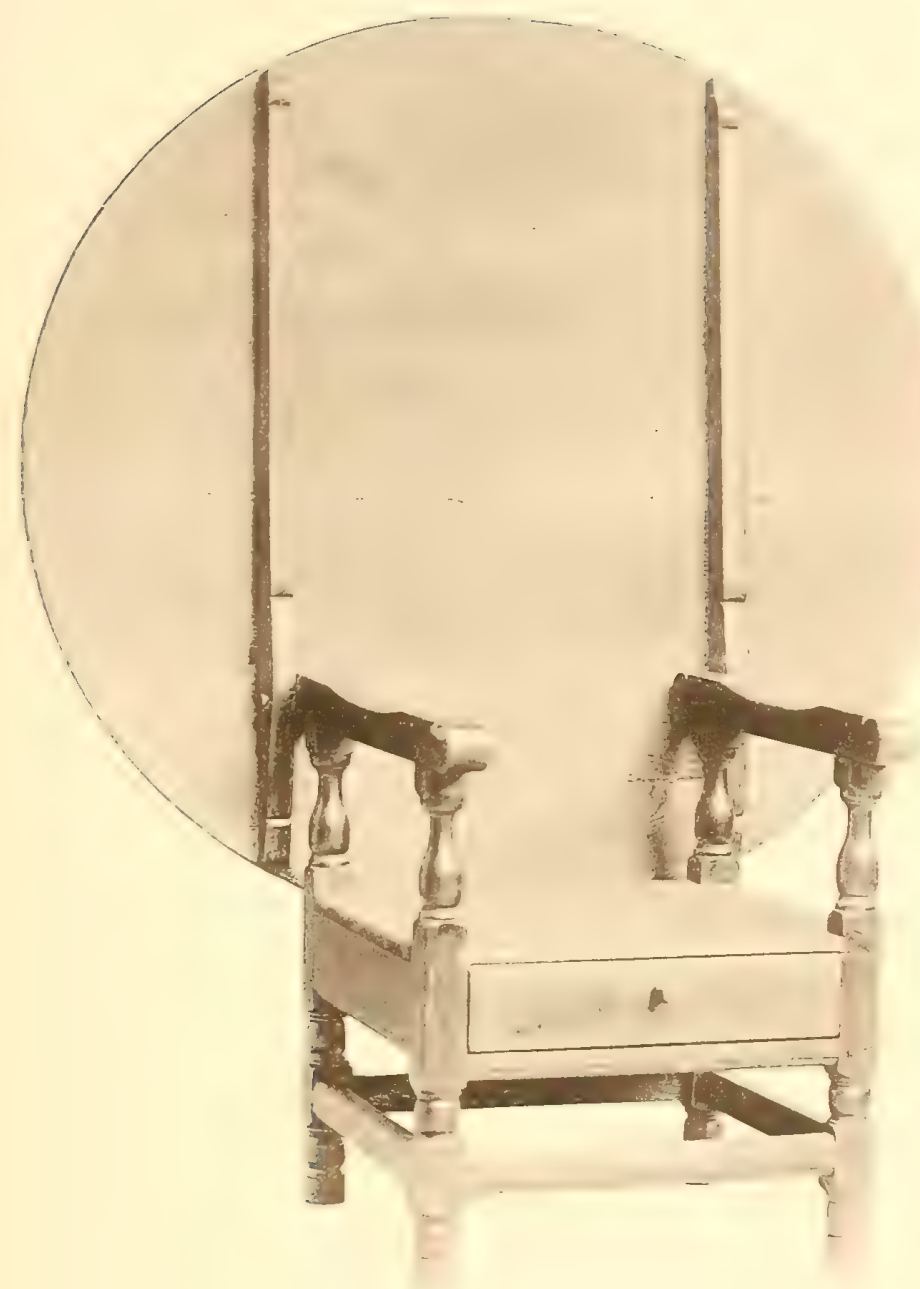



The following extracts from the Boston records will show how china ware began to increase in the beginning of the eighteenth century: "I 6 china cups \& I I china sawcers;" Samuel Shrimpton, I 704. "A parcell of China and Glass ware, I 5 s.;" Elizur Holyoke, I 7 II-I2. "I 2 Chaney Sasers, I 2 S., I I Cups $\mathrm{D}^{\circ}$, I I s.;" Captain Walter Roswell, I7I7. "Five China Dishes, One Doz China Plates, two China Muggs, a China tea Pott, Two china Slopp Basons, Six China Sawsers, four china Cups, \& one China Spoon-dish;" Isaac Caillowell, I7I8. In the inventory of Captain John Charnock, dated 1723 , fortytwo pieces of china ware are referred to, and in that of Governor William Burnet, made in I729, as many as three hundred pieces are mentioned.

To the Delft and china dishes, which began to increase so rapidly in the early part of the eighteenth century, were soon added others of various kinds. One of these was the white stoneware with salt glaze, made in Staffordshire in England. The date of the first importations we shall not here undertake to decide, but there is little doubt that the white stoneware referred to in the following extracts was the celebrated salt-glazed fabric of English origin:-

"To a Parcel of Earthen ware, $£$ I. 5."

"To Ditto yellow Bristo [Bristol] ware, £ I. 5."

"To Ditto white Stone ware, $£ 2 . "$ - Inventory of James Bennett, mariner, Boston, I 735 . 
"In the Shop, I6 pint Mugs Charlstown ware, 6d@, 8s."

“33 Quart ditto, I2 @, £I. I3."

"I62 peices white Stone ware, I2 @, £8. 2."Inventory of Mr. Wigglesworth Sweetser, Boston, I 745 .

With, or very soon after, the salt-glazed wares came the black Jackfield, the tortoise-shell, agate, cauliflower, pine-apple, and melon wares, all of English manufacture. These were often very beautiful in color and in design, and with the china and Delft dishes gave the tables of this period a very rich and attractive appearance.

All the different kinds of china and earthenware here mentioned, together with cream-ware, were advertised for sale in New England newspapers as late as the beginning of the war of the revolution, and good examples are to-day preserved in many New England collections.

Silverware was quite scarce among the early settlers, a cup, or beaker, or a few spoons being the extent in such families as had it at all. It soon began to increase, however, and some estates showed very considerable quantities for a newly settled country. Thus, in the inventory of Thomas Coytemore, of Charlestown, made in I645, I06 ounces of plate are valued at $£ 23$ I $7 \mathrm{~s}_{0}$; in that of Captain William Tyng, of Boston, made in 1653,316 ounces avoir- 
dupois are valued at $£ 60$. The plate which had belonged to Governor Eaton, of New Haven, was apprized, in 1657 , at $£ 107$ II s.; that which had belonged to Henry Shrimpton, of Boston, was apprized, in I666, at $£ 80$; that which had belonged to Thomas Kellond, of Boston, was valued, in $\mathrm{I}_{68}$, at $\mathcal{L}_{\mathrm{I}} 33$. 7.6.; and that which had belonged to Sir William Phips, of Boston, at $£ 415$ in 1696 . Among the articles mentioned are spoons, beakers, tankards, cups, wine bowls, caudle-cups, sugar-dishes, salts, basins, porringers, forks, inkhorns, candlesticks, and shoebuckles.

The use of forks at the table for feeding was introduced into England from Italy in the reign of James I. Some time must have elapsed before their use became general in England, as they do not appear among the effects of the best New England people until late in the century.

The first mention of them that we have found is in the item, "In a Case, silver spoone forke \& knife, $£ \mathrm{I}$," which occurs in the inventory of Antipas Boyes, of Boston, made in I669. Other early instances are the following, namely:-

In r671 the item, "one Case with spoone knife and fork, $7 \mathrm{s.}$, " is found in the inventory of Robert Patteshall, of Boston. In I675, in the inventory of John Freake, of Boston, "eight forkes" are mentioned among the items of his silver plate. In 1676 
"I Silver hafted knife \& forke" are valued at ten shillings in the inventory of Freegrace Bendall, of Boston. In 1684 "one knife and forke $w^{\text {th }}$ silver hafts " are found in the inventory of Thomas Powes, of Boston, and " 8 knifes and Forkes" in that of William Harris, also of Boston. In 1692 " 2 cases of knives \& a doz $z^{n}$ forks" are inventoried at fourteen shillings in the estate of Jeremiah Fitch, of Boston, and in 1693 " 9 forkes" are mentioned in the inventory of James Lloyd, of Boston, as having been a part of his silverware. From this time the mention of forks in the probate records occurs more and more frequently until their use became general.

We have seen that the forks in two of these estates, certainly, were of silver. This was often the case, and it may be interesting to add that the handles of the knives and forks were made of various materials, such as silver, ivory, agate, tortoise-shell, glass, japanned work, bone, horn, and wood.

Six " 4 pronged forks" are found among the items of silverware belonging to the estate of Captain Thomas Gilbert, innholder, of Boston, inventoried in 1719; and we read in Weeden's "Economic and Social History of New England," Boston, I89I, p. 622 , of "one dozen silver forks with three Prongs" ordered from London by Peter Faneuil about I 738.

Glassware was scarce among the early colonists. Glass bottles, drinking glasses, and glass wine cups 


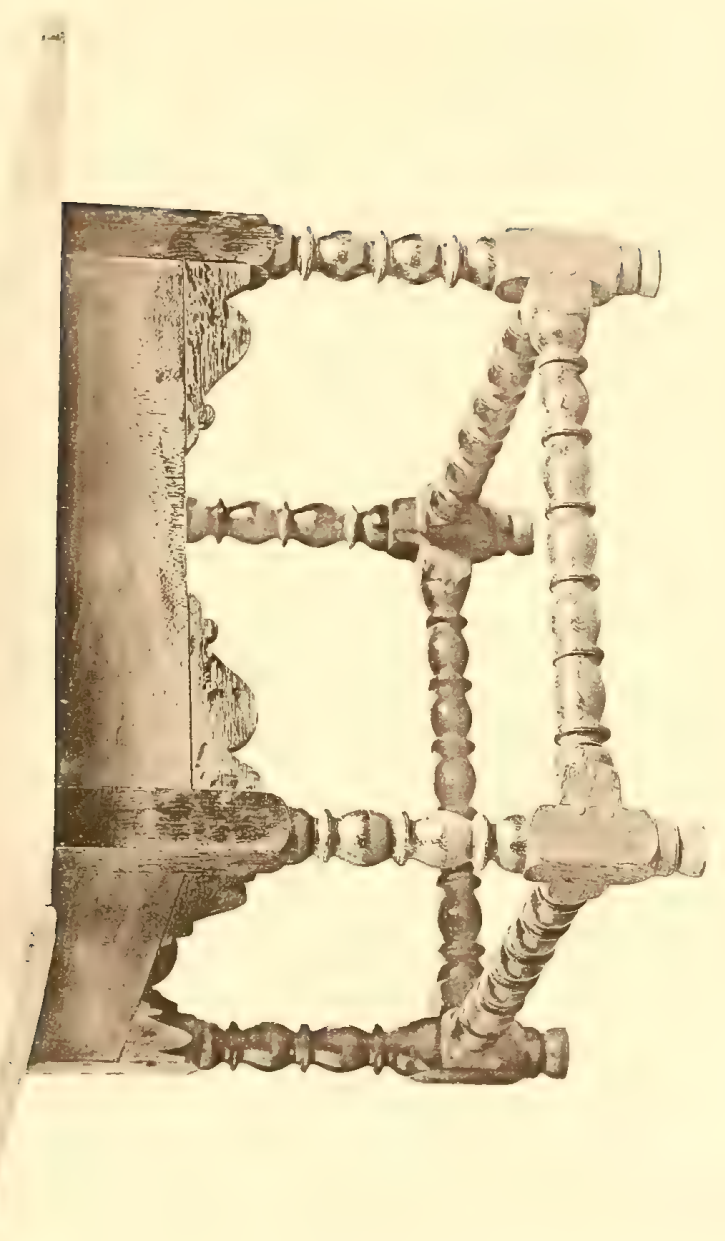



are occasionally found in the inventories. The rarity of glasses for drinking purposes may also be inferred from the not infrequent mention of such other drinking vessels as silver wine cups, pewter wine cups, earthen wine cups, and earthen drinking pots.

Cases of bottles and glass cases now and then appear in the records; the following are instances:-

"I case of bottles." - Inventory of Ephraim Huit, Windsor, Conn., I644.

"A case of bottles with a glasse in it." - Inventory of Major-General Edward Gibbons, Boston, I654.

"A case $w^{\text {th }}$ I 2 quart bottles, $w^{\text {th }}$ a locke, 5 s."

"A case with 12 pinte bottles $w^{\text {th }}$ a locke, 3 s. 6 d." - Inventory of Governor Theophilus Eaton, New Haven, 1657 .

"A Case \& seaven glasses, 5 s." - Inventory of Joseph How, Lynn, Mass., I650-51.

"I Glasse Case with some Glasses \& Earthen dishes, Ios." - Inventory of Henry Webb, Boston, I660.

"A glass case with 9 peeces of earthenware, Ios." - Inventory of Antipas Boyes, Boston, I669.

The cases for bottles were made of wood, and were in the form of a box or little chest. They were sometimes more or less ornamented and furnished with metal mounts. When the lid was raised a number of compartments were brought to view, with a bottle in each. There were sometimes one or more glasses, 
similarly disposed, for drinking the contents of the bottles.

We have neither seen a glass case nor a description of one, but suppose that in construction they resembled the cases for bottles. It will be seen from the above extracts that their contents were not restricted to glassware. An interesting reference to the glass case and its uses is contained in the quotation from Comenius in the chapter on Cupboards (page 50 ).

Much of the table glassware of the eighteenth century that we see to-day is coarsely engraved with zigzag lines, festoons, flowers, and figures. It was also a common practice to flute the lower part of the tumblers and flip glasses.

There were two kinds of painted glassware in use in New England in the eighteenth century worthy of mention. The specimens of the first, which have been preserved, consist chiefly of case bottles, octagonal in shape, with pewter stoppers, which screw on and off. An occasional drinking glass is also seen. The glass is transparent, uncolored, and of inferior quality. The peculiarity of the ware lies in its decoration. It is painted in vitrifiable colors with flowers, wreaths, figures, etc. The colors are red, yellow, blue, green, and gray, with occasional touches of black. The designs and the execution are both exceedingly crude, but the results are very quaint and effective. 


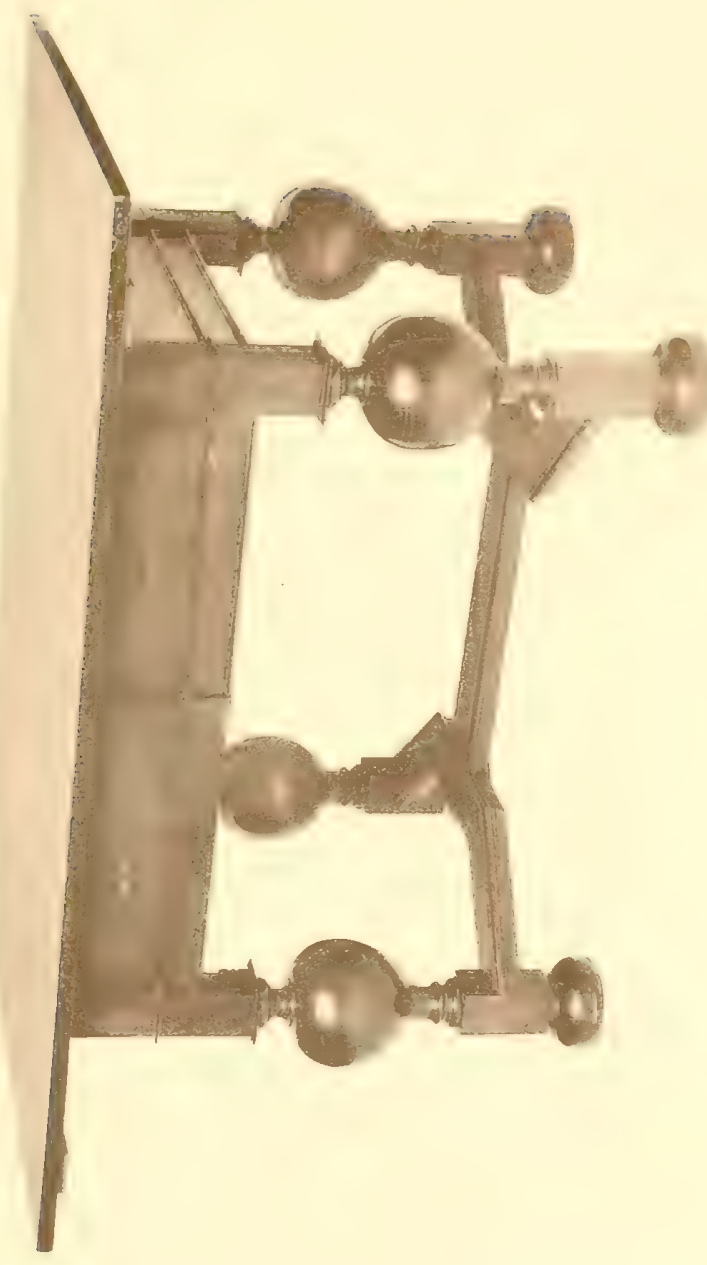

$\dot{E}=$
$\vdots$

$\vdots$
$\vdots$
$\vdots$
$\vdots$
$\vdots$ 

This ware is of German or Dutch manufacture, and began to be brought to this country early in the eighteenth century.

The second kind to which we refer is also an enameled glass, but entirely different in character from the other. The glass, instead of being transparent, is opalized, so as to be nearly white. The designs are chiefly floral, but figures are not uncommon. The colors are various shades of red, yellow, green, blue, and purple, with some black, and against the opalized ground make a very gay and showy appearance. Flip mugs, often very beautiful, and tea cups and saucers, are the pieces the most seen, but all the component parts of tea sets made of this ware are known to collectors. In the inventory of Elizabeth Maxwell, made in Boston in 1733, we find the item, "I pr Glass muggs flowred;" and in that of Captain James Pecker, Boston, I734, "3 painted Glass tea Cupps and Saucers \& r Server" are valued at seven shillings. We are inclined to believe that these objects, especially the tea cups and saucers, were early specimens of the ware now under consideration. This opalized glass is believed to be of Spanish manufacture.

The early history of chocolate, coffee, and tea in New England, as gleaned from the public records, is somewhat as follows:-

In the "Seventh Report of the Boston Record 
Commissioners" we read that at a meeting of the selectmen of Boston, held on January 30, 1670-7I, it was agreed that "Mrs. Dorathy Jones the wife of Mr. Morgan Jones is approved of to keepe a house of publique Entertainment for the sellinge of Coffee \& Chuchaletto."

"Jane the wife of Bartholomew Barnard is aproved of alsoe to keepe a house of publique entertainment for the sellinge of Coffee \& Chucalettoe."

April 24, I671, the selectmen recorded that "Cap" James Johnson \& Abell Porter are aproved of to sell Coffee and Chucalatto for the yeare ensueinge."

These and other licenses were renewed annually for three or four years, after which, for some reason, they seem to have been withheld.

October 30,1676 , the following minute was made by the selectmen:-

"Upon the motion of severall Merchants \& Gentlemen of this towne that some person may be allowed to sell Coffee, John Sparry is aproved of by the select men to keepe a publique house for sellinge of Coffee, if $\mathrm{y}^{\mathrm{e}}$ honored Countie Court shall be pleased to admit him."

At a meeting of the selectmen, April 23, 1677 , John Sparry was approved "to sell Coffie by retayle \& onely Coffee."

April 29, I678, John Sparry was approved "to sell Coffee Chocolatta \& Sydr. by retayle." This privilege was renewed to him in 1680 and in 1682. 

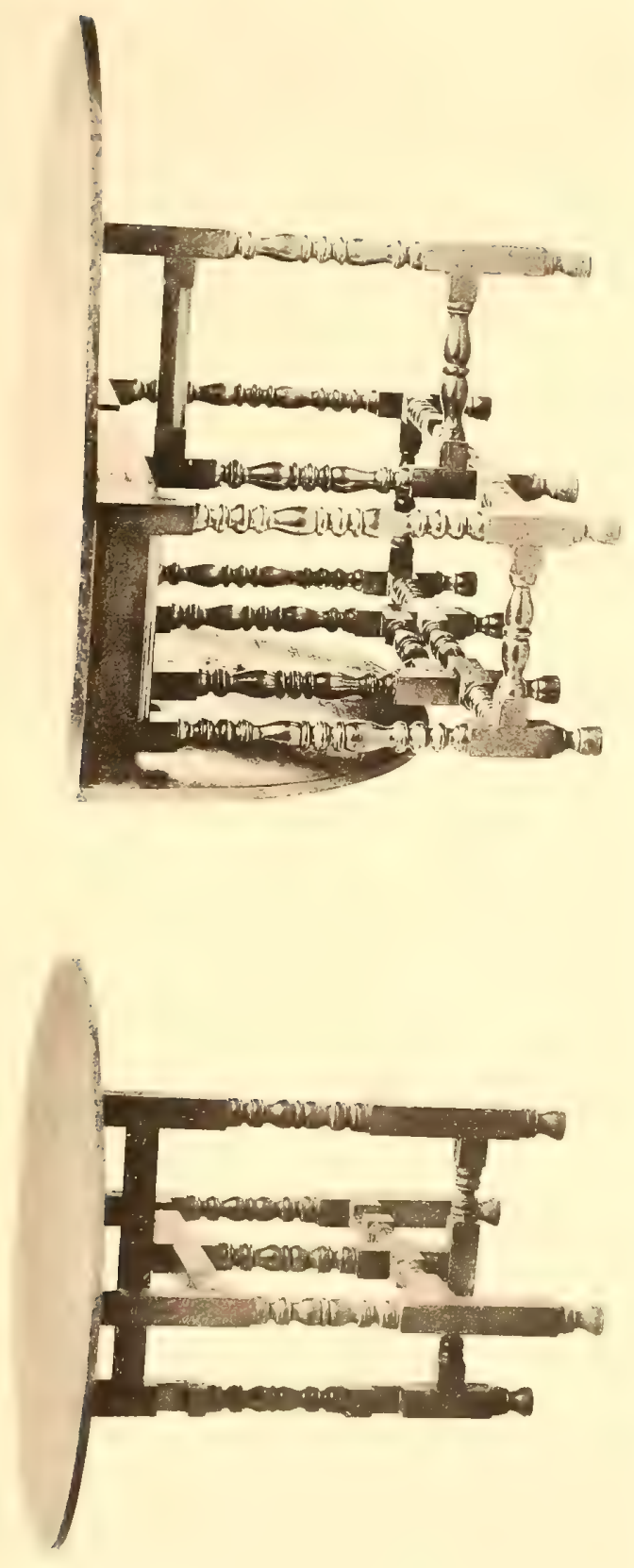

August 29, 1690, among the names of persons to keep "Publique Houses for Entertainm" aproved of by the Selectmen and returned to the Countie Court to be licenced," were those of Benjamine Harris and Daniell Vernon "to sell Coffee, Tee \& Chucaletto."

May I, I69i, Joseph Hill, Benj. Harris \& Robert Gutteridge were recommended by the selectmen of Boston to keep public houses " to sell Coffee Tea \& Chuculetto."

The first indication of the domestic use of coffee that we have noted is in the item, " 4 Coffy dishes, Is. 4 d.," found in the inventory of Mary Marshall, widow of Captain Samuel Marshall, of Windsor, Conn., made in I683. Next, in I686, the item, " 2 Coffee Pots, $7 \mathrm{~d}$.," is found in the inventory of Thomas Thacher, of Boston. In 1697-98 "Coffee Cups" are mentioned in the inventory of Ruth Carter, of Boston. In I704-5 the item, " 2 earthen cupps, I s. 4 d, earthen candlestick \& coffe cup, 6 d. - I S. Io d.," is found in the inventory of Sergeant Nathaniel Stowe, of Middletown; in I 7 I 2, " 2 Coffee dishes," in the inventory of Richard Lord, of Hartford; and in the inventory of Captain Walter Roswell, made in Boston in I7I7, "I Coffe pott" and " 6 Coffe cups" are mentioned. From this time coffee pots and coffee dishes are constantly found in the inventories. 
The earliest allusion to the household use of tea that we have met with is in the item, "I Tinn Teapot," found in the inventory of Doctor Benjamin Orman, late of the Island of Barbadoes, made in Boston in I695. Other early references are as follows: "I Tee Table;" inventory of Captain John Blowers, mariner, Boston, I yo8. "A Tea Pott;" inventory of Elizur Holyoke, Boston, I 7II-I2. "I oval Tea Table Japand." "I Japan Tea Table splitt in ye Leaf;" inventory of John Wharton, Boston, I 7 I 2-I3. "A parcel China 2 old Tea Tables, $£$ I. IO;" inventory of Nicholas Roberts, Boston, I 7 I 5 . "I Small Teapott, $8 \mathrm{~s}$." "Io lbs of Green Tea, at 20 s. £IO." " 5 lbs of Bohee Tea, at 40 s., £io;" inventory of Captain Walter Roswell, above cited, I 7 7. After this date tea tables and tea dishes are found in most of the wealthy estates.

Chocolate is mentioned in 1679 in the inventory of Thomas Scott, of Boston, in such a way as to lead one to think that it had been obtained for domestic use. On the 2 oth of October, I697, Sewall wrote in his diary, "I wait on the Lieut. Governour at Dorchester, and there meet with Mr. Terry, breakfast together on Venison and Chockalatte." In I 704, "4 China Chocolat Cups" were mentioned in the inventory of Samuel Shrimpton, of Boston. 

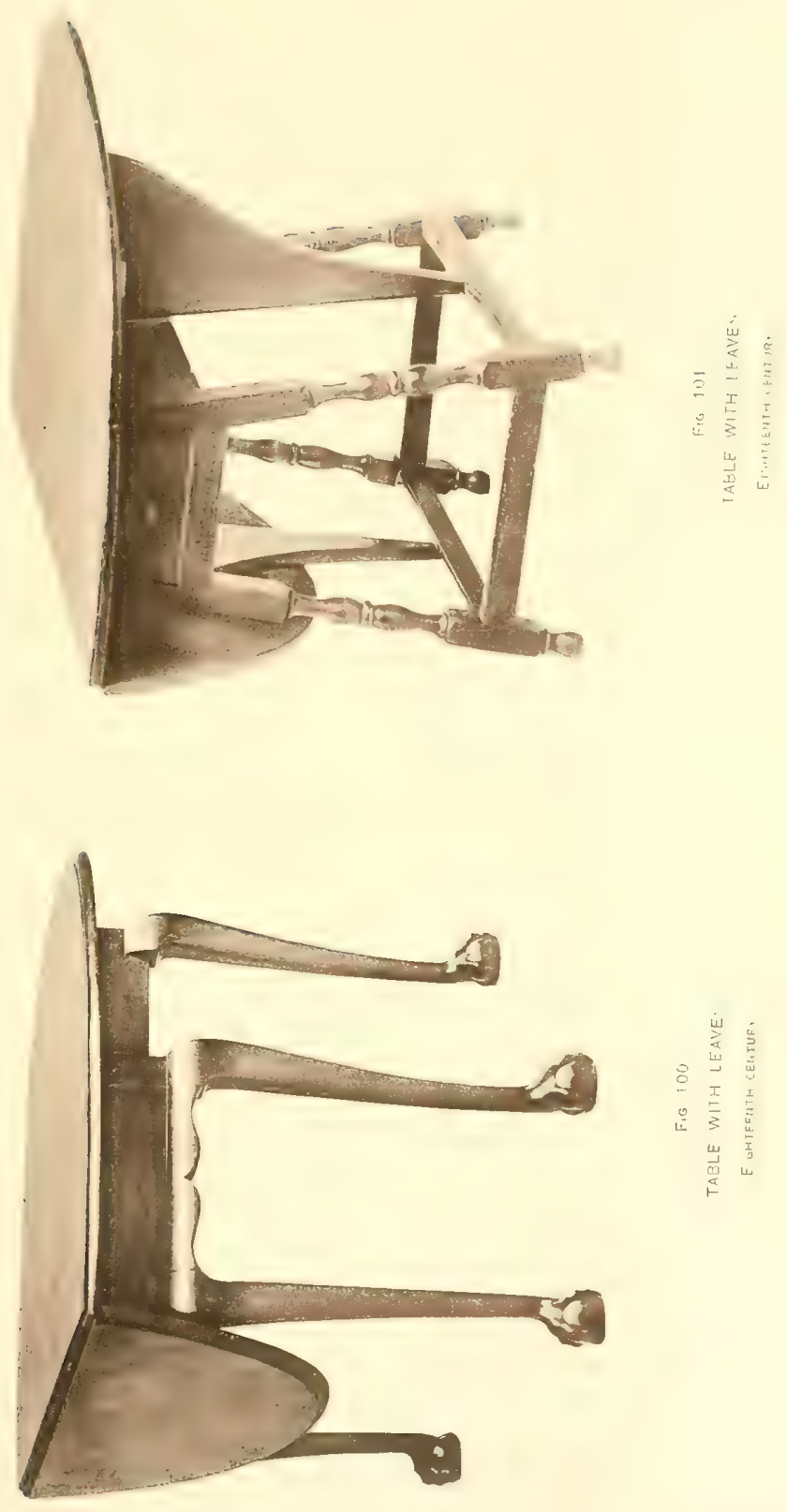



\section{CHAPTER VII.}

\section{CLOCKS.}

Crocks are not infrequently mentioned in the New England records of the seventeenth century, and usually belonged to well-to-do people.

They were of two principal kinds, - one with works driven by weights after the old system, the other with works driven by a spring. The spring clocks were placed upon mantelpieces, cupboards, tables, etc., and were easily moved about; but the clocks with weights were fastened to the wall high up at the side of the room with their weights and chains exposed.

In the inventory of Thomas Coytemore, of Charlestown, made in I645, "a clock" is apprized at $£ \mathrm{I}$, and in that of John Cotton, made in $1652-53$, "I clocke \& Case, In ye great Parlour," are valued at $£ 6$. These, however, are the extremes in prices, the average valuation of thirty-six clocks taken without selection from inventories between the years I645 and I689 being £2. I2.

The kinds of clocks mentioned are few. The ordinary entry is clock. Among the thirty-six above 
referred to there were four with cases, two brass clocks, "a watch clock or alarum;" "A Clock $w^{\text {th }}$ apertenances, In ye Study;" and "a clock, line and lead."

There are among us to-day but few remaining examples of these early colonial timepieces. From these specimens, as well as from those of the same period to be seen in Europe, we may form a tolerably good idea of the clocks in use in New England from the first settlements down to the advent of eight-day clocks in cases reaching from the floor nearly to the ceiling.

The oldest style of clock found in New England, and, we believe, the one altogether the most used in the seventeenth century, is represented in Fig. 107. This clock belongs in the Hosmer collection. It was picked up a few years since in Hartford, Conn., where it had probably been for considcrably more than two centuries. It is made of brass, excepting, of course, the bell and its hammer. Its hight to the top of the perforated plates is ten and a quarter inches, and to the top of the turned ornament on the bell, fourteen and a quarter inches. The front is richly engraved. The dial is six and three sixteenths inches in diameter, and is finished in brass, with black numerals on the hour circle. In the centre of the dial is a wheel to regulate the alarum. This clock was made to stand on a bracket fixed to 
the wall. Others were simply hung against the wall by a loop, and these had a couple of pins projecting from their backs, to be pressed into the wall for steadying the clock.

These clocks are well known to antiquaries. They have become very scarce in this country, but are not uncommon in England, where they are known under various names, as "lantern," "birdcage," "sheepshead," and "button and pillar clocks." They are traced back with certainty to the early part of the sixteenth century, but in giving further details of their history we shall quote from the pen of the late Octavius Morgan, who was not only one of the most noted collectors of old clocks and watches, but was also recognized as the best English authority in matters pertaining to their origin and history.

In $\mathrm{I}_{8} 8_{3} \mathrm{Mr}$. S. James A. Salter pointed out in "Notes and Queries," sixth series, vol. vii. p. I65, the need of a better chronological collection of clocks in the South Kensington Museum; and, in referring to the clocks now under consideration, said :-

"Fifteenth Century clocks. - Under this name the dealers in old art furniture and curiosities sell clocks of considerable beauty and some antiquity. They were made soon after $1_{500}$ and up to 1700. But I doubt if any were really made in the fifteenth century, and the dealers seem to mean that they were made before I600. They are of brass, nearly cubical in figure, about 8-II inches high, and surmounted by a large cupola-shaped exposed 
bell. The dial, brass or of white metal, is well engraved; minutes are not indicated, but the hours are divided into quarters; they had but one - the hour - hand. The original works went but a little over twenty-four hours, and a single weight, regulated by a long pendulum, supplied the power. They stood on brackets, with a slit for the pendulum and two holes for the weight-chain. On the dial the name and locality of the maker were nearly always engraved, and often the date. I have one made by Rich. Rayment, Bury St. Edmunds, date not given. The tone of the bells is extremely beautiful, especially when softened by a pad of buff-leather on the hammer. The earliest of these clocks that I have seen was dated 1539 , the latest I686. I should be glad of information respecting others, - name, locality, and date."

To this communication Mr. Octavius Morgan responded in "Notes and Queries," sixth series, vol. vii. p. 37I, and, besides many other very valuable and interesting facts, gave the following history of these clocks:-

"The domestic clocks divide themselves into two classes, those which go by weights, and those of which the motive power is a coiled spring, which was not applied till about I500; and these spring clocks form the class of chamber and table clocks. The weight clocks, which the dealers are apt to call fifteenth century clocks, are, in fact, the work of the sixteenth and seventeenth centuries - at least, I have never heard of one earlier. The description of these clocks has been given so accurately in 'N. \& Q.,' 6th S. vii. 165, by Mr. Salter, that it is useless to repeat it. But there is something remarkable about them. They are peculiarly English; they are all made of brass, and precisely similar in form and design; and they seem to have been cast upon the world suddenly and early in the sixteenth 

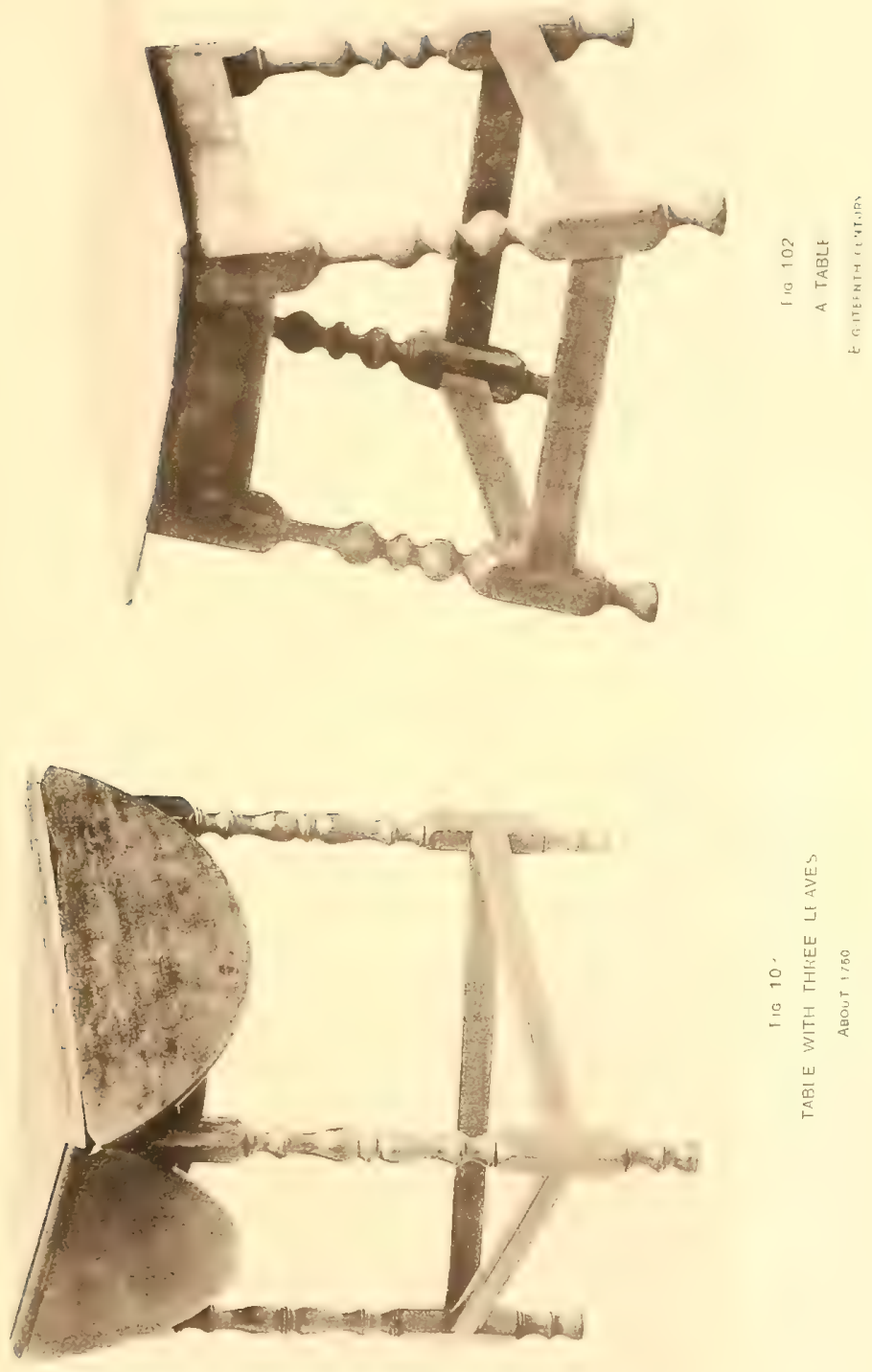

century, and to have lasted unchanged for nearly two centuries. All clockmakers at that time seem to have adopted the same pattern, and to have preserved it without any variation, and with similarity of form, mechanism, and ornament, as though they had worked to a regulation pattern. I cannot help fancying that there may have been a large manufactory or brass foundry, in London or some other place, where the frames and bells were all cast, from which the clockmakers in London and all over the country were supplied with the various parts of clocks, which they fitted together, as they are from Clerkenwell and, I think, Coventry at the present day; for it is difficult to understand how every country clockmaker should have cast, turned, and made his own brass frames and dials precisely similar to those of all the other clockmakers in London and all the provincial towns. And I am strongly disposed to think that the manufacture of clocks and clockwork was at that time, early in the sixteenth century, established at Clerkenwell, and that the country clockmakers were supplied from there; and thus Clerkenwell has continued to be the great manufactory for clocks to the present time. This idea is, I think, somewhat borne out by the fact of the exact resemblance of so many of the perforated brass ornamental plates, above the dials and sides of these clocks, to conceal the bells, which form a cupola at the top. One common pattern has two dolphins with intertwined tails; another has a small square-shaped escutcheon in the centre; whilst a third has only pierced scroll-work. The front plate is generally engraved, the side-pieces being left plain. Some clocks have the name of the maker, the name of the town, and the date engraved on the front, and some on the dial. ...

"Now with regard to the 'movements' of these clocks. All clocks made before 1660 had an escapement consisting of a crown-wheel and a vertical verge with a horizontal balance. In I66r, Ahasuerus Fromantil, a Dutch clockmaker, settled in Lon- 
don, first made clocks with short pendulums, which he exhibited in London in that year, creating a sensation in the town, for all people went to see his clocks. ...

"The old brass clocks went only thirty hours, and were set in motion by a weight attached to a chain, which passed over a sheave having spikes in the groove, which caught in the links of the chain, and required to be drawn up every day. There was a counterpoise at the other end of the chain, and sometimes a single weight was contrived to serve both the going and striking parts, and there was occasionally an alarum."

Another style of clock with weights, very picturesque in appearance, which was in use in New England in the last half of the seventeenth century, is represented in Fig. 108. The specimen here shown belongs to Charles W. Haddock, M. D., of Beverly, Mass., having been purchased by his father, the late Charles Haddock, M. D., also of Beverly, from the descendants of Captain Benjamin Obear.

A notice of this clock, with a very good illustration, was published in the "Salem Observer," February 16, 1881. From this we learn that "it was brought from Amsterdam, Holland, in the year I663, by Captain Foster, whose daughter married Captain Benjamin Obear. From their descendants the clock was purchased by the doctor, in a very dilapidated condition, as it had been considered worthless for the past fifty years. . . . This clock was entrusted to Mr. Geo. A. Collins, of Beverly, now of 198 Essex Street, Salem, to repair, with the instructions to spare 


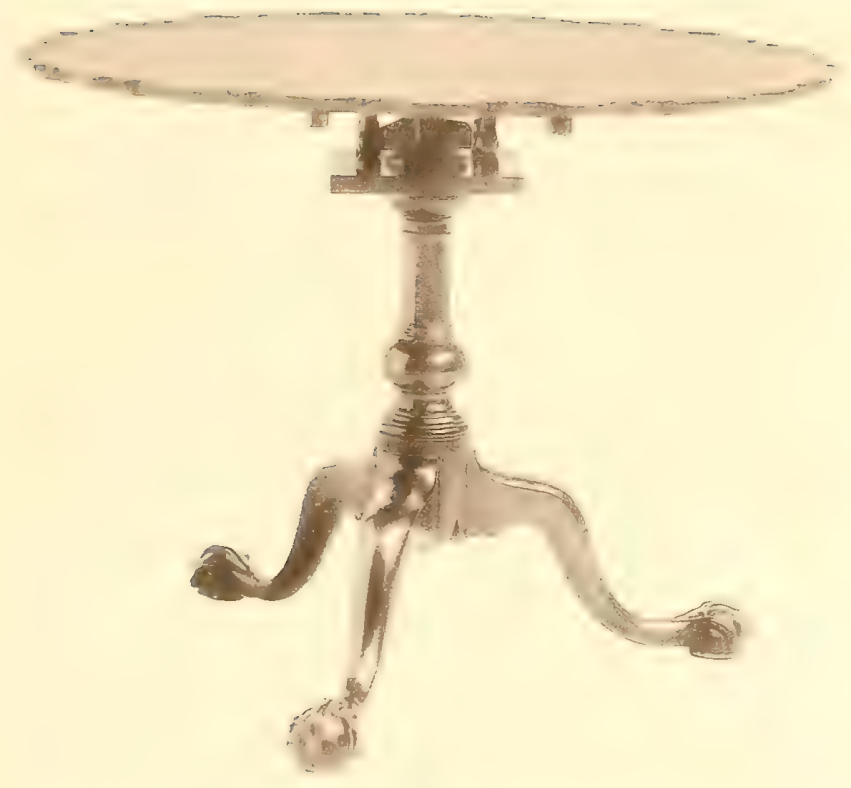

Fis 104

$\therefore$ DLTCH TEA TABLE 

no expense, but to preserve the original design, proportions, and finish, which is one of the most elaborate and beautiful patterns."

According to the best Dutch antiquaries, clocks of this style were made in Holland, especially in its northern provinces, from about 1640 to 1700 .

The movement of this clock is regulated by the bob pendulum and crown escapement; a combination in horology which began with the practical application of the pendulum to clocks by Huyghens in 1657 . But as this escapement was continued indefinitely after the adoption of the long pendulum in I680, it cannot be relied upon as proof that a clock in which it is found was made before the year I680.

To what extent clocks of this kind were brought to New England in the seventeenth century it would now be impossible to tell. The only other example known to the writer is in his own possession. It was bought in 1889 from a farmer in Portsmouth, R. I. It has the same hooded bracket and painted mermaids seen in the Haddock clock, and its movement is also presided over by the bob pendulum and crown escapement.

Another style of Dutch clock in use in Europe in the seventeenth century is shown in Fig. Iog. We have not seen any old examples of this kind in New England, but it is altogether likely that such clocks 
were in use here in the seventeenth century. The specimen here illustrated was bought in Amsterdam in 1886 , and belongs to the writer.

It is highly probable that there were a few spring clocks among the early New England timepieces, as we know that they were in use in England in the seventeenth century. We have, however, no examples of that period to which we are able to refer, nor can we determine from the language of the inventories that any of the thirty-six clocks above referred to were of this variety, as no spring, table, mantel, or chamber clocks are mentioned.

A very good example of the better class of spring clocks made in England from about I650 to I 700 is shown in Fig. I IO. It is in an ebonized case richly mounted in gilded brass. It was made to be looked at from all sides. The back has a door exactly like the one in front, through which is seen the bob pendulum and the back plate richly chased and engraved with the name "Charles Gretton, London," which also appears on the dial over the hour circle. Charles Gretton was admitted as a member of the Clockmakers' Company of London in 1671 , and we know that he was living in 1697 , from his advertisement in the "London Gazette," October 7-I I of that year. This clock belongs to the writer, who bought it in London in the summer of $\mathrm{I} 886$.

We now come to a period in which clocks with 


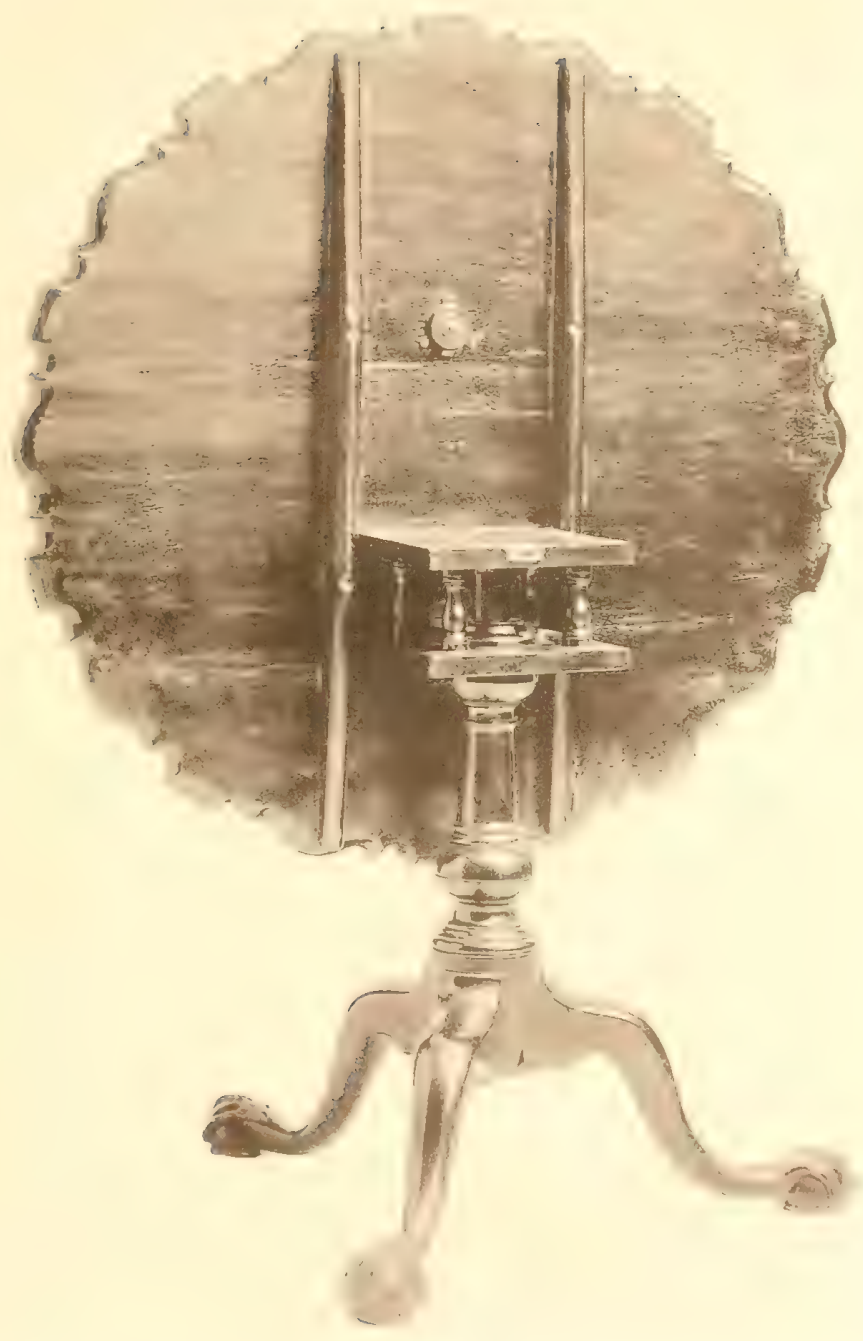

r.o. 195

THE TABLE SHOA IN. FIG 104, W TH TL TURNE: U 

weights assume an entirely new rôle as articles of household furniture. It is believed by those who have studied the matter carefully that clocks did not begin to be inclosed in tall cases till after the adoption of the long pendulum, which dates from the year I680, and that the immediate object of the long clock case was the protection of the pendulum, which from its increased length had become more liable to be disturbed by external influences.

The earliest designs for tall clock cases that are known are those made by Daniel Marot, and published about I 702 .

That they were made considerably earlier than the date of these designs is rendered highly probable by such facts as the following:-

In $188_{3}$ Octavius Morgan said, in "Notes and Queries," sixth series, vol. vii. p. 372, that he then had in his collection one of Thomas Tompion's clocks, with a beautiful set of chimes, in a tall marquetry case made about I 690 .

In 1696 the items, "I clock $£ 20$, in the diningroom," and "I repeating clock, £io, In my Ladie's room," appear in the inventory of Sir William Phips, of Boston. As the average valuation of New England clocks down to this time had been about $£^{2}$ I 2 S., this sudden bound in price is very remarkable, and can be best explained by supposing the first of these clocks at least to have been an eight- 
day clock in a tall and handsome wooden case. It is, moreover, not improbable that Sir William purchased these clocks in London, where he had had many opportunities for seeing the latest fashions, and that he brought them with him when he returned to Boston in 1692 with the royal commission as governor of Massachusetts.

In 1695 "one clock, In the great Hall" was valued at $£$ IO in the inventory of Captain Andrew Craty, of Marblehead; and another at $£ 20$, in I698-99, in the inventory of James Mackman, of Windsor, Conn. For the reason above given these were also, in all probability, early long pendulum clocks in tall cases.

The tall-cased clocks which thus appear to have been introduced into New England in the last decade of the seventeenth century steadily grew in favor. This is shown by the increased number of high-priced clocks inventoried in the early years of the eighteenth century. They were, however, not valued as high as $£ 20$. The prices from I 700 to I7I2, before the currency began to depreciate, ranged from nine up to twelve pounds. After this they rose to $£ 20$ in 1721 ; to $£ 35$ in 1732 ; to $£ 40$ in I738; and finally, in one instance, as high as $£ \mathrm{I} 20$ in 1748 . But this constant advance in price was due almost wholly to the steady depreciation of the paper money in which these values were expressed, 


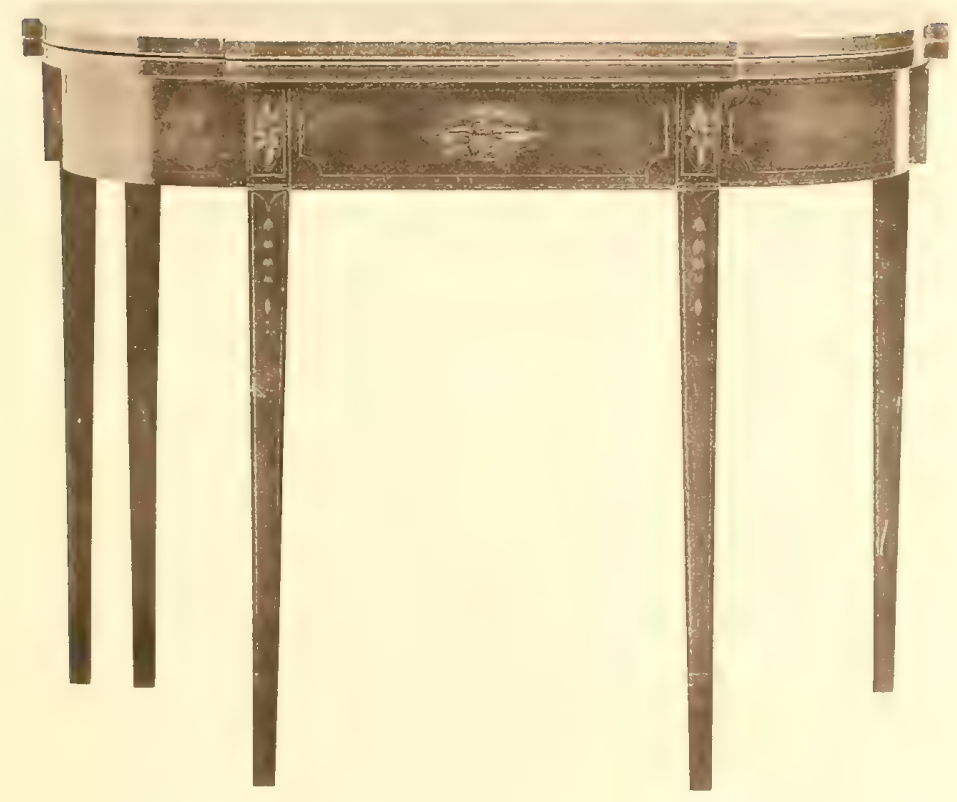

A HEPPELWHITE CARD TAELE 

so that the silver value of none of these high-priced clocks, except the last, reached as high as $£ 20$. It is, therefore, reasonable to suppose that the clocks which we have cited from the inventories of Sir William Phips and Mr. Mackman were placed at too high a figure, a mistake liable to occur to apprizers who had probably never before seen such clocks, and were therefore without guide as to their value.

The new eight-day clocks did not at once drive out the old-fashioned brass clocks. The latter were not only continued in use, but also in many instances were improved as timekeepers by the substitution of the long pendulum for the older escapements. We know that these old clocks were altered in England to keep pace with the improvements of the day, and we have evidence in the following notices that such changes in their mechanism were made in this country also:-

"This is to give Notice to all Gentlemen and others, that there is lately arrived in Boston from London, by the way of Pensilvania, a Clock Maker: If any person or persons hath any occasion for New Clocks, or to have Old Ones turn'd into Pendelums; or any other thing either in making or mending: Let them repair to the Sign of the Clock Dial of the South side of the TownHouse in Boston, where they may have them done at reasonable Rates. Per James Batterson." - The Boston News-Letter, No. 182, October, 1707 .

This notice is repeated in Nos. I 88 and I89, in November of the same year. 
The advertisement of another clockmaker prepared to change the escapements of old clocks is here given :-

"This is to give Notice that Isaac Webb Watch-maker and Clock-maker, that formerly Liv'd the next Door to the Royal-Exchange Tavern near to the East End of the Town-House in Boston, is now Removed over-against the West-End of the said Town-House in the High-street the Second Door from PrisonLane, at the Sign of the Clock Dial that goes against the side of the House: So that if any Person or Persons wants any Clocks to be made, or any Old Clocks to be turned into Pendelums, or Watches and Clocks to be mended, or Glasses, Keys, Springs, or Chains of the best sort; Let them repair to the said Webb, where they may be served on reasonable Terms." - The Boston News-Letter, No. 207, March 29 to April 5, I 708.

It is highly probable from the language of these notices that Isaac Webb had practiced his art a longer time in Boston than James Batterson. How early clockmaking was begun in New England we do not know. In the administration accounts of the estate of Peter Noyes, of Sudbury, Mass., there is an item of seven shillings " $\mathrm{Pd} \mathrm{Mr}$. Smith ye Clockmaker," dated May I6, I694. This is the earliest mention of a clockmaker that we have seen in the New England records.

The following facts relating to the ringing of the bell and care of the town clock of Boston are quoted from the records of the selectmen as published by the Record Commissioners. 
In the "Second Report of the Boston Record Commissioners," we find that at a meeting of the selectmen of Boston on the $4^{\text {th }}$ of June, I649, it was agreed that "Rich. Taylor is to ringe the bell at 9 of the cloke at night and half an houre after foure in the morninge and is to have for his recompence 41. a yeare, begininge his year the 24: 4th mo., 1649."

January 25, 1657, the selectmen ordered that "Richard Taylor is allowed thirty shillings for repairing the clock for his direction to ring by, and is to have five pounds per annum for the future, provided hee bee att charges to keepe a clock and to repayre itt."

In the "Seventh Report of the Boston Record Commissioners," we read that at a meeting of the selectmen of Boston, held on the 26th of October, I668, "Richard Taylor is ord" to haue $£ 5 . \mathrm{p}$. an. for his takeinge care of the towne clocke; the yeare to expire the first day of June next."

February 27, 1670-7I, the selectmen "agreed with Thomas Matson sen. to looke after the towne clocke and keepe it in good repaire from the first of March next for one yeare next ensueinge, $\&$ to have 10 . for his paines about it."

February 23, 1673 , the selectmen "agreed with Giles Dyer to keepe the clocke from the $25^{\text {th }}$ of March next for one yeare for which he is to haue 
$£ 6$, and ordered the treasurer to pay him propor tionablie for Io months past."

March 29, I675, the selectmen " agreed with Giles Dyer for keepinge of the towne clocke for ye yeare ensueinge, for $\mathrm{w}^{\mathrm{ch}}$ he was to be allowed 6 pounds in mony, or other pay equivalent beside his owne town rate."

March 26, I676, the selectmen " agreed with Giles Dyer to keepe the clocke at ye First Meetinge house for the yeare ensueinge for $£ 6$. as in folio 9o."

March 29, I680, the selectmen "allowed Giles Dyer towards settinge up $y^{e}$ clocke at $y^{e}$ north Meetinge House $5^{\text {ld }}, \&$ for keepinge of both Clockes in good $\operatorname{ord}^{\mathrm{r}}$ and attendinge at ye old Meetinge house 4 yeares, $24^{\text {ld }}, \& y^{t}$ at ye north end since it was last set up, I I Id."

July 28, I684, the selectmen "agreed with $W^{\mathrm{m}}$ Sumner blacksmith to pay him $4^{\text {lds }}$ in mony to keepe the clocke at $y^{e}$ North end of the Towne for one yeare to begin the ${ }^{{ }^{\text {st }}}$ of Aug $^{t}$ next \& to pay him for worke done about $\mathrm{s}^{\mathrm{d}}$ clocke the year past, $14^{\mathrm{s}}$ mony."

March 17, 1689-90. "At the meetinge of the Selectmen this day it was Agreed betweene them on the behalfe of the towne and Robert Williams that he shall continue as formerlie to warne the Towne Meetings upon occasion, to ringe the bell at Five of the Clocke in $\mathrm{y}^{\mathrm{e}}$ morninge, Exchange Bell at eleauen 


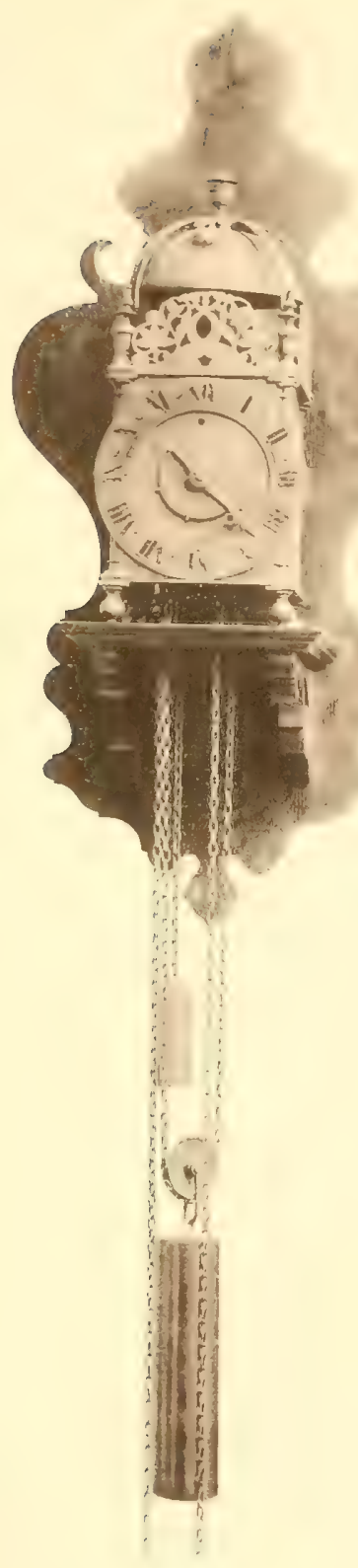



of $\mathrm{y}^{\mathrm{e}}$ clocke, and at nine in the night, \& carfullie looke after \& keepe the Towne clocke in the old Meetinge house."

In the "Eleventh Report of the Boston Record Commissioners," we find the following minute made by the selectmen on February I6, I7OI-2: "Samuell Clough his $\operatorname{acco}^{t}$ for mending the Town house Clock, he is allowed I $2 / 8 . "$

February 28, 1708-9, the selectmen "agreed $\mathrm{w}^{\text {th }}$ Isaac Webb that he alter the Town clock now Standing being in the Old Meeting-House, and make the Same into an eight day Clock, he to find all Materialls for $y^{e}$ doing thereof, and cause the Same to go well to the Satisfaction of the Select men for which he is to be paid the Sume of Thirteen pounds And after the Same is So done he is duly to Attend wind up and Keep clean the Same yearly, to the Select mens Satisfaction and for his $\mathrm{S}^{\mathrm{d}}$. Service he is to be Allowed \& paid fifty two Shillings p. Annum, the $S^{d}$ Select men are to bear $y^{e}$ charge of Joyners worke to inclose the $\mathrm{S}^{\mathrm{d}}$ clock."

Isaac Webb evidently had the care of the town clock till I 7 I7, when Benjamin Bagnall, a celebrated clockmaker, was appointed to the office, and, so far as we are able to tell from the records of the selectmen, held it more or less continuously down to the year 1736 .

It is evident that the clock referred to in the min- 
utes of the selectmen made on the $25^{\text {th }}$ of January, I657, was kept in the house of Richard Taylor. It was, therefore, probably one of the little brass lantern clocks, of the style illustrated in Fig. Io7. This would indicate that the town had not yet obtained a large public or turret clock, such as we may suppose was afterward set up in the First and in the North Meeting Houses.

We have here, then, the names of several men who in succession had the care of the town clocks of Boston for about eighty-seven years. It is fair to assume that the town authorities selected competent men for this duty, and that naturally some of them would be clockmakers by trade, especially after the town clocks had become public clocks. But so far as we have ascertained, none of them were clockmakers before the time of Isaac Webb. Richard Taylor appears to have been merely a bellringer. The trades of Giles Dyer and Robert Williams are not given in the records that we have examined to determine this point. Thomas Matson was a gunsmith, William Sumner a blacksmith, and Samuel Clough a joiner.

From this history of the town clocks of Boston that such mechanics as gunsmiths, blacksmiths, and joiners were selected as their official keepers and repairers down to I 709, and that after this time clockmakers were regularly chosen for this purpose-we 


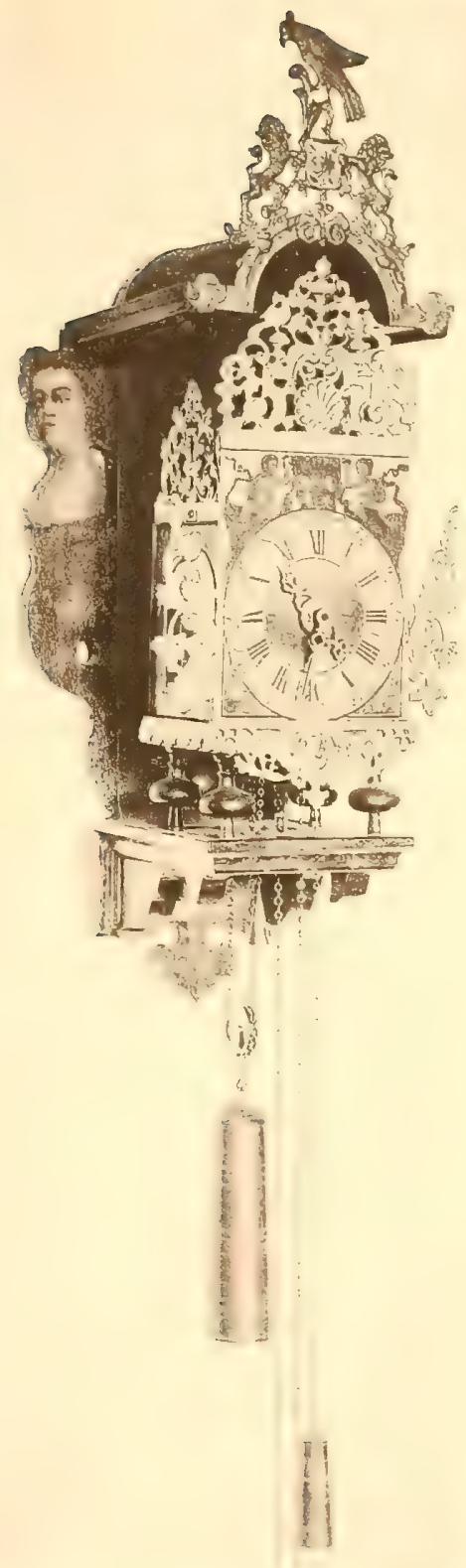



may infer that there were no clockmakers in Boston much before the year 1709 whose reputation for skill in the management and repair of clocks was superior to that of other craftsmen.

This conclusion is somewhat at variance with such facts and considerations as the following: That other fields of labor in New England were supplied with skilled mechanics at a much earlier date; that the existence of a great many clocks and watches in Boston rendered it very desirable on the part of their owners that a good watchmaker should be at hand to keep them in running order; that if the town clocks were turret clocks it would seem that a skillful clockmaker was necessary to set them up; that we have the record of one New England clockmaker as early as 1694; and that we know from a letter published in the "Pennsylvania Magazine," vol. iv. p. 194, that there was "one Clock and Watchmaker" in Philadelphia in I690, a few years only after the town was settled, and how long he had been there is not stated.

These objections are weighty, but hardly sufficient to offset the one salient fact that the care of the public clocks of Boston does not appear to have been intrusted to a clockmaker before the time of Isaac Webb.

It will not seem so incongruous that Thomas Matson, a gunsmith, and William Sumner, a black- 
smith, should have had the care of the town clock of Boston, when we reflect that blacksmiths were the earliest makers of clocks and watches, and that the art of the clockmaker was really a development from the older trade of the blacksmith. Among the members of the Clockmakers' Company of London there were many blacksmiths who were actively engaged in clockmaking, some as late as the close of the seventeenth century.

The most descriptive clockmaker's advertisement to be found in the early files of "The Boston NewsLetter" is the following, taken from No. 447 , November, 1712:-

"These are to give Notice to all Gentlemen, Merchants and Others, That there is lately arriv'd from Great Britain to this Place, Mr. Joseph Essex, who now keeps Shop in Buttler's Buildings in King Street, Boston, and performs all sorts of New Clocks and Watch works, viz, 30 hour Clocks, Week Clocks, Month Clocks, Spring Table Clocks, Chime Clocks, quarter Clocks, quarter Chime Clocks, Church Clocks, Terret Clocks, and new Pocket Watches, new repeating Watches; Likewise doth give any Gentlemen, \&c. Tryal before Payment of either Clock or Watches, and after Payment for 12 months will oblige himself to Change either Clock or Watch, if not liked, or else return his Money again: These Articles to be performed by the abovesaid Joseph Essex and Thomas Badley."

We have no knowledge of any clocks made by James Batterson, Isaac Webb, Joseph Essex, or Thomas Badley. It is, however, not improbable 
that such clocks still exist in New England. The following notice occurs in "The Boston Gazette," No. 73, April 27 to May I, I72I:-

"All Persons that have any Claim or Demand on the Estate of Thomas Badely late of Boston Watchmaker, Deceased Intestate, represented Insolvent; are hereby Notifyed, to bring in their Claims," etc.

In No. 6II of "The Boston News-Letter," December 26 to January 2, I7I5, is an advertisement in which the name of William Claggett occurs. This was, doubtless, the William Claggett who afterwards settled in Newport, R. I., and became there so prominent as a church disputant and so celebrated as a clockmaker. It was probably inserted soon after his arrival in Boston, and is, perhaps, the earliest New England record in which his name appears. It reads as follows:-

"To be Sold a new Fashion'd Monethly Clock \& Case lately arrived from London, also a new Fashion'd Camblet Bed lin'd with Satten, to be seen at Mr. William Clagget jun. Clock-Maker near the Town-House."

In the notice of William Claggett, contained in the "Collections of the Rhode Island Historical Society," vol. vii. pp. 246,247 , we read that he is said to have come to this country from Wales, and to have lived first in Boston. This advertisement proves that he was living in Boston as early as I 7 I 5 , 
and that he was then probably at work there at his trade. That he was not a native of this country is rendered quite certain by a passage in his book, entitled "A Looking-Glass For Elder Clarke and Elder Wightman," etc., published in Newport in I72I, in which (page 23) he makes Elder Clarke speak of him as "a Young Man, and a Stranger just come into the Country, as it were."

Specimens of William Claggett's clocks are preserved in Providence and Newport, R. I.

Benjamin Bagnall, to whom we have already referred, was another excellent clockmaker of this period. According to information furnished by the Reverend W. R. Bagnall, one of his descendants, he was born about 1689, in England, where he undoubtedly learned his trade. He settled in Boston about I7I2, and began then or very soon after to make clocks and to repair watches.

At a meeting of the selectmen of Boston on the I 3 th of August, I7 I 7 , it was voted "that $\mathrm{m}^{\mathrm{r}}$ Joseph Wadsworth, Will ${ }^{\mathrm{m}}$ Welsted Esq ${ }^{\mathrm{r}}$ \& Habijah Savage $\mathrm{Esq}^{\mathrm{r}}$, be desired to Treat $\mathrm{w}^{\text {th }} \mathrm{m}^{\mathrm{r}}$ Benj ${ }^{\mathrm{a}}$ Bagnald $a b^{t}$ makeing a Town Clock."

The following notes relating to this clock were made by the selectmen at their meeting on the gth of September, I 7 18:-

" $\mathrm{M}^{\mathrm{r}}$ Benja Bagnald haveing in now an order for his being paid in full for his makeing the Town-Clock. He now promises the 


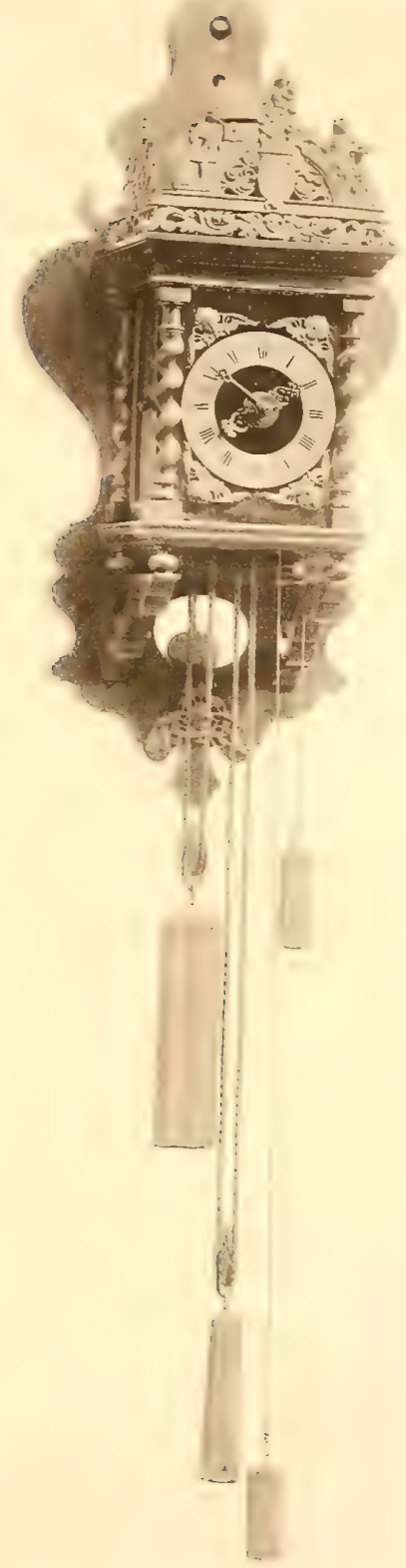

Fic. 109

A DUTCH CLOCK

SEVENTEENTH CENTURY 

Sel. men to do what Shall be further needfull to Compleat \& finish the Same; and if desired he will make the Same to go as an eight day Clock in the place where it now Stands."

The earliest house clock of his make of which wé have any history is now in the possession of $\mathrm{Mr}$. William Durant, of Boston. It is a pendulum clock in a tall case. The original case, which was of pine, is missing, having been replaced in 1872 by one of mahogany. Upon the inside of the lower door of the old case was the inscription, "This clock put up January IO, I $722 . "$

Another clock by Benjamin Bagnall, very similar to the preceding, belongs to the New England Historic Genealogical Society of Boston. Its case, which is quite plain, is made of solid black walnut.

A very fine clock made by Benjamin Bagnall is shown in Fig. III. It is in the Hosmer collection at Hartford. Its case is made of black walnut veneered upon pine. The pine so used is a distinguishing feature of old American-made cases. Most of the old European clock cases have their veneers laid upon oak.

This clock has a well-authenticated history of having belonged to the Reverend Elisha Williams, President of Yale College from 1725 to 1739 . Its dial, as in all of the Bagnall clocks of which we have knowledge, is rather small, being but twelve inches square. Upon the arched extension of the dial 
above is a circular plate silvered and engraved with the name of the maker.

Two clocks made by Samuel Bagnall, of Boston, a son of Benjamin Bagnall, are known to the writer. One belongs to Mrs. W. R. Dupee, of Chestnut Hill, Mass.; the other, a very fine specimen, to Mr. Ebenezer Gay, of Boston. Each has the name Samuel Bagnall on its dial.

The excellence of our older eighteenth century clocks as timepieees has often been commented upon by writers. It has been said that they were fully equal to those made in Europe during the same period. The explanation of this is found in the history now given of some of our early clockmakers. They had learned their trade in England, and came to this country thoroughly equipped to practice it. Moreover, they were enabled to keep pace with European improvements and fashions by means of the clocks which were constantly being imported, as well as by fresh arrivals of clockmakers themselves.

From the beginnings thus briefly traced the use of these tall clocks gradually extended. As timekeepers they were vastly superior to the clocks which had preceded them, and from their beauty and stateliness they became objects of popular desire as furniture.

At first there were but few makers, and these 


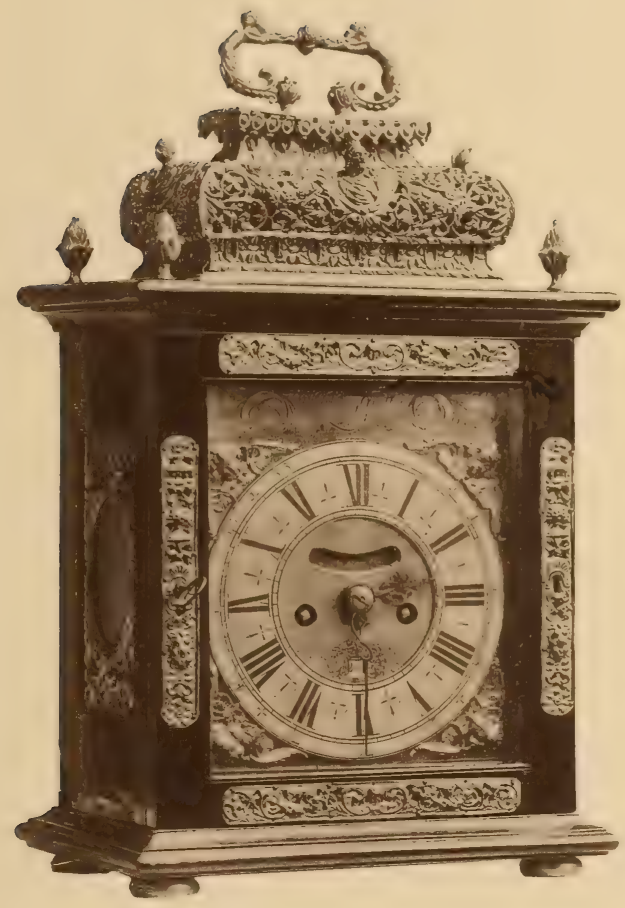

FIC. 110

A SPRING CLOCK BY CHARLES GRETTON, LONDON 

were confined to the larger and more important places. But as the demand increased, clockmaking sprang up at various points in New England, and in the last half of the century was practiced not only in the larger towns, but also in many instances in villages of very inconsiderable size. These facts are well attested by the names and places of the makers, which it was the custom to put on the dials.

In Fig. I 2 is shown a very good clock made by Enos Doolittle, of Hartford, Conn. He began to make clocks there about I772. His first advertisement is found in the "Connecticut Courant," December 15,1772 , and reads as follows:-

"Clocks. All kinds of Clocks, Surveyor's and Mariner's Compasses, Made, Clean'd and Repair'd, by the Subscriber, at the Printing Office in Hartford. And as he has serv'd a regular Apprenticeship to those Branches, with the most noted Workman in this Colony, he flatters himself he shall be able to Supply any Gentlemen that will favour him with their Custom as much to their Satisfaction, and on as reasonable Terms as they can be supply'd elsewhere, and their Favours will be gratefully acknowledged by their humble Servant, Enos Doolittle.

"December $\Upsilon_{3}$, I 772 ."

This clock is in a handsome case made of cherry. On the circular plate at the top of the dial is the inscription, "Enos Doolittle, Hartford." It belongs to Mrs. Henry T. Sperry, of Hartford, Conn., having descended to her from her great-grandfather, General Roger Newberry, of Windsor, Conn. 
The local manufacture of clocks in these early days was almost a necessity, arising from the difficulty of transporting the works of one of these large clocks, to say nothing of its larger wooden case, to any considerable distance, and the need of the proper person to set it up and keep it in running order after it had reached its place of destination. All these difficulties were overcome by having the clock made on the spot, - the works by the village clockmaker and the case by the local cabinet-maker.

Many of the early clock cases in England down to the time of mahogany were finished with veneers made from the burr of walnut, or other woods of beautiful grain, laid upon an oaken ground. In other instances the veneer was a rich marquetry with designs representing foliage, flowers, birds, etc., commonly known as the Dutch marquetry, which became fashionable in England during the reign of William and Mary. Another method of ornamentation was the Chinese and Japanese lacquer work, which was very popular in the early part of the eighteenth century.

In modern days, when the veneer and lacquer work of these old European clock cases have become too much damaged to admit of repair, they are sometimes stripped off, and the oaken ground carved all over in imitation of old work. All the carving that we have seen on tall oaken clock cases has appeared 


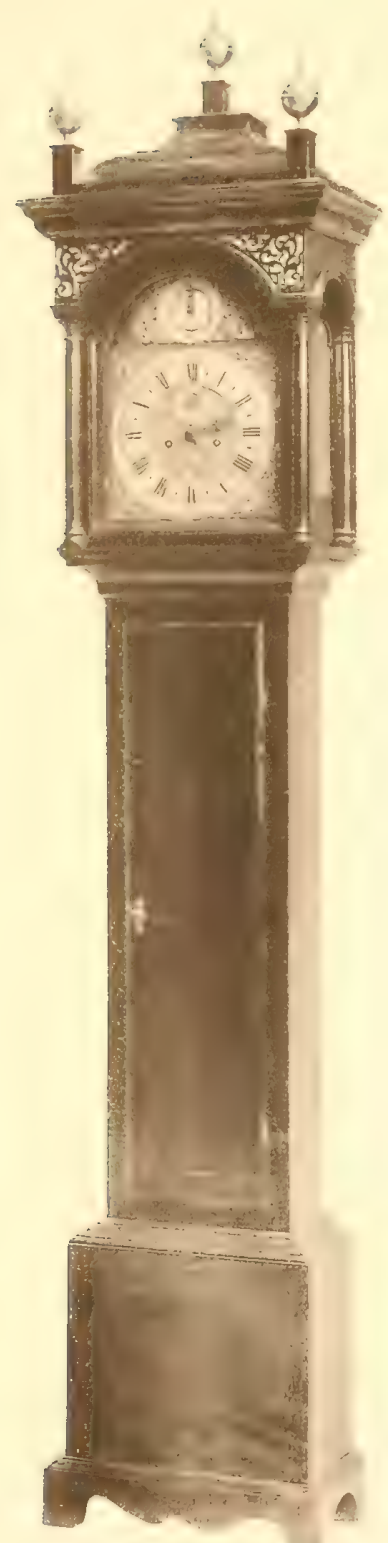

Fig 111 

to be of very recent date. The oak itself was often old and genuine, but the carving had been lately done.

Many of the early clock cases in England were doubtless made with less expense, like the one belonging to Thomas Tompion's clock in the Guildhall collection in London. This case, which is eighty-two inches high, is made of pine or some other soft wood, and colored black. As Tompion died in I7I3, it was probably made between the introduction of the long clock case and this date.

The first tall clock cases that were seen in New England were undoubtedly imported, and served as patterns for those which were afterward manufactured here. The woods of which they were made are seldom specified in the early records. The first mention of them that we have noted is in the following advertisement from "The Boston News-Letter," No. 626, April I6, I7 66:-

"Lately come from London. A Parcel of very fine Clocks, they go a Week, and repeat the Hour when pull'd; in Japan Cases or Wall-Nut. To be Sold by Mr. William Gent, and to be seen at the House of Mr. Peter Thomas in Wings-Lane Boston."

The case of Sir William Phips's clock, valued at $£ 20$, was more probably finished with Dutch marquetry than with lacquer work, as the former was then the Court fashion, which Sir William, being a 
recipient of royal honors, would be likely to follow in selecting a clock in London.

It does not appear that the Dutch marquetry was copied in New England. It required cabinet-makers of special skill for its execution; besides we do not find old examples of such work here, nor mention of them in the inventories.

Japanned clock cases, however, or at least imitations of them, were doubtless made here. We have seen that japanning was practiced in Boston as early as I I I 2, and japanned clock cases are not only mentioned in the inventories down to the middle of the eighteenth century, but examples of the cases themselves are occasionally seen to-day.

In I725, "I fine black Walnut Clock, In the Setting Roome," was apprized at $£ 20$ in the inventory of Henry Franklin, merchant, of Boston; and in I 729 the item, "I Eight Day Clock black Walnut Case, $\delta_{24}$," appears in the inventory of William Welsteed, merchant, of Boston. We have already seen that the cases of two of Benjamin Bagnall's clocks were made of black walnut, one of the solid wood, the other of black walnut veneered on pine.

Black walnut was the wood most in use in Massachusetts for fine cabinet work down to the general adoption of mahogany, and tall clock cases with veneers of this wood are frequently met with in that commonwealth. The native wood the most em- 
ployed in Connecticut for clock cases, and, indeed, for all other kinds of cabinet work in the eighteenth century, was that of the American wild cherry tree.

Clocks with black cases are occasionally mentioned in the inventories. A good deal of furniture in the first half of the eighteenth century was colored black. It is quite likely that many of these black clock cases were made of pine or whitewood.

The earliest record of a mahogany clock case in New England that we have noted is in the following advertisement from "The Boston Weekly NewsLetter," No. 2017 , November I8, I 742 :-

"Just Imported, and to be Sold by Edmund Entwisle, at Mr. Pullen's in Cross-Street, Boston. . . .

"Likewise a fine Clock, a Description of which is as follows, viz. It goes 8 or 9 Days with one winding up, and repeats the Hour it struck last when you pull it, the Dial is I3 Inches on the Square, and arched with a semi-Circle on the Top, round which is a strong Plate with this Motto, (Time shews the Way of Life's Decay) well engrav'd and silver'd; within the Motto-Ring it shews from behind two semi-Spheres, the Moon's Increase and Decrease by two curious painted Faces, ornamented with golden Stars between, on a blue Ground, and a white Circle on the outside divided into Days figur'd at every Third, on which Divisions is shewn the Age by a first Index from the Top, as they pass by the great Circle is divided into three concentrick Collums, on the outmost of which it shews the Minute of each Hour, and the middlemost the Hours, etc., the innermost is divided into $3 \mathbf{I}$ equal Parts figur'd at every other, on which is shewn the Day of the Month by a Hand from the Dial Plate as the Hour and Min- 
ute is; it also shews the Seconds as common, and is ornamented with curious Engravings in the most fashionable Manner. The Case is made of very good Mahogony, with quarter Collums in the Body, broke in the Surface, and raised Pannels, with Quarter Rounds, Cross-Bands, and Strings: The Head is ornamented with gilded Capitals, Bases, and Frise, with new fashion'd Balls composed of Mahogany, with gilt Laves and Flames.

"As the said Mr. Entwisle don't intend to stay above three or four Days in Town, and sells all for ready Money, he will sell at low Prices. The last Day of Sale will be on Saturday, by reason the Ship that he goes in is so well repair'd as to be able to proceed on her intended Voyage."

The first mahogany clock case that we have run across in the inventories belonged to the estate of Thomas Fillebrown, of Boston, apprized in I754. It was in the "Keeping Room," and the item referring to it reads as follows: "A Clock Mehogony Case, \&Io." This valuation was in silver money.

In the last decade of the century clock cases of all kinds, especially of mahogany and cherry, began to be inlaid with little bands or strings of lightcolored woods, such as satin and holly, after the style of Heppelwhite.

The dials of the older eight-day clocks were often very handsomely finished. They were made with a groundwork of brass, on which were placed the hour circle and the seconds dial. These latter were of considerable thickness, and, besides, were made to contrast strongly in color with the background by 


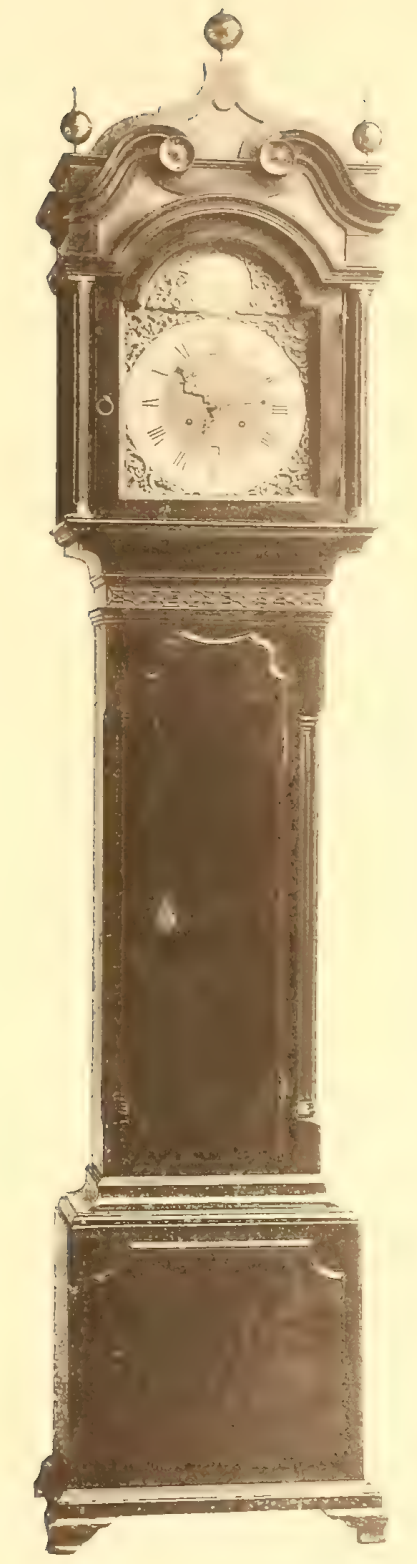



being silvered and marked with black numerals. The portion of the brass ground lying within the hour circle was often richly frosted and engraved. The angles or spandrels outside of this circle were enriched with brass ornaments.

The earlier dials were square-shaped, but in the reign of Queen Anne they began to be made with a semi-circular extension above. This was due, not to any change in the construction of the works, but wholly to the altered shape of the case, the head of which was now built with the arched door and pediment, in obedience to the architectural fashion which a little later wrought a similar change in the high chests of drawers. This arched extension of the dial upwards was variously decorated; sometimes with the moon and stars on a blue ground; sometimes with the figure of Time, or of a ship driven alternately forward and backward by the clock movement. In other instances this space was mainly occupied by a plate on which were graven the name and place of the maker.

These dials continued to be made down to the revolutionary war and probably to some extent during the long struggle. After the war plainer dials of brass began to appear. They were silvered all over, and had the hour circle cut on the surface, instead of being superimposed as in the older clocks.

About I790 white enameled dials, both with and 
without the clock movement, of English manufacture, began to come to New England, and to be sold, wholesale and retail, not only by dealers in clocks and watches, but also in some instances by hardware merchants. These facts are attested by the numerous advertisements found in the newspapers of those days. So that when a clock with a white enameled dial is met with in this country one may know at a glance that it was made after the revolutionary war, and in all probability after the year I790. The cases of these clocks are often made of mahogany or cherry, with the kind of inlay which we have described as belonging to this period.

We find "I genteel wooden Clock \& Case," apprized at $£ 5$, in the inventory of Peter Verstille, of Hartford, Conn., who died in 1778 . This is the earliest mention of wooden clocks that we have seen in our records, though they were probably made, to a limited extent, all through the eighteenth century. It is well known that clocks with wooden wheels were made in Europe in the seventeenth and eighteenth centuries. John Harrison, of Barrow, England, who invented in 1726 the compound or gridiron pendulum, made clocks with wooden wheels. One of his clocks, with its original gridiron pendulum and with the whole of the wheelwork made of oak, is now owned by the Clockmakers' Company of London, and preserved in the Guildhall collection already referred to. 


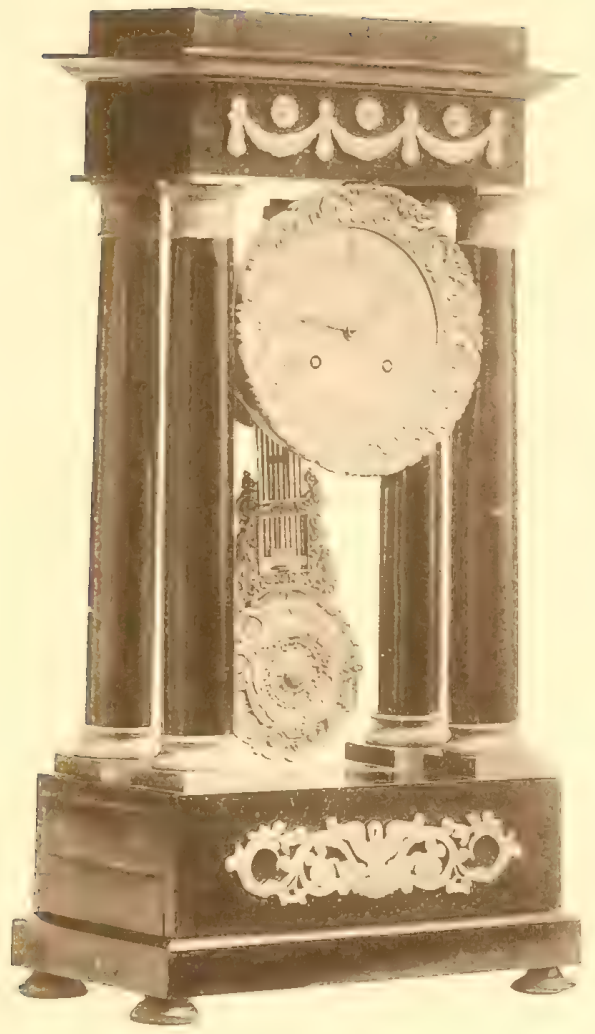

FIG, 113

A FRENCH CLOCK 

Clocks with wooden works, made by Benjamin Cheney, of Hartford, Conn., are well known, which, from the period of this maker, the histories accompanying them, and especially from the older style of their dials, could not have been made much later than the Verstille clock.

During the period of cheaper clocks which followed the revolutionary war the manufacture of long case clocks with wooden works was greatly increased in Connecticut, and remained very prosperous down to I $8 \mathrm{I} 4$, when it was suddenly checked by the introduction of the shelf clock with a short case, invented by the celebrated clockmaker, Eli Terry. Many of the later wooden clocks intended for tall cases were actually used without any case at all, simply hung up against the wall like the German cuckoo clocks and the older brass birdcage clocks, but without any hood or covering over them.

At the present day these old clocks in tall cases are called by a variety of names, such as grandfather clocks, hall clocks, eight-day clocks, and, in England, long clocks. Under what name they went in England when in full fashion we do not know. Chippendale referred to his designs for their cases as "clock-cases" simply. In the New England inventories all through the eighteenth century clock and case is the entry oftenest found. This is occasionally varied with a description of the case, as clcck and 
japanned case, clock with black walnut case, etc. Next in frequency is the expression eight-day clock, and although there were one-day clocks in tall cases, and eight-day spring clocks in little cases to set upon tables and mantelpieces, we are inclined to think that the name eight-day clock was the one by which the tall-case clocks were chiefly known in New England in the eighteenth century. Tall clocks, long clocks, or hall clocks, have not been mentioned in the numerous inventories that we have examined.

Clocks of the kind represented in Fig. II 3 made their appearance in this country at the close of the eighteenth or in the beginning of the nineteenth century. The style originated in France in the reign of Louis $X \cdot V I$, when the taste for classical art had been quickened to such an extent by the discoveries at Herculaneum and Pompeii as to affect architecture and the decorative arts to no inconsiderable degree.

These clocks are usually mounted upon a low pedestal, and covered with a glass case to protect the works from dust. The present specimen is shown without its pedestal and glass covering, as the latter prevented the photographer from getting a good picture of the clock. 


\section{APPENDIX}

A Table of Prices for Foiners' Work in Providence, $R$. I., in 1757, copied from the Original Manuscript in the Possession of Mr. Foseph F. Smith, of Providence, R. I.

RULE AND PRICE OF JOYNERS' WORK.

Providence, March $y^{\mathrm{e}} 24^{\text {th }}: 1757$ made By us Subscribers the Price of Joyners' work.

A Loe Case of Draws @ £33.

Do with Polished handels@ $£ 36$.

Plane Desk@ 645; with Polished handels@ £48.

Desk with two tear of Draws $£ 55^{\circ}$

A high Case of Draws @ $£ 70$.

Maple rule Joynt tables@ $£ 6 \operatorname{Pr}$ foot; old fashen Joynts @ £5. ro.

Common tea table@£io.

Citchen table@£I2.

Beadsted with high Posts, $E \mathrm{I} 2$.

Palet Beadsted@ @I8.

Do with Loe Posts @ Ero.

Trundel Beadsted@ $@ \mathrm{x}$.

Pine Chests with two Draws@ @22.

$\mathrm{D}^{\circ}$ with one Draw @ $£ \mathrm{r} 6$.

Maple Chest with two Draws @ £26.

Dowith one Draw@ @2o.

House Chest @. £IO.

Maple Cradel @ fir. 
Do Pine@£ro.

Common Seat [sea] Chest@ $£ 7$.

Do 4 feet Long @ $£ 8$.

Mehogny Stand table (a) £3o.

D Blackwalnut@ $£ 26$.

Maple Do@£zo.

Maple Candel Stand @ £io.

DoWalnot £i2. Do Mehogny@ @i6.

Mehgny high Case of Drawers @ $£$ roo.

Do with Crown and Claws@ £I50.

Mehogny Chamber table@ $£ 50$.

Mehogny Desk with 2 Draws (a) $£ 90$.

Walnot $\mathrm{D}^{\circ}$ with 2 tear of Draws $£ 75$.

Black walnot high Case of Draws @ $£ 85$.

Mehogny Rule Joynt tables @ E Ir a feet.

Walnot Do@ $£$ [figures gone] a foot.

To Casen of a Desk @ $£ 5$.

A Desk with two teer of Draws \& y $y^{\mathrm{e}}$ Protitions Brought froward $£+1$.

A Bedstid with Cock Tinnonts $£$ Io.

A Desk with two teer of Draws one Square Draw $£ 39$.

Gershom Carpenter.

Grindall Rawson.

Benja Hunt.

JOHN POWER.

Phillip PotTer.

JOSEPH SWEETING.

The prices in this table are given in the inflated Rhode Island currency of the day. What they would have been in silver can only be roughly estimated. They are, nevertheless, very interesting, because they show the relative values of the pieces described in the list. 
A Table of Prices for Cabinet Work in Hartford, Conn., in 1792 ; a Copy of One of the Pamphlets printed by a Society of CabinetMakers, now in the Possession of the Author.

\section{HartFord, August I, I792.}

At a meeting of the Cabinet Makers, held in this City, the following resolutions were agreed on by us, whose names are hereunto affixed, and who have formed ourselves into a. Society for the purpose of regulating the prices of our work; on the principle of dealing in CASH, and of establishing a uniformity in our trade for the general interest of ourselves and customers:

Resolved, That this Society will meet on the afternoons of the first Mondays in November and Fune at 3 o'clock, and September and March, at 6 o'clock annually, for the purpose of making further improvements in our business.

Resolved, That we will strictly conform to the prices which are or shall be affixed to our work; a deviation therefrom, shall be deemed a forfeiture of word and honour.

\section{DESKS.}

For a plain Desk, 3 feet 3 inches in length, and plain feet, with 3 drawers in the head, Ditto of 3 feet 6 inches long, swell'd feet, Ditto 3 feet 8 inches long,

$\begin{array}{rrr}£ 4 & 7 & 0 \\ 5 & 0 & 0 \\ 5 & 6 & 0 \\ 7 & 10 & 0 \\ 8 & 5 & 0 \\ 9 & 0 & 0\end{array}$

Ditto with quarter columns,

A Secretary, made plain, with swell'd feet, length 3 feet 8 inches, 650 Ditto with doors and trays, Ditto swell'd front, 
BOOK CASES.

For a plain Book-Case $3 \frac{1}{2}$ feet long,

Ditto 3 feet 8 inches long, large dental moulding, $\begin{array}{lll}2 & \text { I7 } & 0\end{array}$

Ditto with pediment head, mitre'd doors and balls, Ditto with scrowl'd head and fluted pilasters,

CHEST ON CHEST.

For a plain Chest on Chest, bottom chest $3 \frac{\pi}{2}$ feet long,

Ditto with Columns,

Ditto with scrowl'd head 3 feet 9 inches long,

Ditto swell'd front, claw feet and carv'd mouldings,

BEAUREAUS.

For a plain Bureau, plain feet, 3 feet long, Ditto with swell'd feet, 3 feet 4 inches long, Ditto with swell'd front, 3 feet long,

Ditto 3 feet 4 inches long,

Ditto with claw feet,

Ditto with columns, claw feet and carv'd mouldings,

$\begin{array}{rrr}2 & 18 & 0 \\ 3 & 6 & 0 \\ 4 & 15 & 0 \\ 5 & 0 & 0 \\ 5 & 10 & 0 \\ 6 & 0 & 0\end{array}$

(All trimmings for the above draws excluded.)

TABLES, $8 C$ C.

For a dining Table $4 \frac{1}{2}$ by 5 feet,

$\begin{array}{rrr}2 & \text { I } 2 & 0 \\ 2 & 15 & 0 \\ 2 & 3 & 0 \\ 2 & 0 & 0 \\ \text { I } & 16 & 0 \\ \text { I } & 7 & 0 \\ \text { I } & 9 & 0 \\ \text { I } & 13 & 0\end{array}$

Ditto with six legs,

Ditto 4 by 4 feet, with four legs,

Ditto 3 feet 9 inches, by 4 feet 3 inches,

Ditto $3 \frac{1}{2}$ by 4 feet,

For a plain Breakfast Table,

Ditto with stretchers,

Ditto with drawer trim'd, 
Pembroke Table, ends swell'd and scollop'd top,

For a small Tea Table, top 26 inches with a solid cap,

A plain Tea or Stand Table, top 3 feet 2 inches with box,

Ditto with turn'd top,

Candle Stand,

Fire Screen, with the springs,

Oval Tea Trays, 2 feet 2 inches by 17 inches,

For a circular Card Table, with carv'd moulding, 3 feet long,

Ditto square and plain, without drawers,

Ditto with fluted legs and carved moulding,

Ditto with drawer in front,

For a plain Side Board, 6 feet by 2 ditto,

Ditto with two drawers,

For a Cherrytree Kitchen Table, with a drawer,

Ditto of Pine,

For a Pine Toilet Table,

\section{BEDSTEADS.}

For a plain Cord Bedstead, painted red,

Ditto with pins for sacking, and screw'd,

Ditto painted green,

- I4 0

I. 60

I 80

Ditto plain square high posts without screws and for a cord with plain teaster painted red,

Ditto screw'd and for sacking bottom,

Ditto painted green,

Ditto with six pullies in the teaster,

Ditto with two turn'd posts,

Ditto made of Cherrytree,

Ditto with moulding at the bottom of the two foot posts,

$\begin{array}{rrr}\text { I } & 3 & 0 \\ \text { I } & \text { I } 4 & 0 \\ \text { I } & \text { I } 9 & 0 \\ 2 & I & 0 \\ 2 & 4 & 0 \\ 2 & 4 & 0\end{array}$

280 
Ditto with two claw feet,

Ditto with two fluted posts,

$2 \quad$ I8 0

Ditto Field Beadstead, plain turn'd posts, green,

Ditto with screw caps,

Ditto to turn against the wall, for cord, screwed, painted red without caps,

Ditto with a teaster fram'd to screw on the wall,

Ditto for a sacking bottom,

Ditto for cross ditto,

Ditto painted red with a head board,

Ditto Child's with posts, painted red, for a cord, with truckles,

3. 50

250

280

I 80

I 130

I 160

- Io 0

○ I 20

$\circ$ I3 0

CHAIRS.

For plain Chairs, with 5 bars or banisters for loose seats,

Seats for ditto exclusive of covers,

Chair frames to cover over the rails,

Seats for ditto exclusive of the cover and brass nails,

Chair with two cross slats and top rail, for loose seats,

Ditto with urn'd banisters for loose seats,

I I 0

- 50

- I9 0

$\circ 90$

I I 0

I 90

\section{EASY CHAIRS.}

For an Easy Chair, with plain or fluted legs, stuff'd,

Ditto with claw feet,

$4 \quad 4 \quad 0$

4 10 0

The item last quoted is found at the bottom of page 6 of the printed pamphlet. The remainder of the pamphlet is unfortunately lost. It probably contained a few more articles of furniture before the names of the members of the society. 


\section{N D E X}

Advertisements, 65, 95, 99, i76, 177, Bagnall, Benjamin, clockmaker, 247,

$179,180,183,243,244,250,25 \mathrm{I}, 255$, $257,259$.

Alcock, Dr. Samuel, inventory, 44. Allen, Capt. Bozone, inventory, 27. Allen, Capt. David, inventory, 67 .

Allyn, Matthew, inventory, 195 .

Almery, Aumbry, Ambry, 31, 32, 34, 53 .

Ambrose, Henry, inventory, 69.

American Antiquarian Society, r73, 204.

Ancient Inventories of Furniture, etc., 37,49 .

Ancient and Modern Furniture and Woodwork in the South Kensington Museum, Pollen's, 173.

Anderson, David, inventory, 202.

Antiquarian Societies, inventories of, 6,8 .

Appendix, 91, 163; table of prices for cabinet work, 265-269.

Apthorp, Charles, inventory, I70, 207.

Armoire, 32.

Art Journal, The, 98, I $57,158,174$, 197.

Ash, Thomas, Windsor chairmaker, 183.

Ashmolean Museum at Oxford, I40, I56.

Atwood, John, inventory, 73, 147.

Avery, Jonathan, inventory, 63 .

Badley, Thomas, watchmaker, 250, 25 r.

252.

Bagnall, Samuel, clockmaker, 254.

Bagnall, Rev. W. R., 252.

Baker, John, inventory, 60.

Bailantine, John, inventory, 221.

Bandy legs for furniture, 162,163 .

Banister back chairs, 165,178 .

Barnard, Jane, licensed to sell coffee and chocolate, 230.

Barnes, Thomas, inventory, 220.

Batterson, James, clockmaker, 243 , . $244,250$.

Beal, Sarah, inventory, 4 .

Beath, Adam, inventory, 167.

Bedsteads, prices of, 269,270 .

Beers, William, inventory, 107.

Bellingham, Richard, inventory, 18.

Bellot, Hugh, Bp. of Chester, inventory, 33, 35, 5I ; court-cupboards, $35,36,43$.

Bendall, Freegrace, inventory, 202, 226 .

Bennett, James, inventory, 223 .

Bennett, Mary, inventory, 166.

Béthune, Henri de, Abp. of Bordeaux, inventory, 125.

Betts, Charles Wyllys, bequest of, 56 , 59 .

Betts, John, inventory, 220.

Black walnut, used for furniture, iv, 96, 258 .

Blacksmiths, earliest makers of clocks and watches, 250 .

Blanchard, William, inventory, 2 I9. 
Blish, Abraham, inventory, 102.

Blowers, Capt. John, inventory, 232.

Blowers, Pyam, inventory, I3 1 , 133 .

Board, Anglo-Saxon name for diningtable, I89, 190; and trestles, I9I, I92.

Board chests, 2, I7.

Boardman, W. F. J., slate table of, 204.

Boardman, William G., scrutoir of, 123; roundabout chair, 169 .

Bond, Matthew, inventory, 123.

Bookcase, the word not met with in the $\mathbf{r} 7$ th century, $\mathbf{2} 22$

Bookcase heads, 88 .

Bookcases on the earlier scrutoirs, I23, I28, I 29; doors of, 123; prices for, 268 .

Bosse, Abraham, chairs of, $158,160$.

Boston Gazette, 251 .

Boston News-Letter, The, 65, 129, 243 , 246, 250, 25I, 257, 259 .

Boston Record Commissioners, Reports of, 230, 244, 245, 247 .

Boston records, 223 .

Bottles, cases for, made of wood, 227.

Boxes, carved, first mention of, 5 ; with style of carving rarely seen in New England, 18, 19; carved oaken, of early dates, 22 ; or desks, I10, II 6.

Boyer, French Dictionary of, 126.

Boyes, Antipas, inventory, II6, I99, $215,216,225,227$.

Brackets, found on old chests, 7 .

Brackett, John, inventory, I I0, I13, 158.

Bradford, William, inventory, 5, 147.

Brasses, 85-89, 9I, 10 5, 12I, 204, 205.

Brewster, William, chest, I7; inventory, IIO; chair in Pilgrim Hall, 142 .

Brickwell, Henrie, inventory, 35, I I 5.

Brickwell, Thomas, Esq., inventory, 34. 35 .

Bridges, Edmund, cupboard of, 28 .

Bronsden, Robert, inventory, 79.
Brookhouse, Robert, chair of, 146 .

Brown, William, Jr., 182.

Buckminster, Joseph, inventory, 43.

Budd, Edward, a carver, 29.

Buffets, 3I, 66, 67; definition of, 36 ; first mention of, in New England, 65 ; synonymous with corner cupboards, 66; corner, 68; doors of, 68 ; interiors, 68 ; of mahogany, 69 . Building News, The, 82 .

Bulkeley, Peter, inventory, 219.

Bullock, William, inventory, 48 .

Bureau, derivation of name, $1 \mathbf{1} 2$; in the Musée de Cluny in Paris, 122 ; definition of, by Boyer, 126; in English vocabularies, 130.

Bureau bookcases, 129; desks, 134.

Bureau tables, earliest notice of, I3I, 132 ; found in bedrooms, 133 .

Bureaus, mentioned in an advertisement, 126; chests of drawers, 132, I34; same as scrutoirs, or desks, I 27-I 34; prices for, 268 .

Burnet, William, inventory, 123,221 , 223; chairs of, I 72

Burnham, Edward, 12 I.

Butler, James, inventory, 79

Bynley, John, will of, I89.

Cabinet Dictionary, Sheraton's, $7 \mathbf{I}$, I 75 .

Cabinet-Maker and Art Furnisher, 82,84 .

Cabinet-Maker and Upholsterer's Drawing-Book, Sheraton's, 7 I,

Cabinet work, prices for, 267-270.

Cabinets, 58, I28.

Cadeby, John, inventory, 3 .

Caillowell, Isaac, inventory, 223.

Camden Society, wills published by, 3, 3I, 197

Campbell, James, chest of drawers, 86 . Candle-box, Dr, Gibbon's, 99, 100.

Cane, Henrietta Maria, inventory, 67. Carpenters' wages, 44.

Carpets, not restricted to floor cover. ings, 218 . 
Carter, Ruth, inventory, 23r.

Carve, to, English word, how used, i8.

Carved oaken furniture, iv; boxes, 5 $18,19,22$; chests, 5,6 ; furniture, 6 . Carver and Brewster chairs at Plymouth, I 42.

Carvers, 29.

Carving, the flat, of 17 th century, 2, 18 ; of 16 th century superior, 6 ; on chests, 9, 14-16; colored, 16, 21 ; where practiced, I8; peculiarities of, 19; linear or groove, 19, 20; origin of that found on New England chests and cupboards, 2, 18-20.

Cases of drawers, 12, 91, 94, 105-107. See Chests of drawers.

Castle of Dover, accounts, 30.

Catherine of Braganza, furniture with, 155.

Catlin, Abel, donor of carved oaken box, 22.

Cedar chests, I7, 93 .

Cellarets, 7I. See Sideboards.

Chair, the President's, at Harvard College, $\mathrm{I}_{3} 8$; in Ashmolean $\mathrm{Mu}-$ seum, Oxford, I40, I56; of Connecticut Historical Society, I4I ; of Apostle John Eliot, I42; in Old South Church, Boston, I47, I 58 ; of Rubens, in Royal Museum, Antwerp, I48; at Trinity College, Hartford, I48; of Roger Williams, I5I; given by Charles II. to John EveIyn, 156.

Chairs, scarce in early colonial times, 137; use of stools and forms for seats, 137 ; three distinct types of, in New England, 138 ; turned, found in English farmhouses in last century, 139, 140; of triangular shape in use in Germany and the Netherlands, I4I ; developed from threelegged stools, I42; with arms, much used in New England, I42; different woods employed, I43, I45, I65, I7I, 172; with horizontal slats in the back, 143, 144; with flag bot- toms, 144 , 145 , I53; seats of, made from fibrous bark of trees, 145 ; wainscot, $145^{1}-147,15^{8}, 160$; with leather seats and backs, $147-150$, I 53, I 56-1 58, I60; covered with different fabrics, I50, I 51 ; with stuffing of salt marsh grass, 152 ; abundant by close of I 7 th century, I53; cane, in sets of from six to twelve, I53-I 55, 60 ; earliest record of cane chairs in England, I 56; highbacked leather, of early date, $157-$ 16I ; bandy-legged, I6I ; of Chinese origin, I62; with ball and claw feet, 163,171 ; with horizontal slats in the back, 164 ; with banister backs, r65; easy, I66-168; roundabout, first appearance of, 168,169 ; first mahogany, 169; Chippendale, 169173. 175; Heppelwhite, I7I, IS5, IS6; double, I7I, I73; Windsor, earliest dates for, $176-179$; grounds for belief in English origin of, $18 z-$ I85; advertisements of, I79, I80, IS3; Sheraton, 186,187 ; prices of, 270.

Chamber tables, 84,87 .

Chandler, John, donor of chair, I73.

Chapin, Aaron, sideboard by, $7 z$.

Chapin, Eliphalet, chairmaker, I7I.

Charnock, Capt. John, inventory, 223. Cheney, Benjamin, clockmaker, 263.

Chest on chest, prices for, 268 .

Chests, during the Middle Ages, I; uses of, I, 22, 24; in churches, 1 ; carved, $1-3,6,146$; and paneled, $I$, $6,23,28$; in early records, 2 ; varieties of, $2,3,6$; carving on, 2 , 14I6, 19; its origin, $2,18-20$; without drawers, 6-8, I6; with pine lids, American, 7, 15, 25; with framed and paneled oaken lids, European, 7 ; made of oak, $7,10,14-17,24,25$, 28 ; with one drawer, 8-10, 16,26 ; with two drawers, 9, II, I2, 14-I6, $26,77,7^{8}$; with genuine dates, 9 , I0, 22, 23 ; made in Hartford County, 
Conn., I 5, 24, 25; with three drawers, rare, I6, 78 ; colors employed, I6, $2 \mathbf{1}$; made of pine, I7; of cherry, 78 ; close resemblances between specimens, 17; decoration of, 17 , 20,21 ; decline in popular favor of, 23 ; origin of those found in New England, 23-29; of American manufacture, $24-27$.

Chests of drawers, II-I3, 22, 64; same as cases of drawers, I2, ro5107; not in use in England before I7th century, 73 ; appear in New England records, 73; prices of, 73$75,79,8 \mathrm{x}, 92$; early types of, 74 ; not at first made high, 75,76 ; changes in, 76,77 ; resemblance to early chests with drawers, 77,78 ; made of various woods, $79,81,82$, $87,91-93,96,98$, ro8; with glass and china ware on their tops, $79,8 \mathrm{I}$; mounted on legs, $80,82,83$; with steps for display of glass and crockery, 81, I02-105; with six legs, 82, 83,86 ; six-legged, rare in England, 83,84 ; with four legs, $82,84,86$; the four and six-legged, Dutch and Flemish in origin, 83, 84, 86; with five legs, 84 ; brasses on drawers of, $85,86,89,90$; oldest types of brasses in New England, 85, 86; with flat tops, 86, 88, I08, $\mathrm{r}_{3} \mathrm{I}$; with arched tops, 88,89 ; characteristic details, 88 ; style most in vogue in New England, 89, 90; with writing desks, 90, 91; low chests of drawers, 91; made of oak, 92, 93; of European use before known in England, 92, 93; of Japan work, 95; of black walnut, 96; veneers of, 97,98 ; of mahoganx, 98,100 , IOI; in use till close of I8th century, Io ; turned feet of, IzO.

Chetham Society, inventories of I6th century, 6, 33, 50, 69.

Chetwoode, John, Esq., inventory, 38, 43 .
Chickering, Francis, inventory, I94.

Child, Thomas, inventory, 158.

China ware, 102, 103, 222-224.

Chippendale, Thomas, designs of sideboard tables, 70, 7I; for scrutoirs with bookcases, I28; for bureaus or chests of drawers, 133 ; chairs, I69-172; personal history, $173^{-175}$; excellence of, in carving, 185 ; designs for clock-cases, 263 .

Chocolate, 95; earliest mention of, 230,231 ; domestic use of, 232.

Christ Church College, Oxford, cupboard at, 4r, 42, 45, 46 .

Cicero's Tusculan Questions, desks in frontispiece, II3.

Claggett, William, clockmaker, 25 I.

Clark, James, inventory, 67.

Clark, William (Salem), inventory, 34, 60,61, I I O I 47, 232.

Clark, William (physician, Boston), inventory, I32, 133 .

Clark, William (merchant, Boston), inventory, 206.

Clerkenwell, clocks manufactured at, 237.

Clockmakers, earliest mention of, 244, 249; in Boston, 249.

Clocks, often mentioned in records of I 7 th century, 233; of two principal kinds, 233, 236; prices of, 233,241 , 242 ; spring, 233, 240; with weights, 233 , 24I ; few remaining examples, 234 ; oldest style of, described, 234 ; various names of, in England, 235; I 5 th century, 235, 236; described in Notes and Queries, 235-237; made in Holland, 238,239 ; old brass, 238, 243; tall-cased, 24x, 242; eight-day, 243; care of, in Boston, 244-248; earliest makers of, 250; use of pine in American-made cases, 253; English veneers laid on oak, 253,256 ; excellence of our older timepieces, 254; local manufacture of, 255,256 ; ornamentation of, 256 ; woods used seldom specified, 257 ; 
japanned cases mentioned, 258 ; black walnut most used in Massachusetts, wild cherry in Connecticut, 258 , 259; with black cases, 259 ; earliest records of mahogany case, 259,260 ; cases of, inlaid with lightcolored woods, 260,262 ; dials of, $260-262$; with wooden works, 262 , 263 ; variety of names for, 263 ; with tall case, known here as eightday clocks, 264; French style of, under a glass case, 264 .

Clough, Samuel, mender of Town house clock, 247.

Coates, Thomas, inventory, 100.

Coffee, earliest mention of, 230,231 ; domestic use of, 23 I.

Coggan, John, inventory, 222.

Coggan, Martha, inventory, 73 .

Coit, Thomas Winthrop, donor of chair to Trinity College, Hartford, 149.

Colchester, Conn., cupboard from, 54 . Cole, Mrs. Ann, inventory, I3.

Coleman, John, comer cupboard, 67.

Collections, R. I. Historical Society, $25 \mathrm{I}$.

Collins, George A., clockmaker, 238 .

Collins, Martin, inventory, I9z.

Collins, Rev. Nathaniel, inventory, 6r.

Colonists supplied with skilled labor, 28,249 .

Comedy of Errors, quoted, I I2.

Commodes made in France, 76 .

Condy, William, inventory, 202.

Connecticut Courant, I79, 255 .

Connecticut Gazette, I8I.

Connecticut Historical Society, chests, 8, 17; carved oaken box, 22; chairs, I4I, I55; tables, I95, 200.

Copse, John, inventory, $19 \%$.

Corbet, mention of court-cupboard, $3^{8}$.

Corner cupboards, not called buffets in England, 64; first record of, in
England, 65; in New England now synonymous with buffets, 66, 67 ; distinct in early inventories, 66-6s.

Cotes, Timothy, inventory, 159.

Cotton, John, inventory, 59, 145, 147, I94, 233.

Court-cupboards, $33,34,36$; in New England probate records, 34, 35; in English inventories, $34,35,3^{S}$; in use in England, 35, 38, $4^{\mathrm{I}}$; prices of, $35,36,3^{8}, 41,43$; constructions and use, 36,38 ; definition of, 37 ; print of one in 1627 in Laurea Austriaca, 39; with a drawer, $37,46,52$; of 16 th and 17 th centuries, $38,45,46$; the ancient sideboard, 39; with steps, 39, 40; two in Stationers' Hall, London, $40-42,45$; one in the hall of Christ Church College, Oxford, 4I, 42, 45, 46 ; illustrations of, after Shaw, 4I ; after Halliweil, 4I; variable construction of, 42 ; where found in New England, 42; prices, 42, 43, 45,49 ; uses of, $36-38,44,45,52$; style of, in England, 46; same as livery-cupboards, 47, 5I, 52; with two drawers, 47; and livery-cupboards not mentioned together, 5 I. See Livery-cupboards.

Court of Love, The, quoted for word desk, rog.

Cowperthwaite, John K., I8I.

Coytemore, Catherine, inventory, 222.

Coytemore, Thomas, inventory, 222, 224, 233.

Crafts, John, inventory, 5 .

Craigie, David, inventory, 125.

Cranewise, Andrew, will of, 197 .

Craty, Capt. Andrew, inventory, 79, 94, I 54, 242.

Cross, John, inventory, 220.

Cruft, Capt. Edward, inventory, ro\%.

Cunningham, Nathaniel, inventory, 207.

Cupboards, first use of the word, 30 , 
32 ; open structures, $30,33,45$; inclosed, 31-34, 44, 46, 53-55, 58, 60, 63 ; two classes of, 33,34 ; varieties of, 33, 34, 53; furnished with cloths of various materials, $44,60-$ 62 ; with cushions, $44,6 \mathrm{I}-63,76$; with drawers, $54,55,59,60$; owned and used in Connecticut, 55, 56, 64; made of oak, 56, 59; in use in England, and American colonies, 56, 57 ; without carving, 56; origin of style in I6th century, 57 ; with turned columns, 58 ; lose favor at close of $x 7$ th century, 63; displaced by chests of drawers, 64; new styles of, see Corner cupboard, 64; movable pieces, 66.

Cupboard cloths, 60, 6I.

Cupboard cushions, $6 \mathrm{I}-63$.

Curwen, George R., I04, 2XI.

Cushing, Mrs. James, 2 II.

Customs, The, of New England, Felt's, ro5.

Cutler, John, inventory, 203.

Cutler, Robert, inventory, 27.

Cypress chests, 3, 6, 17 .

Daily Courant, 65, 99, I 26, 129.

Daily Post, 65, 97, I3I.

Danvers, desk from, III.

Davie, Humphrey, Esq., inventory, 218.

Davis, James, inventory, 220.

Davis, Robert, inventory, 88 .

Davison, Nicholas, inventory, 44.

Day, Robert, inventory, IIo.

De Dalby, Thomas, inventory, 30 .

Deerfield, oaken chests at, I6, 25 .

Delft ware, 220-222.

Denison, Mary, il.ventorr, 220 .

Dennie, John, inventory, 169 .

Dennis, Sarah, owner of chairs, tape $100 \mathrm{~m}$, and carved chest, I46.

Desks, coeval with art of writing with pen and ink, ro9; etymology of the word, I09, II 5 ; two rather distinct meanings, IO9; prices of, in New
England inventories, I10, 125, 127; traditional conception of, III ; cloth covering of, II $2, I_{3}$; standing, II 3 , II4; inclosed from table nearly to floor, $\mathrm{I}_{13}$; in the sense of receptacles for books and papers, II4, II 5 ; a mounted variety, I 6 ; good specimens scarce, II6; and bookcases, I28-I3I ; and scrutoir, used interchangeably, 128. See Scrutoir; sometimes called bureau desks, I34; prices for, 267 .

Dewing, Andrew, inventory, 4.

Dickinson, Jonathan, inventory, IOI.

Dickinson, Thomas, inventory, 98.

Dictionarie of the French and English Tongues, Cotgrave's, 36 .

Dictionarium Britannicum, Bailey's, IsS.

Dictionary of Archaic and Provincial Words, Halliwell-Phillipps's, 37.

Dictionary of Obsolete and Provincial English, Wright's, 189.

Dictionnaire de L'Ameublement, Havard's, 95, II 8.

Dinely, Fathergone, inventory, $6 z$.

Dining-rooms, 209, 213, 21 5 ; table, or board, I00, 208.

Doolittle, Enos, clockmaker, 255.

Dover, Lord, chair of, 173 .

Dowden, Leonard, inventory, 79.

Drawing-tables, 194-196.

Dresses and Habits of England, Strutt's, II 2.

Dressing-tables, $84,87,89,108, \mathbf{1} 20$, I 21 .

Dressoir, 31 ; definition of, 36 ; Flemish, 39, 46, 47, 49; used in France in $15^{\text {th }}$ century, $5^{2}$.

Drops, I5, 21 ; invented and first used by Koek, 20 .

Drury, Elizabeth, will of, $3 \mathrm{I}$.

Dryden's use of the word sideboard, 70.

Duffield, William, inventory, 32 .

Dunster, Henry, inventory, 150.

Durant, William, clock of, 253 . 
Durham, cupboard from, 59.

Dupee, Mrs. W. R., clock of, 254.

Dutch and Flemish chairs, I6I.

Dutch marquetry, $256-25^{8}$.

Dwelling-houses of New England, apartments of, 208.

Dyer, Giles, keeper of town clock, $245,246$.

Dyer, John, inventory, 85 .

Earthenware, white, blue, and painted earthen dishes, 219, 221, 224.

Eaton, Governor Theophilus, inventory, 60, 194, 212, 222, 225, 227.

Economic and Social History of New England, Weeden's, 226.

Ecritoire or Escritoire, $124-126,136$.

Eliot, Jacob, inventory, 63 .

Eliot, John, Jr., inventory, 6r, 96.

Embroidery stitches, I53.

Emslie, J. P., drawings by, $4 \mathrm{I}$.

Endicott, John, Governor of Massachusetts, inventory, 206.

Entry, or hall, 209-2II, 218.

Erving, Henry W., oaken desk box of, III.

Essex, Conn., carved oaken furniture from, 74, 112.

Essex County Records, Massachusetts, inventory in, $15 \mathrm{~L}$.

Essex Institute, Salem, Mass., chair at, 146.

Essex, Joseph, clockmaker, 250.

Eustis, David, inventory, 165

Evans, David, inventory, 68.

Evelyn, John, gift of chair to, 156 .

Everill, Abiel, inventory, 69.

Fairweather, Thomas, inventory, 102.

Faneuil, Peter, inventory, 206; silver forks of, 226 .

Farley, E. W., donor of chair to Bowdoin College, 146.

Farmington, Conn., chest from, I6.

Farnum, Joseph, inventory, I 5 r.

Faulkner, Thomas, inventory, 2x9, 222.
Ffellows, John, inventory, 85 .

Fillebrown, Thomas, inventory, 260.

Fireplace tiles, Dutch, 22 I.

Fitch, Jeremiah, inventory, 226.

Flanders chest, 6.

Flowered furniture, 87 .

Forks, first mention of, 225; handles of, 226 ; with three and four prongs, 236.

Foster, Captain, bringer of clock from Amsterdam, 238.

Foster, John, inventory, I02.

Francklin, William, inventory, 44.

Franklin, Henry, inventory, 123, 126, I 30,167 .

Freake, John, inventory, $15 \mathrm{I}, 225$.

Friesland carving, 20.

Fromantil, Ahasuerus, Dutch clockmaker, 237.

Fuller, Horace S., high chest of drawers, 83 ; scrutoir, I20.

Furniture made by a joiner, 3 ; papers on, 52 ; inventory made in Paris, 125 ; in halls, $21 \mathrm{I}, 212$.

Gatchell, Jonathan, inventory, I66.

Gauteir, Andrew, Windsor chairmaker, I $77, \mathrm{x} 84$.

Gauteir, Jacques, Huguenot emigrant, I77.

Gay, Ebenezer, clock of, 254 .

Genealogical Dictionary, Savage's, 29.

Genealogies and Estates of Charlestown, Wyman's, 29.

General Advertiser, The, 70.

Gentleman's and Cabinet-Maker's Director, Chippendale's, I74.

Gibbons, Major-General Edward, inventory, IIO, II3 227.

Gibbs, Benjamin, inventory, II 7 .

Gibson, Christopher, inventory, 45, 62 .

Gilbert, Thomas, inventory, I 54, 226.

Glaseor, William, inventory, 50.

Glassware, on chests of drawers, 79, $8 \mathrm{r}$, 102, 106, 107; scarce, 226; of I8th century, 228, 229.

Glastonbury, Conn., scrutoir from, I20. 
Glover, Mary, inventory, 43.

Goffe, Capt. Christopher, inventory, 203.

Goodwin, John, inventory, I64.

Groodyear, Stephen, inventory, 43, I95.

Gordon, Governor Patrick, Windsor chairs of, 176,184 .

Graves, Rear-Admiral 'Thomas, inventory, 5 \$.

Greenwood, Samuel, inventory, ro2.

Gretton, Charles, clockmaker, 240.

Griffith, William, inventory, 206.

Grunow, Herr C., of Berlin, I8-20.

Guineau, Henry, inventory, 90.

Gutteridge, Robert, licensed to sell coffee, tea, and chocolate, 23 I.

Haddock, Charles W., clock of, 238 .

IIaddock, Mrs. Charles, court-cupboard of, 47 .

Hale, G. H., square table of, 198.

Hale, Samuel, inventory, 63 .

Hall, name not used for entrance way in 1 ith century, 209; the principal living-room, 209; furniture in old colonial, 21 I, 212, 214, 215, 217; other names for, 216 .

Halliwell, James Orchard, 37, 4I, 49, 5 I.

Halliwell-Phillipps, 37, II7, II8, I22.

I Ialsey, Henry, donor of table to Connecticut Historical Society, 195.

Hancock, Governor John, chair of, 173 .

Harris, Benjamin, licensed to sell coffee, tea, and chocolate, $23 \mathrm{r}$.

Harris, Sarah, inventory, 154 .

Harris, William, inventory, 79, 93, 226 .

Harris, William, Jr., Windsor chairmaker, r8r.

Harrison, John, English clockmaker, 262.

Hartford County, Conn., rich in carved oaken woodwork, iii; chests made in, 15,25 .
Harwood, Henry, inventory, 220.

Haugh, Mrs. Anna, inventory, 13.

Hayden, J. H., I95.

Haynes, John, inventory, 5I, 6r, I 50.

Heppelwhite, cabinet-maker, 69, 7r, 72 ; designs of, 108, I34, I35, 167; extensive use of embellishment by, I85, 186; tables with rich inlays, 208.

Heriot Hospital, Edinburgh, oval table at, 199 .

Herte, Agas, will of, 3 .

Hett, Thomas, inventory, $5^{8}$.

Hews, Alpheus, Windsor chairmaker, x80.

Hibbins, Mrs. Ann, inventory, 6I, 218.

Hicks, Richard, inventory, 62.

Hill, John, inventory, 168 .

Hill, Joseph, licensed to sell coffee, tea, and chocolate, 23I.

Historical Account of Massachusetts Currency, Felt's, 207.

History and Antiquities of Hengrave, Suffolk, Gage's, 40.

History of Harvard University, Pierce's, I38.

History of the United States, Bryant and Gay's, 146 .

Hoadly, Charles J., vi.

Hodge, IIannah, inventory, I76.

Hodson, John, inventory, i 56, 203.

Holland ware, 220.

Holyoke, President Edward, I38.

Holyoke, Elizur, inventory, 223, 232.

Homes of other Days, Wright's, Ir3, I 10, I 90 .

Hook, Theodore, table chair of, in Art Journal, 197.

Hooker, Rev. Nathaniel, inventory, I17.

Hooper, Richard, inventory, 203.

Horne, John, I 56 .

Hosmer collection, Io, $16,54,74,84$, I14, I2I ; chairs in, I43, I6I, I72, I87; tables, 200, 20I ; clocks, 234, 253. 
- Hosmer, Stephen, inventory, 4 . Hosmer, Walter, v, 10, 74. See Hosmer collection.

House Beautiful, The, Cook's, 56, 69, 1.4).

How, Joseph, inventory, 227.

Howe, Mrs. Edmund G., oak chest of, ro.

Howel, William, inventory, 9I, 97.

If udson, Mrs. Mary, inventory, 219.

Huit, Ephraim, inventory, 227.

Hulbert, William E., collection of, 9 .

IIuton, Ralf, inventory of, 69 .

Independent Chronicle, The, I79.

Indo-Portuguese furniture, I 55.

Inlays, 9, 72, $18_{5}, 205,208,260,262$.

Inventories, chests, $4,5,8$; Hartford, $5,23,96$; Suffolk County, Mass., 5, 73; Surtees, Camden, and Chetham Societies, 6 ; chests with drawers, II-I3; Connecticut, 23, 220 ; hinges, handles, locks, etc., 27 ; I6th century, 3 I, 32 ; early, of New England, 33, 47, 69; English, $34,35.73$; court-cupboards, 43,44 ; cupboard cloths and cushions, 6063 ; corner cupboards, $66-68$; buffets, 67 ; sideboards, 69 ; chests of drawers, 79; glass and crockery, 79, 102, 103, 106, 107; mahogany furniture, I0O, IOI ; cases of drawers, I06, I07; desks, Iro; scrutoirs, II6, $x_{117}, I_{23}, I_{30}$; bureau tables, I3I, I32; PIymouth, Mass., I37; leather chairs, I47; chairs covered with various fabrics, I 50, I 51 ; Boston, 153; cane chairs in sets, r53, I54; two-back, three-back, etc., chairs, I64; banister-back chairs, 165 , I66; easy, or saddle-cheek chairs, I67, I68; Windsor chairs, I76; Salem, 189 ; slate and stone tables, 203 ; marble tables, 206, 207; furniture in hall, $211,212,217$; furniture in parlor, 213; china ware, 222,223 ; stoneware, 223, 224; silverware,
224, 225; glassware, 227; alluding

to use of tea, 232.

Iron-bound chests, 6 .

Ivory, Benjamin, inventory, $\mathrm{I}_{3}$.

Jacklin, Edmund, inventory, 43.

Jackson, Richard, inventory, 62 .

Japanned furniture, 94, 95 .

Japanning, done in Boston in I712, 95.

Jeffs, John, inventory, 62 .

Jekyll, John, inventory, 103, 217.

Johnson, Capt. Edward, list of trades by, 28 .

Johnson, Capt. James, licensed to sell coffee and chocolate, 230 .

Johnson, John, inventory, $6 \mathrm{r}$.

Joined chests, or framed with panels, $2,4^{-6}$.

Joiners, 3, 28, 9I, r94.

Joiners' work, rule and prices of, 265 , 266.

Jones, Alice, inventory, 189.

Jones, Mrs. Dorathy, licensed to sell coffee and chocolate, 230.

Jones, John, inventory, xoo.

Jones, William H., Heppelwhite chair of, I86.

Fuglans nigra (black walnut), 96 .

Jugs of gray stone, $22 \mathrm{I}$.

Katharine of Arragon, inventory, II 2.

Keayne, Robert, inventory, 135 .

Kellond, Thomas, inventory, $124,225$.

Kien Lung, Emperor of China, 162 .

King, William, inventory, 44.

Kings Arnıs, inventory of its furniture, 53 .

Knight, Richard, a carver, 29.

Knives and forks, 226.

Knocker, Thomas, inventory, 222.

Koek, Peter, inventor of the drop, 20.

Lacquered wares, 94 ; furniture made in Paris, 95.

Lamberton, George, inventory, I94.

Langdon, Josiah, inventory, ro7. 
Langton, Dame Anne, inventory, 69.

Larkins, Hugh, inventory, 22 I.

Laurea Austriaca, 39 .

Lawrence, Daniel, Windsor chairmaker, Iso.

Leager, Jacob, inventory, 222.

Le Blonde, James, inventory, 203.

Lebanon, Conn., dressing or chamber table from, 87 .

Lee, William, inventory, 50.

Leicester, Countesse of, inventory, 5 I.

Lemon, Robert, inventory, 62.

Levyt, Gilys, will of, 3I.

Lichfield, England, District Probate Registry, 38, 48, 49 .

Lidgett, Mary, inventory, 66.

Lids of oaken chests, 7, I 5, 25 .

List of trades in Boston, 28.

Livery-cupboards, iv, 33, 34, 42, 53 ; same as court-cupboards, $47,51,52$; prices, 48, 49; without doors, 49; in some cases inclosed, 49,50 ; uses of, 50-52; described in The Art Journal, 52; cease to be mentioned in records, 64 .

Lloyd, James, inventory, 226.

London Evening Post, 97.

London Gazette, 94, I35.

Long, Capt. Zachariah, inventory, 8o, $103,203.205$.

Lord, Richard, inventory, 58, 6I, 23I ; cane-seat chairs, 155 .

Loring, George B,, chest of drawers, 80.

Ludkin, William, inventory, 27.

Lusher, Mary, inventory, 50.

Lyndali, James, inventory, 220.

Lynn, chest of drawers from, 83; chamber table from, 84 .

Lyon, Irving Whitall, chests of, 7, 9, 14-I6, I20; box of, I9, Ir6; cupboard of, 59; chests of drawers of, $74,83,84,105,120$; dressing or chamber table of, 87 ; chairs of, $\mathrm{x}_{43}, \mathrm{I}_{44}, \mathrm{I} 52,167, \mathrm{I}_{72}, 184$; chair table of, I97; clocks of, 239, 240.
Mackman, James, inventory, 242, 243.

Madison, Conn., chests from, 10, I5; a cupboard, 59 .

Magazine of Art, The, I73.

Mahogany furniture, 69 ; introduced in London in $1720,98,99$; found in American inventories as early as r708, I00, 101 ; chairs, I7I, I72.

Malcom, Daniel, inventory, 132, 133, $17 \mathrm{~S}$.

Mansfield, Conn., a chest from, I4.

Manteltree, place for glass and earthenware, 64 .

Marot, Daniel, designs for clock cases, $24 \mathrm{I}$.

Marshall, Mary, inventory, $23 \mathbf{I}$.

Mason, Sampson, inventory, I07, I 66.

Masters, Giles, inventory, 153 .

Matson, Thomas, to repair the town clock, 245, 249.

Maxwell, Elizabeth, inventory, 229.

McKee, Robert, artist, 196.

Memorial Hall, Deerfield, Mass., oak chest in, 16, 25 .

Memorial History of Boston, Winsor's, I42.

Messinger, Henry, inventory, 28.

Meyrick, Sir Samuel Rush, 4I.

Mico, John, inventory, 66, 122.

Middlefield, Conn., chest of drawers from, 74 .

Middletown, Conn., box from, 19; buffet, 68 .

Milton, in Paradise Regained, has the phrase the stately sideboard, 70 .

Mitchell, Jonathan, inventory, 49.

Mitford, Julian, inventory, 33 .

Morgan, Octavius, best English authority on old clocks and watches, $235,236,24 \mathrm{I}$.

Morton, Thomas, inventory, 3 .

Mountjoy, Josiah, inventory, 164 .

Musée du Mobilier National, 93.

Needle's, The, Excellency, Taylor's, I 52 . 
New England Historic Genealogical Society, clock with solid black walnut case, 253.

New Haven Gazette, The, I8o.

New World of Words, Phillips's, II

New York Gazette, The, I76.

New York Gazetteer, The, 183 .

Newberry, General Roger, 255.

Nichols, John Gough, on court-cupboards, 40

Notch work, I8, 20.

Notes and Queries, 235, 236, 24r.

Noyes, Peter, 244.

Oak, 7, I4, I7, 77; the American white, several shades lighter than the European, 26; chairs of, I45; old transatlantic, 196.

Oaken boxes, 22.

Oaken chests, 3, 10, 15-17, 24, 25; desk, I25.

Obear, Capt. Benjamin, 238.

Old South Church, chair in, 147, I 5 S.

Olivewood, 79; earliest mention of, 93 ; furniture of, seldom found in the inventories, 94.

Orman, Dr. Benjamin, inventory, 232.

Ornaments, 9, I0, I5, I7; the drops, I5; egg-shaped, Norman nail heads and triglyphs, 20,21 .

Orr, James, inventory, 91.

Paddy, William, inventory, 147, I50.

Paine, William, inventory, I 5I.

Palmer, Thomas, Esq., inventory, 132, I33.

Paradise Regained, 70.

Parker, John, inventory, 67 .

Parker, Samuel, inventory, 178 .

Parlor, 213; and dining-room, 216.

Parson Turell's Legacy, ${ }_{3} 8$.

Parsons, Theodosius, I8I.

Patteshall, Robert, inventory, 225.

Peabody, Mass., chest of drawers from, 77 .
Pecker, James, inventory, 167, 229.

Pell, Capt. Edward, inventory, 167.

Pemberton, James, inventory, 206.

Pemberton, Thomas, inventory, 154, 203.

Pennsylvania Chronicle, 178.

Pennsylvania Journal, 176,178 .

Pennsylvania Magazine, 249.

Penrose, Bartholomew, inventory, 100.

Phillipps, Halliwell-. See HalliwellPhillipps.

Phillips's New World of Words, II7, II 8, I 22.

Phillips, John, inventory, I32, I33.

Phips, Sir William, inventory, 63, 154, $225,24 \mathrm{I}, 243,257$

Pickering, John, table of, 198.

Piers the Ploughman, I9o.

Pine, not put in oaken chests in England, 7,26 ; yellow, used in New England for lids, back panels, drawers, etc., 15, 16, 25 ; chests, I7; writing desk, I25.

Pitts, Mrs. Elizabeth, inventory, 206.

Plate, articles of, 225 .

Plumley, Charles, inventory, 100.

Pollen, John Hungerford, quotation from, 173.

Porter, Abell, licensed to sell coffee and chocolate, 230 .

Post Man, The, 65 .

Press, first use of the word, 32 ; synonymous with almery and cupboard, 32, 33, 54 .

Press cupboard, 33, 34, 53, 54 .

Presses, 53 ; receptacles for clothing, 32,54 .

Preston, John, donor of table to Amer. ican Antiquarian Society, 204.

Proctor, John, inventory, $103,168$.

Promptorium Parvulorum, I09, 192.

Public Advertiser, The, 97.

Pulsifer, Joseph, inventory, 154.

Queen Anne houses, 22, 64.

Quercus alba, American white oak, color of, 26. 
Ragland, John, inventory, 153 .

Rainsford, John, inventory, 167.

Rainsford, Jonathan, inventory, 44.

Rainsford, Nathan, inventory, I 16.

Randle, William, 65, 95, I29.

Records of Essex County Court, Mass., 28; of Middiesex County, Mass., 150 .

Richards, Benjamin, inventory, 62 , I5I.

Risden, Robert, inventory, 8.

Rivington, Charles Robert, 40.

Rix, Thomas, inventory, 222.

Roaring Girl, mention of court-cupboard, 37 .

Robbins, Walter, mahogany sideboard of, 72 .

Roberts, Mrs. Henry, Dutch tea table of, 203.

Roberts, Joshua, a japanner, 125 .

Roberts, Nicholas, inventory, 232.

Roberts, O. O., chest of, with two drawers, 9 .

Robinson, George T., authority on old furniture, vi, $52,64,98,155,157$, I 58 , 174.

Robinson, Thomas, inventory, II.

Rogers, Rev. Nathaniel, Ipswich, inventory, 8 .

Rogers, Nathaniel, Boston, sofa, I7r.

Roswell, Capt. Walter, inventory, 124 , $223,231,232$

Rowley, Mass., carved chest from, 7 .

Royse, Daniel, inventory, I 54.

Rubens, Peter Paul, chair of, at Antwerp, 148 .

Salem Observer, 238.

Sallows, Thomas, inventory, 62.

Salmon, John, inventory, 210.

Salter, S. James A., quoted from Notes and Queries, 235.

Sandy's Ghost, word bureau used in, 126.

Savage, Habijah, Esq., selectman of Boston, 252.

Savage, John, inventory, 4 .
Saywell, David, inventory, 27.

Scarlett, Capt. Samuel, inventory, 93.

Schmuck, Henry M., chair of (once Roger Williams's), I5 I.

Scob, word used at Winchester college for box, or desk, Ix4.

Scollay, James, oak desk of, I25.

Scott, Thomas, inventory, 232.

Scrutoirs, 94; new style of desk, II6; the latest noted, II 7 ; prices of, II 7 , I22-I25, I27; definitions of, II 7 , II8; same as writing-desk, II8; the oldest known of, described, II8, II9; feet of, II9, I20; surmounted with cases for books, I22, 123, I28 ; the first noted in this country or in England, 124; held the name for fifty years, 125 ; identity of, with desk and bureau, r26-r3r; disuse of the word, 134 .

Secretaries with siding covers, 135 .

Seeman, E. A., Leipzig, I8.

Selby, Thomas, inventory, 165 .

Sendall, Samuel, inventory, 60.

Settee, or double chair, 171,180 .

Settles, 187, 188.

Sewall, diary of, quoted, 232 .

Sharpe, Richard, inventory, II6, I24.

Sheaffe, Jacob, inventory, 6r, 147 , 212.

Shepard, Edward, maker of chest of drawers, Ios.

Shepherd, Deacon Samuel, inventory, $2 \mathrm{O}_{3}$.

Sheraton, Thomas, London cabinetmaker, 69, 71, 96, 97, 108, 128; chairs of, 146,147 .

Ship chests, 3,17 .

Shipbuilding, when begun, 28.

Shrimpton, Henry, inventory, 27, 225.

Shrimpton, Samuel, inventory, 223, 232.

Sideboard cupboard, or side cupboard, 47.

Sideboard tables, 60-7r, 208.

Sideboards, 69-72; succeeded by lockers, 72. 
Silverware, 224.

Simons, Edwin, $\mathbf{v}$; chest of drawers and dressing-table, 87 ; chairs, I57, 172,187 ; card table, 208.

Simons, Samuel, joiner, 28.

Singer, quotation from, 39.

Snowden, Jedidiah, Windsor chairmaker, 178 .

Solon, L. M., chest of drawers, 88.

South Kensington Museum, 93, 235.

Souther, Nathaniel, inventory, IIO, 113.

Sparry, John, licensed to sell coffee, 230.

Specimens of Ancient Furniture, Shaw's, 4r.

Sperry, Mrs. Henry T., clock of, 255.

Sprague, Capt. Richard, inventory, 79,81 .

Sprague, William, inventory, 197.

Spruce chests, 3 .

Stackhouse, Stacy, Windsor chairmaker, 179 , I80.

Staffordshire stoneware, 223.

Standishes of wood, I35; of various shapes and sizes, I36; Dean Swift's, I36.

Stands, or stand tables, 202.

Starr, Burgis P., cupboard of, 55.

Stationers' Hall, court-cupboards in, $40-42$.

Steps on cupboards for display of plate or china, 39, 40; for chests of drawers, I02-I05.

Stoddard, Anthony, inventory, I 28.

Stone, Rev. Samuel, inventory, 222.

Stools in use for seats, 137.

Stowe, Sergeant Nathaniel, inventory, 231.

Stowe, Rev. Samuel, inventory, 34.

Studies from Old English Mansions, Richardson's, $2 \mathbf{1}$.

Suffolk County, Mass., 5, 73; deeds, 53.

Sumner, William, blacksmith, to keep the clock (Boston), 246.
Surtees Society, 3, 30, 33, 34, 47, 5I, $69,115,189,192$.

Sweetser, Wigglesworth, inventory, 224.

Table, used instead of earlier word, board, I90, I9I.

Table-boards, 188, 192, 193 .

Table dishes, early colonial, 219-229.

Table forks, 225, 226.

Tables, with board and trestles, rgoI92; in use during early colonial period, 193; varieties of, 193, I94; long, for dining purposes, 194, 196; drawing (extension), I94-I96; wood used for, 196, 197, 208; chair, or table chairs, 197; with leaves, or folding, 199, 200; style of, common in New England, 200; with spreading legs, 20r; with triangular beds, 201, 202; stand, or Dutch tea, 202, 203 ; slate and stone, 203-205, 207 ; dressing, 205; marble, 206, 207; Heppelwhite, of the card and Pembroke styles, 208; inlays of, very rich, 208 ; coverings for, 218 ; dishes, 219 ; prices of, 268 , 269 .

Talby, Stephen, inventory, 62 .

Talcott, Colonel Samuel, a settle for house of, I87.

Talcott, Mrs. Thomas G., double chest of drawers, 9I ; steps on chest of drawers, 104; cane chair, 155; chairs, $\mathbf{1} 86$; settle, 188 .

Tall-boy, name for chest of drawers, 89.

Tambour cylinder desks rare, 135.

Taylor, Christopher, inventory, 155.

Taylor, Richard, bellringer, $245,248$.

Tea, early history and domestic use of, 23I, 232.

Tenney, John, inventory, 79 .

Terry, Eli, clockmaker, 263.

Thacher, Thomas, inventory, 93, 103, 23 I.

Thaulow, Museum at Kiel, 26, 57 . Thayer, Nathaniel, inventory, I3. 
Throckmorton, Elizabeth, inventory, | Walnut, black, early attracted attenI 56.

Throop, Amos, Windsor chairmaker, I8r.

Tiles, Dutch, for fireplaces, 220, 22 I.

Tompion, Thomas, clocks of, 24I, 257.

Townsend, James, inventory, 168.

Trestles, 192, 193.

Trinity College, Hartford, President's chair at, 184.

Trowbridge, Stephen, inventory, 166.

Turkey rugs, covers for chairs, I 50152.

Tyldisley, Thurstan, inventory, 69 .

Tyng, Capt. William, inventory, I59, $160,213,214,224$.

United States Chronicle, The, 180.

Upham, Nathaniel, inventory, 62 .

Upsall, Nicholas, inventory, 49

Van den Helm, a Dutch table-maker, 65.

Van Ysendyck, J. J., of Brussels, 20.

Vassall, Lewis, inventory, 130.

Veneer, first mention of, 97 ; woods used for, 98 .

Vernon, Daniel, licensed to sell coffee, 231 .

Verstille, Peter, inventory, $262,263$.

Vincent, Ambrose, inventory, $22 \mathrm{I}$.

Viollet-le-Duc, 31, 52, rog, II3.

Virginia walnut tree wood, 96, 97.

Vredeman de Vries, Hans and Paul, $2 \mathrm{I}, 57$.

Wadsworth, Joseph, selectman of Boston, 252.

Wainscot chairs, $145,146,160$; chests, 2, 4, 6, 13; furniture, 3, 4.

Wainwright, Bp. Jonathan Mayhew, cane chair, I55.

Wakeham, Robert, inventory, 63 .

Walker, Augustine, inventory, 218.

Walker, Mary, inventory, 68, x64.

Walker, Obadiah, inventory, 93, 96. tion of cabinet-makers, 96; veneers, 96-98.

Walpole, Horace, extracts from letters of, 139 .

Walter, Rev. Nehemiah, table of, 204.

Wanton, Joseph, Governor of Rhode Island, leather chair of, $\mathbf{1 4 9}$.

Wardell, William, inventory, 12.

Ware, Capt. John, inventory, 154.

Warner, Thomas, inventory, II

Warner, Capt. William, inventory, 107.

Warr, Abraham, inventory, 219.

Warren, John, inventory, 62 .

Waters, Henry F., collection of, 7,77 , III, I40, I45, I49.

Waters, William C., court-cupboard of, 46 .

Webb, Elisha, inventory, 85 .

Webb, Henry, inventory, 62, 135, 151, I $58,219,227$.

Webb, Isaac, clockmaker, 244, 247, $249,250$.

Wedgewood, Josiah, pottery of, 221.

Welcome, Peter, inventory, 13.

Weld, Daniel, inventory, II.

Weld, Joseph, inventory, 2 I9.

Welland, Capt. John, inventory, ro2, I67.

Welsteed, William, Esq., inventory, 106, 22I, 258; selectman of Boston, 252.

Welsteed, Rev. William, inventory, I03.

Wethersfield, Conn., buffet from, 68 ; chests of drawers from, $8_{3}$, 108 .

Wharton, John, inventory, I02, 232.

Wheeler, Ephraim, inventory, I64.

Wheelwright, Theodore, inventory, 161 .

Whittingham, William, inventory, 1 4 , I35.

Wight, Henry, inventory, 5.

Willard, Daniel, inventory, 130.

Williams, Rev. Elisha, clock, 253. 
Williams, Jacob, inventory, 107. Williams, Robert (trade not given), to keep the clock, 246,248 .

Williams, Roger, Turkey work chair of, 151 .

Williams, Samuel, a joiner, 178 .

Williamson, E., 93.

Wills published by Camden Society, 3,3 I.

Winchester, Caleb, inventory, 166.

Windsor chairs in use in Philadelphia, $\vee$; no mention of, in English newspapers, 182 . See under Chairs.

Windsor, as surname not found in Philadelphia during $I 7$ th and 18 th centuries, 183 .

Windsor, Conn., carved and paneled chest from, 6; chest of drawers from, 87 .

Wing, Robert, inventory, 193.

Winslow, Edward, chair of, 145.

Winslow, Joshua, inventory, 7 I, 207.

Winslow, Samuel, inventory, 96.
Winsor, John, inventory, 8.

Winthrop, Governor John, inventory, I95.

Woddrington, Sir Henry, inventory, 47.

Wolcott, Elisha, inventory, 107.

Wolterton, Gregory, inventory, 62.

Wonder-working Providence, 28.

Wood-carving in Northwestern Europe, I8; its highest degree of perfection, 19.

Woods, hickory, ash, birch, used for turned chairs, 143; oak, for wainscot chairs, 145; wild cherry, mahogany, rosewood, for tables, 208.

Worthylake, George, inventory, I54, 164 .

Yale University, bequests to, 56,59 .

Yung Wing, minister from China, 162.

Zachary, Lloyd, inventory, I76. 

<smiles>C1CC1</smiles> 


